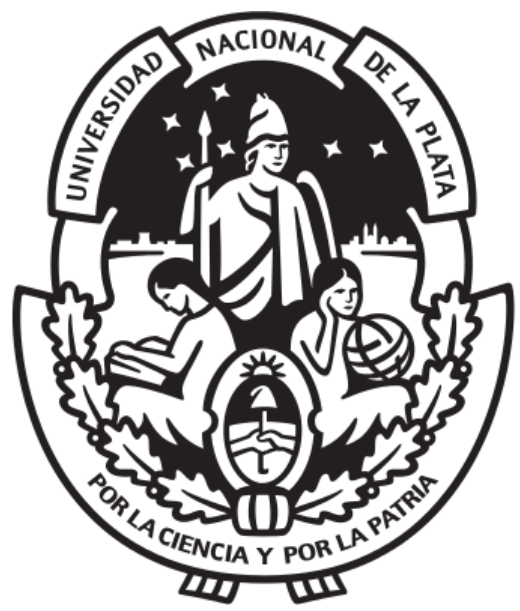

Universidad Nacional de La Plata

Facultad de Ciencias Exactas

Departamento de Ciencias Biológicas

Trabajo de Tesis Doctoral

\title{
ESTUDIO DE LA \\ DESNATURALIZACIÓN EN FRÍO DE \\ PROTEÍNAS MEDIANTE SIMULACIONES COMPUTACIONALES
}

Bio. Yanis Ricardo Espinosa Silva

Director: Prof. Dr. J. Raúl Grigera

La Plata, 2016 
Espinosa Silva, Yanis Ricardo

Estudios de la desnaturalización en frío de proteínas mediante simulaciones computacionales / Yanis Ricardo Espinosa Silva ; José Raúl Grigera ; dirigido por José Raúl Grigera. - 1a ed . - La Plata : Universidad Nacional de La Plata. Facultad de Ciencias Exactas, 2016. Libro digital, PDF

Archivo Digital: descarga y online ISBN 978-950-34-1702-7

1. Biofísica. I. Grigera, José Raúl II. Grigera, José Raúl, dir. III. Título. CDD 571.4 



\section{ESTUDIO DE LA \\ DESNATURALIZACIÓN EN \\ FRÍO DE PROTEÍNAS \\ MEDIANTE SIMULACIONES \\ COMPUTACIONALES}

Tesis Doctoral para optar por el título de Doctor de la Facultad de

Ciencias Exactas de la Universidad Nacional de La Plata.

\section{Dirigida por}

Prof. Dr. J. Raúl Grigera

Universidad Nacional de La Plata

Facultad de Ciencias Exactas

Departamento de Ciencias Biológicas

La Plata, 2016 

A papá, a mamá, al cabezón a Caro y a Nico.

A ellos, que son el motor, la alegría y la bendición de mi vida. ... y por supuesto al nono Marcos. 



\section{Agradecimientos}

Cuando se inicia un proyecto, o cuando se anhela saber como es lo desconocido, se pone en marcha una serie de sentimientos que tratan de hacer el máximo esfuerzo por lograrlo. Cuando salí de casa, lo hice pensado en esto que cada vez está más cerca de suceder y mientras transcurre el último, pero más vital y necesario esfuerzo, es inevitable no pensar que esto sucedió gracias a ustedes:

Mis padres, que me llenaron de aliento y alegría, de risas y sueños. Que siempre, pero siempre, me dijeron que todo iba a salir, no sé como, pero siempre sucedió así. Gracias por esperarme y por soportar la ausencia.

A mi mona hermosa, que apareció cuando empecé esta aventura, y quien me alegra, entiende, soporta y ama, y como si todo esto fuera poco, pronto nos hará padres.

A mi hermano, a quien extraño mucho y en el cual guardo mi confianza absoluta de que será cada día un mejor ser humano y un químico teórico excelente.

Al Dr. Raúl, al que siempre me referí así por respecto, pero que con su humildad y enseñanzas hace que éste formalismo sea más una expresión de admiración y cariño. Gracias por confiar y creer, porque sin conocerme y tan sólo con unos e-mails iniciamos este proyecto del cual le he aprendido tanto.

A Alex, por sus guías y consejos, por tratarme como a un hermano y por motivar el estar acá.

A Ramiro y Celeste, por su ayuda, por lo que me enseñaron de la Argentina, el folklore, la vida gaucha, las guitarreadas, por los recorridos en el campo, pero sobretodo por su amistad incondicional.

A Manux y Marisa, a cada uno en aspectos diferentes, pero al final todo converge en cariño y la preocupación sincera y paternal.

A Ariel Alvarez, porqué a pesar de que como él dice: no me alcanza la vida, siempre tuvo tiempo para ayudarme y corregirme.

A Meyra, un genio, porqué cuando creo que voy bien, me dice: Pará, y si...? y me hace dudar, pensar, revalidar y ver que siempre hay otra manera de pensar.

A Ernesto, simplemente un maestro, por dar el conocimiento de esa manera tan amplia y querer para sus estudiantes siempre lo mejor. 
A Andres, que es el mejor ejemplo de como disfrutar el hacer ciencia.

A Gaston, que me dio el primer consejo para trabajar con el Dr. Raúl y me ayudó mucho.

A Chara, porqué conoce y comparte el quehacer científico que no se encuentra en los libros.

A mis amigos en Colombia, especialmente a Leonardo, Kiko y Rene, por estar siempre atentos de mi familia y nunca olvidarse del parcero.

A mis grandes amigos en Argentina, Efren, Carlos, Guillermo, Julie, Zuly, Eli, Emanuel, Leandro, Jorge G., Diego, Fercho y Caro Medina, por tantas alegrías y momentos compartidos que hacen de esto algo mejor.

A mis amigos en Brasil, Larissa y David. A los chicos del PROCC, a Paulo Ricardo y a Mauricio por sus enseñanzas.

A la gente del IFLY donde inicie mi trabajo doctoral y me hicieron sentir como en casa.

A los Chicos del CEQUINOR, por su ayuda y atención. En especial a Yani B. por la mano con Gaussian y a Lu Tamone por su buena energía.

A la UNLP y al CONICET, que sin su contribución nada de esto sería posible. 


\section{Índice}

Agradecimientos VII

1. Conceptos Básicos 1

1.1. Introducción . . . . . . . . . . . . . 1

1.2. El Efecto Hidrofóbico . . . . . . . . . . . . . . . 2

1.3. Estabilidad y Conformación de Proteínas . . . . . . . . . 3

1.3.1. Algunos Aspectos Termodinámicos . . . . . . . . . 6

1.3.2. Estabilidad Vs. Altas Temperaturas . . . . . . . . . 7

1.3.3. Estabilidad Vs. Bajas Temperaturas . . . . . . . . . . 7

1.3.4. Estabilidad Vs. Alta Presión . . . . . . . . . . . . . . 10

1.4. Diagrama de Fase Proteico T-P . . . . . . . . . . . 11

1.5. Ensamble de moléculas Anfifílicas . . . . . . . . . . . . . 14

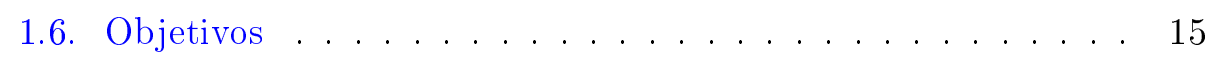

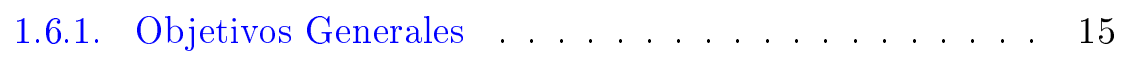

1.6.2. Objetivos específicos . . . . . . . . . . 15

2. Métodos y Análisis de Simulación 21

2.1. Introducción . . . . . . . . . . . . . . . 21

2.2. Simulación por Dinámica Molecular (MD) . . . . . . . . 22

2.2.1. Aproximaciones en MD . . . . . . . . . . . . . . 23

2.2.2. Campo de Fuerzas . . . . . . . . . . . . . 26

2.2.3. Potenciales enlazantes . . . . . . . . . . . 30

2.2.4. Cómputo de fuerzas . . . . . . . . . . . . . 36

2.2.5. Algoritmos de restricciones topológicas . . . . . . . . . . . . 44

2.3. Métodos de Análisis . . . . . . . . . . . . . . . 45

2.3.1. Funciones de Distribución Radial . . . . . . . . . . 45

2.3.2. Raíz de la Desviación Cuadrática Media . . . . . . . 46

2.3.3. Cálculo del Radio de Giro . . . . . . . . . . . . . . . 46

2.3.4. Superficie Accesible al Solvente . . . . . . . . . . 46

2.3.5. Dinámica Escencial (ED) . . . . . . . . . . . 47 
3. Agregación micelar en surfactantes iónicos 53

3.1. Introducción . . . . . . . . . . . . 53

3.2. Materiales y Métodos . . . . . . . . . . . . . . 54

3.2.1. Autoensamble micelar . . . . . . . . . . . . . 54

3.2.2. Sistemas de simulación . . . . . . . . . . . 55

3.2.3. Efectos de la presión . . . . . . . . . . . . . 55

3.2.4. Análisis de Cluster . . . . . . . . . . . . . 55

3.3. Resultados y Discusión . . . . . . . . . . . . . . 56

3.3.1. Autoensamble micelar . . . . . . . . . . . 56

3.3.2. Micelas bajo presión . . . . . . . . . . . . . 58

3.3.3. Solvente de Lennard-Jones . . . . . . . . . . . 62

3.3.4. Efectos de la temperatura . . . . . . . . . . . 62

3.4. Conclusiones . . . . . . . . . . . . . . . 63

4. Agregación micelar en surfactates no iónicos 69

4.1. Introducción . . . . . . . . . . . . . . . . . . 69

4.2. Materiales y Métodos . . . . . . . . . . . . . 70

4.2.1. Parámetros de Optimización . . . . . . . . . . . . . . . . 70

4.2.2. Parámetros de la Simulación . . . . . . . . . . . . . . 72

4.2.3. Efectos de la presión . . . . . . . . . . . . . 73

4.3. Resultados y Discusión . . . . . . . . . . . . . . . . 74

4.3.1. Autoensamble micelar . . . . . . . . . . . . . 74

4.3.2. Efectos de la presión . . . . . . . . . . . . . 78

4.4. Conclusiones . . . . . . . . . . . . . . . 83

5. Modelo Proteico $\quad 89$

5.1. Introducción . . . . . . . . . . . . . . . . . . . . . 89

5.2. Materiales y Métodos . . . . . . . . . . . . . . . . 90

5.2.1. Sistemas de simulación . . . . . . . . . . . . . . 91

5.2.2. Metodología de Simulación . . . . . . . . . . . 92

5.3. Resultados y Discusión . . . . . . . . . . . . . . . . 93

5.3.1. Análisis Estructural . . . . . . . . . . . . . . 93

5.3.2. Análisis de Movilidad . . . . . . . . . . . . . . 97

5.3.3. Análisis por Dinámica Esencial . . . . . . . . . . . 100

5.3.4. Movimientos Esenciales . . . . . . . . . . . . 105

5.3.5. Subespacio PC1/PC2 : Conformación Temporal . . . . 109

5.3.6. Paisaje de energía libre . . . . . . . . . . . . . . 111

5.4. Conclusiones . . . . . . . . . . . . . . 117

$\begin{array}{ll}\text { 6. Conclusión } & 123\end{array}$

$\begin{array}{ll}\text { 7. Perspectivas } & 131\end{array}$ 


\section{Índice de figuras}

1.1. Esquema representativo del efecto hidrofóbico en la agregación de anfifílos. En la gráfica se observa la hidratación de la zona polar (Región hidrofílica) y no polar (Región hidrofóbica). En esta última, las moléculas de agua se ordenan formando una red ordenada de hidratación (Agua Shell) que disminuye la entropía del sistema. Al aumentar la concentración de anfifílos estos se agregan liberando moléculas de agua hacia la región de aguas bulk, aumentando así la entropía del sistema. . . .

1.2. Energía libre de Gibbs $\Delta G(T)$ dependiente de la temperatura. $-T \Delta S(T)$ y $\Delta H(T)$ hacen referencia a la energía entrópica y entálpica de una proteína nativa. En el recuadro superior se observa la energía libre de Gibbs en estado nativo y desnaturalizado para $T_{c}$ y $T_{d}$, que se explican en el texto. (Gráfica modificada de la referencia $[6]) \ldots \ldots \ldots \ldots$

1.3. Proyección en el plano $P$ - $T$, que representa el diagrama de fase elíptico de una proteína. Dentro del elipse la proteína conserva su condición nativa. Fuera de esta la proteína puede ser desnaturalizada por el aumento en $T$ (desnaturalización por calor) o $P$ (desnaturalización por presión), y por el descenso en $T$ (desnaturalización en frío). Cada proceso $N$ - $D$, está caracterizado por diferentes variaciones en $\Delta S$ y $\Delta V$. (Modificado de la referencia [28]) . . . . . . . . . . . . . . . . 12

2.1. Condiciones periódicas de contorno en 2D . . . . . . 26

2.2. Curva potencial para la interacción repulsión-dispersión de Lennard-Jones. . . . . . . . . . . . . . . . . . . 28

2.3. Curva potencial para la interacción Coulómbica entre partículas cargadas de igual signo con y sin campo de reacción (RF). En el último caso $\varepsilon_{r f}=78$ y $r_{c}=0,9 \mathrm{~nm}$. Ambas líneas punteadas difieren sólo en el valor de una constante C, pasamos de una a otra mediante la operación RF-C. . . . . . . . . . 29

2.4. Principio del estiramiento de enlace (izquierda), y su correspondiente potencial armónico (derecha) . . . . . . . . . . 31 
2.5. El pozo potencial de Morse, para una longitud de enlace de $0,15 \mathrm{~nm} \ldots \ldots \ldots \ldots \ldots \ldots \ldots \ldots \ldots$

2.6. Principio de vibración de enlace (izquierda) y función potencial de ángulo de enlace (derecha). . . . . . . . . . . . .

2.7. Diferentes tipos de ángulos diedros impropios. Distorsiones de anillos fuera del plano (izquierda), sustituyentes de anillos (centro) y distorsión del tetraedro (derecha). El ángulo diedro impropio se define para todos los casos como el ángulo entre los planos $(i, j, k)$ y $(j, k, l) \ldots \ldots \ldots \ldots \ldots$

2.8. Función potencial para diedros impropios. . . . . . . . . . . 34

2.9. Principio para el ángulo diedro propio (izquierda, en configuración trans) y el potencial periódico para el diedro propio (derecha). . . . . . . . . . . . . . . 35

2.10. Función potencial para diedro propio de Ryckaert-Belleman . 36

2.11. Método de integración de leap - frog o salto de rana. Recibe este nombre debido a que $r$ y $v$ saltan uno sobre el otro alternadamente al estilo del salto de rana. . . . . . . . . . .

2.12. Actualizaciones de posición requeridas para cada paso de integración. La línea punteada representa el viejo enlace de longitud $d$, mientras que las líneas llenas representan los nuevos enlaces. En A, actualización no restringida. En B, eliminación de las fuerzas que actúan sobre los enlaces. En C, corrección del estiramiento por rotación. $l=d \cos \theta$ y $p=\left(2 d^{2}-l^{2}\right)^{1 / 2}$.

3.1. Modelo molecular de dodecilsulfato implementado en nuestras simulaciones $(\mathrm{O}=$ Oxígeno; $\mathrm{S}=$ Azufre; $\mathrm{C}=$ Carbono). . . .

3.2. Número de agregación de moléculas SDS para las micelas formadas en agua SPC/E y SPC/HW. Cada sistema posee en total 70 monómeros. El término $n$ hacen referencia al número de monómeros que conforman el cluster y $F n$ a su frecuencia durante la simulación. . . . . . . . . . . . . . .

3.3. Distribución en el número de agregación de moleculas de SDS en el tiempo total de simulación a 1 bar y 300 K. En A y B, 70 moleculas de SDS en agua (SPC/E) y agua pesada (SPC/HW). En C y D, 200 moleculas de SDS en agua y agua pesada . . . . . . . . . . . . . .

3.4. Área superficial accesible al solvente. Agregación micelar en función del tiempo en SPC/E y SPC/HW con 200 monómeros de SDS. . . . . . . . . . . . . . .

3.5. Promedio normalizado del número de clusters $\left(\mathrm{N}_{\text {Clust }}\right.$ en Negro) y el número de agregación ( $\mathrm{N}_{A g g}$ en rojo) en función de la presión para micelas en SPC/E y SPC/HW. . . . . . . . . 
3.6. Primer pico de la $g(r)$ normalizada para los $\mathrm{C}_{1}-\mathrm{C}_{12}$ en función de la presión a $T=300 \mathrm{~K}$. La fase micelar se observa a 1 bar, con el aumento de la presión (escalado de presión representado en la gráfica inferior derecha) se evidencian cambios estructurales en la micela. . . . . . . . . . . . . . . 5

3.7. Área de SDS expuesta a agua (línea negra) y agua pesada (línea roja) en función de la presión. Las imágenes inferiores muestran los cambios de geometría obtenidos durante la simulación. . . . . . . . . . . . . .

3.8. Estructura de los agregados de SDS a 4000 bar. La figura A, sugiere la presencia de pequeñas estructuras apiladas de forma lamelar, sin embargo en la figura B (rotando $90^{\circ} \mathrm{A}$ ), se observa que la estructura realmente se agrega en discos apilados formando una varilla. El sistema empleado en este ejemplo posee 200 monómeros de SDS. De igual forma, el cambio de geometría es apreciable en el sistema con 70 monómeros . . .

3.9. Representación gráfica de una micela de SDS en agua y en solvente de LJ. En los recuadros inferiores se observa las respectivas $\mathrm{g}(\mathrm{r})$ para cada tipo de solvente, evidenciando la importancia de la estructura del solvente en la geometría de agregación. 62

3.10. Efectos de la temperatura en la geometría de agregación. . . . 63

4.1. Molécula de TX100. Se observan las regiones hidrofílica e hidrofóbica y el tipo de átomos implementando la nomenclatura de la librería Gromacs. La fracción correspondiente a los tres primeros metilos de la cadena polioxietileno se clasificó dentro de la región hidrofóbica por razones que se explican en el texto. 70

4.2. Cambios en el SASA durante el autoensable micelar. En el cuadro principal (linea negra) SASA total. En los recuadros superiores SASA hidrofóbico e hidrofílico (linea azul y roja, respectivamente). Los valores SASA fueron calculados usando el algoritmo $g \_s a s[16]$ con un radio de sonda de $1,4 \AA$. . . .

4.3. A y B número máximo y promedio de agregación en micelas de TX100 durante el tiempo de simulación, respectivamente. En C, número de cluster formados en función del tiempo. En D, El número de agregación más probable. . . . . . . . . .

4.4. Parámetros estructurales. En A, factor de excentricidad. En B, momento de inercia para los principales ejes de la micela. En C, Radio de giro total (linea azul) y por ejes XYZ (lineas verde, roja y negra, respectivamente). En D, momento de inercia calculado en B. Solo se observa los 20 ns finales de la trayectoria simulada, para un número de agregación de 200 monómeros (Ver figura 4.3A) . . . . . . . . . . . . 
4.5. Autoagregación de moleculas de TX100. En A, condiciones de partida con los monómeros distribuidos aleatoriamente. En $\mathrm{B}$, configuración final de autoensamble donde se observa una micela en prolato. Se han removido las moléculas de agua del sistema para su mejor visualización. . . . . . . . . . .

4.6. Efectos de la presión en la geometría de la micela. En A, calculo de la excentricidad. En B, cambios en el radio de la micela. Los puntos de colores y las barras de error, representan los valores promedio y la desviación estándar, respectivamente. .

4.7. Efectos de la presión en el área superficial accesible al solvente, total (círculos verdes), hidrofílica (círculos rojos) e hidrofóbica (círculos azules). Los puntos de colores y las barras de error, representan los valores promedio y la desviación estándar, respectivamente. .................

4.8. Función de distribución radial, g(r), de los átomos de oxígeno del agua al rededor de la región hidrofílica (átomos de oxígeno del poliéter) de la micela de TX100 en altas presiones. Las flechas indican la dirección del incremento de la presión. En el recuadro inferior se detallan los cambios de densidad cada 1,0 kbar. El valor $\sigma$ de normalización hace referencia al diámetro de una molécula de agua $(0,275 \mathrm{~nm}) . \ldots \ldots \ldots$

4.9. Imágenes instantáneas de la micela de TX100 a 0,1 kbar (A) y 4,0 kbar (B). En la imagen se observa un corte transversal de la micela (en amarillo), y las moléculas de agua a su alrededor (oxígenos en rojo, hidrógenos en blanco). . . . . . . . . .

5.1. Frataxina Yfh1. Los elementos estructurales de la proteína se explican en el texto. . . . . . . . . . . . .

5.2. Configuración inicial de los sistemas simulados. En A, se representa la frataxina dentro de una caja con agua en estado sólido, hielo $I_{h}$, a $215 \mathrm{~K}$ y 1 bar de presión. En B, frataxina en agua líquida ubicada aleatoriamente. Esta configuración fue usada como sistema de partida para 215,293 y $323 \mathrm{~K}$ a 1 bar de presión y para el sistema 3 kbar a 293 K. . . . . . . .

5.3. Raíz de la Desviación Cuadrática Media (RMSD) en los átomos del Backbone de la frataxina para cada condición simulada. El análisis se llevo acabo durante el tiempo total de simulación y en relación a su estructura inicial de referencia obtenida por RMN [13] . . . . . . . . . . . . . .

5.4. Distribución de las distintas conformaciones en relación a las distancias mostradas en el RMSD de la figura 5.3 . . . . . . . 
5.5. Análisis del contenido de estructura secundaria durante el tiempo total de simulación usando las definiciones del DSSP

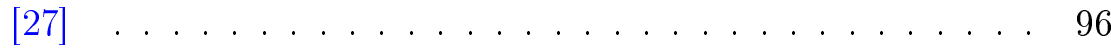

5.6. Raíz de la Fluctuación Cuadrática Media (RMSF) de los átomos del Backbone en la frataxina. . . . . . . . . . . . . 98

5.7. Calculo del $\mathrm{R}_{g}$ de la frataxina en las diferentes condiciones simuladas. . . . . . . . . . . . . . . 99

5.8. Porcentaje de varianza acumulada para los 100 primeros componentes principales calculados. Cada componente muestra la contribución acumulada al movimiento total de la proteína. . 101

5.9. RMSF de la frataxina para cada condición simulada. El tiempo total de simulación de cada trayectoria fue proyectado dentro de los cinco primeros componentes principales con el mayor porcentaje de contribución al movimiento total en cada sistema (Ver figura 5.8). . . . . . . . . . . . . . . 103

5.10. Contenido coseno en los dos primeros PCs en función del tiempo. Linea naranja, Ice $I_{h}$; linea azul, $215 \mathrm{~K}$; linea verde, 293 K; linea roja, 323 K; y linea negra, 3 kbar. . . . . . . . . . . . 104

5.11. Frataxina acoplada a presión creciente de 1 a 3000 bar con incrementos cada 100 bar. (A) Contenido coseno en los dos primeros PCs. (B) Radio de giro. . . . . . . . . . . . . . 105

5.12. Visualización de la dirección y amplitud de los movimientos esenciales en los C $\alpha$ de la frataxina, para los dos primeros PCs en las diferentes conformaciones simuladas. . . . . . . . . 106

5.13. Proyección bi-dimensional (2D) de las trayectorias para cada condición simulada dentro PC1 y PC2. Cada punto representa un confórmero transitorio adoptado por la proteína durante su secuencia temporal. La estructura original resulta por RMN se representa por el rombo blanco. El código de colores representa la secuencia temporal. . . . . . . . . . . . . .

5.14. Proyección bi-dimensional (2D) de la trayectoria de la frataxina acoplada a presión creciente dentro de los primeros componentes princiapales. Cada punto representa un confórmero transitorio adoptado por la proteína en función de la presión. La estructura original resulta por RMN se representa por el rombo blanco. El código de colores representa el rango en el aumento de la presión. Los recuadros de menor tamaño muestran los subestados de la proteína para cada rango de presión analizado. . . . . . . . . . . . . . . . 112

5.15. Análisis de FEL en cada condición simulada, utilizando como coordenadas de reacción las proyección de los $\mathrm{C} \alpha$ en $\mathrm{PC} 1$ y PC2. Los valores de energía libre se dan en $\mathrm{kcal} \mathrm{mol}^{-1}$ indicado por la escala a color. . . . . . . . . . . . . . . . . . 113 
5.16. Representación estructural de máxima probabilidad en (A) Bajas Temperaturas, (B) Alta Presión y (C) Altas Temperaturas. Conformación inicial trasparente, estructura de mayor probabilidad en rojo. . . . . . . . . . . . . . . . . 114

5.17. Área superficial accesible al solvente (SASA).En (A) y (B) SASA hidrofóbica e hidrofílica, respectivamente. Los datos fueron recolectados durante 500 ns de simulación. Frataxina en Ice $I_{h}$ (amarillo), agua líquida a: $215 \mathrm{~K}$ (azul), $293 \mathrm{~K}$ (verde) 323 $\mathrm{K}$ (rojo) y alta presión 3 kbar (negro).SASA hidrofóbica (C) e hidrofílica (D) a presión creciente $\left(\mathrm{P}_{0,1-3,0 k b a r}\right)$ Los puntos y las barras de error representan el promedio y la desviación estandar, respectivamente. . . . . . . . . . . . 115

5.18. En A, promedio de puentes de hidrógeno (PH) entre el agua y la frataxina para cada aumento de presión (las barras de error indican la desviación estandar). En B, conteo de los pares donor-aceptor (D-A) para un radio de corte $R_{C u t}=0,24 \mathrm{~nm}$. Como se observa, con el aumento de la presión el número de pares D-A incrementa. Entre los 600-900 bar, los PH y los pares D-A aumentan con la presión. Una vez se alcanza los 1000 bar el número de PH descienden, mientras los pares DA se mantienen estables hasta $\sim 1700$ bar. Esto indica que con el aumento de la presión la población de pares de D-A incrementan por efecto de la compresión, pero esto no supone la formación PH entre el agua y la proteína. En este cálculo se usó como criterio geométrico una distancia donor-aceptor de $0,24 \mathrm{~nm}$ y un ángulo $D-H-A$ entre $0-45^{\circ} \ldots \ldots 116$

6.1. Cambios en la $g(r)$ con el aumento de la presión. Cada $g(r)$ muestra el cambio de ordenamiento estructural del modelo SPC/E, observándose la pérdida gradual de estructura tetraédrica con el aumento de la presión. En el recuadro superior (linea negra continua) se aprecia la posición del segundo pico, a 1 bar de presión, revelando el componente tetraédrico de la estructura del agua bajo estas condiciones, contrastado con la posición del segundo pico de la $g(r)$ que muestra la presencia la de una estructura simple de geometría hexagonal para el argón líquido (curva a trazos). Así, el incremento de la presión modifica la $g(r)$ del agua haciéndola más parecida a la del argón (curva punteada a 10 kbar). . . . . . . . . . . . . 124 
6.2. Parámetro de orden, $P_{r}$, en función de la presión hidrostática ejercida sobre el sistema (caja de simulación con agua $\mathrm{SPC} / \mathrm{E})$. El modelo expresa la coexistencia de dos contribuciones entrelazadas de hidratación; es decir, una estructura tetraédrica abierta y una hexagonal más compacta. Tomado de $[1] \ldots \ldots \ldots \ldots \ldots \ldots \ldots$

6.3. En A, distribución de los puentes de hidrógeno (HB) en agua SPC/E a $300 \mathrm{~K}$ y 1 bar (negro), 3 kbar (gris oscuro) y $10 \mathrm{kbar}$ (gris claro) obtenidos por MD. Podemos notar de que con el aumento de la presión, la formación de cuatro HB por molécula disminuye, incrementando la población de tres y cinco HB formados, mostrando el debilitamiento de las red de $\mathrm{HB}$ con el incremento de la presión. En B, distribución de los HB a $280 \mathrm{~K}$ a diferentes densidades en función de la presión. Al igual que en A, para las altas presiones $\left(\delta=1,10 ; 1,30 ; 1,40 \mathrm{~g} / \mathrm{cm}^{3}\right)$ se observa una redistribución de los puentes de hidrógeno de 4 a 3 y $5 \mathrm{HB}$ por molécula de agua. Figura A y B, tomadas de $[2,3]$, respectivamente. . . . . . . . . . . . . 126 



\section{Índice de Tablas}

4.1. Parámetros usados en enlaces covalentes de TX100 ${ }^{a}$. . . . . 71

4.2. Parámetros usados para los ángulos de $\mathrm{TX} 100^{a} \ldots \ldots$. . . . 71

4.3. Parámetros usados para los ángulos diedros en $\mathrm{TX}_{100}{ }^{a}$. . . . 72

4.4. Cargas parciales por átomo en $\mathrm{TX} 100^{a}$. . . . . . . . . 73

5.1. Información resumida de los sistemas de simulación generados para la frataxina. . . . . . . . . . . . . . . 92

5.2. Valor promedio del número de residuos que conforman las estructuras secundarias adoptadas por la frataxina en las diferentes condiciones simuladas. . . . . . . . . . . . . 97

5.3. Superposición y RMSIP entre los autovectores de los cinco primeros PCs que definen el subespacio esencial en cada condición simulada, Ice $I_{h}, 215 \mathrm{~K}, 293 \mathrm{~K}, 323 \mathrm{~K}, 3$ kbar y $\mathrm{P}_{0,1-3,0 k b a r} .110$ 



\section{Capítulo 1}

\section{Conceptos Básicos}

\section{Introducción}

Tal vez uno de los retos más importantes que afronta la Biofísica actualmente, es el que refiere al plegamiento proteico. Con los avances en dispersión de rayos X [1] y resonancia magnética nuclear (RMN) [2], se han logrado describir niveles de organización molecular característicos durante el plegamiento proteico, antes de la formación de la estructura funcional nativa. A pesar, de las distinciones estructurales (estructura primaria, secundaria, terciaria, cuaternaria) que puede tener una proteína en su cinética de plegamiento, hasta ahora no ha sido posible una caracterización dinámica que permita predecir de forma global cual será la organización geométrica que optará una proteína funcional.

Al respecto, Levinthal señala que dado el alto número de grados de libertad de una cadena polipeptídica, una proteína puede adquirir una gran cantidad de configuraciones estructurales, $5 \times 10^{47}$ configuraciones para una cadena polipeptídica de 100 aminoácidos, y que si dichas configuraciones son muestreadas a razón de $10^{13}$ por segundo, se requerirán $10^{27}$ años para obtener una estructura nativa. De lo anterior, Levinthal concluye que las búsquedas aleatorias no son una forma eficaz de encontrar el estado correcto de plegamiento proteico [3]. Por tanto, debería existir un mecanismo que conlleve a que los tiempos de plegamiento sean reducidos a escalas de microsegundos.

La paradoja de Levinthal, expuesta anteriormente, solo tiene presente dentro de sus variables conformacionales las interacciones entre aminoácidos. Como sabemos las proteínas están inmersas en una matriz soluble, agua, que en condiciones fisiológicas presentan una concentración de iones y $\mathrm{pH}$ importantes para su estructura.

Para comprender la dinámica de plegamiento proteico, algunos autores abordaron esta problemática analizando los perfiles termodinámicos de la desnaturalización proteica. De igual forma, dado que la vida que conocemos 
se lleva acabo predominantemente en presencia de agua, el entendimiento de las interacciones macromoleculares con agua ha sido durante varias décadas uno de los desafíos más importantes de la biofísica molecular, generándose interrogantes como: ¿cuál es el rol del agua en la estabilización de estructuras moleculares? ¿Cuáles son las fuerzas que dominan en la organización estructural? ¿Cuáles son los mecanismos dinámicos que rigen los movimientos de organización agua-macromolécula y sus fluctuaciones estructurales? O en otras palabras ¿cuál es el aporte del agua al paisaje de energía libre en el autoensamble y organización estructural de macromoléculas? [4]

Para dar respuestas a estos interrogantes es necesaria una descripción termodinámica, cinética y estructural de las propiedades microscópicas de la interface agua-macromolécula. Entonces, al abordar el nivel microscópico encontramos que la temperatura es uno de los parámetros más importantes que definen el comportamiento de la materia viviente, por ejemplo, una proteína estable puede ser desnaturalizada por altas $\left(\sim 60{ }^{\circ} \mathrm{C}\right)$ o bajas (entre $0 \mathrm{y} \sim-20{ }^{\circ} \mathrm{C}$ ) temperaturas [5, 6]. Aunque el término desnaturalización es ampliamente entendido para la desnaturalización por calor, aquella que ocurre por bajas temperaturas es conocida como desnaturalización en frío, la cual también puede ser inducida por alta presión [6, 7]. Sin embargo, en las últimas décadas en el campo de la biología, la presión hidrostática se ha convertido en una importante herramienta fisicoquímica para el estudio de macromoléculas de interés biológico. A pesar de que a nivel microscópico, presiones por debajo de $10 \mathrm{kbar}$, raramente rompen los enlaces covalentes, los efectos predominantes de la presión están implicados en las conformaciones macromoleculares que son mantenidas, en condiciones normales, por fuerzas débiles tales como puentes de hidrogeno, fuerzas de van der Waals y efecto hidrofóbico [8]. En este último, haremos un vital énfasis dados los paradigmas que encierran su definición y modo de acción, y que a su vez, es el eje central de estudio en la presente tesis.

De esta manera, el presente capitulo tiene como finalidad contextualizar al lector en la problemática, las definiciones, los modelos y las teorías que engloban el estudio de las fluctuaciones estructurales en función de la presión y la temperatura centrándonos principalmente en proteínas y surfactantes.

\section{El Efecto Hidrofóbico}

El termino efecto hidrofóbico o también llamada interacción hidrofóbica denota la tendencia, de las sustancias no polares o escasamente polares, a formar agregados en soluciones acuosas. Estas interacciones son importantes en procesos de interacción enzima-sustrato, ensamble de lípidos en biomembranas, agregación de surfactantes, formación de micelas, lamelas, vesículas, efectos cinéticos del solvente, etc. Específicamente en soluciones acuosas donde predominantemente gobierna dicho efecto. 
A temperatura y presión moderada, los solutos no polares son insolubles en agua. Al introducir estos compuesto en agua, esta forma una red extendida de puentes de hidrógeno, conduciendo inevitablemente a la reorganización de las moléculas de agua cercanas a la superficie de la molécula no polar. Es importante resaltar que el agua es el único solvente con la capacidad de formar una red molecular de coordinación tetraédrica, que al estar en contacto con una partícula hidrofóbica envuelve dicha partícula optimizando entre si sus puentes de hidrógeno, formando simultáneamente, una red molecular de coordinación hexagonal. Es por esta razón que el agua es considerada un solvente pobre para compuestos no polares [9].

Uno de los primeros modelos propuestos, que después se convertiría en el primer prototipo para los subsecuentes estudios en el efecto hidrofóbico; fue propuesto por Frank y Evans en 1945 [10]. El modelo, generalmente conocido como el modelo del Iceberg, explica la inusual perdida de la entropía de los gases no polares en agua, en términos de la estructuración de las moléculas de agua cercanas a estos solutos. Esta idea sería interpretada en estudios posteriores, como una esfera de hidratación rígida sobre los solutos no polares, originando estructuras en forma de clatratos. Fenómeno referido como hidratación hidrofóbica.

Podríamos decir entonces, que la interacción de moléculas de agua con solutos no polares es entrópicamente desfavorable, lo que supondría, contra intuitivamente, que la agregación de estos en soluciones acuosas es un proceso altamente entrópico. En 1959 Kauzmann [11] introduce el concepto de interacción hidrofóbica. En él, sugiere que las interacciones atractivas entre moléculas no polares en soluciones acuosas son producto del solvente, resultando de la superposición destructiva de las estructuras formadas durante la hidratación hidrofóbica; lo que implica la liberación de moléculas de agua desde la esfera de hidratación (Shell) hacia el agua bulk (aguas afuera de la región de hidratación) [9] (Ver figura 1.1). Por tanto, el concepto de hidrofobicidad está definido en términos netamente termodinámicos.

\section{Estabilidad y Conformación de Proteínas}

Durante casi un siglo, el plegamiento y estabilidad de proteínas nativas ha recorrido un arduo y extenso camino de investigación. En la actualidad, es ampliamente aceptado que el efecto hidrofóbico juega un papel importante en la estabilidad del plegamiento estructural de proteínas solubles en agua [12]. Es así como la distribución espacial de los aminoácidos no polares, dentro de una proteína nativa, se organizan en un núcleo hidrofóbico que minimiza la exposición al solvente, a lo que, como vimos anteriormente, Kauzmann llamaría interacción hidrofóbica [9, 11], en relación a las interacciones entre cadenas de aminoácidos no polares determinantes en la estabilidad de biopolímeros. 

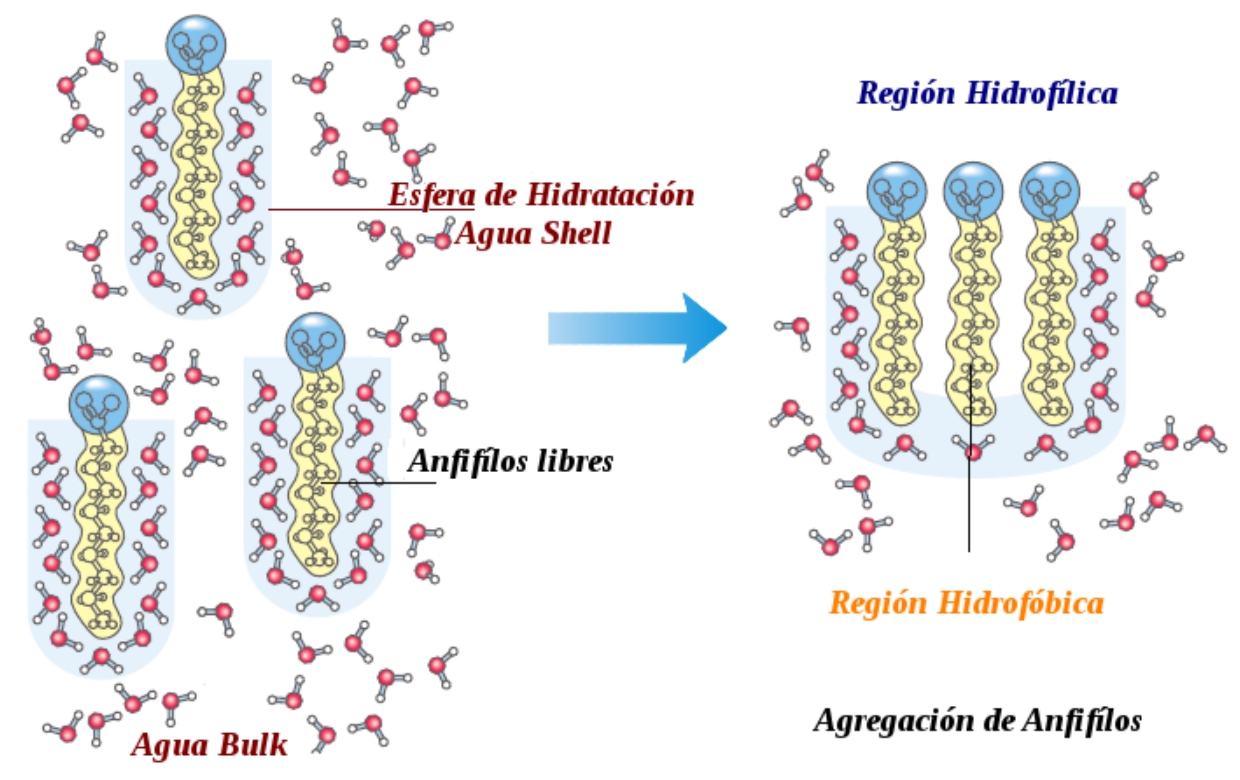

Región Hidrofóbica

Agregación de Anfifilos

Figura 1.1: Esquema representativo del efecto hidrofóbico en la agregación de anfifílos. En la gráfica se observa la hidratación de la zona polar (Región hidrofílica) y no polar (Región hidrofóbica). En esta última, las moléculas de agua se ordenan formando una red ordenada de hidratación (Agua Shell) que disminuye la entropía del sistema. Al aumentar la concentración de anfifílos estos se agregan liberando moléculas de agua hacia la región de aguas bulk, aumentando así la entropía del sistema.

Con este concepto Kauzmann causaría controversia y abre el debate de si ( $i$ ) la estabilidad de las estructuras proteicas es causada por las interacciones de van der Waals entre cadenas hidrofóbicas o sí ( $i i)$ es el agua la que induce la formación del núcleo no polar [9]. Al respecto, Privalov [12] argumenta que la interacción hidrofóbica representa la acción combinada de los dos procesos.

De igual forma, dentro de la estructura nativa existe una variedad de fuerzas intermoleculares entre residuos aminoácidicos que estabilizan la proteína. La primera contribución a la estabilidad de proteínas la proveen los enlaces covalentes, los cuales determinan la estructura y estabilidad del esqueleto proteico. Sin embargo, las energías asociadas con los enlaces covalentes no presentan diferencias significativas en los estados nativo y desnaturalizado [13].

La contribución dominante a la estabilidad de las proteínas involucra fuerzas no covalentes como $[9,13]$ :

- Interacciones electrostáticas de largo alcance, que pueden ser intraproteicas, de agua-proteína y de proteína con especies iónicas presentes en 
el solvente. Estas últimas de vital importancia en la superficie proteica. Dependiendo del signo y la orientación de los patrones de interacción estas pueden ser atractivas o repulsivas.

- Los puentes de hidrógeno que presentan una gran especificidad en su interacción, pueden ser intraproteicos, estabilizando las estructuras secundarias, hélices $\alpha$ y hojas $\beta$, además de la estructura terciaria. Los puentes de hidrógeno entre las moléculas de agua alrededor de la proteína definen las propiedades de la esfera de hidratación, mientras que, los puentes de hidrógeno entre grupos proteicos y el agua, internos y superficiales, repercuten ampliamente en la flexibilidad de la proteína.

- Interacciones de atracción y repulsión de corto alcance tipo van der Waals.

- Las interacciones hidrofóbicas que están fuertemente correlacionadas con la estructura del agua, ocasionando cambios en el volumen del sistema y una disminución de los grados de libertad configuracionales de las moléculas. Así, el número de puentes de hidrógeno por molécula de agua con el soluto no polar es bajo cerca de la esfera de hidratación. Por tanto, estas moléculas de agua son estructuralmente restrictivas, ya que maximizan el número de puentes de hidrógeno entre moléculas de aguas vecinas. Este aumento en la estructuración disminuye la densidad alrededor de la esfera de hidratación en un $30 \%$. Entonces por razones entrópicas, el secuestro de grupos no polares al interior de la proteína es energéticamente favorable.

- Los dipolos permanentes e inducidos, que generalmente son cuantificados como fuerzas de van der Waals, también son importantes en la estabilización de la estructura nativa.

Otro tipo de contribución a los parámetros termodinámicos en la conformación proteica se da por los cambios en la estructura del agua que rodea los grupos polares y no polares, ya que ambos estructuran las moléculas de agua a su alrededor de manera diferente. Por ejemplo, el campo electrostático alrededor de los grupos polares ordena las moléculas de agua en interacciones ion-dipolo y dipolo-dipolo. Por tanto, la energía de solvatación es favorable y la contribución a esta es principalmente entálpica. Sin embargo, estudios por difracción de neutrones de alta energía muestran que las cargas iónicas son disruptivas, lo que lleva a una disminución en el número de puentes de hidrógeno entre moléculas de agua. No obstante, el ordenamiento de las moléculas de agua con la partícula polar está asociada con una reducción en la entropía que contribuye a la energía del proceso. Por su parte, en los residuos no polares se ordena la estructura del agua y se optimizan los puentes de hidrógeno entre las aguas. Se crea un fuerte entorno de hidratación donde la 
autodifusión y la reorientación de las moléculas de agua disminuye alrededor de un $20 \%$, reduciendo la entropía [13].

Finalmente en la superficie de hidratación, es posible encontrar moléculas de agua internas que contribuyen en la estabilidad de la proteína y proveen la flexibilidad necesaria para sus actividades biológicas [14].

\section{Algunos Aspectos Termodinámicos}

Para comprender los aspectos termodinámicos necesarios en la estabilidad proteica, en determinados casos, es suficiente con describir la transición entre dos estados, el estado nativo $N$ y el estado desnaturalizado $D$. Las transiciones $N$ - $D$ en proteínas están dadas por procesos altamente cooperativos. Un modelo simple para expresar la estabilidad en las proteínas es aquel que considera el paso del estado plegado-desplegado como una transición de fase. Así, los cambios en la energía libre están asociados con la transición $\Delta G=$ $G_{D}-G_{N}$. Sin embargo, hay múltiples maneras de inducir la transición en $\Delta G$, lo que lo convierte en una función multidimensional donde todos sus parámetros pueden estar variando independientemente en un experimento, e.j. temperatura $T$, presión $P$, cosolvente $x$, concentración del cosolvente $c x$, $p H$, etc. Entonces,

$$
\Delta G=\Delta G_{0}+f\left(T, P, c_{x}, p H, \ldots\right),
$$

donde $\Delta G_{0}$ depende solamente del estado de referencia. La función $f$, contiene todos los parámetros del sistema que caracterizan la transición de desnaturalización de una proteína en agua. Es decir, cambios de entropía, compresibilidad, calor especifico, expansión térmica, etc. Sí estos parámetros no dependen fuertemente de las condiciones experimentales, una expansión de segundo orden en términos de los parámetros de control $P$, $T$, etc., es suficiente para describir que el límite de la fase está determinado por la condición $\Delta G=0$.

Ahora, de los parámetros asociados con el solvente, consideremos que son constantes y sólo analicemos las variaciones en $P$ y $T$. Entonces, la transición estaría caracterizada por el calor latente, y consecuentemente estará gobernada por la ecuación de Clausius-Clapeyron.

$$
d P / d T=\Delta S / \Delta V,
$$

$\Delta S$ y $\Delta V$ son los cambios de entropía y volumen asociados con la transición, donde ambos valores son dependientes de $P$ y $T$. Por tanto, con la primera derivada del volumen con respecto a $P$ y $T$ obtendremos $\beta_{T}=$ $-(\partial V / \partial P)_{T}$ y $\alpha=(\partial V / \partial T)_{P}$, donde los cambios en volumen respecto a la presión y la temperatura están fuertemente relacionados con la compresibilidad y la expansión térmica de la proteína, respectivamente. En igual 
orden de ideas, la derivada de la entropía con respecto a $P$ y $T$ estará asociada con la expansión térmica y la capacidad calórica $C_{p}=T(\partial S / \partial T)_{P}$, respectivamente.

Si $\Delta S$ y $\Delta V$ en la Ec. 1.2 depende linealmente de $P$ y $T$, la ecuación puede ser integrada, resultando una curva de segundo orden en $P$ y $T$ que puede ser de forma elíptica, parabólica, o hiperbólica.

$$
a P^{2}+b T^{2}+2 c P T+2 f P+2 g T+\text { const }=0
$$

Los coeficientes $a, b, c$, etc., están relacionados con los cambios en los parámetros del sistema, $\Delta \beta_{T}, \Delta \alpha, \Delta C_{p}, \Delta V$ y $\Delta S$ a lo largo de la transición $N-D$ [13].

\section{Estabilidad Vs. Altas Temperaturas}

Durante la transición al estado desnaturalizado inducido por la temperatura, la proteína pasa de un estado estructuralmente bien organizado a otro con características aleatorias, en el que por ejemplo, los aminoácidos hidrofóbicos pueden estar en contacto con el agua. Como hemos venido observando, las moléculas hidrofóbicas en contacto con agua, ordenan la estructura de la misma en lo que denominamos iceberg. Este ordenamiento local es caracterizado por una baja entropía, así como, una baja entalpía dado el alineamiento geométrico de los puentes de hidrógeno. Como consecuencia, estas estructuras están asociadas con un alto calor específico, requiriendo energía para fundirlas. Así, los cambios en el calor específico asociados con la transición $N$ - $D$ están dados por $\Delta C_{P}=C_{p D}-C_{p N}$, donde se asume que este valor es generalmente positivo. Entonces, si $\Delta C_{p}>0$, la diferencia en entalpía, $\Delta H$, en los estados $N-D$ incrementa con la temperatura acorde con $\Delta H(T)=H\left(T_{c}\right)+\Delta C_{p}\left(T-T_{c}\right)$. Al mismo tiempo, la diferencia en la entropía, $\Delta S$, incrementa mientras la estructura del solvente se funde. De esta forma a una temperatura crítica $\left(T_{c}\right)$ o de transición $T=T_{c}$, el término entálpico, $\Delta H$, y el entrópico, $-T \Delta S$, se cancelan y el cambio en $\Delta G$ es igual a cero. En altas temperaturas, $T=T_{c}$, y la transición al estado desnaturalizado es energéticamente más favorable [12,13].

\section{Estabilidad Vs. Bajas Temperaturas}

Un argumento similar al anteriormente expuesto, podría ser utilizado para explicar la desnaturalización por bajas temperaturas. En este caso denominaremos a la temperatura crítica de desnaturalización, $T_{d}$. Así $T<T_{d}$, por ende, a bajas temperaturas el término entálpico decrece llegando a ser negativo y compensando el término entrópico, $T \Delta S$, que se hace positivo al disminuir la entropía. Esto se observa mejor en la figura 1.2, donde el comportamiento de $\Delta G$ para una proteína cualquiera, indica la presencia 


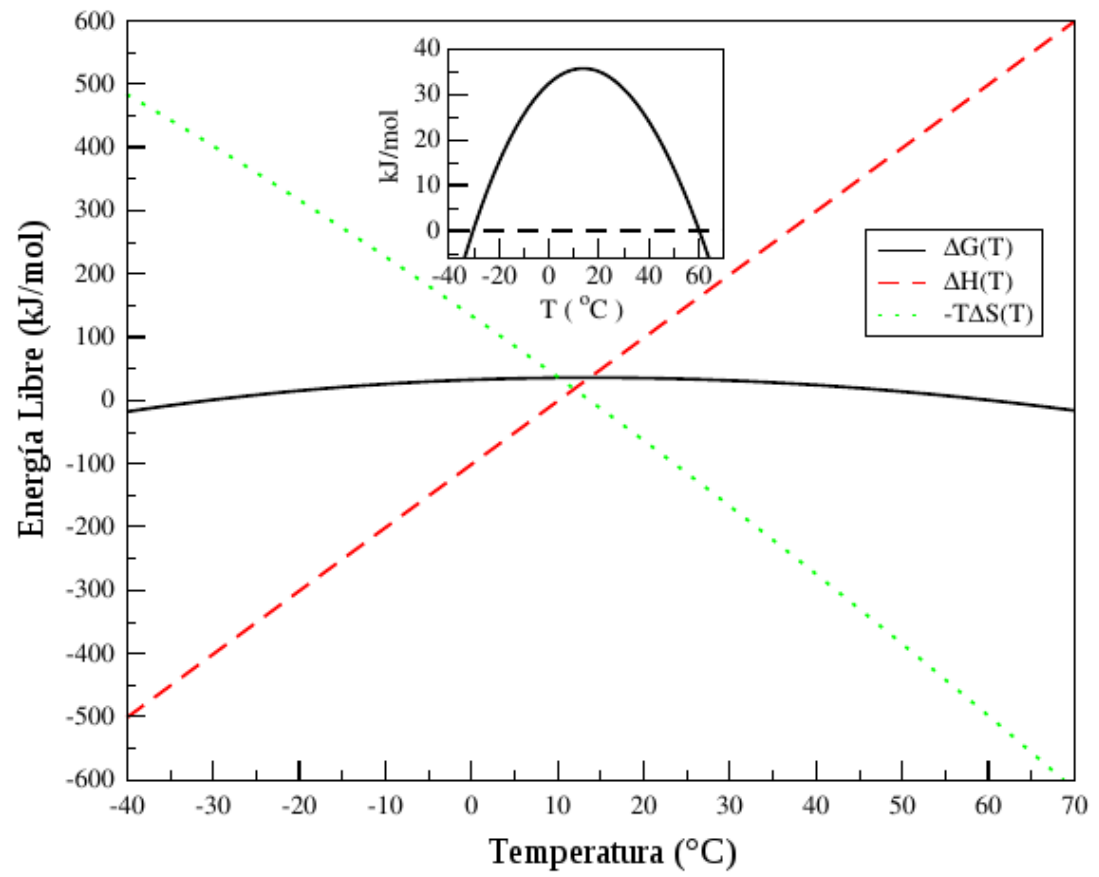

Figura 1.2: Energía libre de Gibbs $\Delta G(T)$ dependiente de la temperatura. $-T \Delta S(T)$ y $\Delta H(T)$ hacen referencia a la energía entrópica y entálpica de una proteína nativa. En el recuadro superior se observa la energía libre de Gibbs en estado nativo y desnaturalizado para $T_{c}$ y $T_{d}$, que se explican en el texto. (Gráfica modificada de la referencia [6]).

de dos fases de transición para $\Delta G(T)=0$. Dichas transiciones corresponden a $T=T_{c}$, para altas temperaturas y $T \approx-30{ }^{\circ} \mathrm{C}\left(T_{d}\right)$, para bajas temperaturas $[6,13]$.

En proteínas típicas como la analizada en la figura 1.2, la desnaturalización en frío ocurre a temperaturas inferiores al punto de congelación del agua, la cual es una característica indeseable desde el punto de vista de los estudios experimentales, que para evitar este inconveniente utilizaban anticongelantes, mutaciones puntuales en la proteína, desnaturalizantes químicos, altas presiones etc., $[15,16]$ modificando cualitativamente $\operatorname{los} T_{c}$ y $T_{d}$ de las proteínas. Sin embargo, hace poco se descubrió que la frataxina, Yfh1 [17], tiene la capacidad de desnaturalizar a $0{ }^{\circ} \mathrm{C}$ en condiciones fisiológicas, obteniendo un mejor perfil termodinámico del proceso. Por ende, es el modelo proteico elegido en la presente tesis para el estudio de la desnaturalización en frío que se presenta en el capítulo 5.

Siguiendo con lo analizado en la figura 1.2, la desnaturalización en frío en proteínas puede ser interpretada desde el punto de vista del efecto hi- 
drofóbico. Por ejemplo, la transferencia de moléculas hidrofóbicas en estado líquido al agua puede ser entendida en términos de la energía libre de Gibbs como: $\Delta G=G_{\text {Agua }}-G_{\text {Soluto }}$. Si $\Delta G$ es positivo, los solutos no polares se organizan unos con otros, evitando las moléculas de agua (debido a que las interacciones agua-agua son favorecidas en relación a las interacciones aguasoluto, los solutos no polares son segregados por el solvente), de esta forma cuando más positivo es el termino $\Delta G$, hay una mayor tendencia de los solutos a agregarse. Si $\Delta G$ es negativo, implica que las moléculas de soluto son solubles en agua.

Un ejemplo de esto lo podemos ver con la energía de transferencia, 24, 4 $\mathrm{kJ} \mathrm{mol}{ }^{-1}$, de moléculas de metano en agua a $25^{\circ} \mathrm{C}$. Donde la contribución entálpica al $\Delta G$ es negativa, $-4,3 \mathrm{~kJ} \mathrm{~mol}^{-1}$, mientras que la contribución entrópica, $-T \Delta S$, es positiva, $28,7 \mathrm{~kJ} \mathrm{~mol}^{-1}$. En otras palabras, la hidratación de solutos no polares se caracteriza por un pequeño valor favorable de entalpía y un elevado valor desfavorable de entropía [6, 12].

Simplificando, en la hidratación hidrofóbica, la primera esfera de hidratación (Shell Water) es más ordenada y forma más puentes de hidrogeno que las aguas fuera de esta esfera (Bulk Water). La formación de cajas de clatrato minimizan la energía libre de las aguas en la shell, aunque, esta energía libre es mayor comparada con las aguas del bulk, por lo cual la energía libre de hidratación de positiva. Cuanto más solutos son agregados al agua estos se agrupan reduciendo en número de aguas en la shell. De esta manera en la interacción hidrofóbica, la agregación de solutos incrementa la entropía y la entalpía del sistema (Ver figura 1.1). Sin embargo, esta (la interacción hidrofóbica) es estabilizada por la entropía y desestabilizada por la entalpía. Asimismo, no debemos olvidar que la interacción hidrofóbica se debilita con la disminución de la temperatura, lo cual es algo contraintuitivo si tenemos presente que la interacción entre átomos incrementa cuando la energía térmica disminuye. Al enfriar una proteína, el efecto estabilizante de la entropía y el desestabilizante de la entalpía, incrementan, indicando que las diferencias entre el agua bulk y shell aumentan con el descenso de la temperatura. Aun así, los términos entrópicos y entálpicos no tiene la misma tasa de cambio. La penalidad entálpica incrementa más rápido con el enfriamiento, conllevando al debilitamiento de la interacción hidrofóbica [6].

De lo anterior, Privalov expone que en el microestado, el mecanismo de desnaturalización en frío, es explicado por la solvatación de los residuos de aminoácidos presentes en el núcleo proteico, favorecida por la contribución entálpica en la hidratación de los aminoácidos polares y no polares $[12,17$, 18]. Sin embargo, Muller argumenta que la compensación entálpica realmente implica la optimización de los puentes de hidrógeno entre las moléculas de agua presentes en la interfase agua-solutos hidrofóbicos [19].

Recientemente, Dias y colaboradores [20], tratan de dar una descripción atómica del mecanismo de desnaturalización en frío dependiente de la tem- 
peratura, modelando homopolímeros no polares utilizando el modelo de agua Mercedes-Benz (MB) [21]. Las moléculas de agua interaccionan con un potencial de van ders Waals y la interacción de los puentes de hidrógenos son modelados con un potencial Gaussiano, favoreciendo la distancia y orientación entre moléculas de agua. Los resultados de las simulaciones muestran que la energía de los puentes de hidrógeno es mayor en las aguas shell que las aguas bulk. En este modelo, en soluciones congeladas es energéticamente más favorable el incremento de la superficie proteica expuesta al solvente, induciendo la desnaturalización proteica. De esta forma, las moléculas de agua forman cajas ordenadas al rededor de los residuos de la proteína por interacciones fuertes en sus puentes de hidrógeno, disminuyendo la entropía del agua e incrementando la entropía asociada con el desplegado proteico, aun así, la entropía total del sistema decrece.

\section{Estabilidad Vs. Alta Presión}

El referirnos a la desnaturalización por presión, nos lleva a 1914 cuando Bridgman reporta el efecto de la presión en la coagulación de albumina [22]. En este artículo, el autor describe cualitativamente los efectos de la desnaturalización por presión, analizando además, el efecto aditivo que tienen las bajas temperaturas en el fenómeno. De esta forma, cuando se somete la albumina a $6000 \mathrm{~atm}$ a $0{ }^{\circ} \mathrm{C}$ ocasiona una rigidez mayor en la estructura proteica en relación a la producida por el sistema a $20{ }^{\circ} \mathrm{C}$. Tal vez, lo más interesante del trabajo de Bridgman es el interrogante que se abre al final del mismo cuando expone:

"No he hecho ningún intento en determinar si la naturaleza de la coagulación producida por presión es igual a la producida por calor. Si uno puede juzgar por las apariencias, los dos pueden ser diferentes."

Después de esto, esta nueva e inadvertida problemática se mantuvo inactiva por más de medio siglo. En 1976, Weber y colaboradores, demuestran que la desnaturalización por presión de la lisozima y el quimiotripsinógeno no ocurren a través de una simple transición, sino por una pluralidad de procesos. Esto propuso la primera evidencia que contradecía el dogma de la desnaturalización proteica; en el cual, la desnaturalización está representada por los estados de reacción plegado-desplegado [8, 23].

En proteínas, la presión puede inducir cambios que van desde pequeños efectos conformacionales, variaciones en la comprensibilidad y la fluctuación en la población de estados intermediarios, hasta la completa perdida del estado nativo. Sin embargo, la estructura secundaria no es sensitiva a la presión, ya que los puentes de hidrógeno en las hélices $\alpha$ y las hojas $\beta$ son altamente incompresibles, incluso a presiones cercanas a $10 \mathrm{kbar}$ [8]. 
Con el paso del tiempo, muchos autores han propuesto teorías para la desnaturalización por alta presión, llegando a un desacuerdo en lo que respecta a la acción de la presión en la organización de los microestados proteicos.

Algunos autores proponen la disminución del efecto hidrofóbico con el aumento de la presión, es decir, se desestabiliza el sistema solvente-proteína y se exponen los residuos no polares al solvente [24-26]. Mientras que para otros, las proteínas en alta presión son penetradas por el solvente, así las interacciones de corto alcance entre aminoácidos son reemplazadas por interacciones con el agua [7]. Esto último, implica que la formación de estructuras nativas sea extremadamente dependiente de la formación de cavidades excluyentes de moléculas de agua [27].

Un ejemplo termodinámico simple, respecto al debate anteriormente expuesto, del efecto de la presión en la constate de equilibrio $K$ de un proceso, está dado por:

$$
\left(\frac{\partial(\ln K)}{\partial p}\right)_{T}=-\Delta V / R T,
$$

donde $\Delta V$ es el cambio de volumen, $R$ la constate universal de los gases, $T$ la temperatura, y $P$ la presión. Entonces, un proceso en el que sea favorecido el aumento de la presión tendría como resultado la disminución del volumen del sistema $(-\Delta V)$. Para el caso de la interacción hidrofóbica, la esfera de hidratación cercana a la superficie de los solutos no polares trasciende de un estado de baja a alta densidad, lo que hace pensar que la presión optimiza la interacción hidrofóbica. Esta afirmación solo es aplicable en valores moderados de presión, ya que eventualmente con el aumento de la presión la interacción hidrofóbica se ve debilitada. De esta forma, en altas presiones la región de hidratación de estructuras no polares, está compuesta principalmente por agua en alta densidad. Como consecuencia, la asociación de partículas no polares y la liberación de las moléculas de agua de la esfera de hidratación no ofrece ninguna ganancia entrópica, lo que desfavorece la interacción hidrofóbica [26].

\section{Diagrama de Fase Proteico T-P}

Generalmente, para un determinado valor de $T$ y $P$, los sistemas tienden a minimizar la energía libre de Gibbs, que en nuestro caso viene dado por el balance de energía libre entre las moléculas de agua y los residuos proteicos. De esta forma, la diferencia entre los estados $\Delta G=G_{D}-G_{N}$, está dada por:

$$
\Delta G=\Delta H-T \Delta S<0,
$$

donde $\Delta H=H_{D}-H_{N}$, y $\Delta S=S_{D}-S_{N}$. Ahora bien, la variación total en la entropía del sistema está dada por $\Delta S=S_{P}+S_{W}$, donde $S_{P}$ 


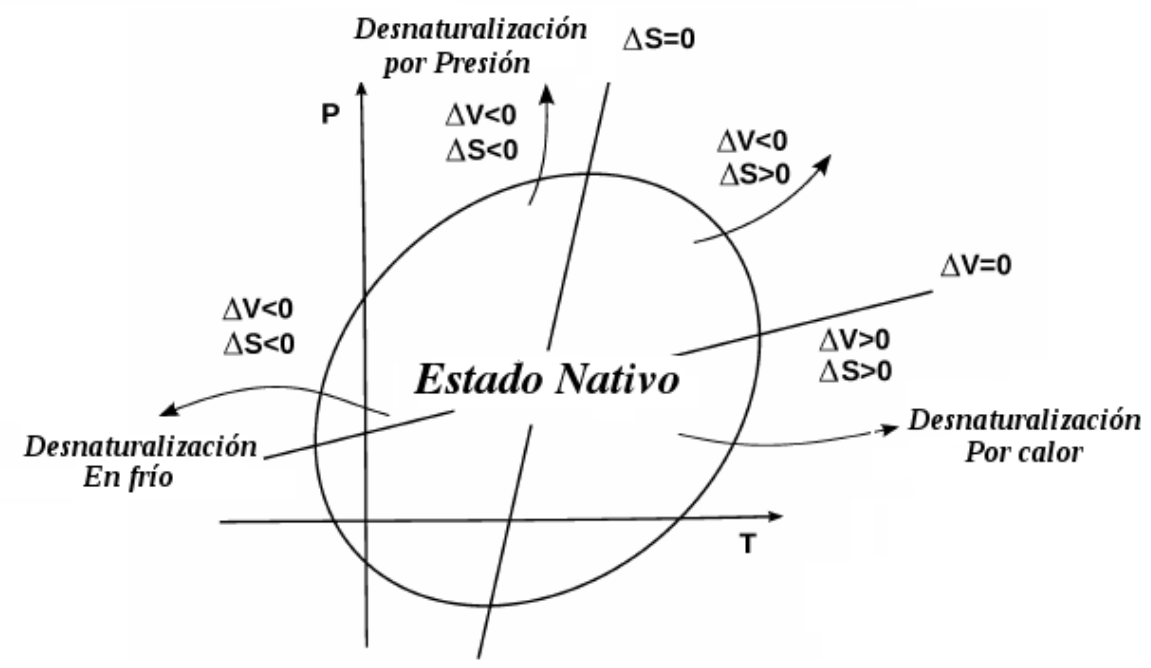

Figura 1.3: Proyección en el plano $P-T$, que representa el diagrama de fase elíptico de una proteína. Dentro del elipse la proteína conserva su condición nativa. Fuera de esta la proteína puede ser desnaturalizada por el aumento en $T$ (desnaturalización por calor) o $P$ (desnaturalización por presión), y por el descenso en $T$ (desnaturalización en frío). Cada proceso $N$ - $D$, está caracterizado por diferentes variaciones en $\Delta S$ y $\Delta V$. (Modificado de la referencia [28]).

y $S_{W}$ hacen referencia a la variación entrópica de los residuos proteicos y las moléculas de agua, respectivamente. En la desnaturalización, la entropía incrementa $\Delta S_{P}>0$. De igual manera, la contribución al $\Delta H$ es positiva, $\Delta H_{P}>0$; que como hemos venido analizando, la entalpía en las proteínas aumenta al desplegarse. Por tanto, la contribución al $\Delta G$, por parte del $\Delta H_{P}-T \Delta S_{P}$, puede ser positivo o negativo dependiendo de la variación relativa de la temperatura, lo cual no garantiza que la Ec.1.5 sea satisfecha. De allí la importancia del agua en el modelo.

Los datos experimentales del diagrama de fase de estabilidad proteica en el plano de $P$ - $T$, es consistente con la forma elíptica que se muestra en la figura 1.3, según el trabajo presentado en 1971 por Hawley [29]. En relación a este trabajo, es posible calcular el $\Delta G$ del sistema proteína-agua asumiendo los dos estados $N-D$. Sí tenemos en cuenta que la energía interna $U$ del sistema, podemos expresar la variación infinitesimal $d U$, como función de dos cantidades termodinámicas. Así, sí asumimos que el proceso de desnaturalización puede ser descrito por una transformación infinitesimal cuasiestática, aplicando la primera ley de la termodinámica, tenemos:

$$
d U=\delta Q-\delta W
$$


donde $\delta Q$ y $\delta W$, son el calor infinitesimal absorbido y el trabajo infinitesimal hecho por el sistema, respectivamente, a lo largo de la transformación. Ya que a $T$ y $P$ constate, $\delta Q=T d S$ y $\delta W=P d V$, la variación de energía interna para un número constante de partículas $N$, puede ser expresada de la forma:

$$
d U=T d S-P d V \equiv d U(S, V),
$$

y para $H=U+P V$, obtenemos:

$$
d H=d U+P d V+V d P=T d S+V d P \equiv d H(S, P),
$$

y con $G=H-T S$, finalmente obtenemos:

$$
d G=d H-T d S-S d T=-S d T+V d P \equiv d G(T, P)
$$

Por tanto,

$$
d \Delta G=-\Delta S d T+\Delta V d P
$$

donde $\Delta S \equiv S_{D}-S_{N}$, y $\Delta V \equiv V_{D}-V_{N}$. Asumiendo que $\Delta S$ y $\Delta V$ son $T$ y $P$ dependientes, obtenemos:

$$
\begin{aligned}
& \Delta S=\Delta S_{0}+\left(\frac{\partial \Delta S_{0}}{\partial T}\right)_{P}\left(T-T_{0}\right)+\left(\frac{\partial \Delta S_{0}}{\partial P}\right)_{T}\left(P-P_{0}\right), \\
& \Delta V=\Delta V_{0}+\left(\frac{\partial \Delta V_{0}}{\partial T}\right)_{P}\left(T-T_{0}\right)+\left(\frac{\partial \Delta V_{0}}{\partial P}\right)_{T}\left(P-P_{0}\right),
\end{aligned}
$$

integrando las Ec.1.11 y 1.12:

$$
\begin{aligned}
\Delta G(P, T) & =\frac{\Delta \beta}{2}\left(P-P_{0}\right)^{2}+2 \Delta \alpha\left(P-P_{0}\right)\left(T-T_{0}\right) \\
& -\Delta C_{P}\left[\left(T-T_{0}\right)-T_{0} \ln \left(T / T_{0}\right)\right] \\
& +\Delta V_{0}\left(P-P_{0}\right)-\Delta S_{0}\left(T-T_{0}\right)+\Delta G_{0},
\end{aligned}
$$

Así, obtenemos una expresión de la forma predicha en la Ec. 1.3, donde $\Delta G_{0}, \Delta V_{0}$, y $\Delta S_{0}$, son las condiciones de referencia cuando $P_{0}(0.1 \mathrm{MPa})$ y $T_{0}(298 \mathrm{~K})$. Se asume que los parámetros de segundo orden $\Delta \beta, \Delta \alpha, \Delta C_{p}$ son independientes de la presión y la temperatura.

De esta manera y retornando nuevamente a la figura 1.3, la presión máxima a la cual se estabiliza una proteína, $d \Delta G / d T=\Delta S=0$, y a la temperatura máxima a la cual se estabiliza la proteína $d \Delta G / d P=\Delta V=0$. Así, basados en la teoría de Hawley es posible hacer predicciones generales acerca de los cambios en $\Delta V$ y $\Delta S$, tal como se muestra en la figura 1.3. 


\section{Ensamble de moléculas Anfifílicas}

Como hemos venido analizando a lo largo del presente capítulo, en la arquitectura molecular de proteínas el agua toma un rol importante en la estructura tridimensional de la misma. De igual manera, la problemática entorno a las fuerzas que determinan el plegamiento proteico, son extendidas al efecto que estás tienen en la arquitectura molecular de las moléculas anfifílicas ensambladas (el término anfifílico se da desde el punto de vista de la solvatación. Es una característica dual que consiste en una región no polar hidrofóbica, -usualmente cadenas hidrocarbonadas-, y una polar hidrofílica relacionada comúnmente con el grupo de la cabeza; un ejemplo de esto es lo observado en surfactantes como el dodecilsulfato sódico o SDS) [30].

La agregación de moléculas anfifílicas en soluciones acuosas puede generar una variedad de estructuras supramoleculares, dependiendo del anfifílo en estudio, que van desde micelas esféricas, alargadas (rodlike), bicapas, estructuras en multicapas como lamelas, fases cubicas, hexagonales, etc [31]. Es casi generalmente aceptado que el ambiente acuoso es un prerrequisito indispensable para que se lleve a cabo el autoensamble de estas moléculas. Lo cual no implica que no se puedan agregar en otros solventes, como por ejemplo, hidrazina, formamida, etilenglicol, y nitrato de etilamonio [9].

Una de las fuerzas impulsoras generalmente aceptadas en la agregación de anfifílos es la interacción hidrofóbica [32]. En agua, la formación de micelas está dada por una contribución entrópica favorable, además la entalpía y entropía de formación es fuertemente dependiente de la temperatura, por ejemplo y al igual que en las proteínas, a elevadas temperaturas la formación de micelas es favorecida por la ganancia entálpica y contrarrestada por la pérdida entrópica [33]. Por tanto, la dependencia con la temperatura en la formación de micelas en agua, es similar a la solvatación de compuestos no polares, lo que sugiere que este proceso de agregación molecular puede ser descrito en términos de la interacción hidrofóbica. Lo que al igual que en las proteínas nos lleva al eterno debate referente a la interpretación molecular de la agregación de moléculas anfifílicas. Al respecto, Evans y Miller enfatizan en la importancia de las interacciones de van der Waals en la agregación micelar, y Ben-Naim [21], propone que es el solvente el que induce a la contribución de las fuerzas de van der Waals en las interacciones soluto-soluto [9].

Por otra parte, un efecto interesante presente en los anfifílos, es que estos bajo presión presentan cambios de volumen que llegan a ser positivos cuando la presión incrementa considerablemente. Varios autores demuestran experimentalmente en surfactantes iónicos y no iónicos (SDS y Triton X-100, respectivamente) que en rango de presión entre 100-200 Mpa, el número de agregación de los monómeros disminuye, creando micelas de menor tamaño, pero una vez la presión supera $200 \mathrm{Mpa}$, el número de agregación aumenta, generando micelas de mayor tamaño. Estas fluctuaciones en el número de 
agregación micelar evidencian cambios de volúmenes negativos a positivos en función de la presión [34-36]. Sin embargo, como analizaremos en el capítulo 3 , los cambios en el número de agregación en altas presiones conllevan a un cambio en la geometría de agregación que no se condice con la formación de micelas esféricas de mayor tamaño.

\section{Objetivos}

A continuación, se detallan los objetivos a partir de los cuales fue desarrollada la presente Tesis.

\section{Objetivos Generales}

- Establecer el mecanismo de la desnaturalización proteica por bajas temperaturas y alta presión, definiendo con mayor claridad el comportamiento de la interacción hidrofóbica en el proceso.

- Estudiar el efecto de la presión y la temperatura en la agregación y desagregación de surfactantes anfifílicos que permita incorporar información referente a las transiciones estructurales en moléculas con características hidrofóbicas.

\section{Objetivos específicos}

- Estudiar mediante simulación por Dinámica Molecular la desnaturalización en frio de proteínas (bajas temperaturas y alta presión), aportando información dinámica y estructural que esclarezca los mecanismos que intervienen en el proceso.

- Por otra parte, se propone esclarecer la acción de la presión en el autoensamblaje de sistemas anfifílicos, tipo surfactantes, con características altamente hidrofóbicas, buscando incorporar nueva información en el fenómeno de desnaturalización en frío por acción de la presión. 



\section{Bibliografía}

[1] Haydyn DT Mertens and Dmitri I Svergun. Structural characterization of proteins and complexes using small-angle x-ray solution scattering. Journal of structural biology, 172(1):128-141, 2010.

[2] David R Shortle. Structural analysis of non-native states of proteins by nmr methods. Current opinion in structural biology, 6(1):24-30, 1996.

[3] Robert Zwanzig, Attila Szabo, and Biman Bagchi. Levinthal's paradox. Proceedings of the National Academy of Sciences, 89(1):20-22, 1992.

[4] Wolfgang Doster and Marcus Settles. Protein-water displacement distributions. Biochimica et Biophysica Acta (BBA)-Proteins and Proteomics, 1749(2):173-186, 2005.

[5] Miquel Adrover, Veronica Esposito, Gabriel Martorell, Annalisa Pastore, and Piero Andrea Temussi. Understanding cold denaturation: the case study of yfh1. Journal of the American Chemical Society, 132(45):16240-16246, 2010.

[6] Cristiano L Dias, Tapio Ala-Nissila, Jirasak Wong-ekkabut, Ilpo Vattulainen, Martin Grant, and Mikko Karttunen. The hydrophobic effect and its role in cold denaturation. Cryobiology, 60(1):91-99, 2010.

[7] Gerhard Hummer, Shekhar Garde, Angel E García, Michael E Paulaitis, and Lawrence R Pratt. The pressure dependence of hydrophobic interactions is consistent with the observed pressure denaturation of proteins. Proceedings of the National Academy of Sciences, 95(4):1552$1555,1998$.

[8] Jerson L Silva, Andrea C Oliveira, Tuane CRG Vieira, Guilherme AP de Oliveira, Marisa C Suarez, and Debora Foguel. High-pressure chemical biology and biotechnology. Chemical reviews, 114(14):7239-7267, 2014.

[9] Wilfried Blokzijl and Jan BFN Engberts. Hydrophobic effects. opinions and facts. Angewandte Chemie International Edition in English, 32(11):1545-1579, 1993. 
[10] Henry S Frank and Marjorie W Evans. Free volume and entropy in condensed systems iii. entropy in binary liquid mixtures; partial molal entropy in dilute solutions; structure and thermodynamics in aqueous electrolytes. The Journal of Chemical Physics, 13(11):507-532, 1945.

[11] W Kauzmann. Some factors in the interpretation of the protein denaturation. Advances in protein chemistry, 14:1, 1959.

[12] Peter L Privalov. Cold denaturation of protein. Critical reviews in biochemistry and molecular biology, 25(4):281-306, 1990.

[13] Christina Scharnagl, Maria Reif, and Josef Friedrich. Stability of proteins: temperature, pressure and the role of the solvent. Biochimica et Biophysica Acta (BBA)-Proteins and Proteomics, 1749(2):187-213, 2005.

[14] Kazufumi Takano, Jun Funahashi, Yuriko Yamagata, Satoshi Fujii, and Katsuhide Yutani. Contribution of water molecules in the interior of a protein to the conformational stability. Journal of molecular biology, 274(1):132-142, 1997.

[15] Annalisa Pastore, Stephen R Martin, Anastasia Politou, Kalyan C Kondapalli, Timothy Stemmler, and Piero A Temussi. Unbiased cold denaturation: low-and high-temperature unfolding of yeast frataxin under physiological conditions. Journal of the American Chemical Society, 129(17):5374-5375, 2007.

[16] Piero Andrea Temussi. Cold denaturation and protein stability. In Supramolecular Structure and Function 10, pages 75-85. Springer, 2011.

[17] Miquel Adrover, Gabriel Martorell, Stephen R Martin, Dunja Urosev, Petr V Konarev, Dmitri I Svergun, Xavier Daura, Pierandrea Temussi, and Annalisa Pastore. The role of hydration in protein stability: Comparison of the cold and heat unfolded states of yfh1. Journal of molecular biology, 417(5):413-424, 2012.

[18] Domenico Sanfelice, Rita Puglisi, Stephen R Martin, Lorenzo Di Bari, Annalisa Pastore, and Piero Andrea Temussi. Yeast frataxin is stabilized by low salt concentrations: cold denaturation disentangles ionic strength effects from specific interactions. PLoS ONE, 9(5):e95801, 2014.

[19] Norbert Muller. Search for a realistic view of hydrophobic effects. Accounts of Chemical Research, 23(1):23-28, 1990.

[20] Cristiano L Dias, Tapio Ala-Nissila, Mikko Karttunen, Ilpo Vattulainen, and Martin Grant. Microscopic mechanism for cold denaturation. Physical review letters, 100(11):118101, 2008. 
[21] A Ben-Naim. Statistical mechanical study of hydrophobic interaction. ii. interaction among a set of $m$ identical, spherical, and nonpolar solute particles. The Journal of Chemical Physics, 54(9):3696-3711, 1971.

[22] P.W. Bridgman. The coagulation of albumen by pressure. The Journal of Biological Chemistry, (1):511-512, 1914.

[23] Thomas M Li, John W Hook III, Harry G Drickamer, and Gregorio Weber. Plurality of pressure-denatured forms in chymotrypsinogen and lysozyme. Biochemistry, 15(25):5571-5580, 1976.

[24] W Kauzmann. Thermodynamics of unfolding. Nature, 325:763-764, 1987.

[25] Tohru Yamaguchi, Hiroaki Yamada, and Kazuyuki Akasaka. Thermodynamics of unfolding of ribonuclease a under high pressure. a study by proton nmr. Journal of molecular biology, 250(5):689-694, 1995.

[26] J Raúl Grigera and Andres N McCarthy. The behavior of the hydrophobic effect under pressure and protein denaturation. Biophysical journal, 98(8):1626-1631, 2010.

[27] Julien Roche, Jose A Caro, Douglas R Norberto, Philippe Barthe, Christian Roumestand, Jamie L Schlessman, Angel E Garcia, Catherine A Royer, et al. Cavities determine the pressure unfolding of proteins. Proceedings of the National Academy of Sciences, 109(18):6945-6950, 2012.

[28] Filip Meersman, Christopher M Dobson, and Karel Heremans. Protein unfolding, amyloid fibril formation and configurational energy landscapes under high pressure conditions. Chemical Society Reviews, 35(10):908-917, 2006.

[29] SA Hawley. Reversible pressure-temperature denaturation of chymotrypsinogen. Biochemistry, 10(13):2436-2442, 1971.

[30] Gerd Olofsson. Calorimetric studies of the association of amphiphiles in aqueous and nonaqueous solutions. Netsu Sokutei, 19(2):76-85, 1992.

[31] Muruganathan Ramanathan, Lok Kumar Shrestha, Taizo Mori, Qingmin Ji, Jonathan P Hill, and Katsuhiko Ariga. Amphiphile nanoarchitectonics: from basic physical chemistry to advanced applications. Physical Chemistry Chemical Physics, 15(26):10580-10611, 2013.

[32] Charles Tanford. The Hydrophobic Effect: Formation of Micelles and Biological Membranes 2d Ed. J. Wiley., 1980.

[33] Stefan Paula, Willy Sues, Jürgen Tuchtenhagen, and Alfred Blume. Thermodynamics of micelle formation as a function of temperature: 
a high sensitivity titration calorimetry study. The Journal of Physical Chemistry, 99(30):11742-11751, 1995.

[34] Shoji Kaneshina, Mitsuru Tanaka, Tahei Tomida, and Ryohei Matuura. Micelle formation of sodium alkylsulfate under high pressures. Journal of Colloid and Interface Science, 48(3):450-460, 1974.

[35] Nagamune Nishikido, Masamobu Shinozaki, Gohsuke Sugihara, Mitsuru Tanaka, and Shoji Kaneshina. A study on the micelle formation of surfactants in aqueous solutions under high pressure by laser light-scattering technique. i. Journal of Colloid and Interface Science, 74(2):474-482, 1980.

[36] Naoki Baden, Okitsugu Kajimoto, and Kimihiko Hara. High-pressure studies on aggregation number of surfactant micelles using the fluorescence quenching method. The Journal of Physical Chemistry B, 106(34):8621-8624, 2002. 


\section{Capítulo 2}

\section{Métodos y Análisis de Simulación}

\section{Introducción}

Antes de la década de los 50' el desarrollo de la ciencia dependía de la teoría y la experimentación para interpretar los resultados de las mediciones y hacer predicciones de los fenómenos analizados. Aunque, actualmente seguimos manteniendo este esquema como eje central, con el trascurso del tiempo, hemos incluido en el proceso algunas nuevas metodologías de investigación. Tal vez, uno de los hechos que marca el inicio de una nueva metodología en la ciencia se dio en 1953 cuando Metropolis y colaboradores [1], publican un trabajo denominado Equation of State Calculations by Fast Computing Machines donde introducen la simulación computacional como una herramienta para tratar sistemas de varias partículas en dos dimensiones.

Debemos destacar, que el surgimiento de las simulaciones computacionales solo fueron posibles con el desarrollo de los computadores digitales. Por esta razón la evolución de las simulaciones van de la mano con el desarrollo de la capacidad de calculo y la memoria en las nuevas computadoras. Así este método, de carácter complementario y muchas veces alternativo a los modos convencionales de hacer ciencia, el experimental y el teórico, ha ejercido un fuerte impacto en prácticamente todos los campos de la misma. Por esta razón, cada día es más difícil concebir el desarrollo de la ciencia sin el apoyo del calculo computacional [2,3].

Lo que un investigador científico busca con la simulación computacional es resolver los modelos teóricos, usando la resolución numérica de las ecuaciones involucradas, o en otros casos, combinan los métodos analíticos obtenidos por experimentación con aproximaciones computacionales. Así, para estudiar el comportamiento de un sistema dado se hace necesaria la elección e implementación de un modelo adecuado cuyos resultados predice la teoría y los evidencia la experimentación. De esta forma, de una simulación compu- 
tacional se obtendrán predicciones teóricas según sean las características del modelo usado, aun punto tal, de que con un buen modelo computacional los resultados obtenidos por simulación proveen valiosa información para la verificación de teorías [3].

Hasta ahora podemos decir que en una simulación computacional es importante, $(i)$ el modelo y (ii) la capacidad de calculo. Sin embargo, el desarrollo real de una simulación se da en la aplicación del método de simulación. En la actualidad, hay dos métodos de simulación ampliamente extendidos: Monte Carlo y Dinámica Molecular. El primero es un método probabilístico con el cual se pueden obtener propiedades estáticas del sistema, mientras que el segundo, es un método determinista con el que estudian las propiedades dinámicas del sistema o aquellas con dependencia temporal como la viscosidad, la difusión, etc.

En el presente capítulo, nos centraremos en explicar los fundamentos de la técnica de simulación por Dinámica Molecular utilizada en el desarrollo de la presente tesis.

\section{Simulación por Dinámica Molecular (MD)}

La MD es un tipo de cálculo de mecánica molecular que simula los movimientos de particulas, átomos o moléculas de sistemas físicos, a partir de primeros principios y a través de la integración numérica de las ecuaciones clásicas de movimiento propuestas por Newton para todos las particulas, átomos o moléculas del sistema, a medida que evoluciona temporalmente en respuesta a las fuerzas que actúan entre ellas.

Así, las simulaciones por MD resuelven las ecuaciones de Newton para un sistema de $N$ partículas que interaccionan entre sí:

$$
m_{i} \frac{\partial^{2} \mathbf{r}_{i}}{\partial t^{2}}=F_{i}, i=1 \ldots N
$$

El elemento esencial para realizar una simulación por MD es el establecimiento del potencial de interacción, a partir del cual se derivarán las fuerzas que determinarán el comportamiento del sistema. La fuerza $F_{i}$ que actúa sobre el átomo $i$ de masa $m_{i}$ se obtiene calculado la derivada de la función del potencial $V\left(\mathbf{r}_{1}, \mathbf{r}_{2}, \ldots, \mathbf{r}_{N}\right)$ con respecto a su vector de posición $\mathbf{r}_{i}$ :

$$
F_{i}=-\frac{\partial V}{\partial \mathbf{r}_{i}}
$$

Inicialmente se atribuyen a los átomos velocidades en una distribución Maxwelliana compatible con una dada temperatura. Iniciando la simulación con una serie de pequeños incrementos de tiempo, y durante cada paso de tiempo transcurrido se calcula la fuerza que actúa sobre cada partícula. 
Durante la ejecución de las simulaciones las ecuaciones se resuelven simultáneamente en pequeños pasos mientras el sistema evoluciona; cuidando de que la temperatura y la presión permanezcan alrededor de un rango de valores requeridos. Las coordenadas atómicas son registradas a intervalos regulares en el tiempo, lo cual representa la trayectoria del sistema.

La primera suposición de carácter operacional que se realiza sobre el potencial es que para las $N$ partículas que componen el sistema, este puede expresarse como la suma sobre todos los pares posibles.

$$
V\left(\mathbf{r}_{1}, \mathbf{r}_{2}, \ldots, \mathbf{r}_{N}\right)=\sum_{i<j}^{N} V_{i j}
$$

De esta forma, la fuerza sobre cualquier átomo $F_{i}$ se computa a través del calculo de la fuerza entre los pares de átomos no-enlazados $F_{i}=\sum_{j} F_{i j}$ más las fuerzas debidas a interacciones enlazantes (las cuales pueden depender de 1, 2, 3 o 4 átomos), más las fuerzas de restricción y/o externas (que analiremos más adelante).

Luego de los cambios iniciales, el sistema normalmente tiende a alcanzar un estado de equilibrio en el que minimiza su energía. Esto es importante, ya que muchas propiedades macroscópicas pueden extraerse de los datos de salida cuando se promedia sobre una trayectoria de equilibrio. Asimismo, también es posible obtener valiosa información de estos sistemas cuando las simulaciones se realizan fuera del equilibrio.

Dentro de las simulaciones por MD existen una serie de aproximaciones llevadas a cabo por la técnica que son convenientes revisar.

\section{Aproximaciones en MD}

\section{Las simulaciones son Clásicas}

El uso de las ecuaciones de movimiento de Newton implica automáticamente el empleo de la Mecánica Clásica en la descripción del movimiento de los átomos. Esto es correcto para la mayoría de los átomos a temperaturas normales, pero existen excepciones. Los átomos de hidrógeno, al poseer una masa tan pequeña, tienen movimiento de carácter esencialmente mecánico-cuántico. Por ejemplo, un protón puede moverse a través de una barrera de potencial por efecto túnel, lo cual constituye una transferencia del protón a través de un puente de hidrógeno. Este proceso no puede ser descrito por la mecánica clásica.

En la simulación por MD se soluciona este problema tratando a los enlaces covalentes y sus respectivos ángulos como restricciones topológicas o constraints (en el caso de los hidrógenos, se adsorben al átomo pesado al que están unidos). Un motivo práctico para dicho tratamiento resulta del eventual aumento en el paso de integración, lo cual resulta esencial a la ho- 
ra de permitir movimientos realistas, además de un recorrido completo del espacio configuracional.

\section{Los electrones se encuentran en el estado energético fundamental}

En la MD utilizamos campos de fuerzas conservativos, los cuales son solamente función de las posiciones de los átomos. Esto significa que los movimientos electrónicos no son tomados en cuenta: se supone que los electrones ajustan su dinámica instantáneamente al cambiar las posiciones atómicas (aproximación de Born-Oppenheimer), además de permanecer en un estado cuántico no excitado. Esto constituye una buena aproximación en la mayoría de los casos. Aunque, por supuesto, quedan excluidos los procesos de transferencia electrónica, como también aquellos con estados electrónicos excitados. Por tanto, las reacciones químicas en general se encuentran fuera del alcance de ésta técnica. Aunque, estas ultimas pueden estudiarse localmente con el empleo de herramientas híbridas como QM/MM (Mecánica Cuántica/Mecánica Molecular), con las que cuentan la mayoría de los paquetes de MD. En estos casos, se estudia la región de interés con técnicas mecánico-cuánticas y el resto del sistema clásicamente.

\section{Los Campos de Fuerza son efectivos}

Las fuerzas son calculadas a partir de los Campos de Fuerza. Los cuales están compuestos por los potenciales de interacción interatómica y los parámetros que caracterizan a las mismas. Éstos no son verdaderamente parte del método de MD y son susceptibles de modificaciones según se necesite, o bien se actualicen los conocimientos en la materia. Todos los campos de fuerzas disponibles poseen limitaciones (en general no se pueden incorporar polarizaciones y no poseen ajuste fino para los parámetros de enlace, entre otras). La existencia de un gran número de campos de fuerza permite la utilización de diferentes parametrizaciones de acuerdo al tipo de sistema a estudiar.

\section{El Campo de Fuerzas es aditivo y analiza sólo interacciones de a pares}

Esto significa que todas las fuerzas no-enlazantes resultan de la suma lineal de pares de interacciones no-enlazantes.

Las interacciones no-enlazantes que no pueden describirse por interacciones de a pares de átomos, cuyo ejemplo más importante lo constituye la interacción a través de la polarización atómica, son representadas a través de los potenciales efectivos de pares. Los mismos incorporan sólo contribuciones promedio a las interacciones no-enlazantes, no descriptibles por interacciones de a pares. Esto también significa que las interacciones de a pares no 
son puras; en otras palabras que no resultan válidas para pares aislados o para situaciones que difieran demasiado de aquellas para las cuales dichos sistemas fueron parametrizados. En la práctica, los potenciales efectivos de pares resultan ser una muy buena aproximación, siempre que esta última precaución sea debidamente considerada.

\section{Las interacciones de largo alcance son tratadas con radios de corte}

En general se utilizan radios de corte o cut-off, tanto para las interacciones de Lennard-Jones como para las interacciones Coulómbicas. Debido a la convención de la mínima imagen (sólo una imagen de cada partícula en las condiciones periódicas de contorno es considerada para la interacción de a pares), el radio de corte utilizado no puede exceder la mitad de la dimensión más pequeña del sistema (del lado más pequeño de la caja de simulación). Si no es tratado adecuadamente, esto puede presentar problemas para el tratamiento de las interacciones Coulómbicas, tales como la acumulación de cargas en la frontera del radio de corte y/o errores muy groseros en los valores de energía.

\section{Tratamiento de las Condiciones de Contorno}

¿Qué debemos hacer en los límites de nuestro sistema de simulación? Una posibilidad es no hacer nada en especial, es decir el sistema simplemente termina, y los átomos en la cercanía de los límites tendrán menos vecinos que los átomos en el interior. En otras palabras, la muestra estaría rodeada por las superficies. Esta no es una situación realista, dado que, no importa cuán grande sea el sistema simulado, el número de átomos $\mathrm{N}$ sería insignificante en comparación con el número de átomos contenidos en una porción macroscópica de materia (del orden de $10^{23}$ ), y la relación entre el número de átomos en la superficie y el número total de átomos sería mucho más grande que la existente en un sistema macroscópico, haciendo que los efectos de superficie sean mucho más importantes de lo que deberían.

Para minimizar los efectos producidos en la frontera, en una simulación finita de una porción de un sistema extenso, se utilizan las Condiciones Periódicas de Contorno (PBC). Los átomos del sistema a simular son colocados en una caja poliédrica. Este poliedro debe cumplir con la condición de que el espacio normal de tres dimensiones pueda ser particionado en cajas que sean copias idénticas trasladadas de la original. De este modo se eliminan las fronteras del sistema (Ver figura 2.1).

Esto permite remover los problemas indeseados en los bordes que posee un sistema aislado, pero introduce una periodicidad inexistente en el sistema original. Esta característica es beneficiosa para el estudio de sistemas cristalinos, por ejemplo sólidos, donde también son utilizadas.

Por el contrario, si se desea simular sistemas no periódicos tales como 
líquidos o soluciones, se deberá tener en cuenta la aparición de errores debidos a la imposición de la periodicidad. Una manera de evaluar estos errores es estudiar el efecto de la variación del tamaño del sistema (generalmente caracterizado por el número de partículas N). Usualmente estos efectos son sustancialmente menores que los que aparecen en las simulaciones sin PBC.

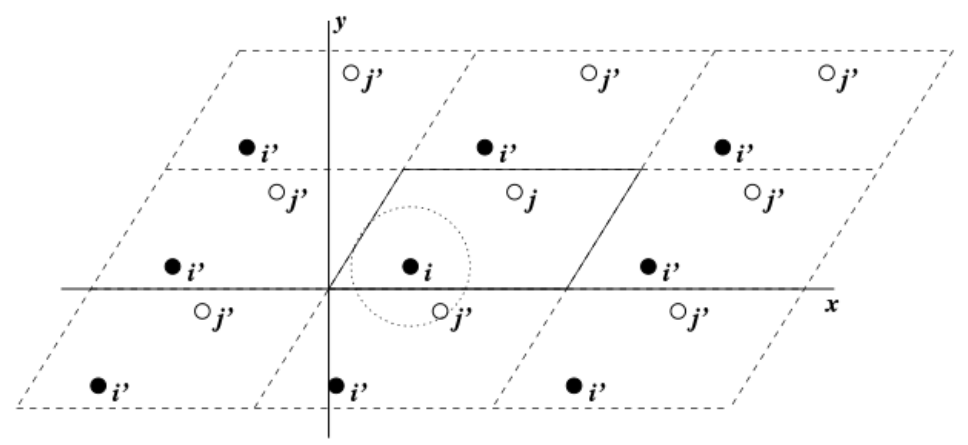

Figura 2.1: Condiciones periódicas de contorno en 2D

\section{Campo de Fuerzas}

Un campo de fuerzas se compone de dos elementos claramente distinguibles:

- El conjunto de ecuaciones (las funciones potenciales) utilizadas para generar las energías potenciales y sus derivadas, las fuerzas.

- Los parámetros utilizados en este conjunto de ecuaciones.

Dentro de un conjunto de ecuaciones pueden utilizarse varios conjuntos distintos de parámetros. Debe tenerse cuidado de que la combinación de ecuaciones y parámetros constituyan un conjunto autoconsistente. En general debe tenerse mucho cuidado al hacer modificaciones ad-hoc de algún subconjunto de parámetros, ya que las distintas contribuciones a la fuerza total son normalmente interdependientes.

Las funciones potenciales pueden subdividirse en tres categorías:

- Potenciales no-enlazantes: de repulsión-dispersión (Lennard-Jones o Buckingham) y electrostáticas (Coulómbicas o Coulómbicas modificadas).

- Potenciales enlazantes: estiramiento del enlace covalente, ángulo de enlace, diedros impropios, y diedros propios.

- Potenciales especiales: restricciones de posición, restricciones de distancia, y restricciones de orientación. 
En el presente trabajo las funciones potenciales utilizadas fueron las siguientes:

\section{Potenciales no-enlazantes}

Las interacciones no-enlazantes son aditivas de a pares y centro-simétricas:

$$
\begin{gathered}
V\left(\mathbf{r}_{1}, \ldots, \mathbf{r}_{N}\right)=\sum_{i<j} V_{i j}\left(\mathbf{r}_{i j}\right) \\
F_{i}=-\sum_{j} \frac{d V_{i j}\left(r_{i j}\right)}{d r_{i j}} \frac{\mathbf{r}_{i j}}{r_{i j}}=-F_{j} ;
\end{gathered}
$$

Donde $r_{i j}$ es la distancia entre el átomo $i$ y el átomo $j$ de nuestro sistema.

Las interacciones no-enlazantes contienen un término de repulsión, otro dispersión, y un término Coulombiano. Los términos de repulsión y dispersión (Fuerzas de London, o de van der Waals) se encuentran combinados. Se los puede modelar de diferentes maneras, ya sea mediante el potencial de Lennard-Jones (o interacción 12-6) o con el potencial de Buckingham (o interacción $e^{-6}$ ), entre otros. Además, átomos cargados (parcialmente) actúan a través del término Coulombiano.

\section{Interacción de Lennard-Jones}

El potencial más utilizado para el modelado de las interacciones de van der Waals es el potencial de Lennard-Jones, propuesto por John LennardJones. Éste puede escribirse, para un par de átomos dados, de la siguiente manera [4]:

$$
V_{L J}\left(r_{i j}\right)=\frac{C_{i j}^{12}}{r_{i j}^{12}}-\frac{C_{i j}^{6}}{r_{i j}^{6}}
$$

Aquí, el término proporcional a $r^{-12}$ representa la contribución repulsiva, mientras que aquel proporcional a $r^{-6}$ se refiere a la contribución atractiva.

Los parámetros $C_{i j}^{12}$ y $C_{i j}^{6}$ dependen del par de átomos considerado para la interacción; consecuentemente los mismos se toman de una matriz de parámetros de Lennard-Jones.

En general, los campos de fuerzas cuentan con tablas de estos parámetros de Lennard-Jones para la interacción entre átomos del mismo tipo. Por ejemplo, para los átomos $i$ y $j$ cuentan con: $C_{i i}^{6}, C_{i i}^{12}, C_{j j}^{6}$ y $C_{j j}^{12}$ mientras que los parámetros cruzados se calculan con las siguientes expresiones (promedio geométrico): $C_{i j}^{6}=\sqrt{C_{i i}^{6} C_{j j}^{6}}$ y $C_{i j}^{12}=\sqrt{C_{i i}^{12} C_{j j}^{12}}$.

La fuerza derivada de este potencial resulta por lo tanto: 


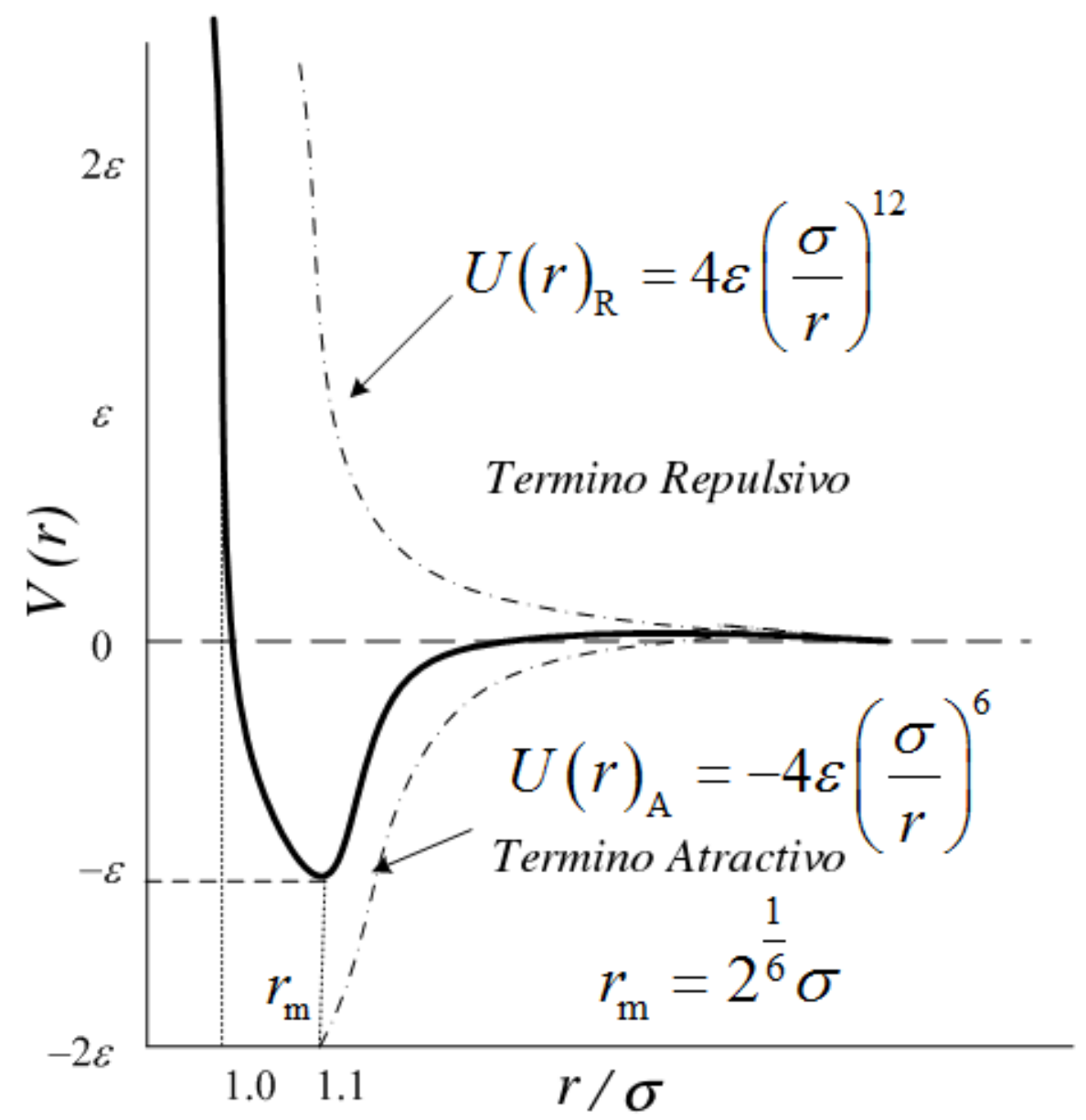

Figura 2.2: Curva potencial para la interacción repulsión-dispersión de Lennard-Jones.

$$
F_{i}\left(\mathbf{r}_{i j}\right)=\left(12 \frac{C_{i j}^{12}}{r_{i j}^{12}}-6 \frac{C_{i j}^{6}}{r_{i j}^{6}}\right) \frac{\mathbf{r}_{i j}}{r_{i j}}
$$

Aunque, el potencial de Lennard-Jones suele escribirse también de la siguiente manera:

$$
V_{L J}\left(\mathbf{r}_{i j}\right)=4 \varepsilon_{i j}\left(\left(\frac{\sigma_{i j}}{r_{i j}}\right)^{12}-\left(\frac{\sigma_{i j}}{r_{i j}}\right)^{6}\right)
$$

donde $\varepsilon_{i j}$ es la profundidad del potencial, y $\sigma_{i j}$ es la longitud de penetración (distancia a la cual el potencial vale cero) (Ver figura 2.2). Del mismo modo que los parámetros $C_{i j}^{12}$ y $C_{i j}^{6}$ se obtienen mediante promedios geométricos, podemos calcular $\varepsilon_{i j}$ y $\sigma_{i j}$ del siguiente modo: $\sigma_{i j}=\frac{1}{2}\left(\sigma_{i i}+\sigma_{j j}\right)$ y 
$\varepsilon_{i j}=\sqrt{\varepsilon_{i i} \varepsilon_{j j}}$

\section{Interacción Coulómbica}

La interacción Coulombiana entre dos partículas cargadas esta dada por:

$$
V_{c}\left(r_{i j}\right)=f \frac{q_{i} q_{j}}{\varepsilon_{r} r_{i j}},
$$

donde $f=\frac{1}{4 \pi \varepsilon_{0}}, \varepsilon_{0}$ es la permitividad eléctrica del vacío $\varepsilon_{r}$ la permitividad eléctrica relativa del medio, y $q_{i}, q_{j}$ las cargas eléctricas de las especies $i$ y $j$ respectivamente. Dicho potencial se encuentra graficado en la figura 2.3.

Por tanto, la fuerza derivada de este potencial es igual:

$$
F_{i}\left(\mathbf{r}_{i j}\right)=f \frac{q_{i} q_{j}}{\varepsilon_{r} r_{i j}^{2}} \frac{\mathbf{r}_{i j}}{r_{i j}}
$$

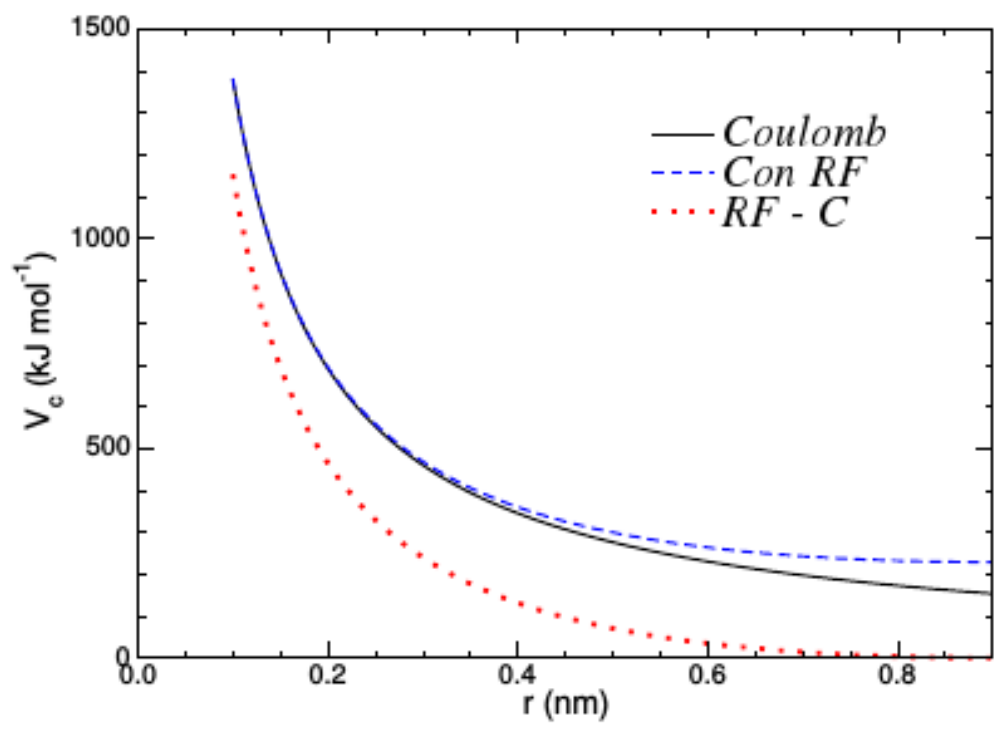

Figura 2.3: Curva potencial para la interacción Coulómbica entre partículas cargadas de igual signo con y sin campo de reacción $(\mathrm{RF})$. En el último caso $\varepsilon_{r f}=78$ y $r_{c}=0,9 n m$. Ambas líneas punteadas difieren sólo en el valor de una constante $\mathrm{C}$, pasamos de una a otra mediante la operación $\mathrm{RF}-\mathrm{C}$.

\section{Interacción Coulómbica con Campo de Reacción (RF)}

La interacción Coulombiana puede ser modificada para sistemas relativamente homogéneos, suponiendo la existencia de un medio dieléctrico continuo por fuera de un determinado radio de corte $r_{c}$ con permitividad eléctrica $\varepsilon_{r f}$ . Podemos expresar entonces dicha interacción del siguiente modo: 


$$
V_{c r f}=f \frac{q_{i} q_{j}}{r_{i j}}\left[1+\frac{\varepsilon_{r f}-1}{2 \varepsilon_{r f}+1} \frac{r_{i j}^{3}}{r_{c}^{3}}\right]-\underbrace{f \frac{q_{i} q_{j}}{r_{c}} \frac{\varepsilon_{r f}}{2 \varepsilon_{r f}+1}}_{C}
$$

En la cual el término constante de la derecha lleva el potencial a cero para $r=r_{c}$. En la figura 2.3 puede verse la interacción Coulombiana modificada. Por tanto, podemos reescribir la ecuación como:

$$
V_{c r f}=f q_{i} q_{j}\left[\frac{1}{r_{i j}}+k_{r f} r_{i j}^{2}-c_{r f}\right],
$$

donde:

$$
\left.k_{r f}=\frac{1}{r_{c}^{3}} \frac{\varepsilon_{r f}-1}{\left(2 \varepsilon_{r f}+1\right.}\right)
$$

y

$$
c_{r f}=\frac{1}{r_{c}}+k_{r f} r_{c}^{2}=\frac{1}{r_{c}} \frac{3 \varepsilon_{r f}}{\left(2 \varepsilon_{r f}+1\right)}
$$

Por tanto la fuerza derivada de este potencial esta dada como:

$$
F_{i j}\left(\mathbf{r}_{i j}\right)=f q_{i} q_{j}\left[\frac{1}{r_{i j}^{2}}-2 k_{r f} r_{i j}\right] \frac{\mathbf{r}_{i j}}{r_{i j}}
$$

\section{Potenciales enlazantes}

Las interacciones enlazantes se basan en una lista fija de átomos. Estas no están compuestas exclusivamente por interacciones de a pares, sino que incluyen también interacciones de 3 y 4 cuerpos, i.e. Interacciones de estiramiento de la longitud de enlace ( 2 cuerpos), de ángulo de enlace ( 3 cuerpos) y de ángulo diedro (4 cuerpos). También se utiliza un tipo especial de diedro (llamado diedro impropio) para que los átomos permanezcan en un determinado plano, o bien para prevenir la transición a una configuración de quiralidad opuesta (imagen especular). De esta manera, al diedro habitual se lo llama diedro propio.

\section{Potencial de estiramiento de la longitud de enlace}

\section{Potencial de Oscilador armónico}

El estiramiento (o compresión) del enlace covalente entre dos átomos $i$ y $j$ puede representarse a través de un potencial armónico:

$$
V_{b}=\frac{1}{2} k_{i j}^{b}\left(r_{i j}-b_{i j}\right)^{2}
$$


Donde la fuerza viene dada por:

$$
F_{b}\left(\mathbf{r}_{i j}\right)=k_{i j}^{b}\left(r_{i j}-b_{i j}\right) \frac{\mathbf{r}_{i j}}{r_{i j}}
$$

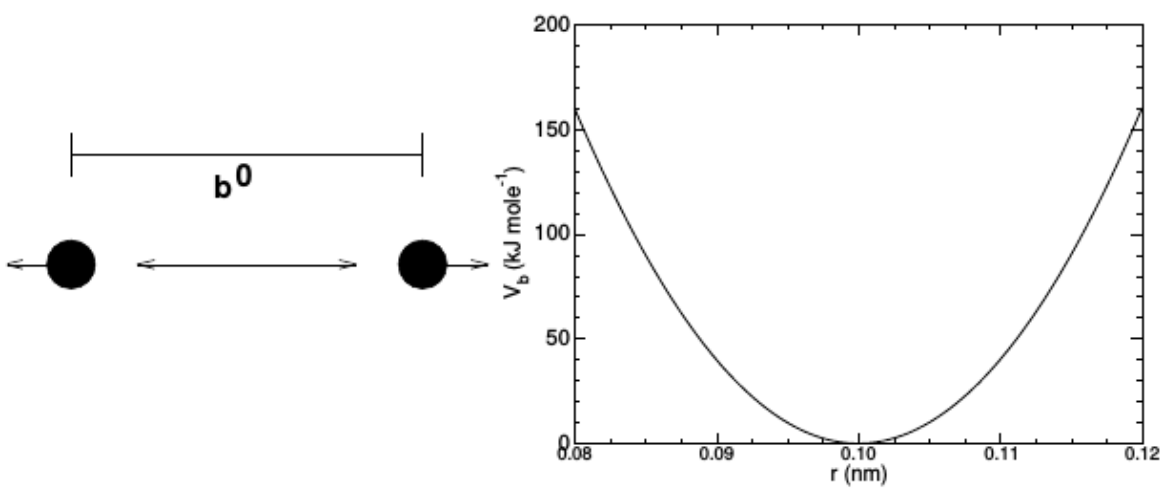

Figura 2.4: Principio del estiramiento de enlace (izquierda), y su correspondiente potencial armónico (derecha).

\section{Potencial de Morse}

Para ciertos sistemas donde se requiere un potencial no-armónico de enlace entre los átomos $i$ y $j$, el potencial de Morse resulta una alternativa muy aceptable [5]. Éste difiere del potencial armónico en que posee un pozo asimétrico además de tener fuerza de enlace cero a distancia infinita. Su forma funcional resulta:

$$
V_{\text {Morse }}\left(r_{i j}\right)=D_{i j}\left[1-e^{-\beta_{i j}\left(r_{i j}-b_{i j}\right)}\right]^{2}
$$

Cuya fuerza correspondiente es:

$$
F_{\text {Morse }}\left(\mathbf{r}_{i j}\right)=2 D_{i j} \beta_{i j} r_{i j} e^{-\beta i j\left(r_{i j}-b_{i j}\right)}\left[1-e^{-\beta_{i j}\left(r_{i j}-b_{i j}\right)}\right] \frac{\mathbf{r}_{i j}}{r_{i j}}
$$

Donde $D_{i j}$ representa la profundidad del pozo potencial en $k J / m o l, \beta_{i j}$ define que tan agudo es el pozo potencial (en $n m^{-1}$ ) y $b_{i j}$ es la distancia de equilibrio en $\mathrm{nm}$ (Ver figura 2.5)

\section{Potencial armónico de ángulo de enlace}

La vibración del ángulo de enlace entre un triplete de átomos $i-j-k$ puede representarse también a través de un potencial armónico sobre el ángulo $\theta_{i j k}$ : 


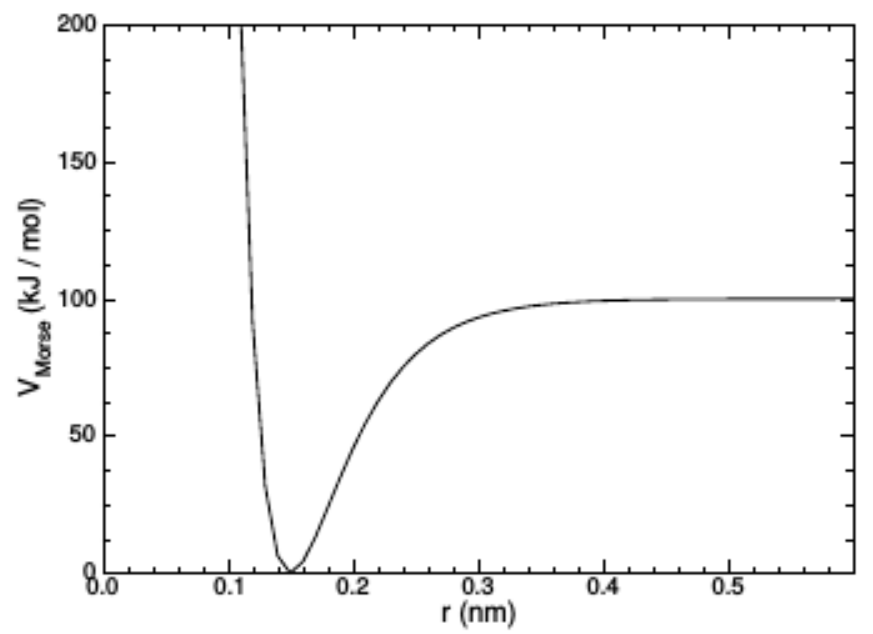

Figura 2.5: El pozo potencial de Morse, para una longitud de enlace de $0,15 \mathrm{~nm}$.

$$
V_{a}\left(\theta_{i j k}\right)=\frac{1}{2} k_{i j k}^{\theta}\left(\theta_{i j k}-\theta_{i j k}^{0}\right)^{2}
$$

Dado que la vibración del ángulo de enlace se representa con un potencial armónico, su forma es la misma que para el potencial armónico de estiramiento de enlace (Figura 2.6).

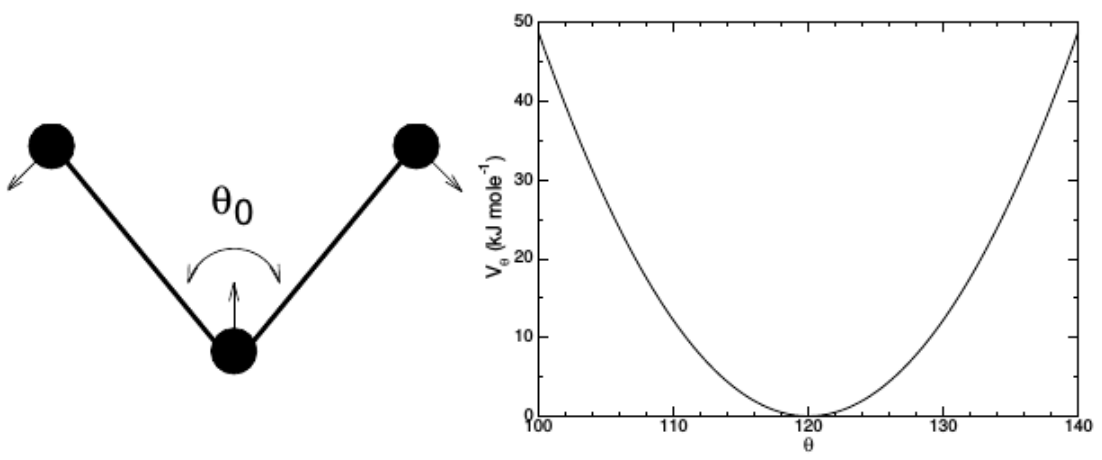

Figura 2.6: Principio de vibración de enlace (izquierda) y función potencial de ángulo de enlace (derecha).

Las ecuaciones para la fuerza vienen dadas por la regla de la cadena:

$$
F_{i}=-\frac{d V_{a}\left(\theta_{i j k}\right)}{d \mathbf{r}_{i}}
$$




$$
F_{k}=-\frac{d V_{a}\left(\theta_{i j k}\right)}{d \mathbf{r}_{k}},
$$

donde, $\theta_{i j k}=\arccos \frac{\left(\mathbf{r}_{i j} \cdot \mathbf{r}_{k j}\right)}{r_{i j} r_{k j}}$

$$
F_{j}=-F_{i}-F_{k}
$$

La nomenclatura $i, j, k$ representa la secuencia de enlace de los átomos $i, j, k$ covalentemente enlazados. El átomo $j$ se encuentra en el medio, los átomos $i$ y $k$ están en los extremos.

\section{Potencial para diedros impropios}

Los diedros impropios son utilizados para mantener la planaridad en aquellos grupos que así lo requieran (anillos aromáticos) además de mantener la quiralidad de aquellos grupos que cuenten con algún carbono asimétrico (casi todos los aminoácidos). En la Figura 2.7 se representan dichos casos esquemáticamente.
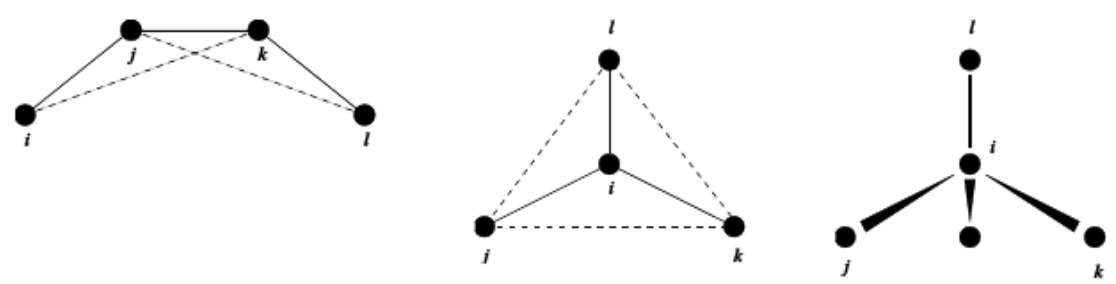

Figura 2.7: Diferentes tipos de ángulos diedros impropios. Distorsiones de anillos fuera del plano (izquierda), sustituyentes de anillos (centro) y distorsión del tetraedro (derecha). El ángulo diedro impropio se define para todos los casos como el ángulo entre los planos $(i, j, k)$ y $(j, k, l)$.

El potencial que caracteriza esta interacción estará dado por la siguiente expresión:

$$
V_{d i}\left(\xi_{i j k}\right)=k_{\xi}\left(\xi_{i j k}-\xi_{0}\right)^{2}
$$

Esto también resulta ser un potencial armónico y se encuentra representado en la Figura 2.8. Cabe destacar que, dado que es un potencial armónico, la periodicidad no es tomada en cuenta, por lo tanto resulta recomendable definir un valor de $\xi_{0}$ lo más alejado posible de $\pm 180^{\circ}$.

\section{Potencial para diedros propios}

La interacción normal para los diedros propios puede ser abordada de dos maneras diferentes; la función periódica clásica o bien una función basada en 


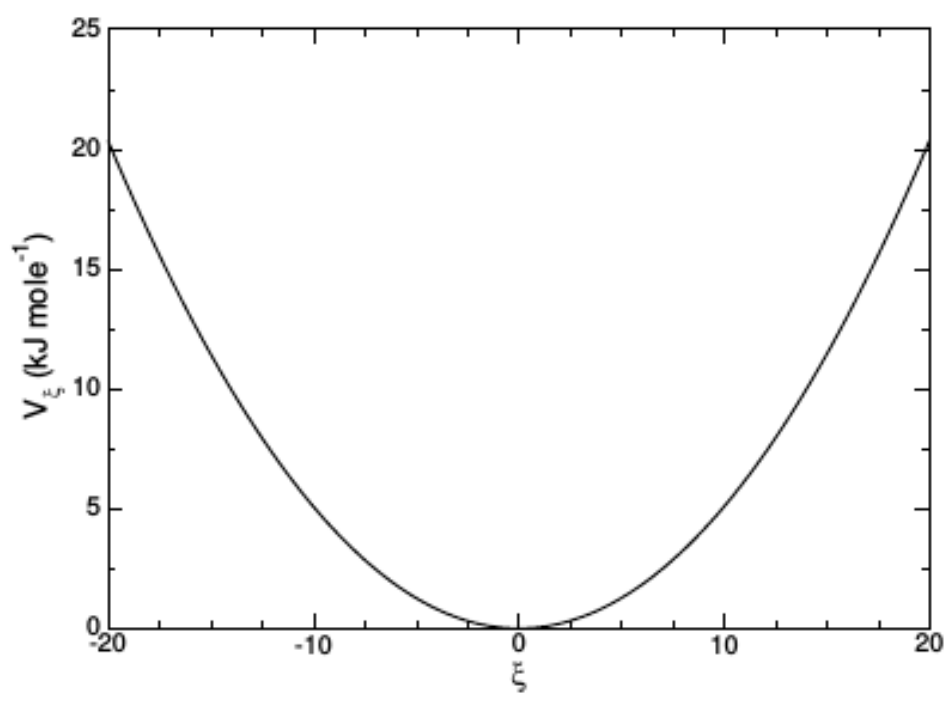

Figura 2.8: Función potencial para diedros impropios.

una expansión de potencias del $\cos \phi$ (el potencial de Ryckaert-Belleman). Esta elección tiene consecuencias ya que, si se elige la función periódica, debe incluirse una interacción especial entre el 1er y 4to átomo de la tétrada que define al diedro.

\section{Diedros propios: Potencial periódico}

Los ángulos diedros propios de definen de acuerdo a la convención IUPA$\mathrm{C} / \mathrm{IUB}$, donde $\phi$ es el ángulo entre los planos $i j k$ y $j k l$, con el cero correspondiente a la configuración cis (átomos $i$ y $l$ del mismo lado) (Ver figura 2.9).

$$
V_{d}\left(\phi_{i j k}\right)=k_{\phi}\left(1+\cos \left(n \phi-\phi_{0}\right)\right)
$$

Aquí, $\phi$ es el ángulo diedro, $\phi_{0}$ es un parámetro de corrimiento y $n$ es la multiplicidad del Potencial.

\section{Diedros propios: Potencial de Ryckaert-Bellemans}

Para alcanos suele utilizarse el siguiente potencial (Ver figura 2.10)

$$
V_{r b}\left(\phi_{i j k l}\right)=\sum_{n=0}^{5} C_{n}(\cos (\psi))^{n}
$$

Donde $\psi=\phi=-180^{\circ}$

Notas: 


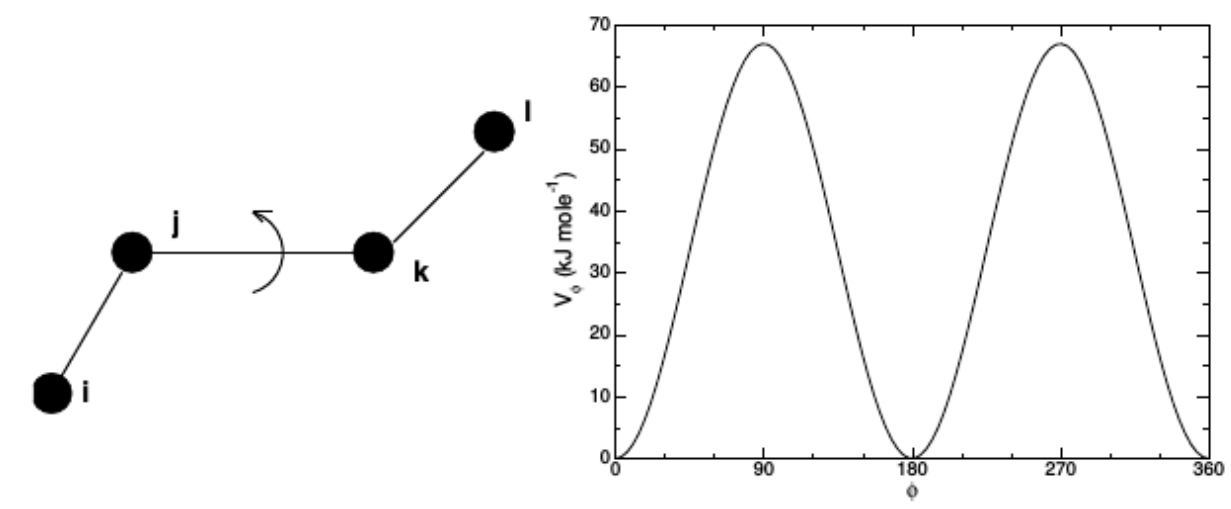

Figura 2.9: Principio para el ángulo diedro propio (izquierda, en configuración trans) y el potencial periódico para el diedro propio (derecha).

- Puede lograrse la conversión de una convención a la otra multiplicando cada coeficiente $C_{n}$ por $\left(-1^{n}\right)$.

- el uso de este potencial implica la exclusión de las interacciones 1-4 de Lennard-Jones,

\section{Interacciones Especiales}

Las interacciones especiales son utilizadas para imponer restricciones sobre el sistema, ya sea para evitar desviaciones desastrosas (por Ej. para equilibrar el sistema una vez solvatado), o para incluir el conocimiento de datos experimentales (por Ej. datos provenientes de experimentos de NMR). En cualquier caso éstas no forman parte del campo de fuerzas y la confiabilidad de sus parámetros no resulta de relevancia.

En el desarrollo del presente trabajo detallaremos las restricciones de posición que han sido usadas para equilibrar el sistema proteico.

\section{Restricciones de posición}

Se utilizan para restringir partículas a una posición fija de referencia $R_{i}$. Pueden emplearse durante el equilibrado del sistema de manera de evitar el reacomodamiento drástico de zonas críticas (por ejemplo, para restringir el movimiento de una proteína sujeta a fuerzas importantes debidas a un solvente que aún no se encuentra equilibrado). Otra aplicación es la de restringir partículas alrededor del borde (cáscara) de una región que se desea simular en detalle. Así, las restricciones mantendrán la integridad del interior. Para casquetes esféricos es recomendable utilizar una constante de fuerza para la restricción que dependa del radio, creciendo desde cero para el interior del casquete hasta un valor elevado en el límite exterior del mismo. 


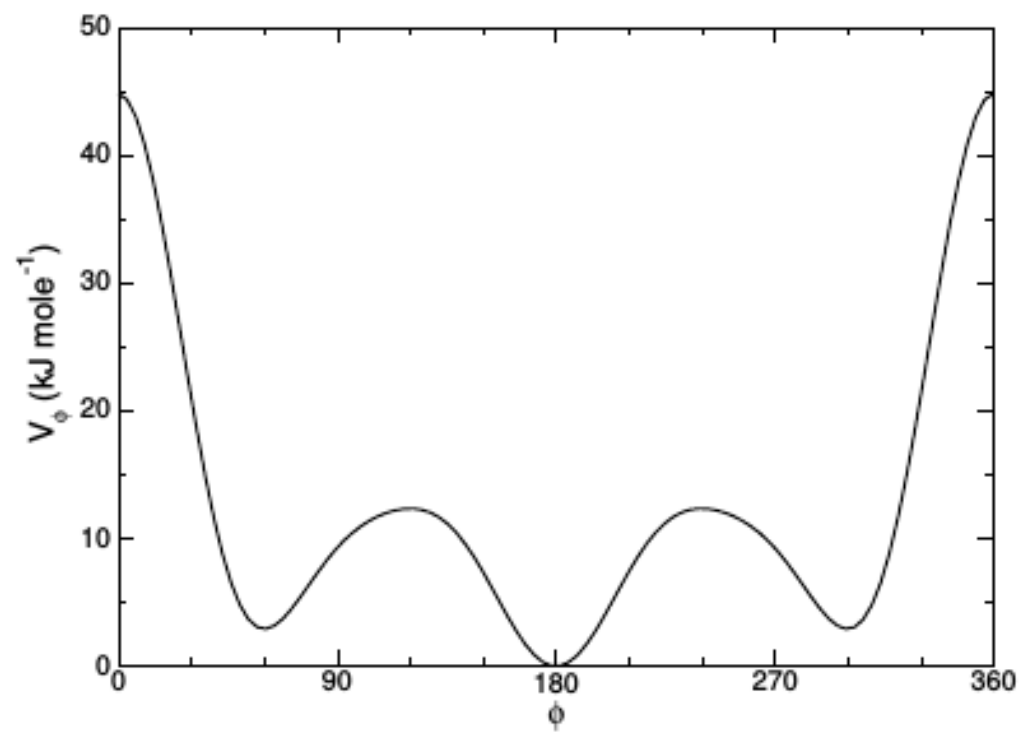

Figura 2.10: Función potencial para diedro propio de Ryckaert-Belleman

Se utiliza la siguiente forma general:

$$
V_{r p}\left(\mathbf{r}_{i}\right)=\frac{1}{2} k_{r p}\left|\mathbf{r}_{i}-R_{i}\right|^{2}
$$

El potencial puede ser escrito sin pérdida de generalidad también como:

$$
\left.V_{r p}\left(\mathbf{r}_{i}\right)=\frac{1}{2}\left[k_{r p}^{x}\left(x_{i}-X_{i}\right)^{2} \widehat{x}+k_{r p}^{y}\left(y_{i}-Y_{i}\right)^{2} \widehat{y}+k_{r p}^{z}\left(z_{i}-Z_{i}\right)^{2} \widehat{z}\right)\right]
$$

Donde las componentes de la fuerza sobre la $i$-ésima partícula son:

$$
\begin{gathered}
F_{i}^{x}=k_{r p}^{x}\left(x_{i}-X_{i}\right) \\
F_{i}^{y}=k_{r p}^{y}\left(y_{i}-Y_{i}\right) \\
F_{i}^{z}=k_{r p}^{z}\left(z_{i}-Z_{i}\right)
\end{gathered}
$$

Las restricciones de posición pueden encender o apagarse para cada dimensión espacial utilizando tres constantes de fuerza diferentes; esto significa que los átomos pueden restringirse armónicamente a un punto, un plano o una recta.

\section{Cómputo de fuerzas}

Toda simulación por MD requiere como entrada un conjunto de coordenadas iniciales y, opcionalmente, velocidades iniciales para todas las partículas 
involucradas. Las primeras suelen provenir de datos experimentales (cristalografía de rayos X, Resonancia Magnética Nuclear, etc.), mientras que las últimas suelen ser generadas inicialmente a partir de una distribución de Maxwell-Boltzmann para una temperatura dada.

\section{Condiciones iniciales}

\section{La topología y el campo de fuerzas}

La topología, incluyendo la descripción completa del campo de fuerzas, debe ser provista. Estos elementos fueron descritos en detalle en la sección anterior. Toda esta información es estática y nunca resulta modificada durante la simulación.

\section{Coordenadas y velocidades}

Así, antes de comenzar una corrida se requieren las coordenadas y velocidades de las partículas, además de las dimensiones de la caja de simulación. El tamaño de la caja queda determinado por tres vectores $b_{1}, b_{2}, b_{3}$, los cuales representan los tres vectores que definen la periodicidad de la caja.

Si la corrida comienza en $t=t_{0}$, las coordenadas en $t=t_{0}$ deben ser conocidas. El algoritmo leap - frog o de salto de rana, utilizado para actualizar el paso de integración $\delta t$ (ver sección 2.2.4.4), requiere que se conozcan las velocidades en $t=t_{0}+\frac{\delta t}{2}$. Si las velocidades $v_{i}, i=1, \ldots, 3 N$ no son conocidas, estas pueden generarse a partir de una distribución de Maxwell-Boltzmann para una dada temperatura $T$ :

$$
p\left(v_{i}\right)=\sqrt{\frac{m_{i}}{2 \pi k T}} e^{-\frac{m_{i} v_{i}^{2}}{2 k T}}
$$

Donde $p\left(v_{i}\right)$ es la probabilidad de que una partícula tenga una velocidad $v_{i} . k$ es la constante de Boltzmann.

\section{Movimiento del centro de masas}

La velocidad del centro de masas normalmente se lleva a cero en cada paso. No existe ninguna fuerza neta externa actuando sobre el sistema y la velocidad del centro de masas debería permanecer constante. En la práctica, de cualquier manera, el algoritmo de actualización desarrolla un cambio lento en la velocidad del centro de masas, y por tanto, en la energía cinética total del sistema, especialmente cuando se acopla un baño térmico. Si estos cambios no se amortiguan, eventualmente se desarrolla un movimiento apreciable del centro de masas para corridas largas, lo cual resultará en una significativa mala interpretación de la temperatura. Lo mismo podría suceder con el movimiento de rotación global, pero solamente cuando se simula 
un cluster de partículas aislado. En sistemas periódicos con cajas llenas de partículas, el movimiento rotacional global se encuentra acoplado a otros grados de libertad y por lo tanto no ocasiona problemas.

\section{Búsqueda de vecinos}

Como se mencionó en la sección 2.2.2, las fuerzas son generadas, ya sea por listas fijas (estáticas) de átomos, o bien por listas dinámicas. Estas últimas son generadas debido a las interacciones no-enlazantes entre un par de partículas cualesquiera.

\section{Generación de listas de pares}

Las fuerzas entre pares no-enlazantes necesitan calcularse solamente para aquellos pares $i, j$ para los cuales la distancia $r_{i j}$ entre la partícula $i$ y la imagen más cercana de la partícula $j$ sea menor que un dado radio de corte $R_{c}$. Algunos de los pares de partículas que satisfacen este criterio deben ser excluidos de la lista, dado que su interacción ha sido totalmente tomada en cuenta por las interacciones enlazantes.

Para realizar dicha lista de vecinos deben hallarse todas las partículas que se encuentran en un entorno (dentro de $R_{c}$ de una dada partícula. Esta búsqueda involucra condiciones periódicas de contorno y por lo tanto la determinación de la imagen más cercana.

El paquete GROMACS utiliza la convención de la imagen más cercana:

- Al calcular las interacciones de corto alcance se tendrá en cuenta solamente la imagen más cercana de todas las correspondientes a una partícula.

- En el caso de las interacciones electrostáticas de largo alcance, esto no siempre es lo suficientemente exacto, y por tanto se utilizan otros métodos de cálculo como Reaction Fields [6], Sumas de Ewald [7], Particle Mesh Ewald (PME) [8] o Particle-Particle Particle-Mesh (PPPM) [9].

Sin condiciones periódicas de contorno debe usarse un algoritmo simple $O\left(N^{2}\right)$. Con condiciones periódicas de contorno puede aplicarse una búsqueda tipo grilla (grid-search), la cual resulta $O(N)$, y por lo tanto menos costosa en términos computacionales.

\section{Calculo de fuerzas}

\section{Energía potencial}

Cuando se computan las fuerzas, también se computa la energía potencial para cada término de interacción. Por lo tanto la energía potencial total resul- 
ta de la suma de varias contribuciones, tales como Lennard-Jones, Coulomb, y las interacciones enlazantes.

\section{Energía cinética y temperatura}

La temperatura viene dada por la energía cinética total del sistema de $N$ partículas:

$$
E_{\text {cin }}=\frac{1}{2} \sum_{i=1}^{N} m_{i} v_{i}^{2}
$$

De aquí, la temperatura absoluta $T$ puede ser computada utilizando:

$$
\frac{1}{2} N_{g l} k T=E_{\text {cin }}
$$

Donde $k$ es la constante de Boltzmann y $N_{g l}$ es el número total de grados de libertad, los cuales pueden calcularse a partir de:

$$
N_{g l}=3 N-N_{c}-N_{c o m}
$$

Aquí $N_{c}$ es el número de restricciones impuestas sobre el sistema. Cuando se realiza una simulación por MD deben ser restados adicionalmente $N_{\text {com }}=$ 3 grados de libertad, dado que las tres velocidades del centro de masas son constantes del movimiento, y normalmente se las hace valer cero. Cuando la simulación es realizada en vacío, puede restarse también la rotación alrededor del centro de masas, en este caso $N_{\text {com }}=6$.

Cuando se utiliza más de un grupo de partículas acoplados independientemente al baño de temperatura, el número de grados de libertad para el grupo $i$ es:

$$
N_{g l}^{i}=\left(3 N^{i}-N_{c}^{i}\right) \frac{3 N-N_{c}-N_{c o m}}{3 N-N_{c}}
$$

La energía cinética puede ser escrita también como un tensor, lo cual resulta necesario frecuentemente para el cálculo de la presión, o bien para sistemas en donde se imponen fuerzas de corte:

$$
E_{\text {cin }}=\frac{1}{2} \sum_{i=1} N m_{i} v_{i} \otimes v_{i}
$$

\section{La presión y el virial}

El tensor de la presión $P$ se calcula como la diferencia entre la energía cinética $E_{\text {cin }}$ y el virial $\Xi$ :

$$
P=\frac{2}{V}\left(E_{\text {cin }}-\Xi\right)
$$


Donde $V$ es el volumen de la caja de simulación. La presión escalar $P$, la cual puede utilizarse para el acoplamiento al baño de presión para sistemas isotrópicos, puede calcularse según:

$$
P=\operatorname{traza}(P) / 3
$$

El tensor $\Xi$ del virial se define como:

$$
\Xi=-\frac{1}{2} \sum_{i<j} \mathbf{r}_{i j} \otimes F_{i j}
$$

\section{Actualización de la configuración}

El algoritmo utilizado para la integración del las ecuaciones de movimiento es el denominado leap - frog o de salto de rana [10]. Este algoritmo utiliza posiciones $r$ a tiempo $t$ y velocidades $v$ a tiempo $t-\frac{\Delta t}{2}$; actualiza tanto posiciones como velocidades utilizando las fuerzas $F(t)$ determinadas por las posiciones al tiempo $t$ :

$$
\begin{aligned}
v\left(t+\frac{\Delta t}{2}\right) & =v\left(t-\frac{\Delta t}{2}\right)+\frac{F(t)}{m} \Delta t \\
\mathbf{r}(t+\Delta t) & =\mathbf{r}(t)+v\left(t+\frac{\Delta t}{2}\right) \Delta t
\end{aligned}
$$

El algoritmo puede visualizarse en la Figura 2.11. Es equivalente al algoritmo de Verlet [11]:

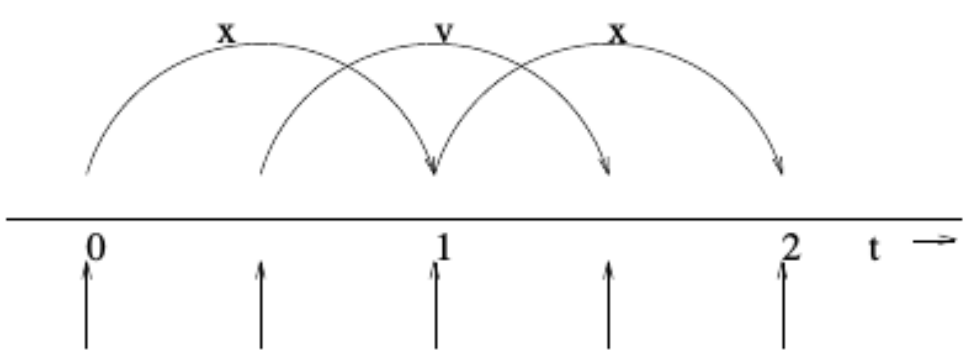

Figura 2.11: Método de integración de leap - frog o salto de rana. Recibe este nombre debido a que $r$ y $v$ saltan uno sobre el otro alternadamente al estilo del salto de rana.

$$
\mathbf{r}(t+\Delta t)=2 \mathbf{r}(t)-\mathbf{r}(t-\Delta t)+\frac{F(t)}{m} \Delta t^{2}+O\left(\Delta t^{4}\right)
$$


Este algoritmo es de $3^{e r}$ orden en $r$ y es reversible en el tiempo. Las ventajas de este algoritmo y su comparación con otros algoritmos de integración temporal pueden encontrarse en la referencia [12].

Las ecuaciones de movimiento se modifican para incorporar el acoplamiento a los baños de presión y temperatura, además de ser extendidas para incluir la conservación de las restricciones, todo lo cual se describe a continuación.

\section{Acoplamiento térmico}

Por varios motivos (durante el equilibrado del sistema, derivan como resultado del truncado de fuerzas y errores de integración, calentamientos debidos a fuerzas externas o de fricción, entre otras), se vuelve necesario controlar la temperatura del sistema. Para esto puede utilizarse el esquema de acoplamiento débil de Berendsen [13], el acoplamiento conocido como Velocity rescale ( $V$-rescale) [14], o el esquema de ensamble extendido de Nosé-Hoover [15] .

\section{Acoplamiento térmico de Berendsen}

El algoritmo de Berendsen reproduce un acoplamiento débil a un baño térmico externo de una dada temperatura $T_{0}$, con cinética de primer orden. El efecto de la aplicación de este algoritmo es el de corregir una desviación térmica de $T_{0}$ del sistema según:

$$
\frac{d T}{d t}=\frac{T_{0}-T}{\tau}
$$

Lo cual significa que una dada desviación térmica decae exponencialmente con una constante de tiempo $\tau$. Este método de acoplamiento tiene la ventaja que la fuerza con la cual se encuentra acoplado el baño puede variarse, adaptándose a las necesidades del sistema: para llevar un sistema al equilibrio puede utilizarse una constante pequeña $(0,01 \mathrm{ps})$, mientras que para lograr corridas confiables de un sistema en equilibrio puede utilizarse una constante mucho mayor $(0,5 \mathrm{ps})$ en cuyo caso prácticamente no se afecta la dinámica conservativa [16]. Usualmente se utiliza una constante de acoplamiento de 0,1 ps.

El flujo de calor desde o hacia el sistema es realizado escalando a cada paso las velocidades de cada partícula mediante un factor $\lambda(t)$, dado por:

$$
\lambda(t)=\left[1+\frac{\Delta t}{\tau_{T}}\left\{\frac{T_{0}}{T(t-\Delta t / 2)}-1\right\}\right]^{1 / 2}
$$

El valor del parámetro $\tau_{T}$ es cercano al de la constante de acoplamiento $\tau$, aunque no exactamente igual: 


$$
\tau=\frac{2 C_{v} \tau_{T}}{N_{g l} k}
$$

Donde $C_{v}$ es la capacidad calorífica total del sistema, $k$ es la constante de Boltzmann y $N_{g l}$ es el número total de grados de libertad. La razón por la cual $\tau \neq \tau_{T}$ es que el cambio en la energía cinética causado por el escalado de las velocidades es parcialmente redistribuido entre las energías cinética y potencial, y por lo tanto el cambio en la temperatura resulta menos que el escalado de la energía. En la práctica, el valor de la relación $\tau / \tau_{T}$ va desde 1 (gas) a 2 (sólido armónico) a 3 (agua). El parámetro $\tau_{T}$ es comúnmente llamado constante temporal de acoplamiento térmico.

El algoritmo de Berendsen resulta estable hasta valores de $\tau_{T} \approx \Delta t$.

\section{Acoplamiento térmico Velocity-rescaling}

Este acoplamiento térmico re-escala la velocidad de las partículas con un término estocástico. A continuación podemos ver cómo actúa sobre la energía cinética del sistema de partículas,

$$
d E_{c}=\left(E_{c}^{0}-E_{c}\right) \frac{d t}{\tau_{T}}+2 \sqrt{\frac{E_{c}^{0} E_{c}}{N_{g l}}} \frac{d W}{\sqrt{\tau_{T}}}
$$

donde $d W$ representa ruido blanco gaussiano y $E_{c} 0$ es la energía cinética del sistema a la temperatura del baño (energía cinética de referencia).

Este termostato utiliza también una constante de acoplamiento $\tau_{T}$, pero el segundo término estocástico asegura un ensamble canónico adecuado. Sin el término estocástico esta ecuación se reduce a la del termostato standard de Berendsen. En el limite $\tau_{T}=0$, la evolución estocástica hace que el sistema termalice instantáneamente. Cuando un sistema está lejos del equilibrio, la parte determinista de la expresión domina, y el algoritmo conduce a un rápido equilibrio térmico como con el termostato de Berendsen. Una vez que el equilibrio se alcanza, el termostato garantiza un muestreo compatible con un ensamble canónico.

\section{Acoplamiento de presión}

Análogamente al acoplamiento térmico, el sistema puede ser acoplado también a un baño de presión. Para ajustar el valor de la presión del sistema puede utilizarse el algoritmo de Berendsen [13] o el esquema de ensamble extendido de Parinello-Raman. Ambos pueden combinarse con cualquiera de los algoritmos para el acoplamiento térmico descritos con anterioridad. 


\section{Baróstato de Berendsen}

El algoritmo de Berendsen re-escala las coordenadas y los vectores de la caja a cada paso de la integración con la matriz $\mu$, lo cual tiene un efecto de una cinética de relajación de primer orden sobre la presión, hacia un valor dado de referencia $P_{0}$ de presión:

$$
\frac{d P}{d t}=\frac{P_{0}-P}{\tau_{P}}
$$

La matriz $\mu$ de escalado viene dada por:

$$
\mu_{i j}=\delta_{i j}-\frac{\Delta t}{3 \tau_{P}} \beta_{i j}\left\{P_{0 i j}-P_{i j}(t)\right\}
$$

Aquí $\beta_{i j}$ es la compresibilidad isotérmica del sistema. En la mayoría de los casos esto será una matriz diagonal, con elementos iguales sobre la diagonal, cuyo valor resulta generalmente desconocido. Alcanza con tomar un valor aproximado del mismo dado que el valor de $\beta_{i j}$ solamente tiene influencia sobre la constante temporal no crítica de la relajación de la presión sin afectar el valor promedio de la presión.

Cuando el escalado es completamente anisotrópico, el sistema debe ser rotado de manera de cumplimentar con las restricciones de la caja. Esta rotación puede aproximarse en el primer orden del escalado, el cual es normalmente menor que $10^{-4}$. La matriz de escalado $\mu^{\prime}$ es:

$$
\mu^{\prime}=\left(\begin{array}{ccc}
\mu_{x x} & \mu_{x y}+\mu_{y x} & \mu_{x z}+\mu_{z x} \\
0 & \mu_{y y} & \mu_{y z}+\mu_{z y} \\
0 & 0 & \mu_{z z}
\end{array}\right)
$$

Las velocidades no se rotan ni se escalan.

El escalado de Berendsen puede también realizarse isotrópicamente, lo cual significa que puede utilizarse una matriz diagonal de tamaño traza $(P) / 3$ en lugar de la matriz $P$.

\section{Baróstato de Parinello-Raman}

Para los casos donde las fluctuaciones de la presión o el volumen son importantes per se (en el cálculo de propiedades termodinámicas), puede resultar problemático, al menos teóricamente, que el ensamble exacto no esté correctamente definido por el esquema del acoplamiento débil.

Para resolver esto pueden realizarse simulaciones utilizando la proximación de Parinello-Raman [17], el cual resulta similar al acoplamiento térmico de Nosé-Hoover.

Con el baróstato de Parinello-Raman los vectores de la caja se representan a través de la matriz $b$ y obedecen la siguiente ecuación matricial de movimiento: 


$$
\frac{d b^{2}}{d t^{2}}=V W^{-1} b^{\prime-1}\left(P-P_{r e f}\right)
$$

El volumen de la caja está dado por $V$, y $W$ es el parámetro matricial que determina la fuerza del acoplamiento. Las matrices $P$ y $P_{\text {ref }}$ representan las presiones instantánea y de referencia respectivamente.

El parámetro matricial (inverso) de masa $W^{-1}$ determina la fuerza del acoplamiento, además del modo en el cual puede ser deformada la caja.

\section{Algoritmos de restricciones topológicas}

Las restricciones topológicas pueden resolverse utilizando diversos algoritmos desarrollados para este fin. En este apartado explicaremos el algoritmo LINCS (Linear Constraint Solver) [18] usado en el desarrollo de la presente tesis.

\section{Algoritmo LINCS}

LINCS es un algoritmo que reconstituye enlaces a su longitud correcta luego de una actualización no-restringida. El método es no-iterativo, dado que siempre se resuelve en dos pasos. Aunque LINCS está basado en matrices, no precisa de la resolución de multiplicaciones entre matrices. El método es rápido y estable, pero sólo puede utilizarse con restricciones de longitud de enlace y restricciones de ángulos de enlace aislados, tales como el ángulo del protón en el enlace $\mathrm{OH}$.

Consideremos un sistema de $N$ partículas, con posiciones dadas por un vector $3 N$, denominado $r(t)$. Para la MD las ecuaciones de movimiento vienen dadas por las ecuaciones de Newton:

$$
\frac{\partial^{2} r}{\partial t^{2}}=M^{-1} F
$$

Donde $F$ es el vector $3 N$ de la fuerza y $M$ es la matriz diagonal $3 N \times 3 N$, conteniendo las masas de las partículas. El sistema se encuentra restringido topológicamente por $K$ ecuaciones de restricción, dependientes del tiempo

$$
g_{i}(r)=\left|r_{i 1}-r_{i 2}\right|-d_{i}=0,
$$

donde $i=1, \ldots, K$.

En el esquema de integración numérica LINCS es aplicado luego de una actualización no-restringida. El algoritmo trabaja en dos pasos (ver figura 2.12). Durante el primer paso se llevan a cero las proyecciones del nuevo enlace sobre el viejo. En el segundo paso se aplica una corrección por estiramiento de enlace debido a la rotación. Puede verse una derivación completa del algoritmo en la referencia [18]. 


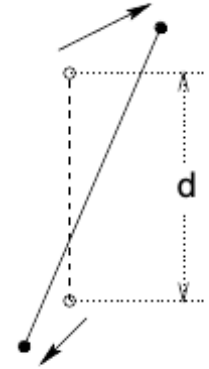

A

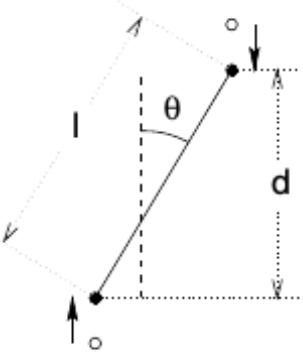

B

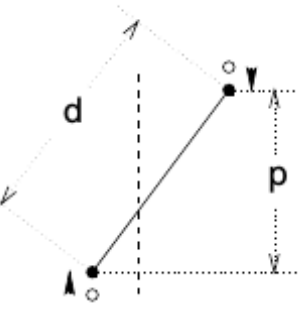

$\mathrm{C}$

Figura 2.12: Actualizaciones de posición requeridas para cada paso de integración. La línea punteada representa el viejo enlace de longitud $d$, mientras que las líneas llenas representan los nuevos enlaces. En A, actualización no restringida. En B, eliminación de las fuerzas que actúan sobre los enlaces. En $\mathrm{C}$, corrección del estiramiento por rotación. $l=d \cos \theta$ y $p=\left(2 d^{2}-l^{2}\right)^{1 / 2}$

\section{Métodos de Análisis}

En esta sección explicaremos de manera general algunos de los análisis implementados en nuestras simulaciones durante desarrollo del presente trabajo.

\section{Funciones de Distribución Radial}

La Función de Distribución Radial $(g(r))$ de una función de correlación de a pares $g_{A B}(r)$ entre las partículas del tipo $A$ y $B$ se define de la siguiente manera:

$$
\begin{aligned}
g_{A B}(r) & =\frac{\left\langle\rho_{B}(r)\right\rangle}{\left\langle\rho_{B}\right\rangle_{\text {local }}} \\
& =\frac{1}{\left\langle\rho_{B}\right\rangle_{\text {local }}} \frac{1}{N_{A}} \sum_{i \in A}^{N_{A}} \sum_{i \in B}^{N_{B}} \frac{\delta\left(r_{i j}-r\right)}{4 \pi r^{2}}
\end{aligned}
$$

donde $\left\langle\rho_{B}(r)\right\rangle$ es la densidad de partículas de tipo $B$ a una distancia $r$ alrededor de las partículas de tipo $A, \mathrm{y}\left\langle\rho_{B}\right\rangle_{\text {local }}$ es la densidad de partículas de tipo B promediada sobre todas las esferas alrededor de las partículas de tipo $A$ con radio $r_{\max }$.

Normalmente el valor de $r_{\max }$ es la mitad de la mínima longitud de la caja. En la práctica, la función de densidad de partículas $\delta$ es reemplazada por un histograma construido dividiendo el sistema en casquetes esféricos (que van desde $r$ hasta $r+d r$ ). 


\section{Raíz de la Desviación Cuadrática Media}

Podemos calcular la Raíz de la Desviación Cuadrática Media (RMSD) de un grupo de átomos en una molécula con respecto a una estructura de referencia. Para esto se realiza primero un ajuste por Mínimos Cuadrados de la estructura dada a la configuración de referencia y luego, mediante el cálculo del RMSD, se estudia la desviación de la estructura respecto de la referencia. Este ajuste inicial se hace para evitar considerar en el análisis el movimiento de traslación y rotación de la molécula estudiada como un todo, y así poder considerar sólo los cambios conformacionales que en ella se producen. Puede calcularse el RMSD de toda la molécula de interés o de parte de ella. Por ejemplo, es muy común el estudio del RMSD de los carbonos $\alpha$ al estudiar la estabilidad de proteínas.

Si el número de átomos a considerar para el cálculo es $N$, obtenemos el RMSD a un dado tiempo $t$, respecto de una estructura de referencia (con posiciones $r_{i}(0)$ y masas $\left.m_{i}, i=1, N\right)$ mediante la siguiente expresión:

$$
\operatorname{RMSD}(t)=\left[\frac{1}{M} \sum_{i=1}^{N} m_{i}\left\|r_{i}(t)-r_{i}(0)\right\|^{2}\right]^{1 / 2},
$$

donde $M=\sum_{i=1}^{N} m_{i}$ y $r_{i}(t)$ son la suma de las masas de los $N$ átomos considerados y sus posiciones al tiempo $t$, respectivamente.

\section{Cálculo del Radio de Giro}

También podemos tener una medida aproximada de cuan compacta es la estructura a estudiar y cómo cambia esa distribución de masa en función del tiempo analizando el radio de giro $\left(R_{g}\right)$ de la molécula, definido como:

$$
R_{g}(t)=\left(\frac{\sum_{i=1}^{N}\left\|r_{i}(t)\right\|^{2} m_{i}}{M}\right)^{1 / 2}
$$

donde las distancias $r_{i}(t)(i=1, N)$ son las posiciones de los $N$ átomos de la molécula considerados para el análisis, tomadas desde su Centro de Masas. $m_{i}$ es la masa del $i$-ésimo átomo y $M=\sum_{i=1}^{N} m_{i}$ la suma de las mismas.

\section{Superficie Accesible al Solvente}

El estudio del Área Superficie Accesible al Solvente (SASA) [19], consiste en recorrer la superficie proteica (o de algún otro sistema que se esté estudiando) utilizando una sonda esférica de radio igual al del modelo de solvente utilizado. De este modo puede identificarse cuál es esta superficie expuesta, diferenciando a su vez el comportamiento de regiones hidrofílicas e hidrofóbicas. Este último puede estudiarse en función del tiempo, permitiendo la 
identificación de posibles cambios conformacionales como los observados en la formación de micelas.

\section{Dinámica Escencial (ED)}

Las transiciones conformacionales en las proteínas son esenciales para su función. Sin embargo, el acceso a los movimientos atómicos de una proteína en solución durante dichas transiciones no son del todo fácil. Para esto, las metodologías por simulación computacional son herramientas valiosas para estudiar el detalle atómico de las dinámicas conformacionales en proteínas. Aunque, la extracción de los movimientos funcionalmente relevantes en una simulación no es sencillo.

Una solución para superar esta dificultad es el uso de coordenadas colectivas para definir el subespacio (que se obtiene al reducir la dimensión de un conjunto de datos), en el que se espera que el movimiento funcional de la proteína tenga lugar. Debido a que estos movimientos principales podrían, en muchos casos, estar vinculados a la función de proteínas, la dinámica en el subespacio generado por estos movimientos se denomina Dinámica Esen$\operatorname{cial}(\mathrm{ED})$.

Un método para definir el subespacio escencial e identificar los movimientos colectivos en una proteína es el Análisis de Componentes Principales (PCA). El PCA es un análisis estadístico multivariante que implica diagonalización de una matriz de correlación para un conjunto de observables de los cuales se obtendrán los componentes principales. Así, un PCA puede llevarse a cabo en un gran número de configuraciones generadas por una trayectoria MD.

\section{Fundamento teórico}

Consideremos un $N$ de observables dinámicos $x_{1}, x_{2}, \ldots, x_{N}$ (representado por el vector columna $N$-dimensional $x$ ) que define el espacio de estados en un sistema de interés. Para cualquier distribución de tales características observables, y proporcionando el comportamiento estadístico de $x$ en cualquiera del total de estados en el espacio o dentro de una subparte del mismo, podemos definir la $N \times N$ matriz de correlación $\tilde{C}$ de la distribución a través de:

$$
\begin{aligned}
& \tilde{C}=\left\langle\Delta x \Delta x^{T}\right\rangle, \\
& \Delta x=x-x_{r e f},
\end{aligned}
$$

donde $x_{r e f}$ es un valor de referencia arbitrario de $x$ que se elije de acuerdo con el tipo de observables y la información cosiderada, $\Delta x^{T}$ es la transposi- 
ción de $\Delta x$ (i.e., en el vector fila $N$-dimensional), y \langle\rangle representa el promedio de la distribución.

Para las ecuaciones 2.58 2.59 tenemos que:

$$
[\tilde{C}]_{l, l^{\prime}}=\left\langle\Delta x_{l} \Delta x_{l^{\prime}}\right\rangle l, l^{\prime}=1,2, \ldots, N,
$$

Indicando que cuando $x_{r e f}=\langle x\rangle$ (como en la mayoría de las aplicaciones en coordenadas atómicas, la referencia es igual a la media de las posiciones) la matriz de correlación coindice con la matriz de covarianza, es decir, cada elemento de la matriz provee la covarianza de dos observables. Además, la ecuación 2.60 muestra que $\tilde{C}$ es una matriz simetrica con autovalores reales y autovectores ortonormales. Por lo tanto, la matriz de transformación $\tilde{T}$ proporciona

$$
\tilde{T}^{T} \tilde{C} \tilde{T}=\left\langle\tilde{T}^{T} \Delta x \Delta x^{T} \tilde{T}\right\rangle=\left\langle\Delta q \Delta q^{T}\right\rangle=\Lambda,
$$

donde $\Lambda$ es la matriz de correlación diagonalizada con los autovalores $\lambda$ y $\Delta q=\tilde{T}^{T} \Delta x$ son los vectores observables expresados en un conjunto de autovectores $(n)$. Así, de la ecuación 2.61, se deduce que:

$$
\begin{aligned}
\left\langle n_{l}^{T} \Delta x \Delta x^{T} n_{l^{\prime}}\right\rangle & =\left\langle\Delta x^{T} n_{l} \Delta x^{T} n_{l^{\prime}}\right\rangle=\left\langle\Delta q_{l} \Delta q_{l^{\prime}}\right\rangle \\
& =\lambda_{l} \delta_{l, l^{\prime}}
\end{aligned}
$$

Así, $\tilde{C}$ es una matriz positiva donde sus autovalores estan dados por la media cuadrática de la proyección de $\Delta x$ dentro de los autovectores $n$ de la matriz de correlación. Por tanto, dichos autovectores pueden servir para definir un nuevo conjunto base ortonormal y describir el espacio de estados del sistema proporcionando un nuevo $N$ de observables dinámicos $\left(\Delta q_{1}, \Delta q_{2}, \ldots, \Delta q_{N},\right)$ dado por las combinaciones lineales de los originales.

Sí ahora consideramos un vector unitario $v$ arbitrario expresado en el conjunto base de autovectores

$$
\begin{gathered}
v=\sum_{l=1}^{N} a_{l} n_{l}, \\
\sum_{l=1}^{N} a_{l}^{2}=1,
\end{gathered}
$$

podemos obtener la proyección cuadrática media de $\Delta x$ en $v$ como:

$$
\begin{aligned}
& \left\langle\left(\Delta x^{T} v\right)^{2}\right\rangle \\
& =\left\langle\left(\Delta x^{T} \sum_{l=1}^{N} a_{l} n_{l}\right)^{2}\right\rangle=\left\langle\left(\sum_{l=1}^{N} a_{l} \Delta x^{T} n_{l}\right)^{2}\right\rangle
\end{aligned}
$$




$$
\begin{aligned}
& =\left\langle\left(\sum_{l=1}^{N} a_{l} \Delta q_{l}\right)^{2}\right\rangle=\left\langle\sum_{l=1}^{N} \sum_{l^{\prime}=1}^{N} a_{l} a_{l^{\prime}} \Delta q_{l} \Delta q_{l^{\prime}}\right\rangle \\
& =\sum_{l=1}^{N} \sum_{l^{\prime}=1}^{N} a_{l} a_{l^{\prime}}\left\langle\Delta q_{l} \Delta q_{l^{\prime}}\right\rangle=\sum_{l=1}^{N} a_{l}^{2} \lambda_{l},
\end{aligned}
$$

Así, usando la ecuación 2.65 se establece que :

$$
\sum_{l=1}^{N} a_{l}^{2} \lambda_{l}=\lambda_{1}+\sum_{l=2}^{N} a_{l}^{2}\left(\lambda_{l}-\lambda_{1}\right) .
$$

Ordenando los autovalores en orden decreciente, es decir, $\lambda_{1} \geq \lambda_{l}$, tenemos que, $\sum_{l=2}^{N} a_{l}^{2}\left(\lambda_{l}-\lambda_{1}\right) \leq 0$, por tanto,

$$
\lambda_{1} \geq\left\langle\left(\Delta x^{T} v\right)^{2}\right\rangle,
$$

de esta forma,

$$
\left.\left\langle\left(\Delta x^{T} v\right)^{2}\right\rangle \leq\left\langle\left(\Delta x^{T}\right) n_{1}\right)^{2}\right\rangle .
$$

En esta última ecuación se observa claramente que el autovector de la matriz de correlación correspondiente al mayor autovalor proporciona la dirección en el espacio de estados maximizando la proyección cuadrática media de los vectores observables en $\Delta x$. De esta misma forma como obtuvimos espacio ortogonal de el primer autovector podemos obtener el mismo resultado para el segundo autovector y para cualquier otro autovector en el subespacio.

Al final, los autovectores en la matriz de corrección proporcionan un nuevo conjunto de datos, equivalente a una rotación en los ejes originales, adecuando a los observables en una mejor distribución que se traduce en la maximización de la media cuadrática de las proyecciones en $\Delta x$.

Para las distribuciones anisotrópicas un procedimiento de este tipo permite definir un subespacio de pocas dimensiones (subespacio esencial) que describe la mayor parte del comportamiento del sistema, en otras palabras, las propiedades de los observables originales pueden ser en gran parte reconstruidos mediante el uso de un conjunto limitado de nuevos observables que se definen por los autovectores del subespacio esencial [20, 21]. 



\section{Bibliografía}

[1] Nicholas Metropolis, Arianna W Rosenbluth, Marshall N Rosenbluth, Augusta $\mathrm{H}$ Teller, and Edward Teller. Equation of state calculations by fast computing machines. The journal of chemical physics, 21(6):10871092, 1953.

[2] William J Kaufmann and Larry L Smarr. Supercomputing and the Transformation of Science. WH Freeman \& Co., 1992.

[3] G. Gutiérrez. ELEMENTOS DE SIMULACION COMPUTACIONAL.Dinámica Molecular y Método de Monte Carlo. Chile, 2001.

[4] J E Lennard-Jones. Cohesion. Proceedings of the Physical Society, 43(5):461-482, 1931.

[5] Philip M Morse. Diatomic molecules according to the wave mechanics. ii. vibrational levels. Physical Review, 34(1):57, 1929.

[6] Wilfred F van Gunsteren, Herman JC Berendsen, and Johan AC Rullmann. Inclusion of reaction fields in molecular dynamics. application to liquid water. Faraday Discussions of the Chemical Society, 66:58-70, 1978 .

[7] Paul Peter Ewald. Die berechnung optischer und elektrostatischer gitterpotentiale. Annalen der Physik, 369(3):253-287, 1921.

[8] Mark J Abraham and Jill E Gready. Optimization of parameters for molecular dynamics simulation using smooth particle-mesh ewald in gromacs 4.5. Journal of computational chemistry, 32(9):2031-2040, 2011.

[9] Brock A Luty, Ilario G Tironi, and Wilfred F van Gunsteren. Latticesum methods for calculating electrostatic interactions in molecular simulations. The Journal of chemical physics, 103(8):3014-3021, 1995.

[10] Roger W Hockney and James W Eastwood. Computer simulation using particles. CRC Press, 1988. 
[11] Loup Verlet. Computer experiments on classical fluids. i. thermodynamical properties of lennard-jones molecules. Physical review, 159(1):98, 1967.

[12] HJC Berendsen and WF Van Gunsteren. Practical algorithms for dynamic simulations. Molecular-dynamics simulation of statisticalmechanical systems, pages 43-65, 1986.

[13] Herman JC Berendsen, J Pl M Postma, Wilfred F van Gunsteren, ARHJ DiNola, and JR Haak. Molecular dynamics with coupling to an external bath. The Journal of chemical physics, 81(8):3684-3690, 1984.

[14] Giovanni Bussi, Davide Donadio, and Michele Parrinello. Canonical sampling through velocity rescaling. The Journal of chemical physics, 126(1):014101, 2007.

[15] William G Hoover. Canonical dynamics: equilibrium phase-space distributions. Physical Review A, 31(3):1695, 1985.

[16] HJC Berendsen. Transport properties computed by linear response through weak coupling to a bath. In Computer Simulation in Materials Science, pages 139-155. Springer, 1991.

[17] Michele Parrinello and Aneesur Rahman. Polymorphic transitions in single crystals: A new molecular dynamics method. Journal of Applied physics, 52(12):7182-7190, 1981.

[18] Berk Hess, Henk Bekker, Herman JC Berendsen, Johannes GEM Fraaije, et al. Lincs: a linear constraint solver for molecular simulations. Journal of computational chemistry, 18(12):1463-1472, 1997.

[19] Byungkook Lee and Frederic M Richards. The interpretation of protein structures: estimation of static accessibility. Journal of molecular biology, 55(3):379-IN4, 1971.

[20] Isabella Daidone and Andrea Amadei. Essential dynamics: foundation and applications. Wiley Interdisciplinary Reviews: Computational Molecular Science, 2(5):762-770, 2012.

[21] Steven Hayward and Bert L De Groot. Normal modes and essential dynamics. In Molecular Modeling of Proteins, pages 89-106. Springer, 2008. 


\section{Capítulo 3}

\section{Agregación micelar en surfactantes iónicos}

\section{Introducción}

La agregación y estabilidad de surfactantes anfifílicos bajo efectos de presión y temperatura son temas ampliamente discutidos en la literatura [1-5]. Los resultados obtenidos por técnicas experimentales como: conductividad, dispersión de la luz, sondas fluorescentes y dispersión de neutrones de ángulo reducido, indican que las micelas son formadas en solución acuosa a 1 bar de presión cuando las moléculas de surfactantes alcanzan la concentración micelar critica (CMC).

En el caso particular del Dodecilsulfato Sódico (SDS) con el incremento de la presión el número de agregación decrece alrededor de 1 kbar, desensamblando las micelas. Con aumentos progresivos de presión se hace evidente la aparición de grandes agregados que son interpretados como una re-entrada a la fase micelar con un mayor número de agregación [1-6]. Como es ampliamente aceptado el efecto hidrofóbico es el responsable del ensamble micelar. Sin embargo, es sabido que a presiones superiores a $1 \mathrm{kbar}$ el agua cambia su estructura, la red de puentes de hidrógenos se empieza a debilitar y el efecto hidrofóbico se hace despreciable. Este hecho parece ir en contra de la formación de grandes agregados micelares en alta presión. Recientemente Baltasar y colaboradores [7] usando ultrasonido en soluciones de dodecanoato de sodio en agua, reportan que este sistema en alta presión, sufre una transición de fase con estructura lameloidea a 2,5 kbar.

Con el fin de contribuir en la aparente discrepancia, hemos estudiado el comportamiento del SDS en solución acuosa, tomando como hipótesis que sí el rol más importante en la agregación micelar esta dado por la estructura del solvente, el efecto hidrofóbico debería verse favorecido si la red de puentes de hidrógenos del agua es más fuerte, y por ende la cinética de agregación micelar en función de la presión debería cambiar en agua y agua pesada. 
En el presente capitulo analizaremos estos planteamientos, desarrollando un modelo de agregación micelar con el surfactante iónico SDS usando para esto simulaciones por Dinámica Molecular (MD).

\section{Materiales y Métodos}

Los sistemas empleados en este estudio fueron una mezcla de moléculas de Dodecilsulfato Sódico en agua y agua pesada. Para esto empleamos cajas cubicas de simulación que contenía moléculas de SDS en agua a una concentración de $500 \mathrm{mM}$, variando el modelo de agua en cada caja. Así, para agua pura, $\mathrm{H}_{2} \mathrm{O}$, usamos el modelo Simple Point Charge (SPC/E)[8] y para agua pesada, $\mathrm{D}_{2} \mathrm{O}$, el modelo Simple Point Charge Heavy Water (SPC/HW) [9].

\section{Autoensamble micelar}

Las simulaciones se llevaron a cabo utilizando el paquete Gromacs 4.5.3 $[10,11]$. Para el estudio del ensamble micelar de surfactantes anfifílicos se generaron micelas de SDS mediante autoagregación, usando el modelo molecular de SDS desarrollado por Sammalkorpi y colaboradores [12] (Ver figura $3.1)$.

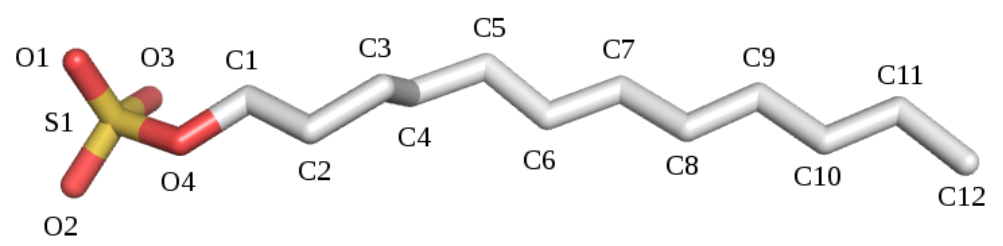

Figura 3.1: Modelo molecular de dodecilsulfato implementado en nuestras simulaciones $(\mathrm{O}=$ Oxígeno; $\mathrm{S}=$ Azufre; $\mathrm{C}=$ Carbono $)$.

Inicialmente, preparamos dos sistemas de partida que contenían 70 y 200 monómeros de SDS e igual número de iones de sodio, ubicados aleatoriamente en una caja cubica ( $X=Y=Z=6,07 \mathrm{~nm}$, sistema de 70 monómeros y $X=Y=Z=8,03 \mathrm{~nm}$ sistema de 200 monómeros) que contenía 6667 y 16972 moléculas de agua, respectivamente. El campo de fuerza utilizado fue el Gromos 43A1 [13]. El sistema fue equilibrado con un ensamble NpT a 300 K y 1 bar de presión, utilizando el termostato $V$-rescale [14] y el barostato de Berendsen [15], con constantes de acople de 0,1 ps y 1,0 ps, respectivamente. Para el calculo de las interacciones electrostáticas y de Lennard-Jones se aplico un radio de corte de 1,2 nm; usado para el cálculo de las interacciones electrostáticas el método de Reaction Field [16]. El paso de integración durante las simulaciones fue de $2 \mathrm{fs}$, manteniendo las restricciones topológicas para las moléculas de SDS mediante el algoritmo LINCS [17]. 


\section{Sistemas de simulación}

Los sistemas simulados en este trabajo contenían moléculas de SDS, agua y contraiones de sodio, ubicados aleatoriamente. Para el modelo de agua $\mathrm{SPC} / \mathrm{E}$ variamos el numero de moléculas de soluto y solvente, generando dos sistemas que contenían 70 y 200 moléculas de SDS, equilibrando las cargas del surfactante con igual número de contraiones. La concentración final en cada caja de simulación fue de $\sim 500 \mathrm{mM}$. El mismo proceso fue realizado para el modelo de agua pesada SPC/HW.

Las cuatro cajas se simularon a 1 bar de presión y una temperatura de 300 K. El tiempo total de simulación para la micelización fue de 100 ns para los 70 monómeros y 200 ns para los 200 monómeros, tomando para nuestros análisis los datos producidos durante todo el tiempo de simulación.

\section{Efectos de la presión}

Para estudiar el efecto de la presión tomamos como sistema de partida la micela ya formada. Para esto acoplamos los sistemas de 70 y 200 monómeros de SDS a presiones crecientes de 1 a 4000 bar. El sistema con 70 moléculas SDS fue simulado durante 10 ns para cada presión (aumentos de presión cada 100 bar) y se analizaron los 5 ns finales después de equilibrar el sistema. Para el sistema con 200 moléculas de SDS se simuló para cada presión 100 ns (aumentos de presión cada 500 bar) y se colectaron para los análisis datos correspondientes los $50 \mathrm{~ns}$ finales.

\section{Análisis de Cluster}

Para los análisis de agregación micelar se utilizó el criterio de conectividad de Stillinger [18], el cual se basa solamente en la distancia entre partículas. Así, consideramos que dos moléculas son miembros del cluster (grupo) cuando la distancia entre los átomos de carbono $C_{6}$ (Ver figura 3.1) es menor o igual a $3 / 2$ de su diámetro $\sigma\left(R_{c u t}=0,60 \mathrm{~nm}\right)$. Para la selección de las moléculas usamos el algoritmo de Stoodart [19] calculando la conectividad durante cada paso de simulación.

Podemos definir la probabilidad, $P_{s}$, de encontrar un cluster de $s$ monómeros como [20] :

$$
P_{s}=\frac{n(s) s}{N},
$$

donde $n(s)$ es el número de agregados de $s$ monómeros y $N$ el número total de monómeros. El cociente $n(s) / N$ puede ser considerado como una frecuencia relativa. Así, $P_{s}$ satisfase la condición de normalización. 


$$
\sum_{s=1}^{N} P_{s}=1
$$

El proceso de agregación también fue analizado utilizando la función de distribución radial, $g(r)$, para todos los pares de moléculas de SDS, tomando el primer pico de la $g(r)$ entre los átomos de carbono $C_{1}$ y $C_{12}$ (Ver figura 3.1) en función de la presión. El área superficial accesible a solvente (SASA) del SDS fue calculada usando el algoritmo $g$ _sas [11] con un radio de sonda de $1,4 \AA$.

\section{Resultados y Discusión}

\section{Autoensamble micelar}

Nosotros estudiamos la formación micelar de 70 y 200 moléculas de SDS en agua $\mathrm{SPC} / \mathrm{E}$ y $\mathrm{SPC} / \mathrm{HW}$ a $T=300 \mathrm{~K}$ y $P=1$ bar. El valor de temperatura utilizado es ligeramente mayor a la temperatura micelar critica (CTM) reportada para el SDS [21]. Consideramos un sistema pequeño de 70 monómeros acorde con el número de agregación experimental del SDS, 55-75 [22]. Por su parte, el sistema de 200 monómeros de SDS fue elegido para evaluar el modelo de agregación, ya que se reporta que un alto número de moléculas de SDS no muestra diferencias significativas en el proceso de autoensamble micelar [12].

El criterio adoptado para definir la formación micelar está basado en una clasificación geométrica definida por la distancia de los átomos de carbono seis, $\mathrm{C}_{6}$, presentes en todas las moléculas de SDS (Ver figura 3.1), tal como se explico en la sección 3.2.1 de Materiales y Métodos.
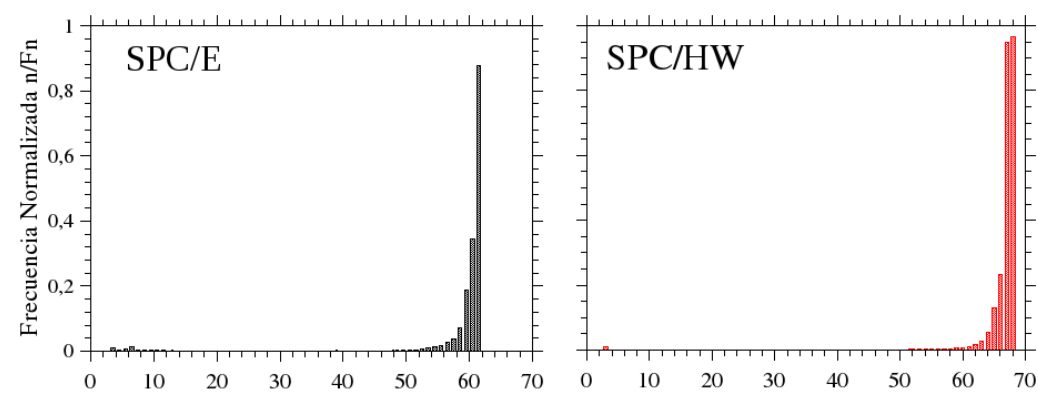

Número de Agregación

Figura 3.2: Número de agregación de moléculas SDS para las micelas formadas en agua SPC/E y SPC/HW. Cada sistema posee en total 70 monómeros. El término $n$ hacen referencia al número de monómeros que conforman el cluster y $F n$ a su frecuencia durante la simulación. 
En la figura 3.2, se muestra el tamaño del cluster normalizado en relación a su número de agregación. El número máximo de agregación para el sistema de 70 moléculas de SDS en SPC/E fue de 62 monómeros, en tanto que bajo la misma concentración en $\mathrm{SPC} / \mathrm{HW}$ se formaron micelas de tamaño entre 65 y 67 monómeros.

El aumento en el número de agregación micelar en agua SPC/HW en relación al agua $\mathrm{SPC} / \mathrm{E}$, es consistente con los datos experimentales. Así, el $\mathrm{D}_{2} \mathrm{O}$ favorece el efecto hidrofóbico dadas las diferencias energéticas que hacen a los puentes de deuterio más fuertes que los puentes de hidrógeno, cambiando la propiedades fisicoquímicas del agua pesada (respecto al agua: viscosidad, $23 \%$ mayor; Temperatura de máxima densidad, $11,23{ }^{\circ} \mathrm{C}$; y capacidad calórica, $12 \%$ mayor) [23-27].

Para determinar si los resultados de nuestro modelo dependían del tamaño, generamos un sistema de 200 monómeros a $500 \mathrm{mM}$. Los resultados muestran que no hay diferencias significativas durante la formación de micelas con el aumento en el tamaño del sistema (Ver figura 3.3).

A
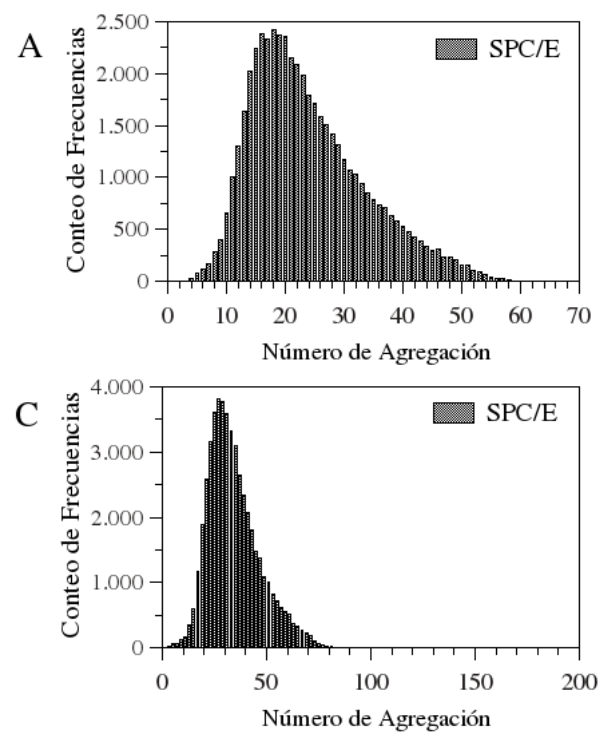

B
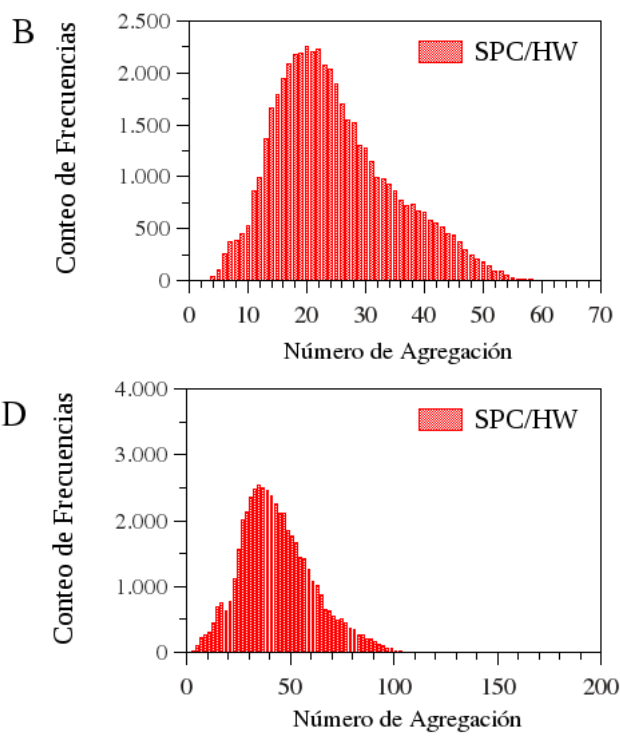

Figura 3.3: Distribución en el número de agregación de moleculas de SDS en el tiempo total de simulación a 1 bar y $300 \mathrm{~K}$. En A y B, 70 moleculas de SDS en agua (SPC/E) y agua pesada (SPC/HW). En C y D, 200 moleculas de SDS en agua y agua pesada

Por otra parte, nosotros monitoreamos la cinética de agregación micelar calculando el área superficial accesible a solvente, durante el tiempo de simulación. En la Figura 3.4, se observa el SASA para el sistema de 200 monómeros en 16972 moléculas de agua y agua pesada, SPC/E y SPC/HW, respectivamente. Nosotros observamos que las micelas son formadas alrede- 
dor de los primeros $20 \mathrm{~ns}$, pero hacia el final del tiempo de simulación el área expuesta al solvente es menor en agua pesada, con una disminución del SASA del $18 \%$ respecto al agua, indicando la formación de agregados más compactos en SPC/HW.

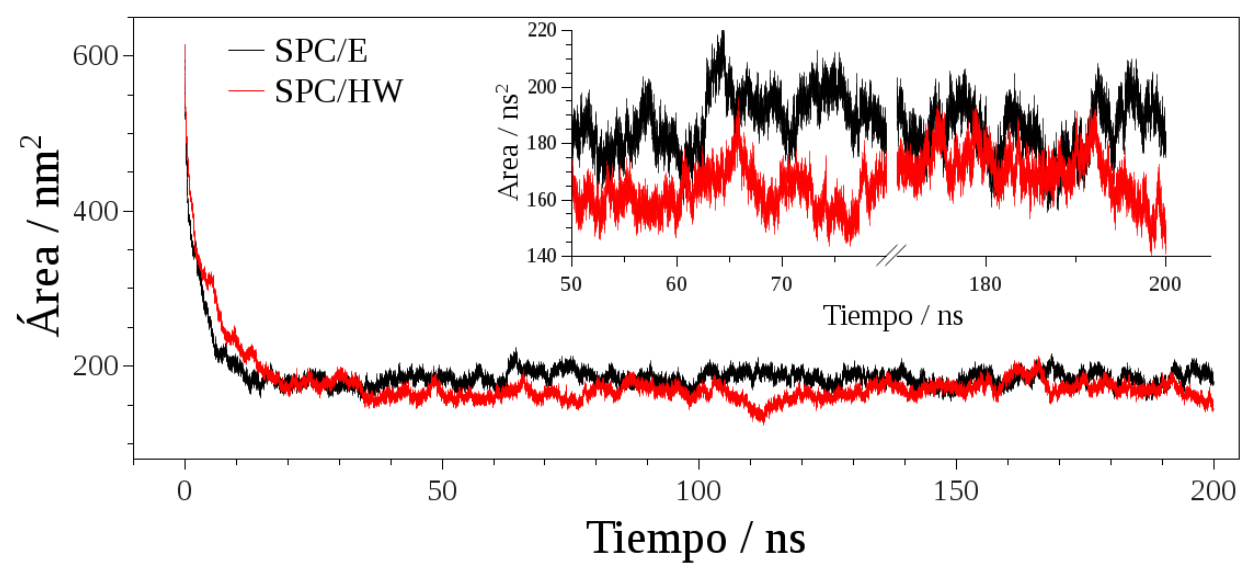

Figura 3.4: Área superficial accesible al solvente. Agregación micelar en función del tiempo en SPC/E y SPC/HW con 200 monómeros de SDS.

En los análisis experimentales, la diferencia de polaridad entre $\mathrm{H}_{2} \mathrm{O}$ y $\mathrm{D}_{2} \mathrm{O}$, afecta la hidrofobicidad de los surfactantes conllevando a la disminución de la CMC en $\mathrm{D}_{2} \mathrm{O}$ [23]. Nuestros resultados por MD son similares a los experimentales, debido a las diferencias de carga parcial en los átomos de $\mathrm{O}, \mathrm{H}$ y $\mathrm{D}$ correspondientes a cada modelo; donde el momento dipolar en $\mathrm{SPC} / \mathrm{HW}$ es $3 \%$ mayor que en SPC/E [8, 9, 28].

\section{Micelas bajo presión}

Nosotros analizamos el comportamiento de las micelas en función de la presión, calculando el número de clusters $\left(\mathrm{N}_{\text {Clust }}\right)$ y número de agregación $\left(\mathrm{N}_{A g g}\right)$ de los monómeros de SDS en SPC/E y SPC/HW. En la figura 3.5 observamos que micelas en agua SPC/E a presiones superiores a los 1000 bar el $\mathrm{N}_{\text {Agg }}$ disminuye y alcanza su mínimo cerca de los 1400 bar. En el rango de los 1500 - 2000 bar el $\mathrm{N}_{A g g}$ llega a su máximo valor y con el aumento progresivo de la presión el sistema se estabiliza mostrando un $\mathrm{N}_{A g g}$ mayor al inicial. Por su parte, la curva de $\mathrm{N}_{\text {Clust }}$ alcanza su máximo a los 1200 bar y desciende monotónicamente hasta los 2200 bar, disminuyendo el $\mathrm{N}_{\text {Clust }}$ con el aumento de la presión.

En SPC/HW observamos un desplazamiento de los valores en función de la presión sin cambios aparentes en su comportamiento en relación al sistema en SPC/E. Así, para SPC/HW el $\mathrm{N}_{A g g}$ presenta un mínimo entre 1000 - 1200 bar y un máximo entre los $1400-1600$ bar. El $N_{\text {Clust }}$ se hace 


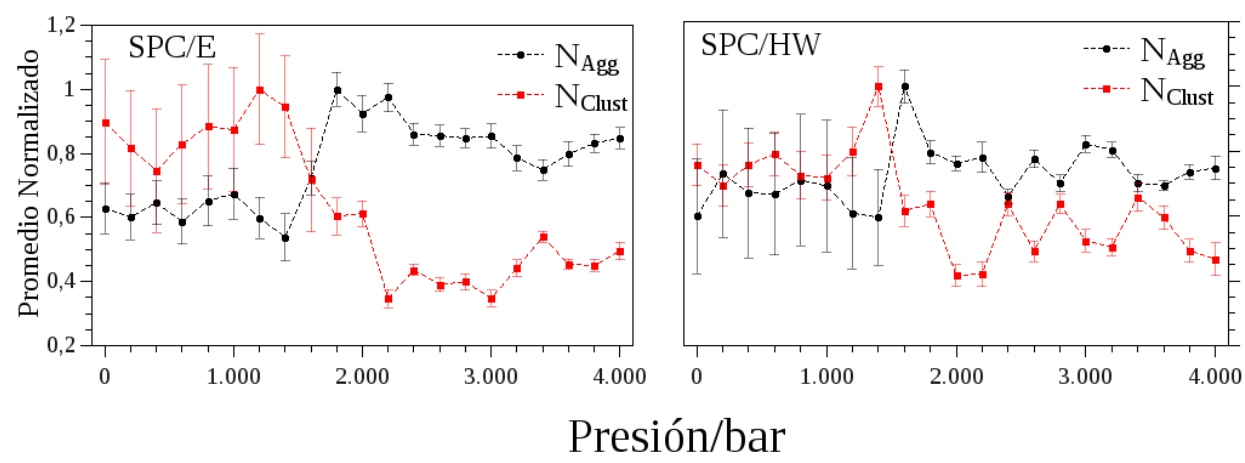

Figura 3.5: Promedio normalizado del número de clusters ( $\mathrm{N}_{\text {Clust }}$ en Negro) y el número de agregación ( $\mathrm{N}_{A g g}$ en rojo) en función de la presión para micelas en SPC/E y SPC/HW.

máximo cerca 1400 bar.

Nuestros resultados son consistentes con los reportes experimentales, donde presiones superiores a los 1000 bar disminuyen el $\mathrm{N}_{A g g}$ e incrementan la concentración de monómeros libres (aumenta CMC), ocasionando la redistribución de las moléculas de surfactante en micelas de menor tamaño y por tanto incrementando la concentración micelar $\left(\mathrm{N}_{\text {Clust }}\right)$. Por encima de los 1500 bar se promueve el incremento del número de agregación (desciende la CMC), el descenso de la concentración micelar y la formación de micelas (Clusters) más grandes [1, 5, 6, 29].

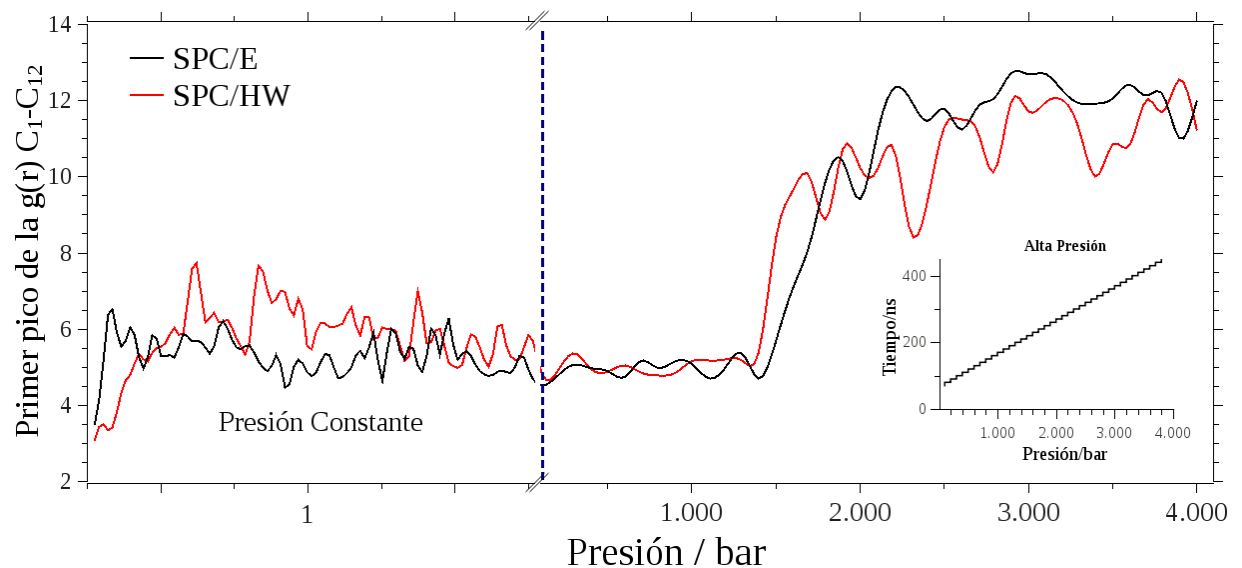

Figura 3.6: Primer pico de la $g(r)$ normalizada para los $\mathrm{C}_{1}-\mathrm{C}_{12}$ en función de la presión a $T=300 \mathrm{~K}$. La fase micelar se observa a 1 bar, con el aumento de la presión (escalado de presión representado en la gráfica inferior derecha) se evidencian cambios estructurales en la micela.

Sin embargo, nosotros proponemos que para presiones superiores a 1500 
bar, la geometría inicial se pierde y los agregados podrían formar otro tipo estructuras que promuevan el incremento en el número de agregación. En la figura 3.6, caracterizamos los efectos de la presión sobre las micelas formadas, acoplandolas a presiones crecientes en el rango de $1-4000$ bar a $T=300 \mathrm{~K}$. Las estructuras fueron evaluadas tomando el primer pico de la función de distribución radial de los átomos de carbono $\mathrm{C}_{1}-\mathrm{C}_{12}$ en función de la presión. Se observó que con el aumento de presión el sistema no pierde totalmente su estado de agregación, pero si su geometría. El $\mathrm{C}_{1}$ de una molécula de SDS se invierte $180^{\circ}$ en relación con el $\mathrm{C}_{1}$ de la molécula de SDS adyacente, así la distancia interatómica entre los primeros vecinos $\mathrm{C}_{1}-\mathrm{C}_{12}$ disminuye en función de la presión una vez esta supera los 1500 bar generando agregados monómericos de mayor tamaño.Por tanto, en nuestras simulaciones observamos que con el incremento de la presión se generan grandes agregados con geometría lamelar. Esto indicaría que no podemos concluir que con el aumento de la presión obtendremos micelas esféricas de mayor tamaño.

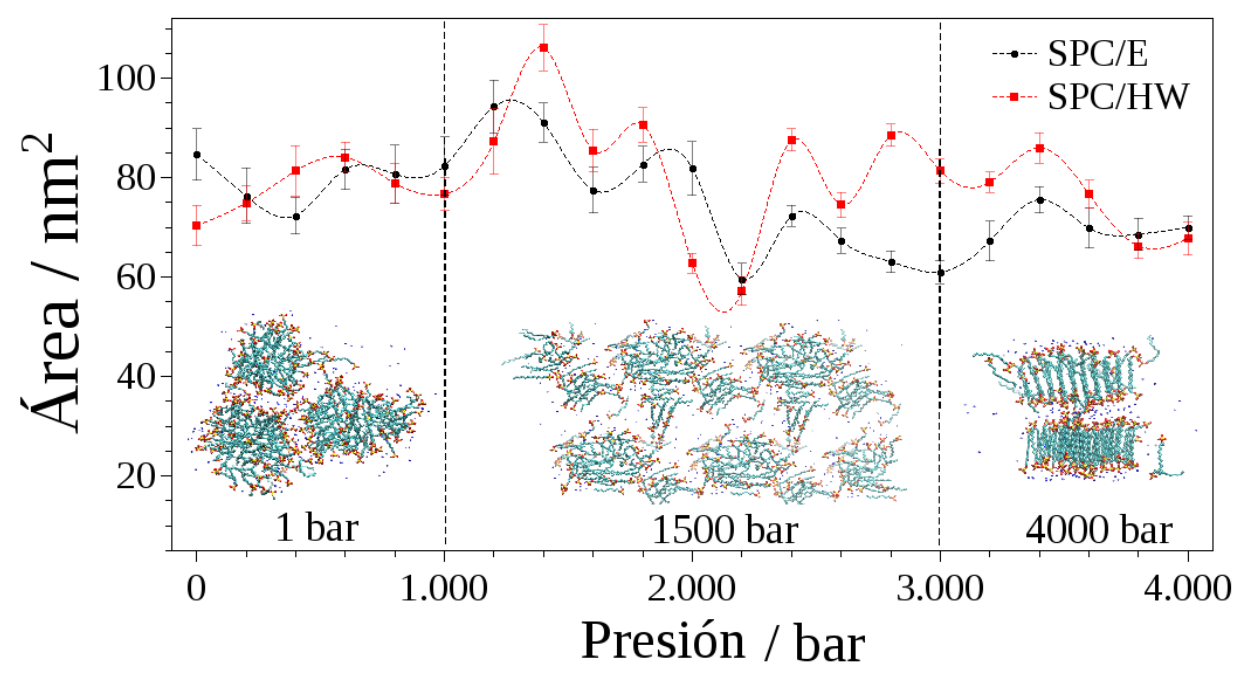

Figura 3.7: Área de SDS expuesta a agua (línea negra) y agua pesada (línea roja) en función de la presión. Las imágenes inferiores muestran los cambios de geometría obtenidos durante la simulación.

Cuando analizamos la cinética de agregación en altas presiones calculando el SASA para cada valor de presión, como se representa en la figura 3.7, observamos que a 1 bar las moléculas anfifílicas de SDS forman micelas esféricas bien definidas ya que su cabeza polar interactúa con los contraiones en solución, mientras las colas hidrofóbicas se orientan hacia el centro de la micela. Cuando la presión incrementa cerca de los 1500 bar, el agua pierde su estructura tetraédrica, debilitando el efecto hidrofóbico [30, 31], lo que expone parcialmente el núcleo interno de la micela al solvente causando 
el desensamble micelar. Con un aumento mayor en la presión (4000 bar) se forman agregados de mayor $\mathrm{N}_{A g g}$ con geometría lamelar, los cuales son interpretados experimentalmente como micelas de mayor tamaño que conservan la geometría observada a 1 bar [1].

Sin embargo, recientemente en un trabajo publicado por Baltasar y colaboradores [7], donde se analiza el efecto de la presión en la agregación de monómeros de Dodecanoato de Sodio, se observa que con el aumento de la presión ocurre una transición de la fase micelar hacia una fase en gel con geometría lamelar, la cual es posible gracias a los cambios estructurales que sufre el agua en alta presión. Así, el agua presenta una transición de liquido de baja densidad a liquido de alta densidad una vez supera los $250 \mathrm{Mpa}$, favoreciendo la organización de las moléculas de surfactante en estructuras de mayor tamaño.

La figura 3.7 muestra una estructura lamelar con el aumento de la presión. Sin embargo, como se observa en la figura 3.8, al cambiar la perspectiva de la imagen correspondiente al sistema a 4000 bar, indica que la fase lamelar no es consistente en su estructura con un bicapa extendida, por el contrario, presenta pequeñas piezas en bicapas en forma de discos [32]. Un efecto similar es observado por Chen y Ruckenstein [33,34] quienes reportan los efectos de la selectividad del solvente en los cambios de la morfología de agregación de copolímeros utilizando simulaciones por dinámica disipativa de partículas (DPD).
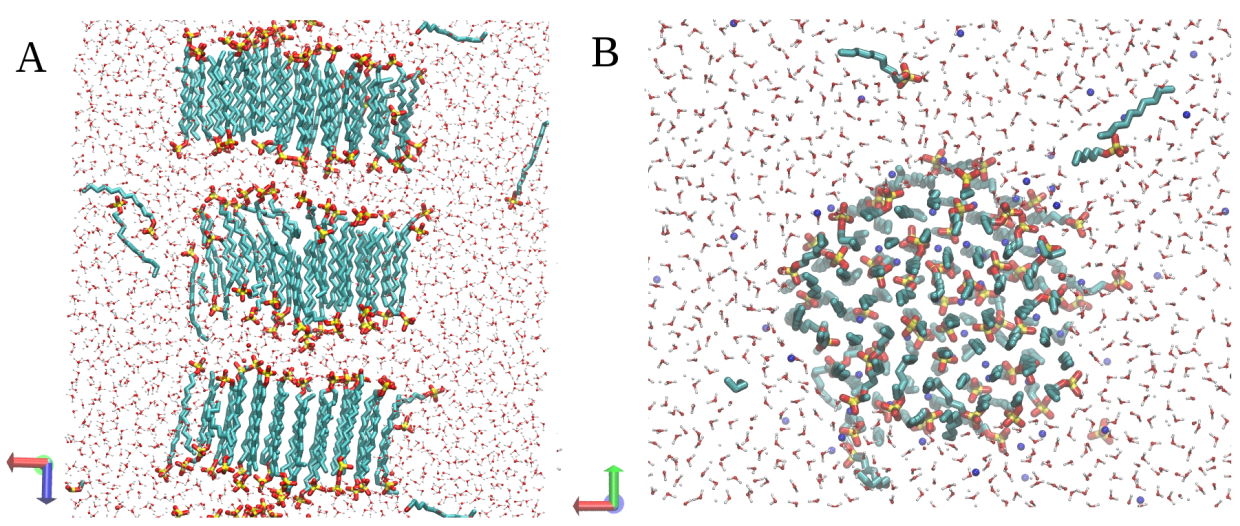

Figura 3.8: Estructura de los agregados de SDS a 4000 bar. La figura A, sugiere la presencia de pequeñas estructuras apiladas de forma lamelar, sin embargo en la figura B (rotando $90^{\circ} \mathrm{A}$ ), se observa que la estructura realmente se agrega en discos apilados formando una varilla. El sistema empleado en este ejemplo posee 200 monómeros de SDS. De igual forma, el cambio de geometría es apreciable en el sistema con 70 monómeros 


\section{Solvente de Lennard-Jones}

Dada la importancia de la estructura del agua en el efecto hidrofóbico y en los cambios de geometría de agregación con el aumento de la presión, quisimos evaluar el efecto de un solvente de Lennard-Jones (LJ) sobre las micelas de SDS. Para esto, reemplazamos las moléculas de agua por el solvente LJ en una caja de simulación con micelas formadas. Los parámetros del potencial LJ corresponden a un diámetro efectivo $\sigma$ de $0,3166 \mathrm{~nm}$ y un mínimo de energía de $2,72 \mathrm{~kJ} / \mathrm{mol}$. Los sistemas fueron simulados por $50 \mathrm{~ns}$.

En solventes no estructurados con características apolares es evidente la pérdida total del efecto hidrófóbico. En nuestro solvente de LJ, las colas hidrocarbonadas se exponen al solvente y el estado de agregación se rige por las interacciones electrostáticas [35, 36], observándose la perdida de la estructura esférica en la micela, reordenándose hacia una micela inversa en Worm-like (forma de lombriz) que evita el confinamiento de los contraiones de sodio y los redistribuye a lo largo de su eje donde neutralizan sus cargas con las cargas de los átomos de azufre (Ver figura 3.9 ).

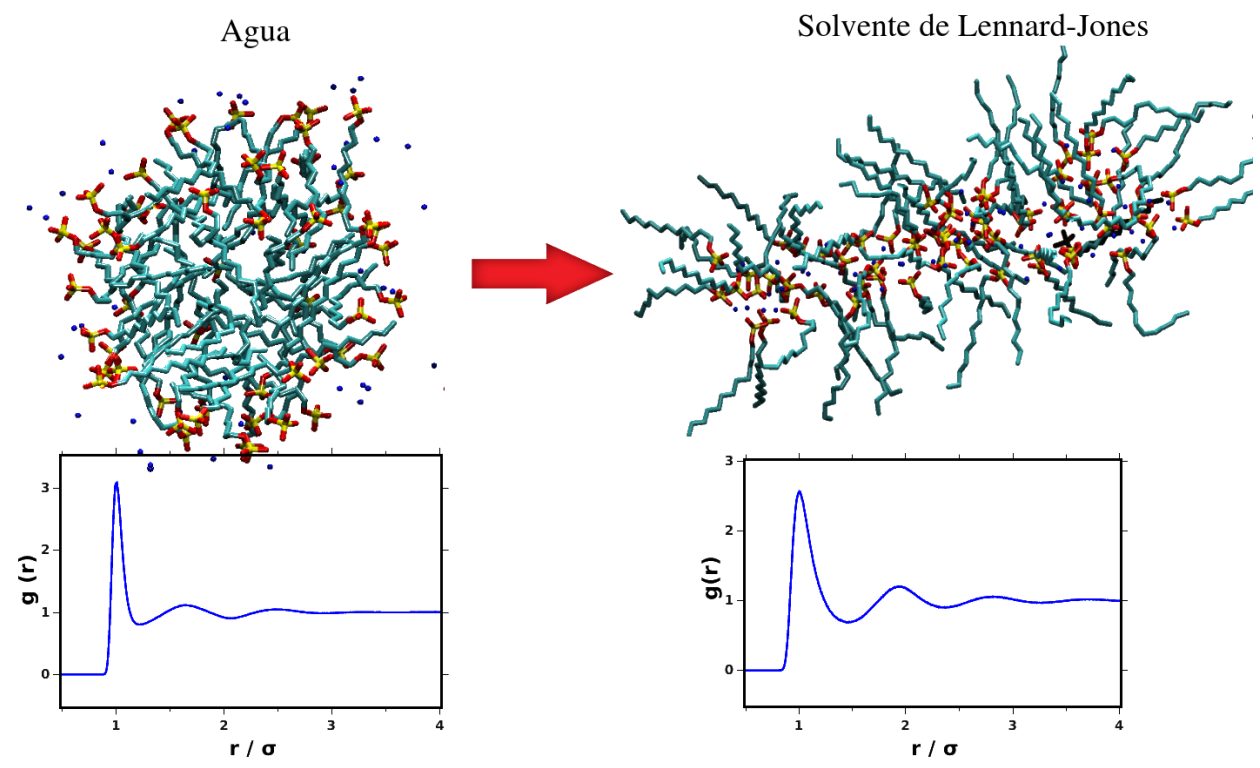

Figura 3.9: Representación gráfica de una micela de SDS en agua y en solvente de LJ. En los recuadros inferiores se observa las respectivas g(r) para cada tipo de solvente, evidenciando la importancia de la estructura del solvente en la geometría de agregación.

\section{Efectos de la temperatura}

La agregación micelar es un proceso termodinámicamente favorable y espontáneo, i.e., el cambio en la energía libre, $\Delta G$, es negativa [37]. En la 
micelización a temperatura ambiente, la mayor contribución a la energía libre es el termino entrópico, $-T \Delta S$, que favorece el efecto hidrofóbico. Por tanto, si la temperatura decrece la contribución del término entrópico, $-T \Delta S$, decrece también. Por otra parte, a altas temperaturas la entropía del sistema incrementa y la agregación de las regiones no polares no generaría entropía adicional, como consecuencia esperaríamos que la agregación de monómeros dependiera principalmente de la interacción polar $(\Delta H)$ [21, 37]. Para validar esta hipótesis construimos cinco cajas de simulación que contenían 200 monómeros de SDS ubicados al azar a 1 bar de presión para las temperaturas $253,273,300,363$, y $700 \mathrm{~K}$, donde cada uno de estos sistemas fueron simulados por $200 \mathrm{~ns}$.

En la figura 3.10 se muestran los cambios estructurales a 1 bar desde 253 a $700 \mathrm{~K}$. Los análisis a $253 \mathrm{~K}$ mostraron que el sistema a bajas temperaturas podría evolucionar a una estructura en rod-like similar a las altas presiones. Con el aumento de la temperatura, $273 \mathrm{~K}$, se observa un estado intermedio antes de la formación de micelas con geometría regular observadas a $300 \mathrm{~K}$. A temperaturas de $363 \mathrm{~K}$, la geometría cambia y se observa la aparición de estructuras de mayor tamaño cuyos monómeros interactúan con un mayor grado de desorden perdiendo su geometría esférica. Por último, a $700 \mathrm{~K}$, observamos la presencia de una micela inversa debido al cambio de estado de las moléculas de agua, fase de vapor, donde la interacción polar es la responsable del cambio de geometría.

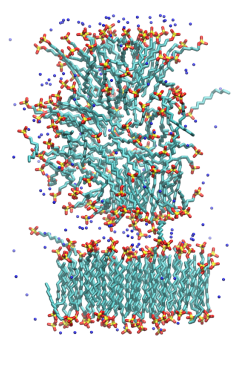

$253 \mathrm{~K}$

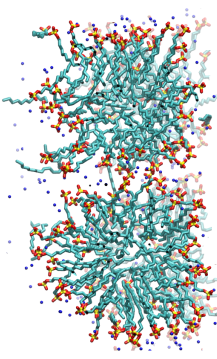

$273 \mathrm{~K}$

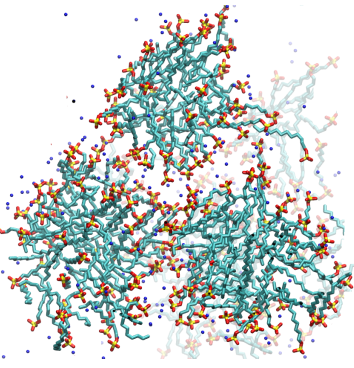

$300 \mathrm{~K}$

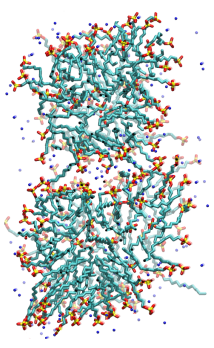

$363 \mathrm{~K}$

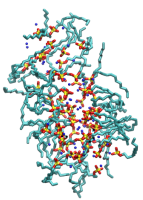

$700 \mathrm{~K}$

Figura 3.10: Efectos de la temperatura en la geometría de agregación.

\section{Conclusiones}

Los resultados obtenidos en este trabajo mostraron que las micelas de SDS en agua son desensambladas a presiones superiores a 1 kbar e inferioes a 1,5 kbar. Con el aumento de la presión se evidencia el rearreglo de la geometría micelar hacia estructuras lamelares en forma de pequeños discos. Estos cambios en función del aumento en la presión son explicados al considerar el cambio en la estructura del agua, donde la estructura tetraédrica, 
baja densidad, cambia a una estructura predominantemente hexagonal, alta densidad. Estos cambios en el solvente ocasionan una inhibición gradual del efecto hidrofóbico con el aumento de la presión. Por tanto, las micelas son formadas en condiciones normales de presión por la asociación de las cadenas no polares en las moléculas de SDS, exponiendo la cabeza polar al solvente donde su carga es neutralizada por los contraiones de sodio. Alrededor de 1 kbar, el efecto hidrofóbico se debilita permitiendo la exposición de las cadenas no polares. Con un mayor incremento en la presión, el sistema se compacta, las cadenas no polares se asocian por una débil atracción y se expone parte de su superficie al solvente sin una mayor restricción por parte de las moléculas de agua. Al mismo tiempo, las cabezas polares se asocian con sus contraiones produciendo una estructura más compacta que favorece el aumento del número de agregación. Estos resultados se relacionan ampliamente con los resultados experimentales, que demuestran la perdida de la estructura esférica y la presencia de estructuras lameloideas en alta presión [7].

Con respecto a los efectos de la temperatura, nosotros observamos que para bajas temperaturas se producen estructuras similares que en altas presiones. Esto es explicado sí consideramos que el efecto hidrofóbico depende de la contribución entrópica $(-T \Delta S)$ a la energía libre. Sin embargo, para bajas y altas temperaturas la asociación de solutos no polares no incrementa la entropía del sistema pero si modifica la estructura de agregación.

Finalmente, los procesos de variación geométrica en la cinética de agregación observados en surfactantes anfifílicos son similares a los procesos de desnaturalización de proteínas bajo la acción de la temperatura y la presión [38], brindando valiosa información para la compresión del plegamiento proteico. 


\section{Bibliografía}

[1] Nagamune Nishikido, Masamobu Shinozaki, Gohsuke Sugihara, Mitsuru Tanaka, and Shoji Kaneshina. A study on the micelle formation of surfactants in aqueous solutions under high pressure by laser light-scattering technique. i. Journal of Colloid and Interface Science, 74(2):474-482, 1980.

[2] Kimihiko Hara, Naoki Baden, and Okitsugu Kajimoto. Pressure effect on water solvation dynamics in micellar media. Journal of Physics: Condensed Matter, 16(14):S1207, 2004.

[3] JS Collura, DE Harrison, CJ Richards, TK Kole, and MR Fisch. The effects of concentration, pressure, and temperature on the diffusion coefficient and correlation length of sds micelles. The Journal of Physical Chemistry B, 105(21):4846-4852, 2001.

[4] R De Lisi, S Milioto, and N Muratore. Thermodynamics of micellization of sodium alkyl sulfates in water at high temperature and pressure. Langmuir, 17(26):8078-8084, 2001.

[5] Shoji Kaneshina, Mitsuru Tanaka, Tahei Tomida, and Ryohei Matuura. Micelle formation of sodium alkylsulfate under high pressures. Journal of Colloid and Interface Science, 48(3):450-460, 1974.

[6] Kimihiko Hara, Hideo Suzuki, and Noboru Takisawa. High-pressure studies of a fluorescence probe for the critical micelle concentration in sodium dodecyl sulfate. The Journal of Physical Chemistry, 93(9):37103713, 1989.

[7] Eduardo Hidalgo Baltasar, Mercedes Taravillo, Pedro D Sanz, Valentín G Baonza, and Beİrengeİre Guignon. Role of water structure on the high pressure micellization and phase transformations of sodium dodecanoate aqueous solutions. Langmuir, 30(25):7343-7352, 2014.

[8] HJC Berendsen, JR Grigera, and TP Straatsma. The missing term in effective pair potentials. Journal of Physical Chemistry, 91(24):6269$6271,1987$. 
[9] J Raul Grigera. An effective pair potential for heavy water. The Journal of Chemical Physics, 114(18):8064-8067, 2001.

[10] Herman JC Berendsen, David van der Spoel, and Rudi van Drunen. Gromacs: A message-passing parallel molecular dynamics implementation. Computer Physics Communications, 91(1):43-56, 1995.

[11] David Van Der Spoel, Erik Lindahl, Berk Hess, Gerrit Groenhof, Alan E Mark, and Herman JC Berendsen. Gromacs: fast, flexible, and free. Journal of computational chemistry, 26(16):1701-1718, 2005.

[12] Maria Sammalkorpi, Mikko Karttunen, and Mikko Haataja. Structural properties of ionic detergent aggregates: a large-scale molecular dynamics study of sodium dodecyl sulfate. The Journal of Physical Chemistry B, 111(40):11722-11733, 2007.

[13] D Van der Spoel, E Lindahl, and B Hess. the gromacs development team, gromacs user manual version 4.6.5 (2013).

[14] Giovanni Bussi, Davide Donadio, and Michele Parrinello. Canonical sampling through velocity rescaling. The Journal of chemical physics, 126(1):014101, 2007.

[15] Herman JC Berendsen, J Pl M Postma, Wilfred F van Gunsteren, ARHJ DiNola, and JR Haak. Molecular dynamics with coupling to an external bath. The Journal of chemical physics, 81(8):3684-3690, 1984.

[16] Wilfred F van Gunsteren, Herman JC Berendsen, and Johan AC Rullmann. Inclusion of reaction fields in molecular dynamics. application to liquid water. Faraday Discussions of the Chemical Society, 66:58-70, 1978.

[17] Berk Hess, Henk Bekker, Herman JC Berendsen, Johannes GEM Fraaije, et al. Lincs: a linear constraint solver for molecular simulations. Journal of computational chemistry, 18(12):1463-1472, 1997.

[18] Frank H Stillinger Jr. Rigorous basis of the frenkel-band theory of association equilibrium. The Journal of Chemical Physics, 38(7):1486$1494,1963$.

[19] Spotswood D Stoddard. Identifying clusters in computer experiments on systems of particles. Journal of Computational Physics, 27(2):291-293, 1978.

[20] D Stauffer. A. aharony introduction to percolation theory, 1994.

[21] Stefan Paula, Willy Sues, Jürgen Tuchtenhagen, and Alfred Blume. Thermodynamics of micelle formation as a function of temperature: 
a high sensitivity titration calorimetry study. The Journal of Physical Chemistry, 99(30):11742-11751, 1995.

[22] Noriyuki Yoshii, Kensuke Iwahashi, and Susumu Okazaki. A molecular dynamics study of free energy of micelle formation for sodium dodecyl sulfate in water and its size distribution. The Journal of chemical physics, 124(18):184901, 2006.

[23] N James Chang and Eric W Kaler. The structure of sodium dodecyl sulfate micelles in solutions of water and deuterium oxide. The Journal of Physical Chemistry, 89(14):2996-3000, 1985.

[24] V Yu Bezzobotnov, S Borbely, L Cser, B Farago, IA Gladkih, Yu M Ostanevich, and Sz Vass. Temperature and concentration dependence of properties of sodium dodecyl sulfate micelles determined from small angle neutron scattering experiments. The Journal of Physical Chemistry, 92(20):5738-5743, 1988.

[25] B Cabane, R t Duplessix, and Th Zemb. High resolution neutron scattering on ionic surfactant micelles: Sds in water. Journal de Physique, 46(12):2161-2178, 1985.

[26] LA Bastardo, R Mészáros, I Varga, T Gilanyi, and PM Cleasson. Deuterium isotope effects on the interaction between hyperbranched polyethylene imine and an anionic surfactant. The Journal of Physical Chemistry B, 109(33):16196-16202, 2005.

[27] Sz Vass Török, Gy Jákli, and E Berecz. Comparison of sodium dodecylsulfate apparent molar volumes and micellar aggregation numbers. In Trends in Colloid and Interface Science II, pages 221-223. Springer, 1988.

[28] Tomasz Róg, Krzysztof Murzyn, Jeannine Milhaud, Mikko Karttunen, and Marta Pasenkiewicz-Gierula. Water isotope effect on the phosphatidylcholine bilayer properties: a molecular dynamics simulation study. The Journal of Physical Chemistry B, 113(8):2378-2387, 2009.

[29] Naoki Baden, Okitsugu Kajimoto, and Kimihiko Hara. High-pressure studies on aggregation number of surfactant micelles using the fluorescence quenching method. The Journal of Physical Chemistry B, 106(34):8621-8624, 2002.

[30] Osvaldo Chara, Andrés N McCarthy, and J Raúl Grigera. Crossover between tetrahedral and hexagonal structures in liquid water. Physics Letters A, 375(3):572-576, 2011. 
[31] C Gastón Ferrara and J Raul Grigera. Free energy of solubility of non-polar particles in water: The role of pressure. Chemical Physics, 434:15-19, 2014.

[32] William M Gelbart and Avinoam Ben-Shaul. The ânewâ science of âcomplex fluidsâ. The Journal of Physical Chemistry, 100(31):1316913189, 1996.

[33] Houyang Chen and Eli Ruckenstein. Formation of complex colloidal particles: morphologies and mechanisms. Soft Matter, 8(34):8911-8916, 2012.

[34] Houyang Chen and Eli Ruckenstein. Self-assembly of $\pi$-shaped copolymers. Soft Matter, 8(5):1327-1333, 2012.

[35] E Rodenas and E Perez-Benito. Sizes and aggregation numbers of sds reverse micelles in alkanols obtained by fluorescence quenching measurements. The Journal of Physical Chemistry, 95(11):4552-4556, 1991.

[36] Huiying Cao, Naiyan Lu, Baiyong Ding, and Ming Qi. Regulation of charged reverse micelles on particle charging in nonpolar media. Physical Chemistry Chemical Physics, 15(29):12227-12234, 2013.

[37] Wilfried Blokzijl and Jan BFN Engberts. Hydrophobic effects. opinions and facts. Angewandte Chemie International Edition in English, 32(11):1545-1579, 1993.

[38] Cristiano L Dias, Tapio Ala-Nissila, Jirasak Wong-ekkabut, Ilpo Vattulainen, Martin Grant, and Mikko Karttunen. The hydrophobic effect and its role in cold denaturation. Cryobiology, 60(1):91-99, 2010. 


\section{Capítulo 4}

\section{Agregación micelar en surfactates no iónicos}

\section{Introducción}

Las micelas pueden ser consideradas un prototipo de moléculas biológicas cuya forma se auto-organiza a partir del autoensamble de surfactates anfifílicos [1]. La estructura, función, termodinámica y dinámica conformacional de estos sistemas son generalmente estudiados por perturbación térmica, presión o por alteraciones en las condiciones de la solución e.g. adición de sales o aditivos [2-5].

Un interés particular radica en los estudios por alta presión, ya que a pesar de los datos experimentales sobre los efectos de la presión en micelas y proteínas, aun no ha sido posible crear un marco de referencia que explique totalmente el proceso $[5,6]$. Un punto particular de controversia se da en los cambios de volumen en función de la presión. Según el principio de Le Chatelier el incremento de la presión es un proceso acompañado por un cambio negativo en el volumen del sistema [7]. Aunque la magnitud de cambio del volumen puede llegar a ser muy pequeño con el incremento de la presión (i.e. en moléculas de tipo proteico) [6], algunos estudios confirman que la magnitud del cambio podría estar relacionada con el tamaño de las cavidades presentes en el sistema[8]. Aun así, este no es el único parámetro que se ve influenciado con el aumento de la presión. Sin olvidar, que la formación de cavidades depende de la naturaleza química de la molécula y que lo realmente complicado es la cuantificación precisa de la contribución de aquellos parámetros implicados en el cambio de volumen del sistema, i.e., hidratación, interacción hidrofóbica, cavidades y electrostricción.

A diferencia de la proteínas que se pueden desnaturalizar con el aumento de la presión, los agregados micelares no se desnaturalizan al ser comprimidos isotrópicamente y en algunos casos pueden presentar nuevos tipos de arreglos conformacionales $[9,10]$. Por tanto, en las micelas los efectos de la presión 
subyacen en aquellas interacciones capaces de reflejar los cambios ocurridos en el limite de las fases con el incremento de la presión [9-11].

En el presente capítulo quisimos estudiar el ensamble de moléculas neutras en agua, buscando representar el confinamiento geométrico y la reducción de volumen del sistema, para así lograr una representación real que posteriormente nos permitiera obtener información fidedigna una vez el sistema es sometido en alta presión. Para esto, nosotros analizamos los efectos de la presión en micelas de surfactante no iónico, Tritón X-100 (TRX100), mediante simulaciones por Dinámica Molecular (MD)

\section{Materiales y Métodos}

\section{Parámetros de Optimización}

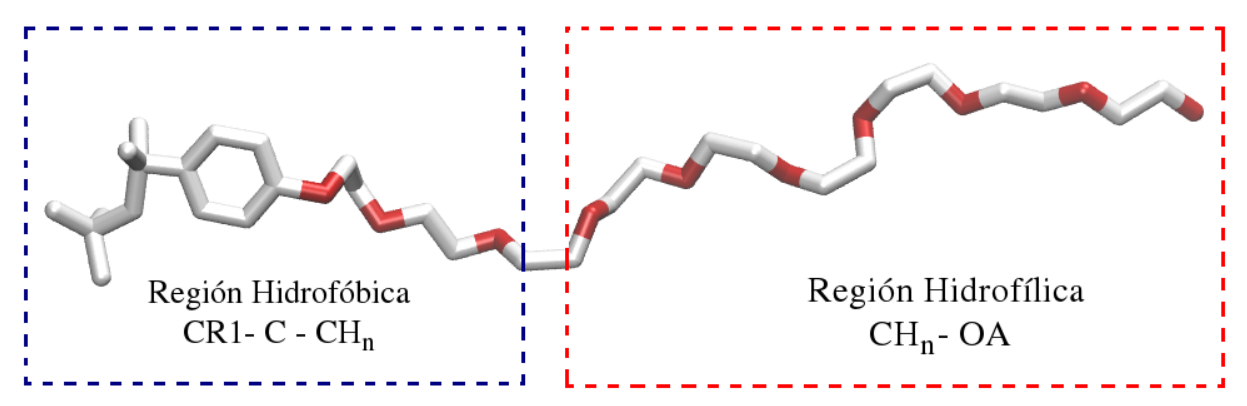

Figura 4.1: Molécula de TX100. Se observan las regiones hidrofílica e hidrofóbica y el tipo de átomos implementando la nomenclatura de la librería Gromacs. La fracción correspondiente a los tres primeros metilos de la cadena polioxietileno se clasificó dentro de la región hidrofóbica por razones que se explican en el texto.

Debido a que las moléculas de surfactante de TX100 no se encuentran incluidas en los campos de fuerza de Gromacs, nosotros desarrollamos y optimizamos sus parámetros moleculares con el fin de crea una micela capaz de autoensamblarse. Para esto, se incluyó dentro de la librería de Gromacs el campo de fuerza Gromos $53 \mathrm{~A} 6_{O X Y+D}$ calibrado y optimizado para éteres y poliéteres [12].

Seguidamente, se construyó una topología molecular para el TX100 basados en los cálculos por Mecánica Molecular (MM) del campo de fuerza Gromos 53A6 $O X Y+D$ y optimizamos su geometría a partir de cálculos mecánico cuánticos (QM) con el nivel de aproximación teórica B3LYP $/ 6-311+\mathrm{G}(\mathrm{d})$ [13] implementando Gaussian03 [14]. Creando así, una molécula de TX100 con 9,5 unidades de oxietileno, como se observa en la Figura 4.1, y cuyos parámetros son presentados en las Tablas 4.1-4.4. 
Tabla 4.1: Parámetros usados en enlaces covalentes de TX100 ${ }^{a}$.

\begin{tabular}{cccc}
\hline Tipo $i$ & Tipo $j$ & $b_{0}(\mathrm{~nm})$ & $k_{b}\left(10^{6} \mathrm{kj} \mathrm{mol}^{-1} \mathrm{~nm}^{-2}\right)$ \\
\hline $\mathrm{CR} 1$ & $\mathrm{CR} 1$ & 0,139 & 10,8 \\
$\mathrm{CH}_{n}$ & $\mathrm{CH}_{n}$ & 0,153 & 7,15 \\
$\mathrm{CH}_{n}$ & $\mathrm{C}$ & 0,153 & 7,15 \\
$\mathrm{CR} 1$ & OA & 0,136 & 10,2 \\
$\mathrm{CH}_{n}$ & OA & 0,143 & 8,18 \\
\hline
\end{tabular}

${ }^{a}$ Se incluye la longitud del enlace $b_{0}$ y la constate de fuerza de oscilación del enlace $k_{b}$.

Las constantes de fuerza son simétricas $i-j=j-i$.

Tabla 4.2: Parámetros usados para los ángulos de TX100 ${ }^{a}$.

\begin{tabular}{ccccc}
\hline Tipo $i$ & Tipo $j$ & Tipo $k$ & Ángulo $\phi_{0}$ & $k_{\phi}\left(\mathrm{kj} \mathrm{mol}^{-1} \mathrm{rad}^{-2}\right)$ \\
\hline $\mathrm{C}$ & $\mathrm{CH}_{n}$ & $\mathrm{C}$ & 109,5 & 520,0 \\
$\mathrm{CH}_{n}$ & $\mathrm{C}$ & $\mathrm{CH}_{n}$ & 109,5 & 520,0 \\
$\mathrm{CH}_{n}$ & $\mathrm{C}$ & $\mathrm{CR} 1$ & 109,5 & 520,0 \\
$\mathrm{C}$ & $\mathrm{CR} 1$ & $\mathrm{CR} 1$ & 120,0 & 560,0 \\
$\mathrm{CR} 1$ & $\mathrm{CR} 1$ & $\mathrm{CR} 1$ & 120,0 & 560,0 \\
$\mathrm{CR} 1$ & $\mathrm{CR} 1$ & $\mathrm{OA}$ & 120,0 & 560,0 \\
$\mathrm{CR} 1$ & $\mathrm{OA}$ & $\mathrm{CH}_{n}$ & 111,0 & 530,0 \\
$\mathrm{OA}$ & $\mathrm{CH}$ & $\mathrm{CH}_{n}$ & 111,0 & 530,0 \\
$\mathrm{CH}_{n}$ & $\mathrm{OA}$ & $\mathrm{CH}_{n}$ & 111,0 & 530,0 \\
\hline
\end{tabular}

${ }^{a} \phi_{0}$ hace referencia a los ángulos de enlace y $k_{\phi}$ a la constante de fuerza de flexión en $\phi_{0}$.

Las constantes de fuerza son simétricas $i-j-k=k-i-j$.

Como se puede observar en la Tabla 4.3, se presentan tres ángulos diedros consecutivos e idénticos (indicados con el superíndice ${ }^{c}$ ) del tipo $O-C-C-$ $O$, organizados en una serie de tres confórmeros del orden gauche-gauchetrans que se repiten a lo largo de las 9,5 unidades de oxietileno. Por su parte, los ángulos diedros del tipo $C-C-O-C$ (indicado con el superíndice ${ }^{b}$ ), solo presentan una única conformación en trans que se extiende a lo largo del polioxietileno.

La selección y asignación de los parámetros para los ángulos diedros se fundamenta en el trabajo de Funchs y colaboradores [12], quienes comparan los perfiles de energía entre los ángulos diedros $O-C-C-O$ y $C-C-$ $O-C$ para diéteres vecinales y poliéteres. Ellos demuestran, que cambios progresivos en la conformación de ángulos diedros $O-C-C-O$ de trans a gauche, y de ángulos diedros $C-C-O-C$ de gauche a trans, reproducen las propiedades de hidratación experimentales para este tipo de sistemas. Esto es debido a que en los ángulos diedros $O-C-C-O$ de un diéter vecinal se induce una preferencia por la configuración gauche en relación a la trans, "efecto gauche", reduciendo la repulsión electrostática oxigeno-oxigeno. 
Tabla 4.3: Parámetros usados para los ángulos diedros en $\mathrm{TX}_{100^{a}}$.

\begin{tabular}{ccccccc}
\hline Tipo $i$ & Tipo $j$ & Tipo $k$ & Tipo $l$ & $k_{\phi n}$ & $\cos \delta_{\phi n}$ & $\mathrm{~m} m_{\phi n}$ \\
\hline $\mathrm{C}$ & $\mathrm{CH}_{n}$ & $\mathrm{C}$ & $\mathrm{CH}_{n}$ & 5,44 & +1 & 3 \\
$\mathrm{CH}_{n}$ & $\mathrm{C}$ & $\mathrm{CH}_{n}$ & $\mathrm{C}$ & 5,44 & +1 & 3 \\
$\mathrm{CH}_{n}$ & $\mathrm{C}$ & $\mathrm{CR} 1$ & $\mathrm{CR} 1$ & 41,8 & -1 & 2 \\
$\mathrm{CR} 1$ & $\mathrm{CR} 1$ & $\mathrm{OA}$ & $\mathrm{CH}_{n}$ & 7,11 & -1 & 2 \\
$\mathrm{CH}$ & $\mathrm{CH}_{n}$ & $\mathrm{OA}$ & $\mathrm{CH}_{n}$ & 0,931 & -1 & $1^{b}$ \\
$\mathrm{OA}$ & $\mathrm{CH}_{n}$ & $\mathrm{CH}_{n}$ & $\mathrm{OA}$ & 6,787 & +1 & $3^{c}$ \\
$\mathrm{OA}$ & $\mathrm{CH}_{n}$ & $\mathrm{CH}_{n}$ & $\mathrm{OA}$ & 6,787 & +1 & $3^{c}$ \\
$\mathrm{OA}$ & $\mathrm{CH}_{n}$ & $\mathrm{CH}_{n}$ & $\mathrm{OA}$ & 6,787 & -1 & $1^{c}$ \\
\hline
\end{tabular}

${ }^{a} m_{\phi n}$ es el factor de multiplicidad, $\cos \delta_{\phi n}$ coseno del cambio de fase y $k_{\phi n}$,

la constante de fuerza de torsión para el ángulo diedro.

${ }^{b}$ Los parámetros para los ángulos diedros $C-C-O-C$ fueron seleccionados para una única conformación en trans a lo largo del polioxietileno según la referencia [12].

${ }^{c}$ Los parámetros para los ángulos diedros $O-C-C-O$ fueron seleccionados en tres confórmeros sucesivos, gauche-guache - trans, para las 9,5 unidades de oxietileno presentes en la molécula de TX100 según la referencia [12].

Por otra parte, en la tabla 4 se detallan los grupos de cargas utilizados en la molécula de TX100 para cada grupo de átomos acorde al campo de fuerza Gromos 53A6 $O X Y+D$ [12]. Asimismo, la asignación de los grupos de carga está dada según las regiones hidrofílica e hidrofóbica en la molécula de TX100 (Ver figura 4.1). Para definir estas regiones, nos basamos en datos experimentales por Resonancia Magnetica Nuclear (RMN), Espectroscopia nuclear de efecto Overhauser 2D (NOESY), y Espectroscopia de Difusión Ordenada por RMN 2D (DOSY) [15]. Por lo tanto, a pesar de que la molécula de TX100 no presenta un limite hidrofóbico e hidrofílico bien definido $[2,15]$, los datos por NOESY 2D revelan la presencia de interacciones intermoleculares que correlacionan, las resonancias de los grupos metilo terminal y los protones aromáticos de la región hidrofóbica, p-ter-octilfenil, con los tres primeros grupos metileno en la cadena de polioxietileno de moléculas de TX100 adyacentes, durante el proceso de micelización [15]. Definiendo así estos tres grupos metilo como hidrofóbicos.

\section{Parámetros de la Simulación}

En este trabajo se llevaron a cabo simulaciones por Dinámica Molecular utilizando el paquete Gromacs 4.6.3 [16, 17] e implementando el campo de fuerza Gromos 53A6 $O X Y+D$ [12]. Como modelo de agua usamos el Simple Point Charge (SPC/E) [18] y como modelo de estudio para autoensamble micelar de surfactantes no iónicos en agua, creamos un modelo atómico de la molécula de Tritón X-100, tal como se explicó en el apartado anterior (4.2.1). 
Tabla 4.4: Cargas parciales por átomo en $\operatorname{TX}_{100}{ }^{a}$.

\begin{tabular}{cc}
\hline Tipo $i$ & $q(\mathrm{eV})$ \\
\hline $\mathrm{C}$ & 0,000 \\
$\mathrm{CH}_{n}$ & 0,000 \\
$\mathrm{CR} 1$ & 0,000 \\
$\mathrm{OA}$ & $-0,580$ \\
$\mathrm{CH}_{n}$ (enlazados a OA) & 0,290 \\
\hline$a^{a}$ Las cargas parciales fueron asigandas según la referencia [12]
\end{tabular}

Inicialmente, hidratamos una caja cubica de dimensiones $X=Y=Z=$ 11, $826 \mathrm{~nm}$ con 200 moléculas de TX100 y 49034 moléculas de agua, totalmente distribuidos al azar. El número de moléculas de TX100 usado en estas simulaciones se seleccionó de acuerdo con los reportes del número de agregación $\left(\mathrm{N}_{A g g}\right)$ experimental observado en la formación de este tipo de micelas; el cual puede variar según la técnica, la concentración, el pH y adición de sales $[2-4,15]$.

Posteriormente, se realizó una primera minimización de energía sobre el sistema con el método Steepest Descent durante 5000 pasos; seguido de una segunda minimización por el método Conjugate Gradient [27] para un valor de convergencia, $\leq 10 \mathrm{~kJ} \mathrm{~mol}^{-1} \mathrm{~nm}^{-1}$.

Después de la minimización de energía el sistema fue acoplado a un baño de temperatura usando el termostato $V$-rescale [19], $T=300 \mathrm{~K}$, en un ensamble NpT con el barostato de Berendsen, $p=1$ bar [20]. Las constantes del tiempo de acople fueron de 1.0 y 0.1 ps para el barostato y termostato, respectivamente.

Las interacciones de Lennard-Jones y las fuerzas electrostáticas fueron calculadas dentro de una radio de corte de 1,0 nm. Por su parte, cálculo de las fuerzas electrostáticas se llevo acabo por el método de Particle-Mesh Ewald (PME) [21]. El paso de integración en las simulaciones fue de $2 \mathrm{fs,}$ manteniendo las restricciones topológicas para la longitud en los enlaces del sistema utilizando el algoritmo LINCS [22]. En todas las simulaciones se usaron condiciones periódicas de contorno en cada dirección. El tiempo de simulación para el autoensamble micelar fue de 100 ns.

\section{Efectos de la presión}

Una vez el sistema logra por si solo autoensamblarse, tomamos la nueva micela como sistema de partida para estudiar el efecto de la alta presión. Acoplamos el sistema micelar a incrementos progresivos de presión cada 200 bar hasta alcanzar los 4000 bar de presión. Cada incremento fue simulado durante 20 ns (para un total de $400 \mathrm{~ns}$ ), analizando los 5 ns finales de cada valor de presión una vez el sistema logra el equilibrio. 


\section{Resultados y Discusión}

\section{Autoensamble micelar}

Como una primera validación del modelo molecular propuesto para el TX100 evaluamos la cinética de autogregación y formación de estructuras micelares. Para esto, creamos una caja cubica de simulación que contenía agua y TX100 en una concentración de 200 mM. La Concentración Micelar Critica (CMC) experimental para esta molécula oscila entre $0,15-0,25$ $\mathrm{mM}$ [5, 23-25]. Debido al costo de calculo computacional que tiene simular a escala atómica este tipo de sistemas en contracciones tan bajas, hemos seleccionado 0,2 $\mathrm{M}$ de acuerdo a estudios en MD hechos por Yordanova y colaboradores, en sistemas de la serie Tritón X-100 y 114. Los cuales obtienen excelentes resultados en la validación de parámetros como: el tamaño micelar, el número de agregación y el coeficiente de partición, en función de la temperatura y concentración de surfactante [26].

La cinética de agregación micelar es monitoreada en función del tiempo, calculando el Área Superficial Accesible al Solvente (SASA) hidrofílica, hidrofóbica y total. Como se observa en la figura 4.2 las micelas son formadas durante los primero 20 ns de simulación. Como es de esperarse, debido a que la formación de micelas es un proceso dominado por el efecto hidrofóbico, la cinética de agregación parece ser dominada por la asociación de la región no polar en la moléculas de TX100, formándose el núcleo hidrofóbico de la micela rededor de los primeros 10 ns de simulación.

Por su parte, la cadena de polioxietileno es expuesta al solvente y requiere más tiempo para compactase y estabilizar el sistema micelar. Esto posiblemente es debido a su capacidad de asociación con el agua, tomándole más tiempo establecer sus esferas de hidratación.

Otro aspecto importante en el autoensamble micelar, es el análisis del número de agregación, $\mathrm{N}_{A g g}$, y el número de micelas (cluster), $\mathrm{N}_{\text {Clust }}$, durante el tiempo de simulación. Para esto, utilizamos el algoritmo de agrupación no jerarquica GROMOS [28], el cual toma las estructuras con el mayor número de vecinos como el centro del cluster y a partir de este re-define sus primeros vecinos y calcula el tamaño del cluster. El criterio de agrupación es calculado por medio de un radio de corte de distancia $\left(\mathrm{r}_{c u t}\right)$ entre estructuras. Así, para determinar la distribución del tamaño de los agregados durante el tiempo de simulación usamos un $\mathrm{r}_{\text {cut }}=0,35 \mathrm{~nm}$.

En la figura 4.3A (Máximo $\mathrm{N}_{A g g}$ ) y 4.3B ( $\mathrm{N}_{A g g}$ promedio) es evidente que la micela se autoensambla. Una vez el sistema supera los 80 ns de simulación se forma una única micela con un $\mathrm{N}_{A g g}=200$ moléculas de TX100. Así mismo, la figura 4.3C confirma lo observado en el análisis por SASA de la figura 4.2, donde el número de micelas o clusters desciende rápidamente durante los primeros 20 ns de simulación, formado un agregado con un $\mathrm{N}_{A g g}$ 


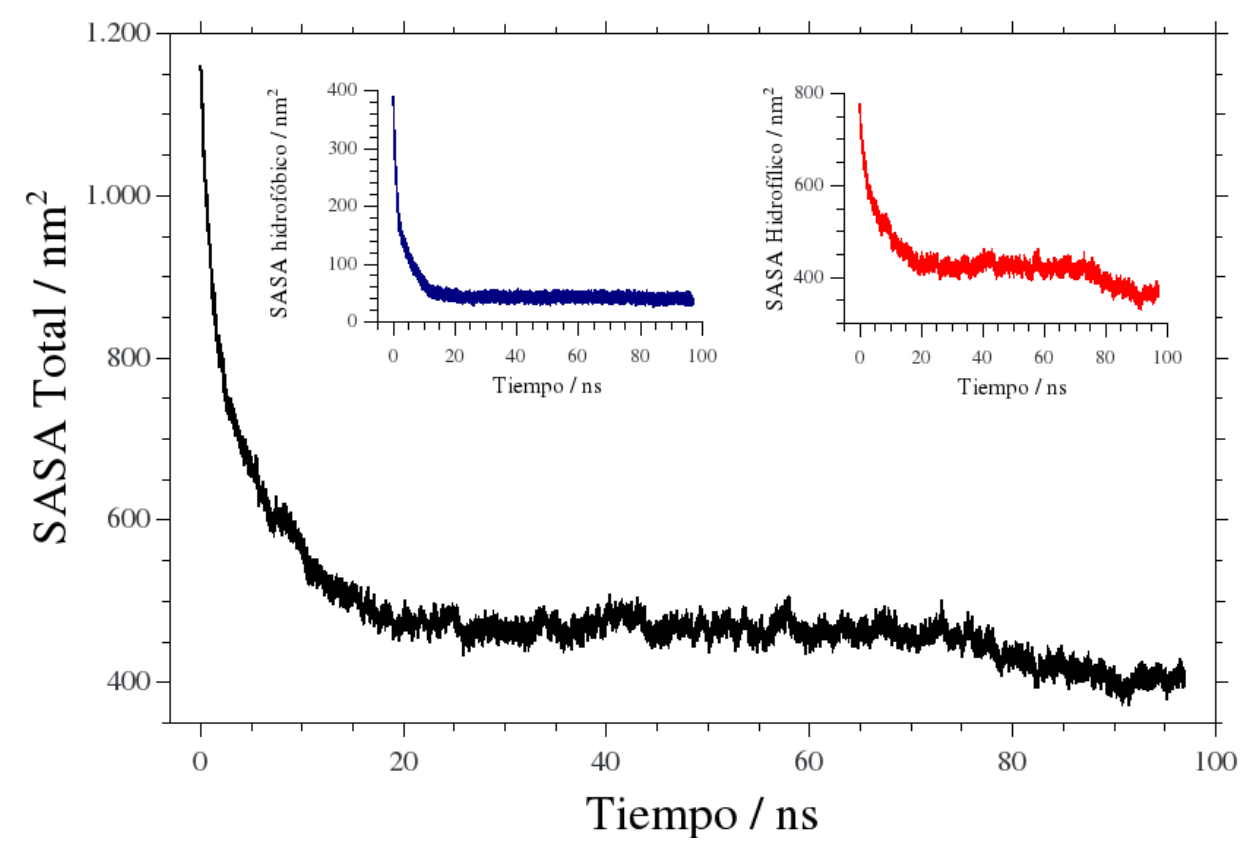

Figura 4.2: Cambios en el SASA durante el autoensable micelar. En el cuadro principal (linea negra) SASA total. En los recuadros superiores SASA hidrofóbico e hidrofílico (linea azul y roja, respectivamente). Los valores SASA fueron calculados usando el algoritmo $g \_$sas [16] con un radio de sonda de $1,4 \AA$.

máximo de 150 monómeros (Ver figura 4.3A). Sin embargo, a pesar de que la micela de TX100 se agrega durante los primeros 20 ns de simulación, se observa un segundo descenso en su SASA una vez superados los 70 ns (Ver figura 4.2), este hecho esta relacionado con el aumento en el número de agregación (Ver figura 4.3A y 4.3B) y la formación de una única micela (Ver figura 4.3C).

Por último, si nosotros definimos la probabilidad, $P_{t}$, de encontrar un cluster de $t$ monómeros de TX100, como:

$$
P_{t}=\frac{n(t) t}{N},
$$

donde $n(t)$ es el número de agregados de $t$ monómeros y $N$ número total de monómeros. Entonces, $n(t) / N$ es considerada como una frecuencia relativa y $P_{t}$ satisface la condición de normalización.

$$
\sum_{t=1}^{N} P_{t}=1
$$

Por tanto, podemos calcular el número de agregación más probable du- 
rante el tiempo total de simulación, que como se observa en la gráfica 4.3D es de 150 monómeros.
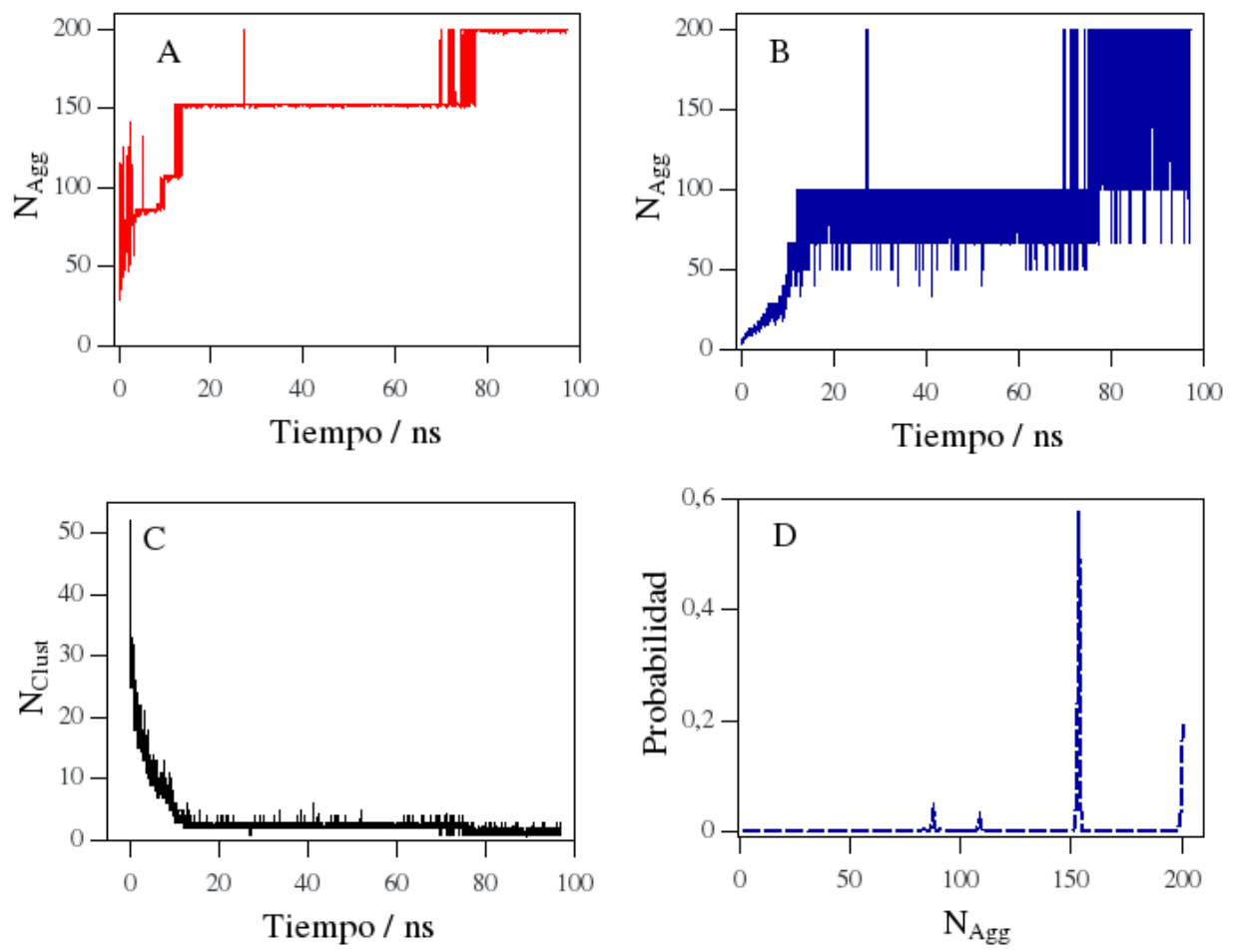

Figura 4.3: A y B número máximo y promedio de agregación en micelas de TX100 durante el tiempo de simulación, respectivamente. En C, número de cluster formados en función del tiempo. En D, El número de agregación más probable.

Definida la cinética de agregación, el $\mathrm{N}_{\text {Agg }}$ y el $\mathrm{N}_{\text {Clust }}$, quisimos analizar algunos parámetros estructurales en la micela. Así, para obtener la geometría del agregado usamos el parámetro de excentricidad, $\varepsilon$, definido como:

$$
\varepsilon=1-\frac{I_{\min }}{I_{\text {avg }}}
$$

donde $I_{\text {min }}$ es el momento de inercia a lo largo del eje principal de menor magnitud y $I_{\text {avg }}$ es el promedio de los momentos de inercia para los tres ejes. Los valores de evaluación de $\varepsilon$, van de 0 a 1 . Así, agregados con un $\varepsilon=0$ corresponden a formas altamente simétricas con geometría esférica. Por su parte, altos valores de $\varepsilon$ corresponden a progresiones hacia formas elípticas $[26,29,30]$.

En la figura 4.4A, analizamos el comportamiento de $\varepsilon$ en función del tiempo observando que el factor de excentricidad durante toda la trayectoria 

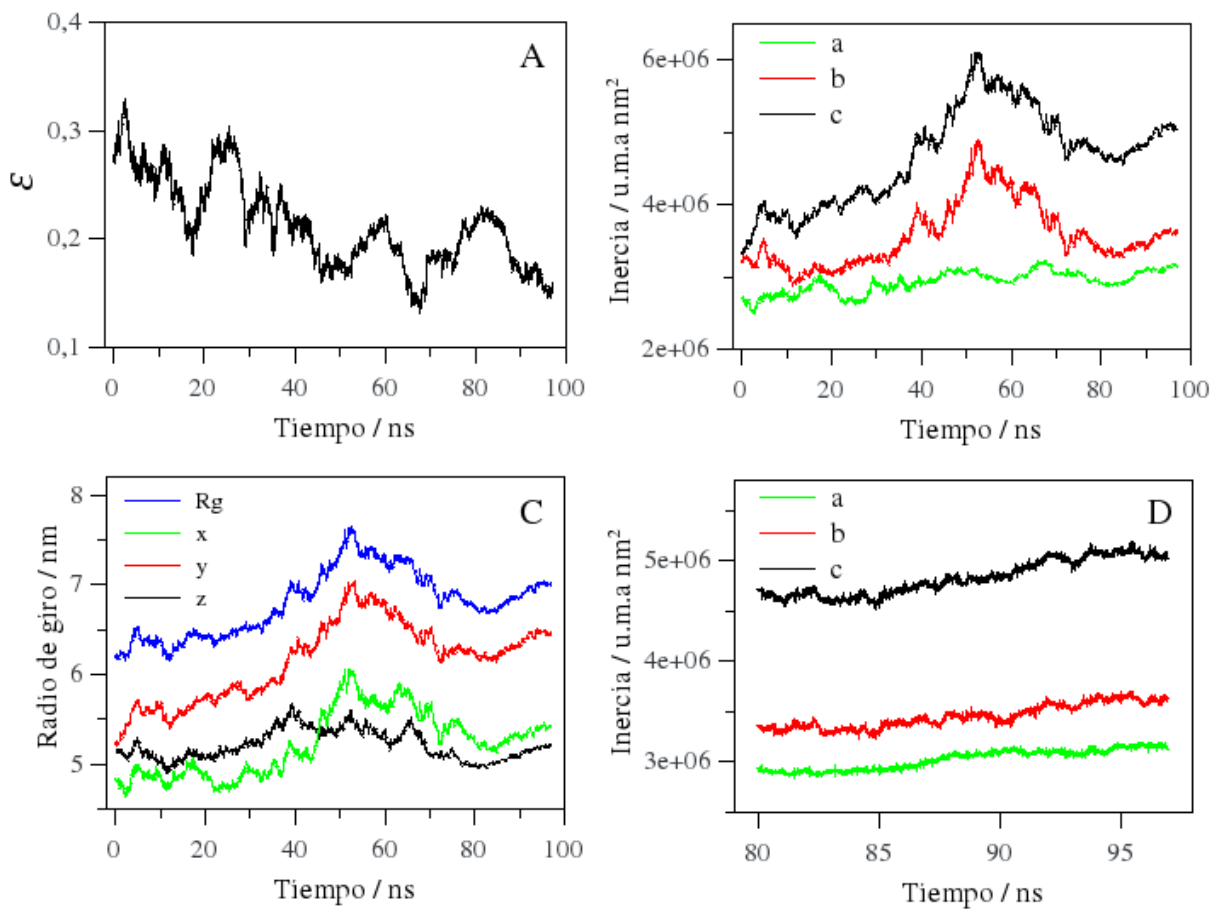

Figura 4.4: Parámetros estructurales. En A, factor de excentricidad. En B, momento de inercia para los principales ejes de la micela. En C, Radio de giro total (linea azul) y por ejes XYZ (lineas verde, roja y negra, respectivamente). En D, momento de inercia calculado en B. Solo se observa los 20 ns finales de la trayectoria simulada, para un número de agregación de 200 monómeros (Ver figura 4.3A).

oscila entre $0,2-0,3$. Por tanto, la geometría de agregación no es totalmente esférica y podría tratarse de un esferoide. Al analizar el radio de giro $\left(\mathrm{R}_{g}\right)$ (Figura 4.4C) durante el tiempo de simulación, observamos que el eje $Z$ tiene un comportamiento diferente a los ejes $X Y$. Si nosotros calculamos a partir del $\mathrm{R}_{g}$ los ejes principales de inercia en la micela, podemos obtener los semiejes $a, b$ y $c$ y establecer una relación entre los ejes. Así, sí hay dos ejes largos de longitud aproximada y otro corto estaremos ante un elipsoide en oblato. Por su parte, si uno de los ejes es largo y los otros dos más cortos (aproximadamente iguales) obtendremos un elipsoide en prolato [31] (Ver figura 4.5). En la figura $4.4 \mathrm{~B}$ y D calculamos los momentos de inercia durante el tiempo total de formación de la micela (Figura 4.4B), observando que una vez esta se autoemsambla hay dos ejes largos. Al llegar a los 80 ns uno de ellos se hace más corto, quedando tan solo un eje de mayor longitud (Figura 4.4D), lo que parece indicar una posible transición esfera-elipsoide prolato, durante el tiempo de simulación. 


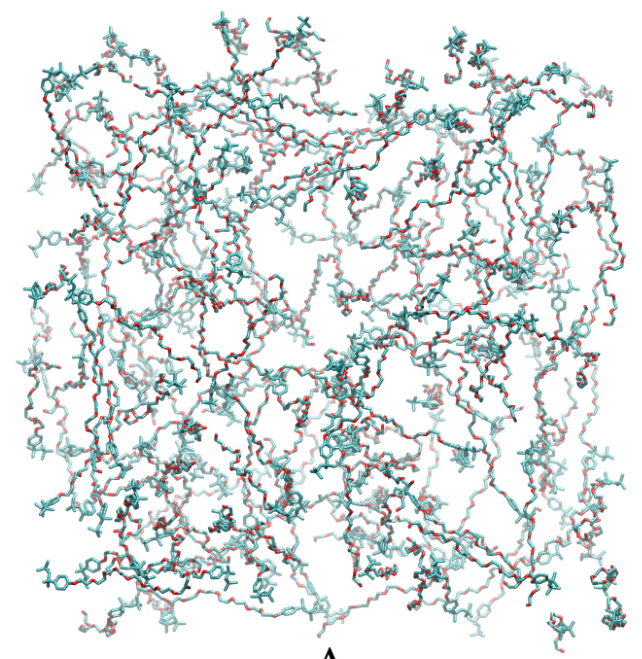

A

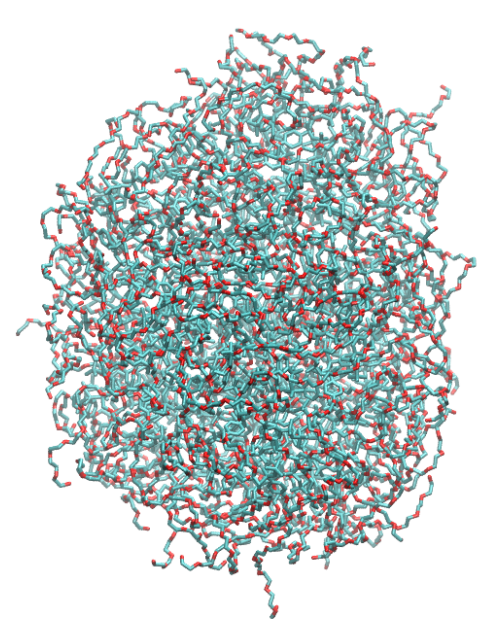

B

Figura 4.5: Autoagregación de moleculas de TX100. En A, condiciones de partida con los monómeros distribuidos aleatoriamente. En B, configuración final de autoensamble donde se observa una micela en prolato. Se han removido las moléculas de agua del sistema para su mejor visualización.

Esta misma tendencia es observada en estudios por RMN NOESY, donde al aumentar la agregación micelar por efectos de la concentración las micelas esfericas cambian su forma a elipsoides [15]. Un efecto similar es observado en estudios de simulación con técnicas híbridas de MD-CG (Dinámica Molecular de Grano Grueso) donde micelas de TX100 con $\mathrm{N}_{A g g}>140$ se estabilizan en forma de prolato [31].

\section{Efectos de la presión}

Para estudiar el efecto de la presión, hemos generado una micela por autoensamble usando el sistema TX100 - Agua en una caja de simulación con conformaciones totalmente al azar. Obteniendo así, una micela con geometría esferoide en prolato donde sus cadenas hidrofóbicas se orientan hacia en interior y son protegidas por una cubierta externa hidrofílica compuesta por grupos éter (Ver figura 4.5).

En la figura 4.6A, podemos observar el efecto de la presión en la geometría del sistema. Cuando la micela es sometida a altas presiones su valor de excentricidad desciende por debajo de 0,1 ; indicando que con el incremento de la presión la geometría de la micela tiende a ser más esférica.

Asumiendo que en altas presiones la micela es esferica y calculando su radio de giro como la media cuadrática de la distancia entre el centro de masa y la superficie, podemos obtener el radio de la micela, $\mathrm{R}_{s}$, en relación al $\mathrm{R}_{g}$ como $[26,30]$ : 


$$
R_{s}=\sqrt{\frac{5}{3}} R_{g}
$$

En la figura 4.6B, podemos observar que el radio de la micela decrece con el aumento de la presión. Sin embargo, en las regiones de baja presión $(<1,5$ kbar $)$ y alta presión $(>1,5$ kbar) se observan leves aumentos en el radio de la micela. Por ejemplo, entre los $1-1,5$ kbar hay un leve aumento en el valor de $\mathrm{R}_{s}$. Una vez se supera los 1,5 kbar de presión $\mathrm{R}_{s}$ desciende nuevamente hasta $\sim 2,2$ kbar. Una vez aquí, su valor vuelve a incrementar hasta alcanzar los 2,6 kbar.
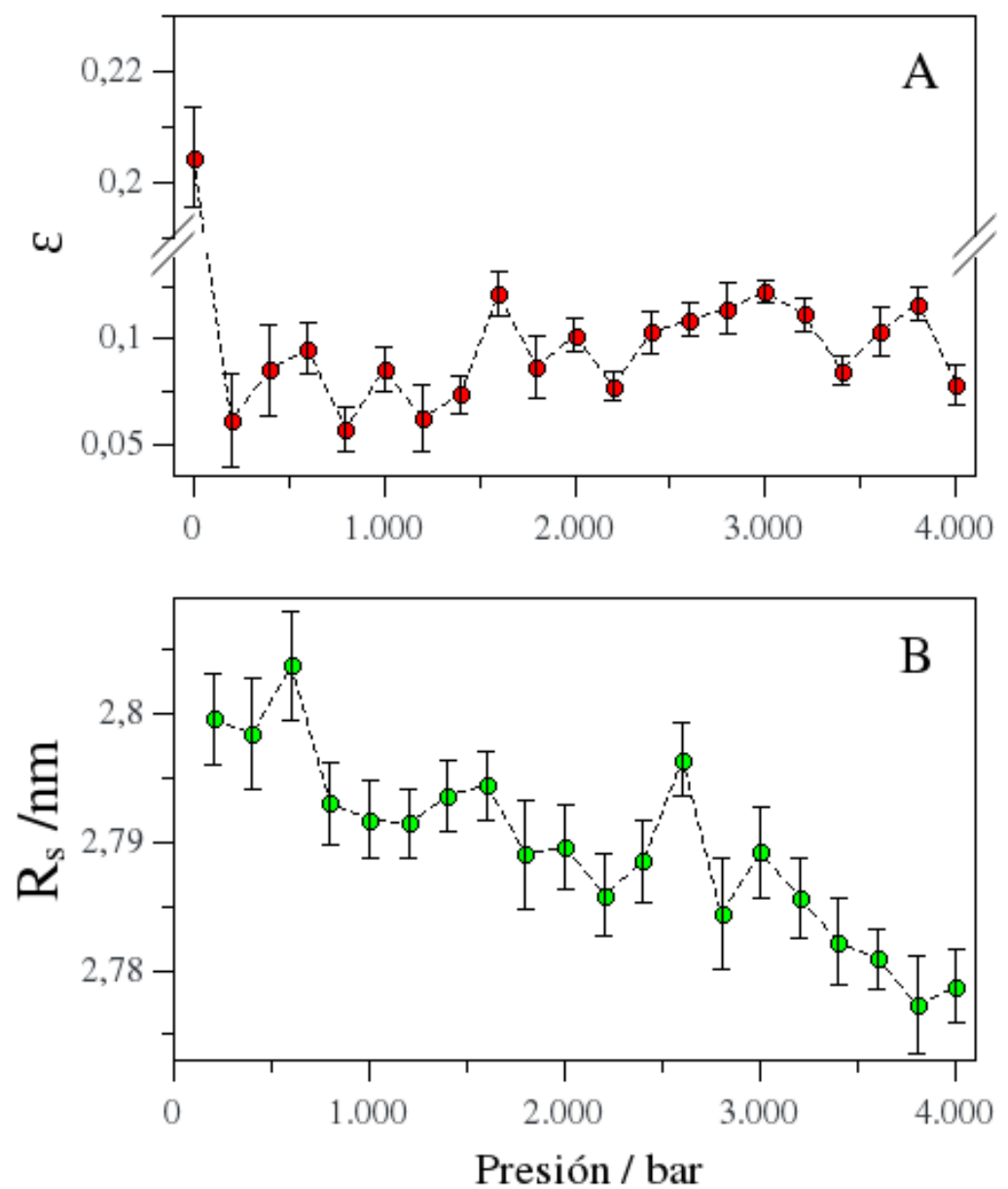

Figura 4.6: Efectos de la presión en la geometría de la micela. En A, calculo de la excentricidad. En B, cambios en el radio de la micela. Los puntos de colores y las barras de error, representan los valores promedio y la desviación estándar, respectivamente. 
Es evidente que existe una dinámica en $\mathrm{R}_{s}$, cuando la micela es sometida a altas presiones. Cuando nosotros calculamos las variaciones en el SASA por efectos de la presión, notamos que los leves incrementos observados en el radio de la micela son debidos al efecto del solvente (Ver figura 4.7).
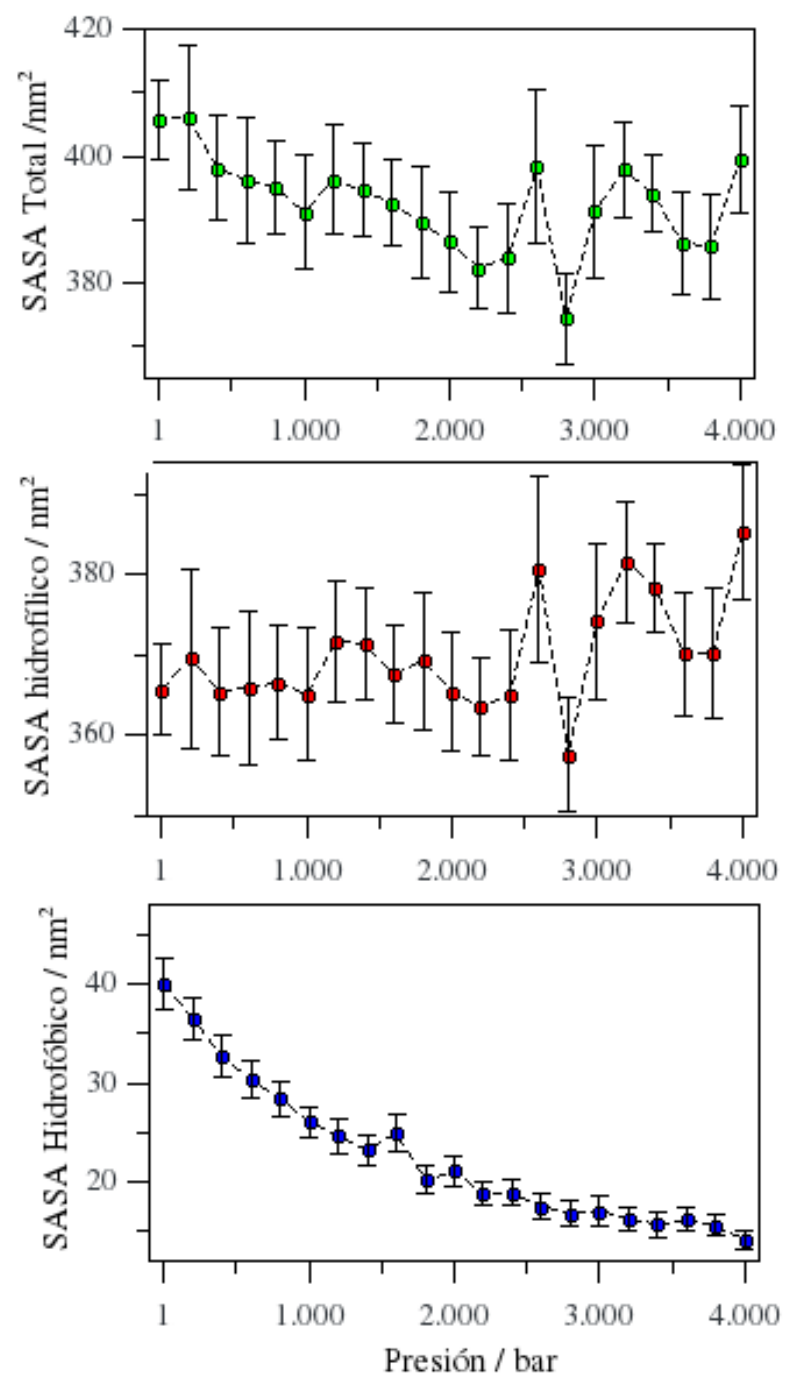

Figura 4.7: Efectos de la presión en el área superficial accesible al solvente, total (círculos verdes), hidrofílica (círculos rojos) e hidrofóbica (círculos azules). Los puntos de colores y las barras de error, representan los valores promedio y la desviación estándar, respectivamente.

En otras palabras, con el aumento de la presión el SASA total e hidrofílico de la micela incrementa entre los $1-1,5 \mathrm{kbar}$; posteriormente desciende y alrededor de los 2,3 kbar volvemos a observar un incremento en los valores. Es importante notar que, y en comparación con el SASA total, el SASA 
hidrofílico tiende a incrementar levemente con la presión. Por tanto, esto parece indicar que las fluctuaciones en el $\mathrm{R}_{s}$ son debidas en su mayoría a un incremento en la solvatación del área hidrofílica. Por su parte, el SASA hidrofóbico disminuye con el incremento de la presión y no evidenciamos un posible contacto con el solvente. Debido quizás, al gran tamaño de la región de cabeza de la micela (Ver figura 4.1, región hidrofílica) que resguarda el núcleo hidrofóbico y dificulta el contacto con las moléculas de agua.

Un efecto similar se observa al estudiar la dinámica de solvatación del agua en micelas de TX100 y dodecilsulfato sódico (SDS) en alta presión, por espectroscopia de fluorescencia resuelta en el tiempo. Donde, debido al alto número de agregación y a una mayor área en el grupo de cabeza, capaz de formar una red de puentes de hidrógeno con el agua, se genera una esfera de hidratación de mayor espesor y más organizada en micelas de TX100 en relación con las micelas de SDS. Lo que sugiriere diferencias en la estructura de hidratación al rededor de las micelas con el incremento de la presión $[1,32]$.

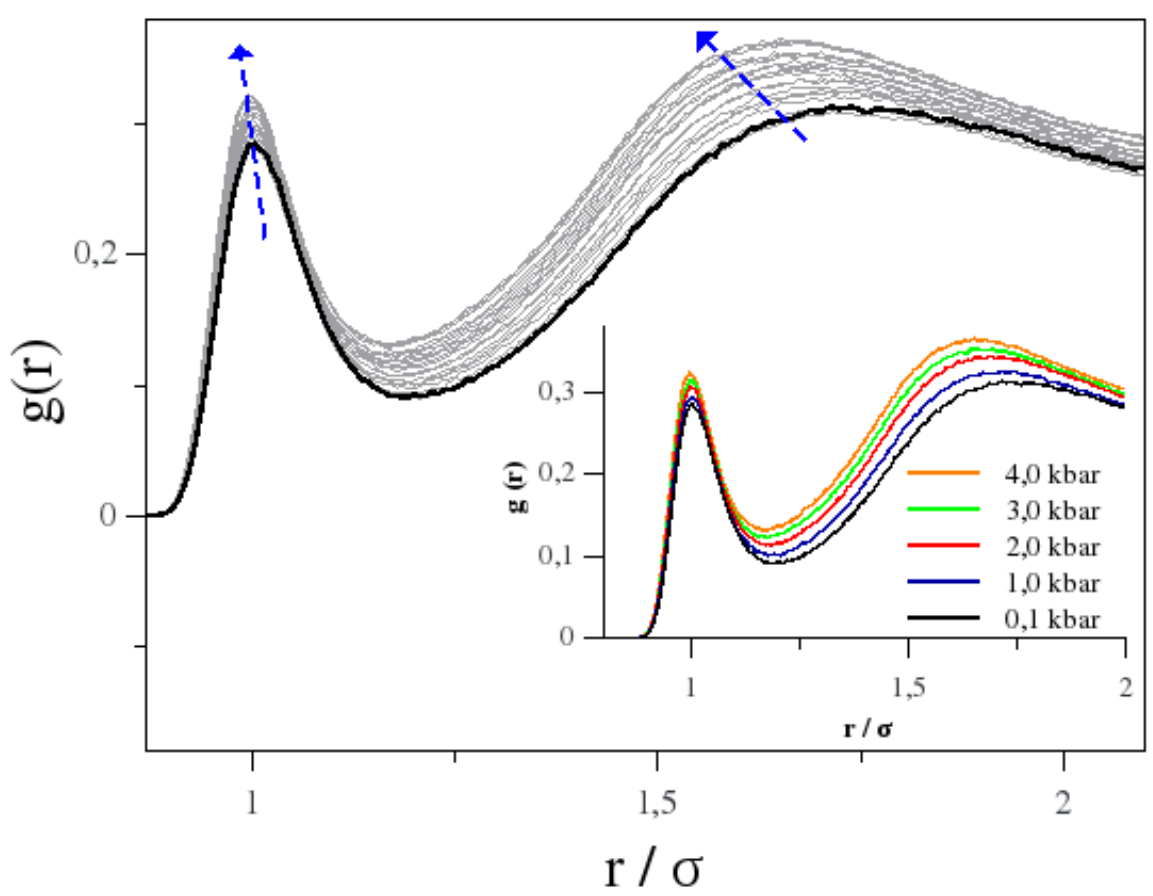

Figura 4.8: Función de distribución radial, g(r), de los átomos de oxígeno del agua al rededor de la región hidrofílica (átomos de oxígeno del poliéter) de la micela de TX100 en altas presiones. Las flechas indican la dirección del incremento de la presión. En el recuadro inferior se detallan los cambios de densidad cada 1,0 kbar. El valor $\sigma$ de normalización hace referencia al diámetro de una molécula de agua $(0,275 \mathrm{~nm})$. 
Por lo anterior, quisimos confirmar si los incrementos en el SASA y el $\mathrm{R}_{s}$, podría estar asociado con la entrada de agua al interior de la micela. Para esto, calculamos la densidad de moléculas de agua al rededor de la región hidrofílica por medio de una función de distribución radial, g(r). Como se observa en la figura 4.8, el primer y segundo pico de la g(r) aumentan con el incremento de la presión, indicando una mejor compactación de las moléculas de agua al rededor de la región hidrofílica de la micela. Así, a pesar de que incrementos en la presión comprimen la micela reduciendo el núcleo hidrofóbico (Ver figura 4.7), el incremento en el SASA total e hidrofílico es debido al ingreso de agua al interior de la micela.
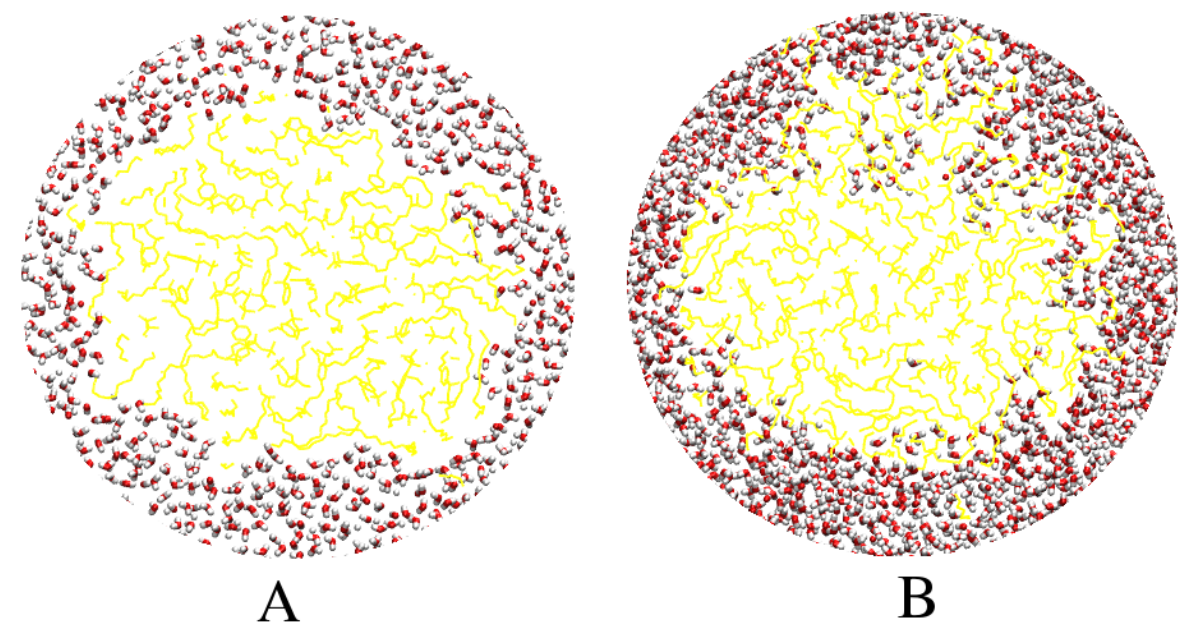

Figura 4.9: Imágenes instantáneas de la micela de TX100 a 0,1 kbar (A) y 4,0 kbar (B). En la imagen se observa un corte transversal de la micela (en amarillo), y las moléculas de agua a su alrededor (oxígenos en rojo, hidrógenos en blanco).

De esta forma, las variaciones en el radio de la micela solo pueden ser explicadas teniendo en cuenta la naturaleza de la región de cabeza del surfactante. De manera tal, que los cambios en la esfera de hidratación al rededor de la región hidrofílica es la responsable de los cambios en la dinámica estructural de la micela.

Estudios realizados en micelas de tipo $C_{i} E_{j}$ (n-alquilpoli-oxietilen-eter) por dispersión de neutrones de ángulo reducido (SANS) indican, que en altas presiones los cambios en el volumen parcial de la micela están determinados por la perdida de la esfera de hidratación alrededor del poliéter [33]. Por su parte Hara y colaboradores [25] sugieren que un efecto primario de las altas presiones en micelas de TX100 es el cambio en la CMC, que a su vez esta estrechamente relacionado con el ingreso de agua a la micela. En nuestras simulaciones, este último efecto se puede se inspeccionar visualmente en la figura 4.9 . 


\section{Conclusiones}

En el presente capítulo, nosotros generamos, optimizamos y validamos la topología molecular del TX100 que sirvió como modelo para la agregación y formación de una micela no iónica, con parámetros geométricos y de agregación acordes con los registros experimentales. Al final de $100 \mathrm{~ns}$ de simulación logramos obtener por autoensamble de monómeros libres una micela elipsoide en prolato con un número de agregación más probable de 150 monómeros.

Así, una vez la micela es acoplada en alta presión se observó como la geometría inicial sufre una transición elipsoide-esfera y como su radio presenta leves incrementos debido a cambios en la dinámica de solvatación.

Como es sabido, la estructura del gua se ven fuertemente influenciada por la presión, la cual genera anomalías en la geometría del agua liquida [34, 35]. De esta forma las primeras esferas de coordinación alrededor del soluto son desestabilizadas, se re-distribuyen los puentes de hidrógeno y la densidad del agua cambia [35]. Por tanto, la perdida de la red de hidratación y los cambios de densidad llevan al agua a comportase como un liquido simple no estructurado [36], y a penetrar al interior de la micela. Así mismo, dadas las características moleculares de la micela de TX100, donde el gran tamaño de su región hidrofílica de cabeza permite el ingreso de moléculas de agua, como si se tratase de un elemento poroso.

A pesar de que en nuestras simulaciones no evidenciamos la exposición del núcleo hidrofóbico hacia el solvente, si observamos que los cambios en el radio de la micela están íntimamente ligados con el ingreso de agua y que este efecto se relaciona con los cambios en el volumen parcial de la micela observados experimentalmente [5, 25].

Finalmente, aunque en nuestras simulaciones con TX100, y a diferencia de aquellas con SDS en el Capitulo 3, nosotros no observamos cambios en el $\mathrm{N}_{A g g}$ de la micela por efecto de la presión. Esto es debido principalmente al tamaño del sistema el cual fue simulado a una concentración mil veces mayor a la CMC del surfactante y por lo tanto la caja de simulación podría no tener espacio suficiente para disgregar la micela y generar esferas de hidratación para cada uno de los monómeros libres. En otras palabras, haría falta un mayor número de moléculas de agua que incrementarían el costo computacional, y que no estamos en condiciones de poder afrontar con nuestra actual capacidad de cálculo. Aun así, la dinámica de agregación, geometría y propiedades de solvatación han sido bien representadas por el modelo en concordancia cualitativa con los datos experimentales. 



\section{Bibliografía}

[1] Kimihiko Hara, Naoki Baden, and Okitsugu Kajimoto. Pressure effect on water solvation dynamics in micellar media. Journal of Physics: Condensed Matter, 16(14):S1207, 2004.

[2] Robert J Robson and Edward A Dennis. The size, shape, and hydration of nonionic surfactant micelles. triton x-100. The Journal of Physical Chemistry, 81(11):1075-1078, 1977.

[3] Vijay Patel, Debes Ray, Vinod K Aswal, and Pratap Bahadur. Triton x100 micelles modulated by solubilized cinnamic acid analogues: The ph dependant micellar growth. Colloids and Surfaces A: Physicochemical and Engineering Aspects, 450:106-114, 2014.

[4] JA Molina-Bolivar, J Aguiar, and C Carnero Ruiz. Growth and hydration of triton $\mathrm{x}-100$ micelles in monovalent alkali salts: a light scattering study. The Journal of Physical Chemistry B, 106(4):870-877, 2002.

[5] Naoki Baden, Okitsugu Kajimoto, and Kimihiko Hara. High-pressure studies on aggregation number of surfactant micelles using the fluorescence quenching method. The Journal of Physical Chemistry B, 106(34):8621-8624, 2002.

[6] Catherine A Royer. Revisiting volume changes in pressure-induced protein unfolding. Biochimica et Biophysica Acta (BBA)-Protein Structure and Molecular Enzymology, 1595(1):201-209, 2002.

[7] Jean-Baptiste Rouget, Tural Aksel, Julien Roche, Jean-Louis Saldana, Angel E Garcia, Doug Barrick, and Catherine A Royer. Size and sequence and the volume change of protein folding. Journal of the American Chemical Society, 133(15):6020-6027, 2011.

[8] Julien Roche, Jose A Caro, Douglas R Norberto, Philippe Barthe, Christian Roumestand, Jamie L Schlessman, Angel E Garcia, Catherine A Royer, et al. Cavities determine the pressure unfolding of proteins. Proceedings of the National Academy of Sciences, 109(18):6945-6950, 2012. 
[9] Yanis Ricardo Espinosa Silva and J Raul Grigera. Micelle stability in water under a range of pressures and temperatures; do both have a common mechanism? RSC Advances, 5(86):70005-70009, 2015.

[10] Eduardo Hidalgo Baltasar, Mercedes Taravillo, Pedro D Sanz, Valentín G Baonza, and Beİrengeİre Guignon. Role of water structure on the high pressure micellization and phase transformations of sodium dodecanoate aqueous solutions. Langmuir, 30(25):7343-7352, 2014.

[11] DP Bossev, SR Kline, JN Israelachvili, and ME Paulaitis. Pressureinduced freezing of the hydrophobic core leads to a 11â h1 phase transition for c12e5 micelles in d2o. Langmuir, 17(25):7728-7731, 2001.

[12] Patrick FJ Fuchs, Halvor S Hansen, Philippe H Huİnenberger, and Bruno AC Horta. A gromos parameter set for vicinal diether functions: Properties of polyethyleneoxide and polyethyleneglycol. Journal of Chemical Theory and Computation, 8(10):3943-3963, 2012.

[13] Mattias P Andersson and Per Uvdal. New scale factors for harmonic vibrational frequencies using the b3lyp density functional method with the triple- $\zeta$ basis set $6-311+\mathrm{g}(\mathrm{d}, \mathrm{p})$. The Journal of Physical Chemistry A, 109(12):2937-2941, 2005.

[14] M. J. Frisch, G. W. Trucks, H. B. Schlegel, G. E. Scuseria, M. A. Robb, J. R. Cheeseman, J. A. Montgomery, Jr., T. Vreven, K. N. Kudin, J. C. Burant, J. M. Millam, S. S. Iyengar, J. Tomasi, V. Barone, B. Mennucci, M. Cossi, G. Scalmani, N. Rega, G. A. Petersson, H. Nakatsuji, M. Hada, M. Ehara, K. Toyota, R. Fukuda, J. Hasegawa, M. Ishida, T. Nakajima, Y. Honda, O. Kitao, H. Nakai, M. Klene, X. Li, J. E. Knox, H. P. Hratchian, J. B. Cross, V. Bakken, C. Adamo, J. Jaramillo, R. Gomperts, R. E. Stratmann, O. Yazyev, A. J. Austin, R. Cammi, C. Pomelli, J. W. Ochterski, P. Y. Ayala, K. Morokuma, G. A. Voth, P. Salvador, J. J. Dannenberg, V. G. Zakrzewski, S. Dapprich, A. D. Daniels, M. C. Strain, O. Farkas, D. K. Malick, A. D. Rabuck, K. Raghavachari, J. B. Foresman, J. V. Ortiz, Q. Cui, A. G. Baboul, S. Clifford, J. Cioslowski, B. B. Stefanov, G. Liu, A. Liashenko, P. Piskorz, I. Komaromi, R. L. Martin, D. J. Fox, T. Keith, M. A. Al-Laham, C. Y. Peng, A. Nanayakkara, M. Challacombe, P. M. W. Gill, B. Johnson, W. Chen, M. W. Wong, C. Gonzalez, and J. A. Pople. Gaussian 03, Revision C.02. Gaussian, Inc., Wallingford, CT, 2004.

[15] Pavletta S Denkova, Luk Van Lokeren, Ingrid Verbruggen, and Rudolph Willem. Self-aggregation and supramolecular structure investigations of triton $\mathrm{x}-100$ and sdp2s by noesy and diffusion ordered $\mathrm{nmr}$ spectroscopy. The Journal of Physical Chemistry B, 112(35):10935-10941, 2008. 
[16] David Van Der Spoel, Erik Lindahl, Berk Hess, Gerrit Groenhof, Alan E Mark, and Herman JC Berendsen. Gromacs: fast, flexible, and free. Journal of computational chemistry, 26(16):1701-1718, 2005.

[17] Berk Hess, Carsten Kutzner, David Van Der Spoel, and Erik Lindahl. Gromacs 4: algorithms for highly efficient, load-balanced, and scalable molecular simulation. Journal of chemical theory and computation, $4(3): 435-447,2008$.

[18] HJC Berendsen, JR Grigera, and TP Straatsma. The missing term in effective pair potentials. Journal of Physical Chemistry, 91(24):62696271, 1987.

[19] Giovanni Bussi, Davide Donadio, and Michele Parrinello. Canonical sampling through velocity rescaling. The Journal of chemical physics, 126(1):014101, 2007.

[20] Herman JC Berendsen, J Pl M Postma, Wilfred F van Gunsteren, ARHJ DiNola, and JR Haak. Molecular dynamics with coupling to an external bath. The Journal of chemical physics, 81(8):3684-3690, 1984.

[21] Mark J Abraham and Jill E Gready. Optimization of parameters for molecular dynamics simulation using smooth particle-mesh ewald in gromacs 4.5. Journal of computational chemistry, 32(9):2031-2040, 2011.

[22] Berk Hess, Henk Bekker, Herman JC Berendsen, Johannes GEM Fraaije, et al. Lincs: a linear constraint solver for molecular simulations. Journal of computational chemistry, 18(12):1463-1472, 1997.

[23] Daoyong Yu, Fang Huang, and Hai Xu. Determination of critical concentrations by synchronous fluorescence spectrometry. Analytical Methods, 4(1):47-49, 2012.

[24] Dirk Linke. Detergents: an overview. Methods in enzymology, 463:603617, 2009.

[25] Kimihiko Hara, Hiroaki Kuwabara, Okitsugu Kajimoto, and Kankan Bhattacharyya. Effect of pressure on the critical micelle concentration of neutral surfactant using fluorescence probe method. Journal of Photochemistry and Photobiology A: Chemistry, 124(3):159-162, 1999.

[26] Denitsa Yordanova, Irina Smirnova, and Sven Jakobtorweihen. Molecular modeling of triton x micelles: Force field parameters, self-assembly, and partition equilibria. Journal of Chemical Theory and Computation, 11(5):2329-2340, 2015.

[27] D Van der Spoel, E Lindahl, and B Hess. the gromacs development team, gromacs user manual version 4.6.5 (2013). 
[28] Xavier Daura, Karl Gademann, Bernhard Jaun, Dieter Seebach, Wilfred F van Gunsteren, and Alan E Mark. Peptide folding: when simulation meets experiment. Angewandte Chemie International Edition, 38(1-2):236-240, 1999.

[29] Alexander D MacKerell Jr. Molecular dynamics simulation analysis of a sodium dodecyl sulfate micelle in aqueous solution: decreased fluidity of the micelle hydrocarbon interior. The Journal of Physical Chemistry, 99(7):1846-1855, 1995.

[30] Chrystal D Bruce, Max L Berkowitz, Lalith Perera, and Malcolm DE Forbes. Molecular dynamics simulation of sodium dodecyl sulfate micelle in water: micellar structural characteristics and counterion distribution. The Journal of Physical Chemistry B, 106(15):3788-3793, 2002.

[31] Antonio De Nicola, Toshihiro Kawakatsu, Camillo Rosano, Massimo Celino, Mattia Rocco, and Giuseppe Milano. Self-assembly of triton $\mathrm{x}-100$ in water solutions: A multiscale simulation study linking mesoscale to atomistic models. Journal of chemical theory and computation, 11(10):4959-4971, 2015.

[32] Kimihiko Hara, Hiroaki Kuwabara, and Okitsugu Kajimoto. Pressure effect on solvation dynamics in micellar environment. The Journal of Physical Chemistry A, 105(30):7174-7179, 2001.

[33] M Lesemann, H Nathan, TP DiNoia, CF Kirby, MA McHugh, JH Van Zanten, and ME Paulaitis. Self-assembly at high pressures: Sans study of the effect of pressure on microstructure of c8e 5 micelles in water. Industrial $\&$ engineering chemistry research, 42(25):6425-6430, 2003.

[34] Jeffrey R Errington and Pablo G Debenedetti. Relationship between structural order and the anomalies of liquid water. Nature, 409(6818):318-321, 2001.

[35] Ernesto R Caffarena and J Raúl Grigera. On the hydrogen bond structure of water at different densities. Physica A: Statistical Mechanics and its Applications, 342(1):34-39, 2004.

[36] Osvaldo Chara, Andrés N McCarthy, and J Raúl Grigera. Crossover between tetrahedral and hexagonal structures in liquid water. Physics Letters A, 375(3):572-576, 2011. 


\section{Capítulo 5}

\section{Modelo Proteico}

\section{Introducción}

La desnaturalización en frío de proteínas, principalmente aquella que se da por la transición del estado plegado-desplegado en función de las bajas temperaturas, es una propiedad general de las proteínas globulares [1-4]. A pesar de que los detalles referentes a la desnaturalización por bajas temperaturas esta sujeto a debate, una de las mejores predicciones, hasta ahora, la ofrece la ecuación de Gibbs-Helmholtz la cual propone la disminución de la interacción hidrofóbica, incrementando así la hidratación de los grupos no polares de la proteína a bajas temperaturas [1-3].

Uno de los problemas que presenta el estudio de la desnaturalización por bajas temperaturas, es el acceso experimental al punto de transición de los estados plegado-desplegado para los modelos proteicos en estudio, debido a que la transición ocurre a temperaturas inferiores a los $0^{\circ} \mathrm{C}[2-4]$. Por tanto, gran parte de los estudios modifican los sistemas usando agentes desestabilizantes como elevados valores $\mathrm{pH}$, desnaturalizantes químicos, altas presiones; combinado algunas veces con la inserción de mutaciones puntuales que disminuyen la estabilidad de la proteína $[5,6]$.

La modificación de los sistemas para los estudios por bajas temperaturas surgieren cambios en las condiciones nativas del buffer que hacen muy difícil extrapolar los resultados a condiciones fisiológicas. Un adelanto significativo a esta problemática experimental es la identificación de la proteína, Yfh1, cuya desnaturalización ocurre cerca de $\operatorname{los} 0^{\circ} \mathrm{C}$ en condiciones fisiológicas [5-7], evitando uno de los problemas más importantes en el estudio de la desnaturalización por bajas temperaturas, el congelamiento del agua.

La proteína Yfh1 de Saccharomyces cerevisiae, es ortóloga a la frataxina humana, hfra, responsable de la enfermedad neurodegenerativa de Friedreich, denominada, ataxia de Friedreich (FRDA) [8]. La FRDA es una enfermedad autosómica recesiva neurodegenerativa que afecta el sistema nervioso central y periférico. El gen X25 ubicado en el locus FRDA del cromosoma 9q13 es el 
responsable de codificar los 210 aminoácidos que conforman la frataxina en humanos y que presenta homólogos bien caracterizados en Escherichia coli, Caenorhabditis elegans y Saccharomyces cerevisiae [6, 9].

Asimismo, las frataxinas son proteínas con características inusuales de unión a hierro, por ejemplo la Yfh1 se une a dos iones de hierro. A diferencia de otras proteínas que coordinan hierro a través de cisteínas y que pueden ser co-ayudadas por histidinas y grupos ácidos, las frataxinas lo hacen a través de glutamatos y aspartatos expuestos a su superficie[10]. Estudios indican que el aumento en la concentración de hierro conlleva a la formación de agregados oligoméricos de hasta 48 subunidades de Yhf1 capaces de unir hasta 48 átomos de hierro. Esta capacidad de secuestrar átomos de hierro de forma no tóxica, sugiere que la Yfh1 puede tener un funcionamiento similar a la ferritina [11]. Por tanto, sin el correcto funcionamiento de las frataxinas las células no serían capaces de soportar el estrés oxidativo que producen las mitocondrias por el aumento de las concentraciones tóxicas de hierro, el cual es uno de los principales factores de causa para la ataxia de Friedreich [8].

La Yfh1 se caracteriza por presentar la más baja estabilidad térmica por bajas temperaturas en comparación con sus ortólogos [12]. La resolución estructural de la Frataxina por espectroscopia de Resonancia Magnética Nuclear (RMN) [13] es consistente con el motivo $\alpha-\beta$ sandwich. Inicialmente la región $\mathrm{N}$-terminal presenta 11 residuos no estructurados, mientras los residuos 12 - 15 forman una hélice $3_{10}$. Los 18 residuos de la región $\mathrm{N}$-terminal son de naturaleza dinámica y es la región de unión al dominio globular de la proteína. El dominio globular está formado por dos $\alpha$-hélices terminales [residuos 19-42 (H1) y 109-120 (H2)] orientadas en forma paralela. La región de las hojas $\beta$, está formada por cinco hojas $\beta$ antiparalelas entre los residuos 50-55 (S1), 60-65 (S2), 69-74 (S3), 79-84 (S4) y 88-94 (S5). Adicionalmente una sexta hoja $\beta$ formada por los residuos $97-100$ (S6) que se conecta a la hélice $\mathrm{H} 2$ por un loop de ocho aminoácidos, región denominada dominio S6-loop (Ver figura 5.1) [10, 13]. El bajo punto isoeléctrico de la Yfh1, 4.34, evidencia una carga neta negativa de -15 , producto de los 23 residuos de Asp y Glu presentes en la superficie de los elementos estructurales H1-S1 y S2, de los cuales 11 residuos están altamente conservados entre los ortólogos [13].

\section{Materiales y Métodos}

Las simulaciones por Dinámica Molecular (MD) fueron realizadas utilizando el paquete Gromacs 4.6.3 [14, 15] bajo el campo de fuerza Gromos 54A7 [16, 17]. Para los estudios de desnaturalización en frío utilizamos la estructura de la frataxina de $S$. cerevisiae resuelta por RMN, disponible en Protein Data Bank, código 2GA5 [13], usando como modelo de agua, el Simple Point Charge (SPC/E) [18]. 


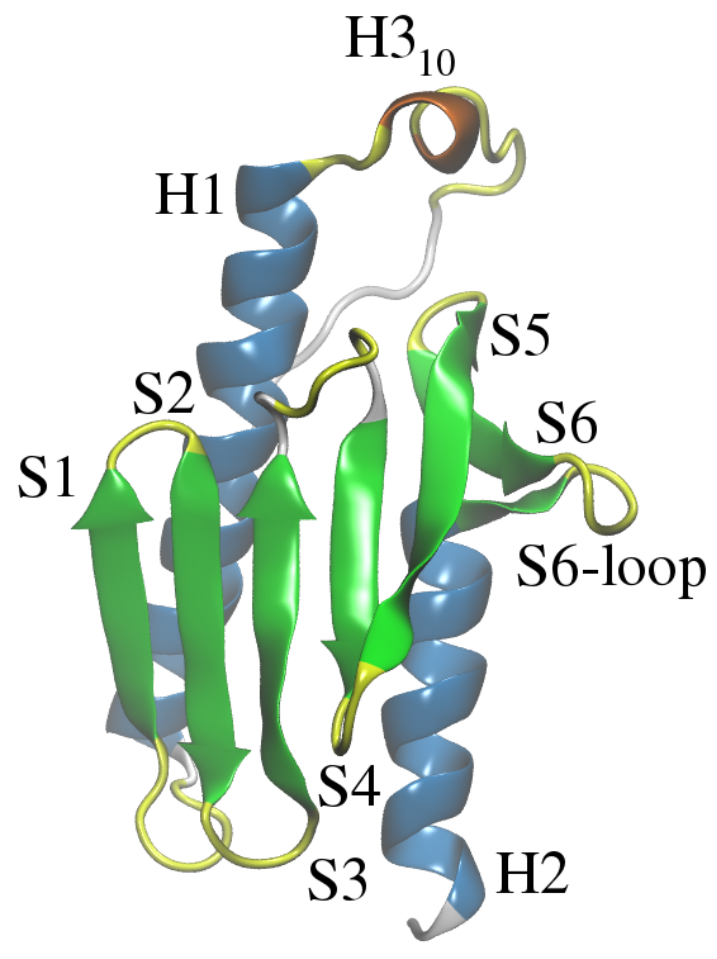

Figura 5.1: Frataxina Yfh1. Los elementos estructurales de la proteína se explican en el texto.

\section{Sistemas de simulación}

Como sistemas de partida se crearon cinco cajas cubicas de simulación, con dimensiones $X=Y=Z=6,75 \mathrm{~nm}$, las cuales contenían una molécula de frataxina y 9630 moléculas de agua. Para bajas temperaturas se crearon dos sistemas que se simularon a $215 \mathrm{~K}$ y 1 bar de presión. Las condiciones de partida para uno de estos sistemas contenía agua en estado sólido (hielo $I_{h}$,) (Ver figura 5.2A). En los sistemas de simulación restantes se utilizaron moléculas de agua ubicadas aleatoriamente y en estado liquido (Ver figura 5.2B). Así, el segundo sistema de bajas temperaturas fue simulado a 215 $\mathrm{K}$ en agua liquida. Como sistema control, se simulo la frataxina a $293 \mathrm{~K}$. Adicionalmente, simulamos para altas temperaturas un sistema a $323 \mathrm{~K}$. Los sistemas anteriormente mencionados a 1 bar de presión. Para altas presiones, la frataxina fue simulada a $3 \mathrm{kbar}$ y $293 \mathrm{~K}$ (Ver Tabla 5.1).

$\mathrm{El}$ valor de baja temperatura para la simulación fue elegido según la temperatura de fusión del modelo SPC/E, $215 \mathrm{~K}$ [19, 20]. Asimismo, la temperatura del sistema control se asignó dada la temperatura de máxima estabilidad experimental de la frataxina, $\sim 293 \mathrm{~K}[5,26]$. 


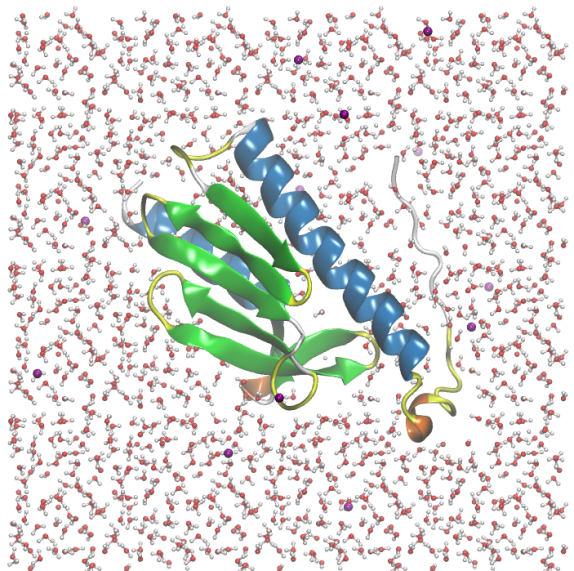

A

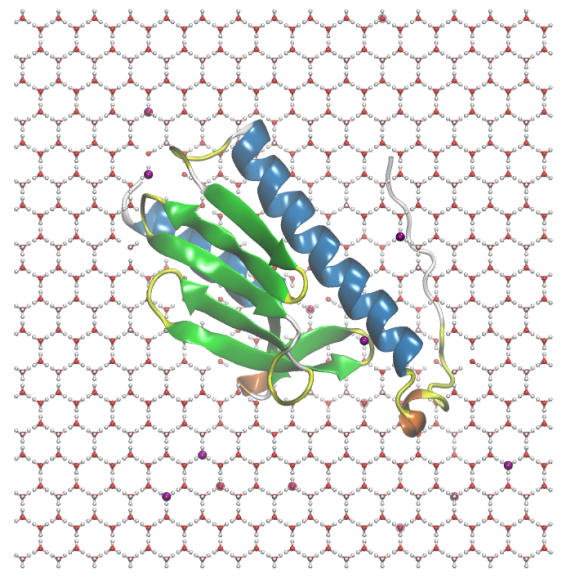

B

Figura 5.2: Configuración inicial de los sistemas simulados. En A, se representa la frataxina dentro de una caja con agua en estado sólido, hielo $I_{h}$, a $215 \mathrm{~K}$ y 1 bar de presión. En B, frataxina en agua líquida ubicada aleatoriamente. Esta configuración fue usada como sistema de partida para 215, 293 y $323 \mathrm{~K}$ a 1 bar de presión y para el sistema 3 kbar a $293 \mathrm{~K}$.

\section{Metodología de Simulación}

Sobre los sistemas de simulación se realizó una primera minimización de energía por el método Steepest Descent durante 5000 pasos y una segunda minimización por el método de Conjugate Gradient [21] para un valor de convergencia, $\leq 10 \mathrm{~kJ} \mathrm{~mol}^{-1} \mathrm{~nm}^{-1}$. Durante la minimización de energía se restringió la posición de los átomos del Backbone (esqueleto peptídico) de la proteína, usando una constante harmónica de $1000 \mathrm{~kJ} \mathrm{~mol}^{-1} \mathrm{~nm}^{-1}$ en cada dirección Cartesiana, permitiendo la organización del solvente alrededor de la proteína.

Después de la minimización los sistemas fueron acoplados a un baño de temperatura, usando el termostato $V$-rescale [22] sin acople de presión, ensamble NVT, manteniendo la restricción de posición sobre los átomos del

Tabla 5.1: Información resumida de los sistemas de simulación generados para la frataxina.

\begin{tabular}{lcccc}
\hline Sistemas & $\begin{array}{c}\text { Temperatura } \\
(\mathrm{K})\end{array}$ & $\begin{array}{c}\text { Presión } \\
(\text { bar })\end{array}$ & Distribución del agua & Fase del agua \\
\hline Ice $I_{h}$ & 215 & 1 & Hexagonal & Solida \\
$215 \mathrm{~K}$ & 215 & 1 & Aleatoria & Líquida \\
$293 \mathrm{~K}$ & 293 & 1 & Aleatoria & Líquida \\
$323 \mathrm{~K}$ & 323 & 1 & Aleatoria & Líquida \\
$3 \mathrm{kbar}$ & 293 & 3000 & Aleatoria & Líquida \\
\hline
\end{tabular}


backbone en la proteína, durante 5 ns. A continuación, aun manteniendo la restricción, los sistemas fueron acoplados a 1 bar de presión, ensamble NpT, durante $5 \mathrm{~ns}$.

Seguidamente, eliminamos la restricción de posición sobre el backbone proteína. Los sistemas fueron simulados en un ensamble NpT para las correspondientes temperaturas, usando el barostato de Parrinello-Rahman [23]. Las constantes del tiempo de acople para el barostato y termostato fueron de 1.0 y 0.1 ps, respectivamente. El tiempo de simulación de cada sistema fue de $500 \mathrm{~ns}$.

Las interacciones de Lennard-Jones fueron calculadas dentro de una radio de corte de 1,0 nm. Para el cálculo de las fuerzas electrostáticas se utilizo el método de Particle-Mesh Ewald (PME) [24]. El paso de integración en las simulaciones fue de $2 \mathrm{fs}$, manteniendo las restricciones topológicas para la longitud en los enlaces de la proteína utilizando el algoritmo LINCS [25]. En las simulaciones se utilizaron condiciones periódicas de contorno en todas las direcciones.

Es muy importante resalta que para los análisis de nuestras simulaciones hemos eliminado la región laxa no estructurada de la frataxina, comprendida desde el residuo 1 al 18, con el fin de minimizar el ruido en nuestros análisis, ya que esta región presenta un moviendo aleatorio que sobrestima la fluctuación conformacional de la proteína. Hecho constatado en una análisis previo de los resultados.

\section{Resultados y Discusión}

Nosotros presentamos para el estudio de la desnaturalización proteica en frío y por altas temperaturas, como sistema de simulación, la frataxina Yfh1 en solvente explícito. Para esto planteamos un sistema con agua estructurada hexagonalmente del tipo hielo $I_{h}$, basados en el concepto del efecto hidrofóbico, donde la estructuración del solvente es muy importante para que este se lleve acabo. Dado que la frataxina es la primera proteína en reportar desnaturalización a $0^{\circ} \mathrm{C}$ de manera natural [7], quisimos analizar los cambios estructurales que esta sufre al estar sometida a la temperatura de fusión. De igual forma, realizamos nuestros análisis en sistemas en agua liquida a 215, 293, $323 \mathrm{~K}$, esta ultima para estudiar la desnaturalización por altas temperaturas, así como en altas presiones, donde sometimos la frataxina a presiones hidrostáticas de 3 kbar.

\section{Análisis Estructural}

Para el análisis de las trayectorias nosotros utilizamos el tiempo total, $500 \mathrm{~ns}$, de cada una de las simulaciones, las cuales se realizaron para cinco diferentes configuraciones: $(i) 215 \mathrm{~K}$, agua solida en hielo $I_{h}$ (Ice $I_{h}$ ); (ii) 215 
K, agua líquida; (iii) $293 \mathrm{~K}$, agua liquida; (iv) $323 \mathrm{~K}$, agua liquida; hasta aquí los cuatro primeros sistemas a 1 bar de presión, $(v) 3 \mathrm{kbar}$, agua liquida a $293 \mathrm{~K}$ (Ver figura 5.2).

Inicialmente analizamos el efecto de la temperatura y la presión sobre la estructura global de la proteína, para esto monitoreamos la Raíz de la Desviación Cuadrática Media (RMSD) de los átomos del backbone durante el tiempo total de simulación (Ver figura 5.3). Este análisis nos permitió evaluar la divergencia estructural de la proteína durante el tiempo de simulación en relación a su estructura inicial de referencia obtenida del PDB.

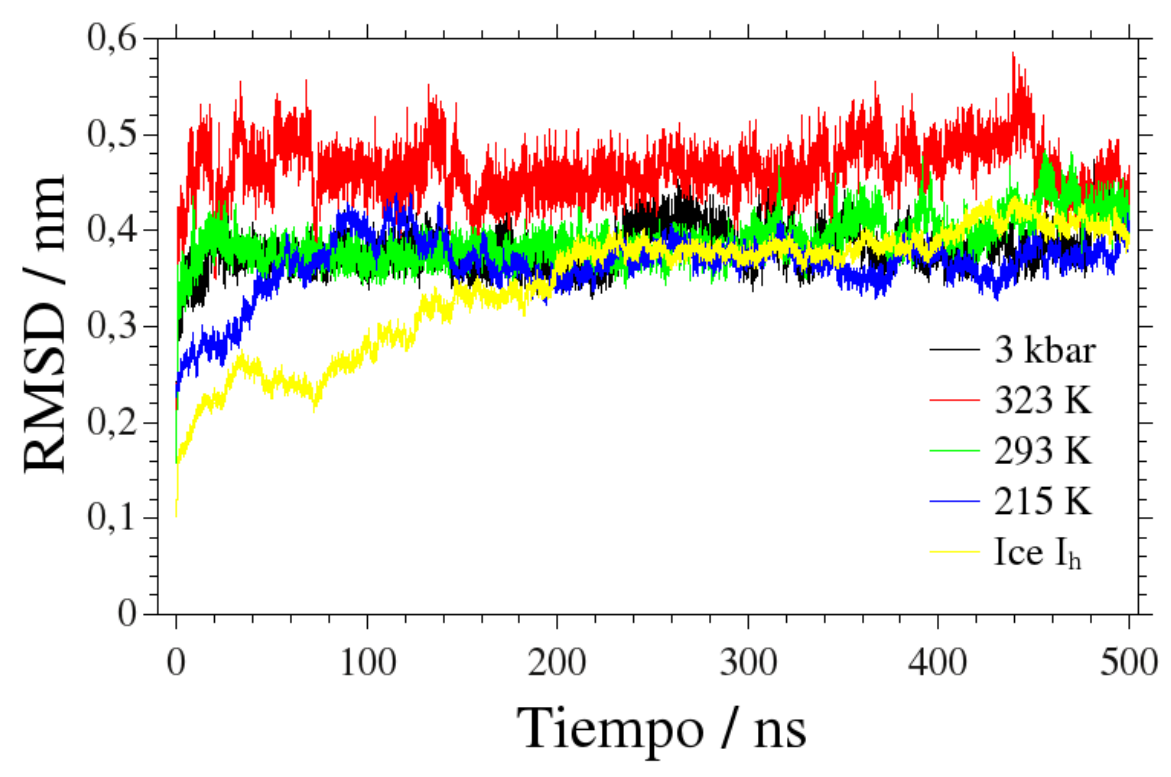

Figura 5.3: Raíz de la Desviación Cuadrática Media (RMSD) en los átomos del Backbone de la frataxina para cada condición simulada. El análisis se llevo acabo durante el tiempo total de simulación y en relación a su estructura inicial de referencia obtenida por RMN [13]

La proteína a $215 \mathrm{~K}$ en Ice $I_{h}$, presenta una desviación inicialmente creciente hasta $\sim 240 \mathrm{~ns}$, adoptando una conformación más estable alrededor de los $0,38 \mathrm{~nm}$ (Ver figura 5.3). Sin embargo, cerca de los 100 y $200 \mathrm{~ns}$ el sistema parece tener conformaciones levemente estables que va explorando durante la simulación. Cerca de los 420 ns, observamos un leve aumento del RMSD cerca de los 0,4 $\mathrm{nm}$. Esto se puede ver más claramente en la figura 5.4, donde la Raíz Cuadrática Media (RMS) de la distribución de los pares de átomos que definen la estructura, muestra que la proteína en Ice $I_{h}$, presenta 4 poblaciones bien definidas a 0,$11 ; 0,16 ; 0,19 ; 0,24 \mathrm{~nm}$ de distancia de la estructura de referencia durante el tiempo de simulación. El RMSD del sistema a $215 \mathrm{~K}$ converge alrededor de los $0,36 \mathrm{~nm}$ después de los $200 \mathrm{~ns}$ (Ver figura 5.3) y se observó la distribución de sus valores de RMS centrado 
en dos poblaciones muy próximas a 0,09 y $0,13 \mathrm{~nm}$ (Ver figura 5.4), con una pequeña población no muy bien definida cerca de los 0,18 nm. Asimismo, el sistema $215 \mathrm{~K}$ mostró una menor distribución de sus valores RMS (de $0,4$ a $2,4 \mathrm{~nm})$ en comparación con el sistema Ice $I_{h}(0,4$ a $3,4 \mathrm{~nm})$ lo que indica una mayor estabilidad en $215 \mathrm{~K}$ en relación a la proteína en Ice $I_{h}$. El sistema a $293 \mathrm{~K}$ presentó un RMSD bastante estable durante el tiempo de simulación, alcanzando durante los primeros 20 ns un valor de RMSD de $0,4 \mathrm{~nm}$ que se mantendrá hasta los $450 \mathrm{~ns}$, donde seguidamente evidenciamos un leve aumento hacia 0,42 nm (Ver figura 5.3). Sus valores de RMS muestran dos poblaciones definidas en 0,14 y $0,22 \mathrm{~nm}$ (Ver figura 5.4). Para $323 \mathrm{~K}$, nosotros observamos la mayor distribución de los valores RMS, desde 0,8 hasta $4,2 \mathrm{~nm}$, con la presencia de una población definida a los $0,28 \mathrm{~nm}$ y otra no tanto a los $0,15 \mathrm{~nm}$. Acorde con el RMS, el análisis por RMSD para este sistema mostró el valor más alto, que oscila alrededor de los $0,48 \mathrm{~nm}$. Por ultimo, en RMSD para sistema en alta presión, fue estable durante la simulación, con un valor de desviación de $\sim 0,38 \mathrm{~nm}$, lo cual concuerda con el RMS que mostró la existencia de un único grupo bien definido en 0,14 nm y uno muy leve a $0,19 \mathrm{~nm}$.

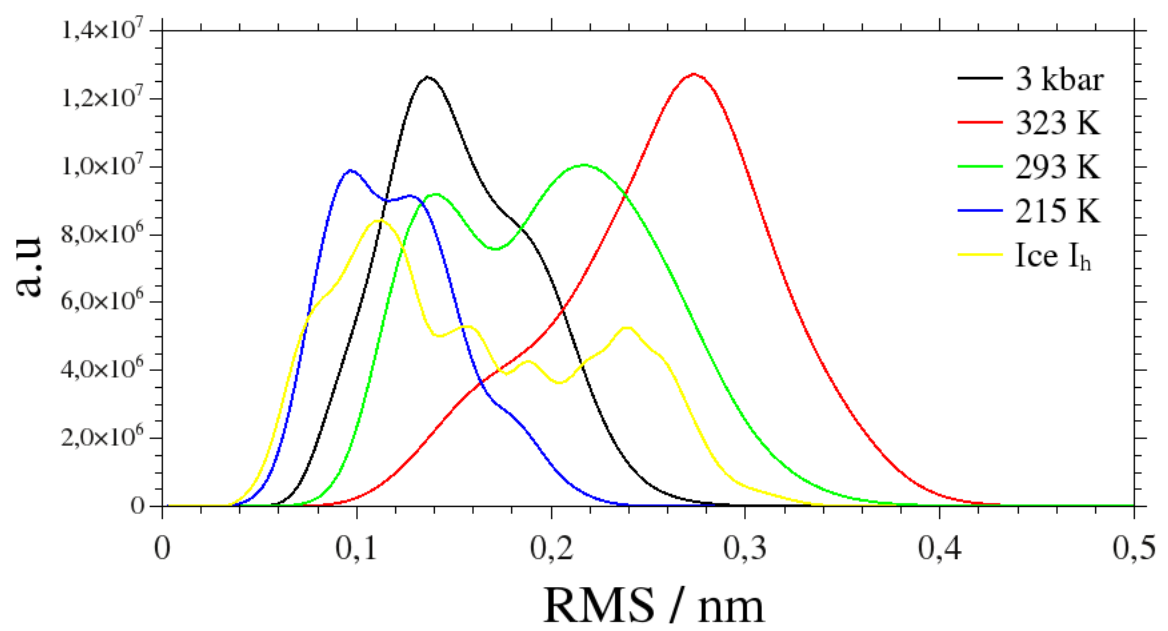

Figura 5.4: Distribución de las distintas conformaciones en relación a las distancias mostradas en el RMSD de la figura 5.3

Es de remarcar, que el sistema Ice $I_{h}$, presenta una mayor fluctuación en relación al sistema a $215 \mathrm{~K}$ en estado líquido, esto es debido posiblemente a la transición que realiza el agua de estado sólido a líquido durante la simulación, originando una mayor perturbación en la estructura proteica. Por otra aparte, el sistema a $293 \mathrm{~K}$ presentó un RMSD estable tal como se indica experimentalmente para esta temperatura [5, 26]. Como es de esperar el sistema con mayor perturbación térmica, $323 \mathrm{~K}$, presentó los mayores valores de RMSD y RMS. Sín embargo, este último indica una predilección 
del sistema por una conformación bien definida, efecto muy parecido a lo ocurrido en alta presión solo que con valores menores de RMSD y RMS.

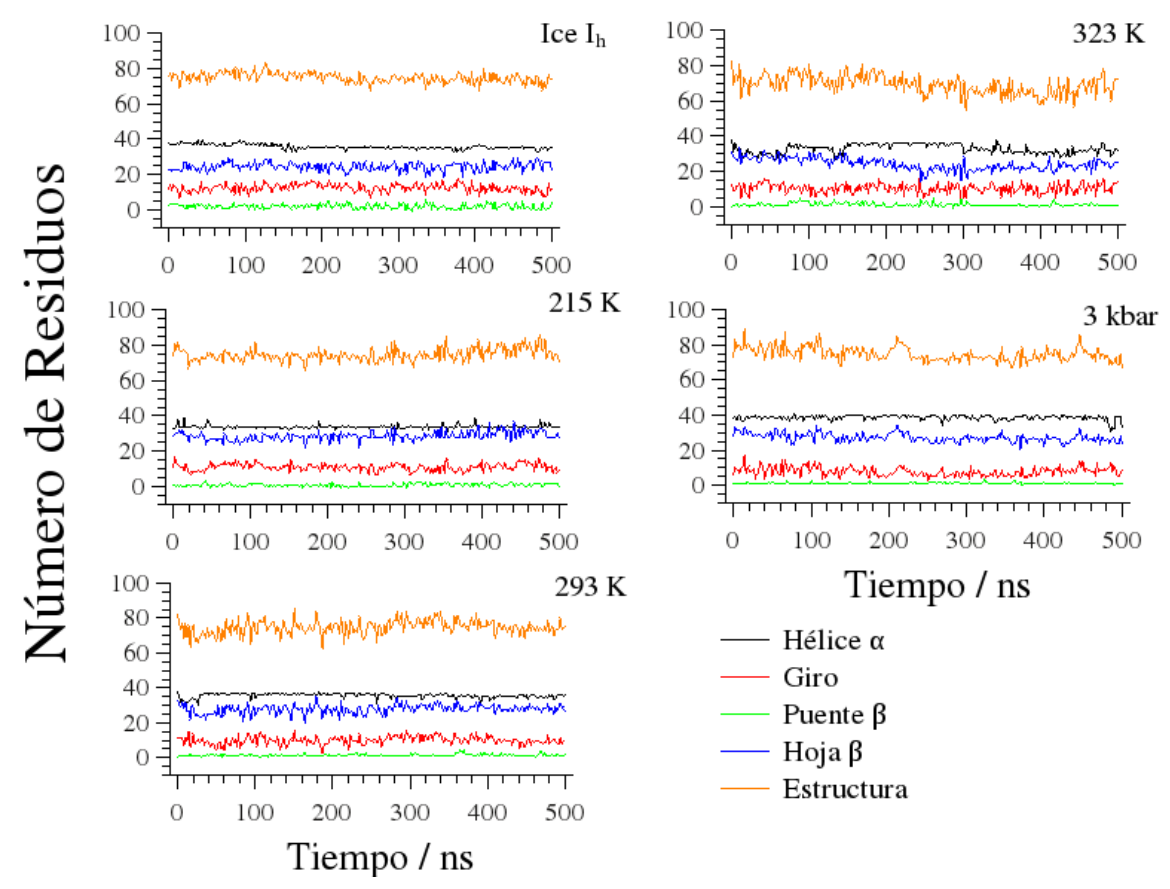

Figura 5.5: Análisis del contenido de estructura secundaria durante el tiempo total de simulación usando las definiciones del DSSP [27]

Teniendo en cuenta los análisis anteriormente expuestos, hemos mostrado que la frataxina presenta variaciones conformacionales en función de la temperatura y la presión. Para determinar sí los sistemas están presentando procesos de desnaturalización evaluamos el contenido de estructura secundaria utilizando las definiciones del Dictionary of Secondary Structure for Proteins (DSSP) [27].

En la figura 5.5 representamos la evolución temporal del recuento total de los residuos que hacen parte de los diferentes tipos de estructuras secundarias presentes en la frataxina para cada una de las condiciones simuladas. En un primer análisis podemos observar en la frataxina a $323 \mathrm{~K}$, que el recuento de residuos de la estructura total (Calculada como la sumatoria de los residuos de $\alpha$-hélice + Hoja $\beta+$ Puente $\beta+$ Giro) empieza a disminuir después de los 250 ns de simulación. Esto puede analizarse con más detalle en la Tabla 5.2, donde se observa para $323 \mathrm{~K}$ el menor valor de estructura total en relación a las condiciones simuladas, siendo notoria la perdida de estabilidad de las $\alpha$-hélices y las hojas $\beta$ durante el tiempo de simulación; lo que explicaría su alto valor de RMSD. En relación a los demás sistemas simulados, estos presentan un recuento de estructura total sin cambios significativos (Ver tabla 5.2). Sin embargo, el sistema a 3 kbar presenta el mayor número de 
Tabla 5.2: Valor promedio del número de residuos que conforman las estructuras secundarias adoptadas por la frataxina en las diferentes condiciones simuladas.

\begin{tabular}{lccccr}
\hline & Ice $I_{h}$ & $215 \mathrm{~K}$ & $293 \mathrm{~K}$ & $323 \mathrm{~K}$ & $3 \mathrm{kbar}$ \\
\hline Estructura & 74,77 & 74,64 & 74,52 & 68,96 & 74,81 \\
Hojas $\beta$ & 24,52 & 28,67 & 27,72 & 24,20 & 27,15 \\
Puente $\beta$ & 2,09 & 0,9 & 1,37 & 1,43 & 1,12 \\
Giro & 12,47 & 11,13 & 9,76 & 10,53 & 7,91 \\
Hélice $\alpha$ & 35,67 & 33,94 & 35,66 & 32,80 & 38,63 \\
\hline
\end{tabular}

residuos en las $\alpha$-hélices, indicando una mayor estabilidad con el aumento de la presión. En relación a sus hojas $\beta$, estas permanecen invariantes en relación al sistema control a $293 \mathrm{~K}$. Por otra parte, las hojas $\beta$ son más estables a $215 \mathrm{~K}$ en relación a todas las condiciones simuladas, pero presenta una disminución en la estabilidad de sus $\alpha$-hélices. Caso contrario ocurre en Ice $I_{h}$, donde observamos $\alpha$-hélices estables y hojas $\beta$ inestables.

Es importante notar que el sistema control no presenta variaciones significativas en su estructura, permitiendo una adecuada comparación entre sistemas. De igual forma, no evidenciamos perdida de la estructura secundaria en ninguna de las condiciones simuladas, debido a que este proceso requiere más tiempo de simulación, pero si una tendencia en el comportamiento de la proteína bajo cada condición simulada que iremos explorando en los siguientes apartados.

\section{Análisis de Movilidad}

Como es de esperar la movilidad de los átomos en la proteína aumenta en relación directa con la temperatura. Por tanto, nosotros comparamos la Raíz de la Fluctuación Cuadrática Media (RMSF) de los átomos del backbone para cada residuo de la frataxina en las cinco condiciones simuladas (Ver figura 5.6).

Nosotros observamos que el patrón de fluctuación en Ice $I_{h}$ es más alto de lo que se esperaba, superando el sistema a $215 \mathrm{~K}$. Sin embargo, la región $\mathrm{N}$-terminal de H1, comprendida entre los residuos 28-38 presenta baja fluctuación, lo que podría interpretarse como una persistencia a mantener su formación en $\alpha$-hélice. Contrario a esto, H2, presenta una mayor fluctuación de los residuos $C$-terminales, aunque la región con estructura secundaria que presenta la mayor fluctuación corresponde a los últimos residuos, 40-42, presentes en H1. Seguidamente, encontramos una región laxa (loop) de unión a la primera hoja $\beta, \mathrm{S} 1$, que presenta el mayor valor de fluctuación para este sistema (Ver figura 5.6). Para las estructuras en hojas $\beta$, S3 presenta la mayor movilidad y en menor medida S4 y S5.

$\mathrm{Al}$ comprar estos resultados con el sistema a $323 \mathrm{~K}$, observamos un au- 


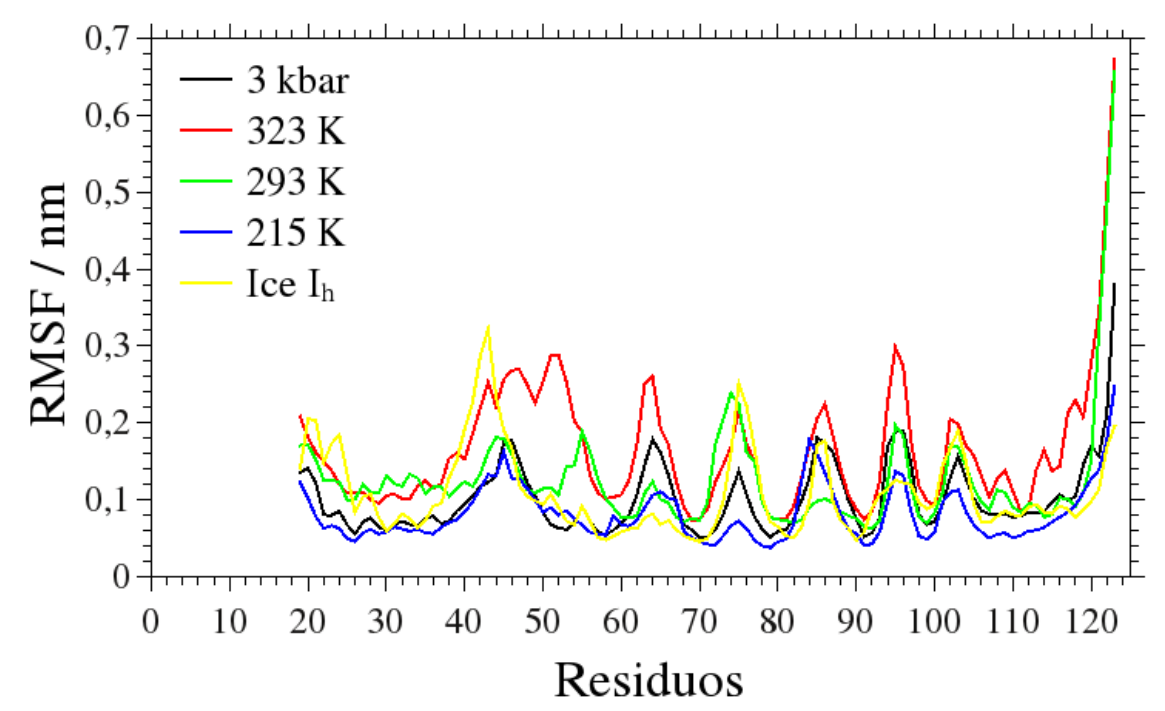

Figura 5.6: Raíz de la Fluctuación Cuadrática Media (RMSF) de los átomos del Backbone en la frataxina.

mento en la fluctuación de H1, que inicia desde el residuo 34 y se extiende hasta el residuo 54 de S1. Así mismo, S1 presenta una alta fluctuación en todos sus residuos $(50-55)$, lo que parece indicar una tendencia a perder la estructura de hoja $\beta$. De igual forma, S2, S3, S4 y S5, presentan una mayor movilidad en las regiones $C$-terminales que están en contacto con los giros de unión a hojas $\beta$. Por ultimo, la región H2, presenta una movilidad creciente desde la región $\mathrm{C}$-terminal hasta la $\mathrm{N}$-terminal, indicando posiblemente, su tendencia hacia la desnaturalización. Cabe destacar que la región comprendida entre los residuos 120-123, son residuos terminales no estructurados y de allí sus altos valores de fluctuación, en especial para los sistemas con mayor movilidad térmica.

Los resultados observados en nuestra simulación, para los sistemas en alta y baja temperatura, son acordes con los resultados experimentales [7, 26], donde la frataxina a bajas temperaturas presenta una persistencia de $\alpha$-hélice en H1, mientras que en altas temperaturas H1 no mantiene su estructura local. Sin embargo, para ambas temperaturas hay una mayor persistencia de $\mathrm{H} 1$ en relación con $\mathrm{H} 2$, al igual que en nuestras simulaciones. Por otra parte, aunque las hojas $\beta$ se despliegan completamente en ambas temperaturas, en nuestras simulaciones esta tendencia es más evidente a $323 \mathrm{~K}$, donde S1 muestra altos valores de RMSF para todos sus residuos. Aun así, todas las hojas $\beta$, a excepción de S6-loop, mostraron altos valores de RMSF en sus residuos $C$-terminales, tendencia que en Ice $I_{h}$ solo se evidencia en S3 y S4.

En la totalidad de la estructura el sistema a $293 \mathrm{~K}$ se mantiene estable, 
con un aumento de su RMSF en la región C-terminal de S3 y como es de esperarse por la fluctuación térmica, en los residuos 120-123. Por su parte $215 \mathrm{~K}$ presento valores de RMSF bajos, pero con patrones de fluctuación similares, en algunas regiones, a 3 kbar. Al analizar este ultimo sistema, es evidente que el aumento de la presión restringe la movilidad de los residuos en la proteína. Curiosamente desde el residuo 19 hasta el 60 observamos un patrón de fluctuación similar a $215 \mathrm{~K}$. Aun así, el sistema a 3 kbar tiende a ser levemente más fluctuante. H1 presenta menor RMSF que H2, y al igual que $323 \mathrm{~K}$, la región $\mathrm{C}$-terminal de unión a los giros de $\mathrm{S} 2, \mathrm{~S} 3$,S4 y S5 son las que presentan mayor fluctuación.

Hasta ahora nuestros análisis parecen indicar, que las regiones en hojas $\beta$ presentan similitudes en el comportamiento de sus residuos para las diferentes condiciones simuladas, en tanto que las $\alpha$-hélices tienden a mostrar patrones de diferenciación.

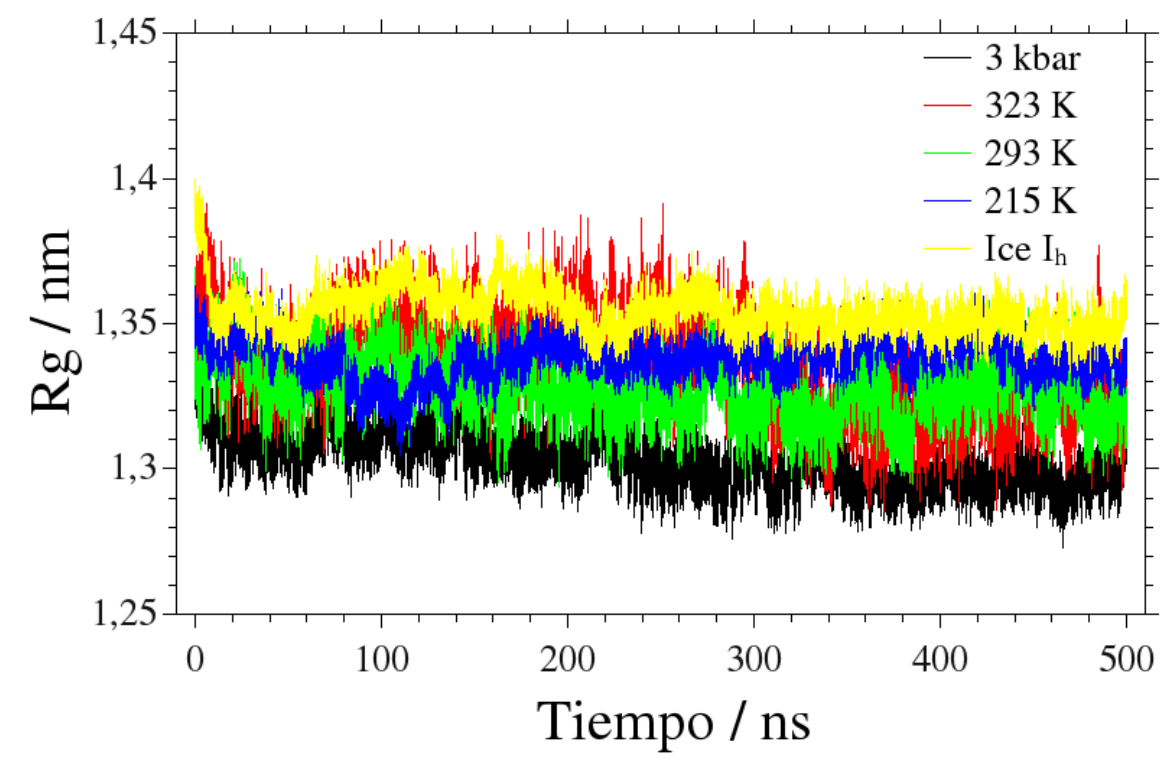

Figura 5.7: Calculo del $\mathrm{R}_{g}$ de la frataxina en las diferentes condiciones simuladas.

Adicionalmente, analizamos el Radio de Giro $\left(\mathrm{R}_{g}\right)$ de la frataxina para cada una de las condiciones simuladas. Nosotros observamos que el $\mathrm{R}_{g}$ se ve disminuido con el aumento de la presión (Ver figura 5.7). Este resultado sugiere que el sistema bajo esta condición ve disminuida su movilidad al compactarse, de allí la restricción en la movilidad de sus residuos observada en el RMSF de la figura 5.6. Una tendencia similar la observamos en el sistema a $323 \mathrm{~K}$, que a pesar de presentar una alta fluctuación en el $\mathrm{R}_{g}$ durante el tiempo de simulación, (al igual que RMSD, el $\mathrm{R}_{g}$ indica que el sistema posiblemente explora una variedad de estados conformacionales), cerca de 
los 300 ns observamos que el sistema ve reducido su $\mathrm{R}_{g}$ de aproximadamente 1,36 nm a 1,32 nm. En comparación con los sistemas a bajas temperaturas, en especial Ice $I_{h}$ que presenta el valor más alto de $\mathrm{R}_{g}$, este parece indicar que la frataxina a bajas temperaturas se expande.

Nuestros resultados por simulación son similares a los resultados experimentales reportado por Schuler y colaboradores [28], donde la frataxina disminuye su $\mathrm{R}_{g}$ con el aumento de la temperatura. Por tanto, durante la desnaturalización por calor ocurre un colapso en la estructura que disminuye su $\mathrm{R}_{g}$, mientras que en la desnaturalizacíon en frío la expansión de la proteína es la responsable del aumento en el $\mathrm{R}_{g}$.

Las variaciones conformacionales analizadas hasta ahora, muestran que existen características diferenciables entre la desnaturalización térmica y por presión. Sin embargo, parecen haber similitudes entre la desnaturalización por bajas temperaturas y la desnaturalización por presión. Para corroborar de manera más detallada, si existen similitudes entre los diferentes métodos de desnaturalización nosotros realizamos un análisis de las trayectorias que nos permitió estudiar el comportamiento esencial de nuestra proteína.

\section{Análisis por Dinámica Esencial}

Con el objetivo de realizar una evaluación detallada de los movimientos relevantes ocurridos en nuestras dinámicas, nosotros analizamos las trayectorias por medio de Análisis de Componentes Principales (PCA). Con este análisis, es posible obtener de forma detallada la dirección y la amplitud de los movimientos proteicos implicados en los cambios conformacionales de la proteína [29]. Así, podemos obtener los movimientos esenciales de nuestra proteína durante la simulación. En otras palabras, podemos describir su Dinámica Esencial (ED).

Para este análisis hemos agregado un nuevo sistema de simulación, que inicia con la frataxina en la misma configuración inicial de los sistemas representados en la figura 5.2B, donde mantuvimos invariantes los procesos de minimización de energía y ensamble NVT con restricción de posición sobre los átomos del backbone en la proteína. Una vez estabilizado el sistema, fue acoplado a un rango de presión de 1 bar a 3 kbar $\left(\mathrm{P}_{0,1-3,0 k b a r}\right)$, en pasos crecientes de 100 bar, donde el sistema se simuló para cada presión durante 10 ns, obteniendo un total de 310 ns de simulación. La Metodología de Simulación se mantuvo tal y como se presenta en la sección 5.2 de Materiales y Métodos .

Para el PCA nosotros diagonalizamos las posiciones atómicas de los $\mathrm{C} \alpha$ en una matriz de covarianza durante todo el tiempo de simulación. Cada elemento de la matriz de covarianza $\mathrm{C}$ esta representado por:

$$
C_{i, j}=\left\langle q_{i}-\left\langle q_{i}\right\rangle\right\rangle\left\langle q_{j}-\left\langle q_{j}\right\rangle\right\rangle
$$


donde $q_{i}$ y $q_{j}$ son las coordenadas de los átomos $i$ y $j$. Con esto obtenemos la proyección de la trayectoria en autovectores con sus correspondientes autovalores.

Con el calculo de los autovalores nosotros podemos obtener la contribución de la fluctuación de cada componente principal (PC) a la fluctuación total en la proteína. La figura 5.8 muestra el porcentaje de varianza acumulada que aportan los 100 primeros componentes principales de cada sistema simulado, o dicho de otra manera la contribución de cada componente al movimiento total de la proteína.

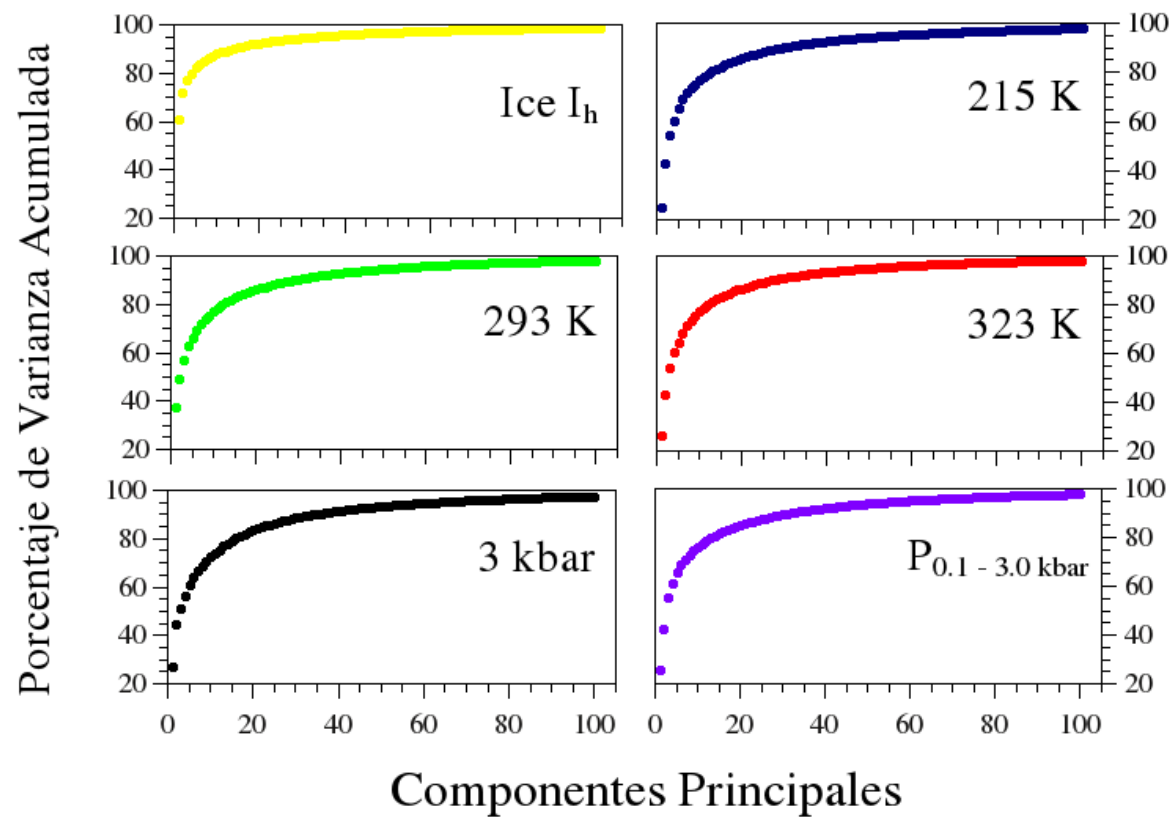

Figura 5.8: Porcentaje de varianza acumulada para los 100 primeros componentes principales calculados. Cada componente muestra la contribución acumulada al movimiento total de la proteína.

Nosotros seleccionamos como relevantes para nuestros análisis los cinco primeros componentes (mayor amplitud) que representan al rededor del: $82 \%$ de los movimientos en Ice $I_{h}, 65 \%$ en $215 \mathrm{~K}, 66 \%$ en $293 \mathrm{~K}, 65 \% 323 \mathrm{~K}$, $61 \%$ en 3 kbar y $66 \%$ en $\mathrm{P}_{0,1-3,0 k b a r}$. Es interesante notar que el primer componente del sistema Ice $I_{h}$ representa el $61,12 \%$ de los movimientos en la frataxina, siendo el valor más alto para este componente en relación a todos los sistemas simulados.

Obtenido el subespacio esencial, responsable de los movimientos que ocurren en nuestras dinámicas, proyectamos dentro de los primeros cinco componentes cada una de las trayectorias representadas en RMSF de la figura 5.9. Los patrones de fluctuación obtenidos por la proyección de las trayectorias 
muestran que el primer componente, $\mathrm{PC} 1$, para todos los sistemas, ha excepción de $\mathrm{P}_{0,1-3,0 k b a r}$, presentan fluctuaciones en sus residuos muy similares a las obtenidas para el RMSF del backbone de la proteína de la figura 5.6. No obstante, es importante notar que $(i)$ la fluctuación de los residuos pertenecientes a la primera $\alpha$-hélice en Ice $I_{h}$, es la mayor en relación con los otros sistemas, y (ii) en los primeros dos PCs recae la mayor fluctuación atómica de los sistemas simulados (Ver figura 5.9). Si bien, el sistema $\mathrm{P}_{0,1-3,0 k b a r}$ no presenta una fluctuación dominante en ninguno de los cinco PCs analizados, debemos tener presente que el aumento de la presión restringe la movilidad de los átomos, tal como se observa en el sistema $3 \mathrm{kbar}$, lo cual no impide que podamos seguir analizando los cambios estructurales que puedan presentar la frataxina bajo estas condiciones.

Por tanto, centramos nuestros análisis de movimientos esenciales en la proteína, en el aporte de los dos primeros componentes para cada condición simulada.

Como evaluación control de nuestros análisis por ED, analizamos la correlación de los movimientos difusivos en random (Aleatorios) con el movimiento de la proteína por medio del Contenido Coseno en los dos primeros componentes. Este análisis permite determinar sí el movimiento representado en cada PC durante la simulación es un proceso aleatorio. Por tanto, sí el contenido coseno es cercano a 1 , los movimientos observados son representativos de una distribución en random [30].

De esta forma, el contenido de coseno, $C_{i}$, del componente principal, $p_{i}$, es obtenido por [31]:

$$
C_{i}=\frac{2}{T}\left(\int \cos (i \pi t) p_{i}(t) d t\right)^{2}\left(\int p_{i}^{2}(t) d t\right)^{-1}
$$

donde $t$ es el tiempo total de simulación. Adicionalmente por medio del análisis de contenido coseno podemos obtener información acerca de los cambios conformacionales que ocurren en la proteína durante la MD [32].

En la figura 5.10 nosotros evaluamos el contenido coseno en función del tiempo, observando en PC1 que el sistema a $323 \mathrm{~K}$ presentó el mayor valor de los sistemas simulados cerca de los 100 ns $(\sim 0,47)$ para después caer a valores muy cercanos a cero pasado este tiempo. Seguidamente, cerca de los $250 \mathrm{~ns}$, los sistemas a $215 \mathrm{~K}$ y 3 kbar presentaron valores coseno de 0,45 y 0,39 respectivamente. Por su parte el sistema Ice $I_{h}$ tuvo un valor de 0,22 cerca a los $200 \mathrm{~ns}$, mientras que el contenido coseno del sistema control, 293 $\mathrm{K}$, fue muy bajo durante toda la simulación. Es importante señalar que la variación en estos picos coinciden con los periodos de variación del RMSD de la figura 5.3, confirmando así las transiciones conformacionales en la proteína que venimos evidenciando en el contenido de estructura secundaria y $\mathrm{R}_{g}$ de cada condición simulada.

Por su parte, en PC2 observamos que el contenido coseno es más alto en 


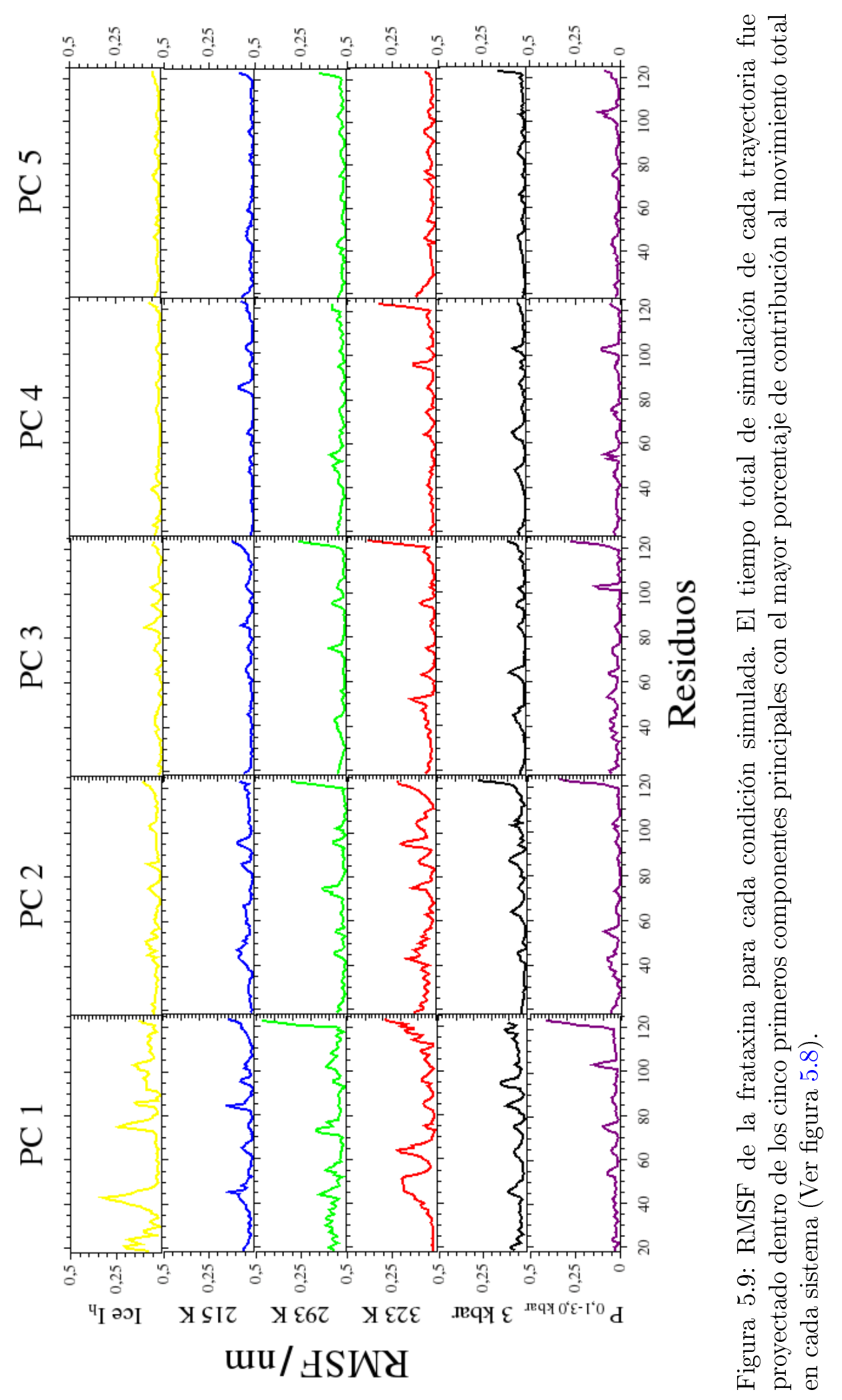




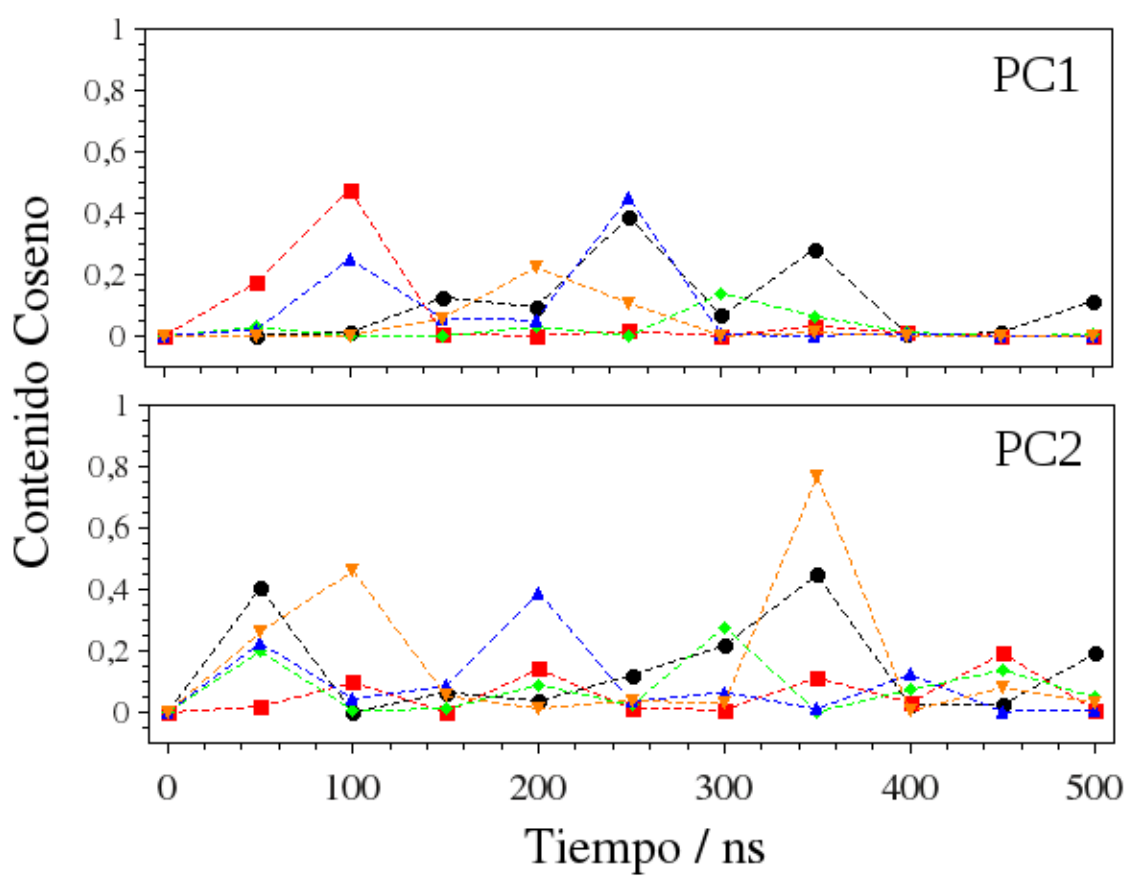

Figura 5.10: Contenido coseno en los dos primeros PCs en función del tiempo. Linea naranja, Ice $I_{h}$; linea azul, $215 \mathrm{~K}$; linea verde, $293 \mathrm{~K}$; linea roja, 323 $\mathrm{K}$; y linea negra, 3 kbar.

los sistemas de bajas temperaturas y alta presión, llegando hacer, cerca de los $350 \mathrm{~ns}$, de 0,77 en Ice $I_{h}$, y 0,44 en 3 kbar.

Dado que el sistema frataxina acoplado a presión creciente, $\left(\mathrm{P}_{0,1-3,0 k b a r}\right)$, presenta una escala de tiempo diferente a los sistemas anteriormente expuestos y una presión variante durante el tiempo de simulación, hemos analizado el contenido coseno de este sistemas en función de la presión. En la figura 5.11A, se observa en PC1 un primer aumento del contenido coseno a los 700 bar, para después caer casi a cero. Unas vez alcanzado los 1700 bar el contenido coseno empieza a incrementar levemente hasta tomar su máximo valor $(0,50)$ a los 2300 bar. Esto parece indicar que la frataxina sufre una transición antes de los 1000 bar y una segunda pasados los 2000 bar, tal como se evidencia en el $\mathrm{R}_{g}$ de la figura 5.11B. De igual forma, el $\mathrm{R}_{g}$ parece indicar que la proteína sufre un proceso de compresión y expansión en función de la presión. Por ultimo en $\mathrm{PC} 2$ el contenido coseno llegar a ser más alto que en PC1 0,64 a 1200 bar.

Finalmente, nuestros análisis por contenido coseno permiten obtener información de los cambios conformacionales ocurridos durante las MD, indicando que los tiempos de simulación son óptimos para evidenciar la convergencia de los movimientos colectivos en las estructuras, lo cual es indicador 

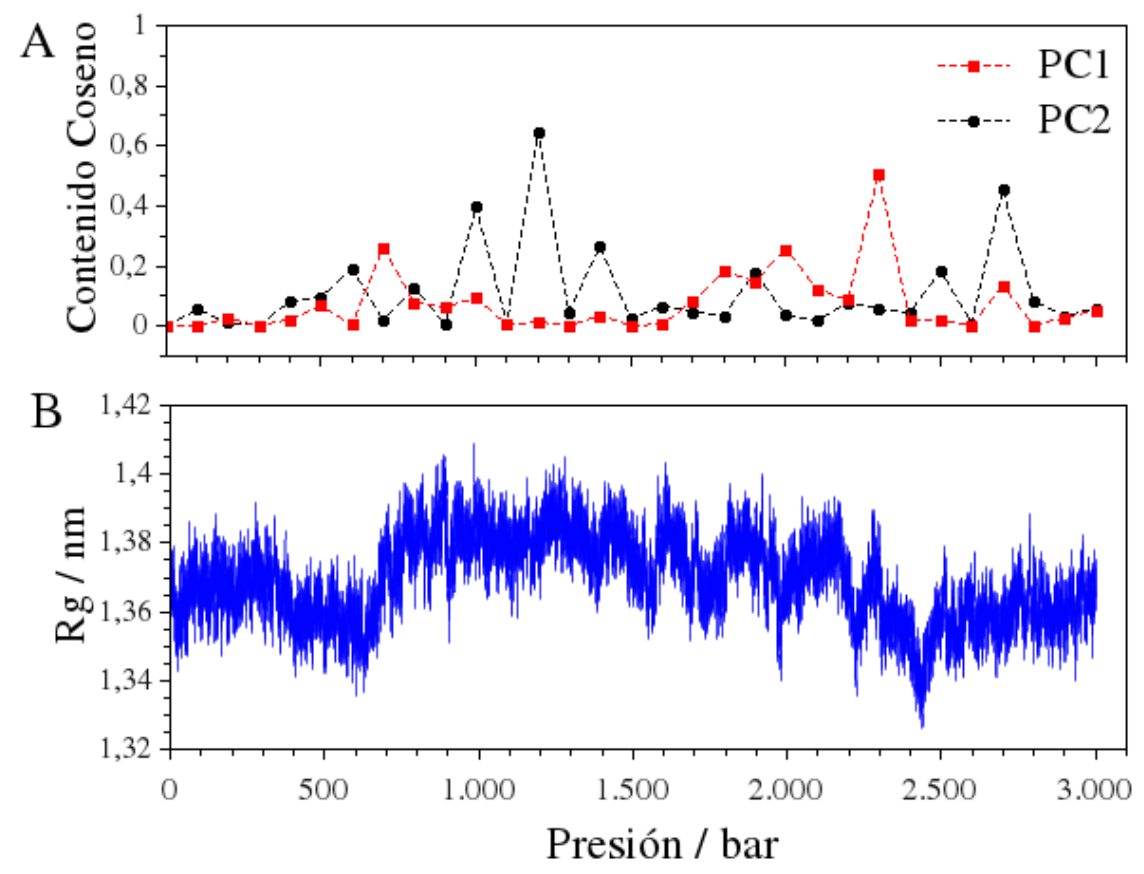

Figura 5.11: Frataxina acoplada a presión creciente de 1 a 3000 bar con incrementos cada 100 bar. (A) Contenido coseno en los dos primeros PCs. (B) Radio de giro.

de un buen muestreo en cada una de las condiciones simuladas [30, 31].

\section{Movimientos Esenciales}

Nosotros analizamos los movimientos dominantes en nuestras simulaciones proyectando las trayectorias dentro de los dos primeros componentes para cada condición simulada, representando en la figura 5.12, las proyecciones de las estructuras promedio en PC1 y PC2. En esta representación la dirección de los movimiento de cada $\mathrm{C} \alpha$ provee una proyección extrema para los dos componentes, donde los autovectores de cada C $\alpha$ (dirección) son proporcionales a la magnitud de sus autovalores (amplitud). En un primer análisis observamos que los movimientos en los dos primeros componentes varían en cada sistema. Sin embargo, estos presentan una tendencia relacionada, primero, con el cierre y apertura de la estructura y segundo, con el movimiento giratorio de sus hélices.

El PC1 en Ice $I_{h}$ mostró en $\mathrm{H} 1$ un movimiento rotativo que relaja y abre la hélice. Igualmente se observó alta actividad en las hojas S3, S4 y S5 que tienen a separarse entre ellas. Por su parte, en PC2 observamos una expansión en la estructura que aleja las $\alpha$-hélices. Estos movimientos concuerdan 


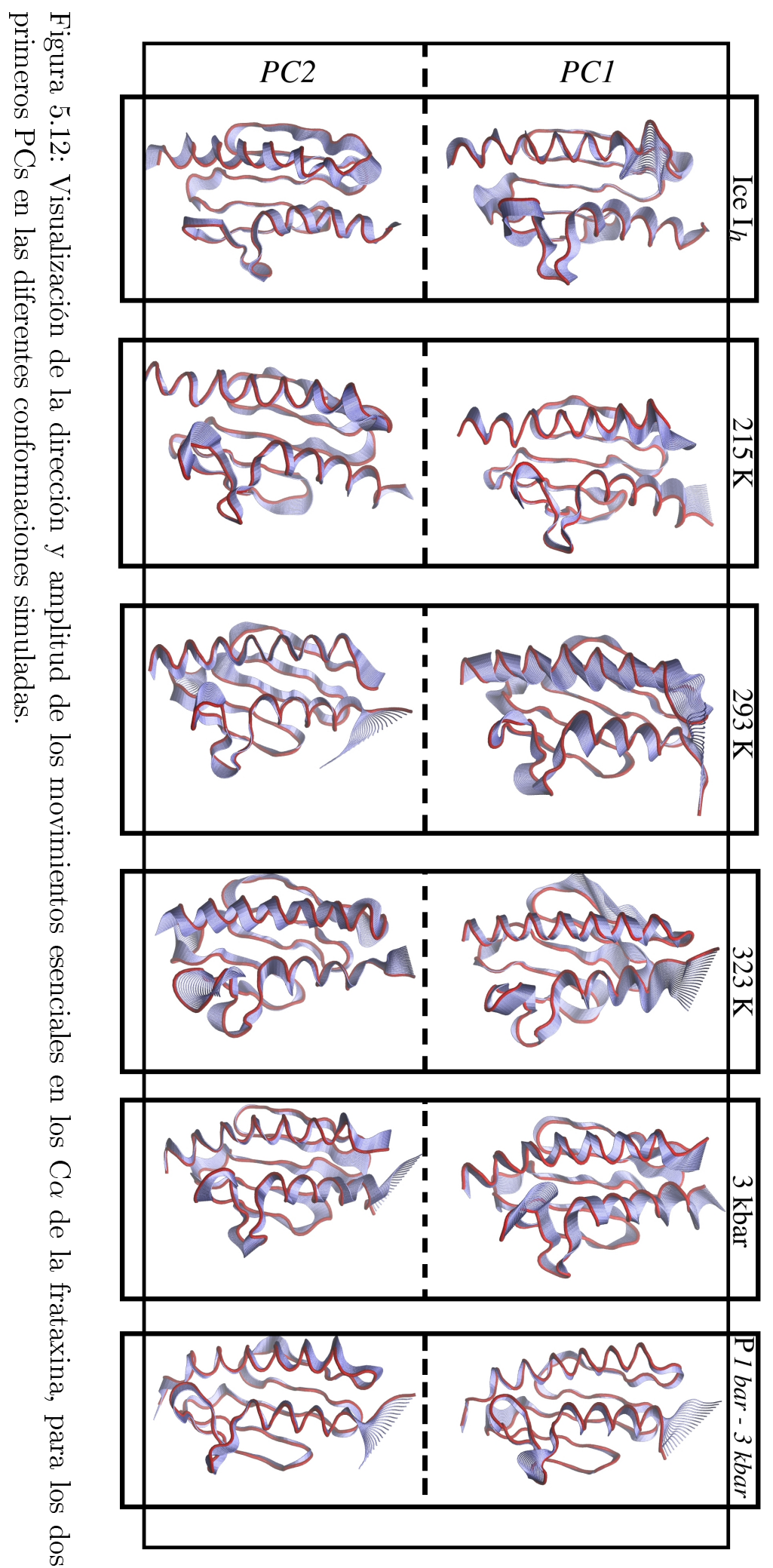


con lo analizado en el $\mathrm{R}_{g}$ y el RMSF de la figura 5.7 y 5.9, respectivamente. Por su parte a $215 \mathrm{~K}$, observamos que en PC1 la frataxina tiende a abrir sus hojas S4 y S5. En las $\alpha$-hélices evidenciamos movimientos de flexión que oscilan entre el acercamiento de $\mathrm{H} 2$ con la región $\mathrm{C}$-terminal de $\mathrm{H} 1$, mientras la región $\mathrm{N}$-terminal en $\mathrm{H} 1$ se aleja de las hojas S6- S5, esto explica la dinámica de su de $\mathrm{R}_{g}$ (Ver figura 5.7). En $\mathrm{PC} 2, \mathrm{H} 2$ tiende a rotar y abrir su región C-terminal, mientras S1 y S2 tienden a separarse. A $293 \mathrm{~K}$, no observamos movimientos relativos a la rotación de las $\alpha$-hélices y separación de las hojas $\beta$. Tal como observamos en el RMSF de la figura 5.9 la zonas de mayor fluctuación y por ende de mayor movimiento son las zonas laxas de unión entre H1-S1, S1-S2, S3-S4 y S6-H2 y los residuos C-terminales no estructurados en H2, que presentan alta amplitud en sus movimientos; además de un desplazamiento paralelo entre las $\alpha$-hélices, sin evidenciar acercamiento o distanciamientos entre ellas. En PC2 se observan movimientos similares a PC1 solo que en sentido opuesto y en menor amplitud. Este comportamiento en $293 \mathrm{~K}$ es de esperarse ya que bajo esta condición la estructura presenta la mayor estabilidad. En el caso de la frataxina a $323 \mathrm{~K}$, para PC1 observamos que H1 es más estable durante el tiempo de simulación, por su parte en $\mathrm{H} 2$ el movimiento de rotación tiende a abrir su estructura cerca de la región $\mathrm{N}$-terminal, mientras que las hojas $\beta$ S1 y S2 tienden a separase. Así mismo, la región $\mathrm{C}$-terminal de $\mathrm{H} 2$, al igual que en $293 \mathrm{~K}$ y debido a la fluctuación térmica, presenta altos valores de fluctuación (Ver figura 5.9) así como una alta amplitud en sus movimientos. PC2 por su parte, en H1 presentó movimientos de rotación que abre la estructura cerca de su región $\mathrm{C}$-terminal al igual que una elevada amplitud en los movimientos entre el loop de unión H1-S1 y S6-loop-H2.

En los análisis por alta presión para el sistema acoplado directamente a 3 kbar, observamos en PC1 un movimiento de curvatura en H1 debida a la compresión, lo cual concuerda con su bajo $\mathrm{R}_{g}$ (Ver figura 5.7). Por su parte $\mathrm{H} 2$, presentó movimientos de rotación antihorario, mientras las regiones laxas de la estructura se compactan, lo que tiende a deformar las hojas $\beta$ S2, S3, S4, y S5, que presentan mayor fluctuación en el RMSF de la figura 5.9. Por su parte PC2 presentó desplazamiento entre las estructuras secundarias, en dirección opuesta a PC1 y con alta amplitud en el movimiento de la región $\mathrm{C}$-terminal de $\mathrm{H} 2$. El sistema de frataxina acoplado a presión creciente, $\mathrm{P}_{0,1-3 k b a r}$, en $\mathrm{PC} 1$ presentó apertura en sus $\alpha$-hélices H1 y H2 en las regiones $\mathrm{N}$-terminal y $\mathrm{C}$-terminal, respectivamente. Siendo esta ultima la que presenta mayor amplitud en sus movimientos (Ver figura 5.12). Por otra parte, solo se observan movimientos en las zonas laxas de unión entre S1-S2, S3-S4, S6-loop-H2, esta ultima en mayor amplitud. En PC2, se mantiene la misma tendencia que en $\mathrm{PC} 1$, en direcciones diferentes y con menor amplitud. Sin embargo, H1 presenta movimientos de rotación en su región C-terminal (Ver figura 5.9 y figura 5.12) que buscan abrir la hélice. 
Para obtener una mejor descripción de la dirección y amplitud de los movimientos en cada sistema y su correlación, calculamos la superposición de los cinco primeros componentes principales que definen el subespacio esencial en cada sistema. Con esto, los cinco primeros autovectores, que poseen el mayor autovalor, fueron evaluados computando la Raíz Cuadrática Media de los Productos Internos de cada vector (RMSIP):

$$
R M S I P=\frac{1}{5}\left(\sum_{i=1}^{5} \sum_{j=1}^{5}\left(n_{i} \cdot v_{j}\right)\right)^{1 / 2}
$$

donde $n_{i}$ y $v_{j}$, son los autovectores en los diferentes sistemas. De forma tal que, 1 determina una perfecta superposición de los movimientos.

La tabla 5.3 muestra los valores de superposición y RMSIP, calculados para los cinco primeros PCs que definen el subespacio esencial en cada simulación. Como venimos describiendo en la interpretación cualitativa de los movimientos, la proyección de las trayectorias presentan una baja similaridad en sus movimientos. Al analizar los valores de superposición entre los componentes de cada sistema observamos que no existe una correspondencia de superposición entre cada uno de los cinco primeros PCs para los sistemas a bajas temperaturas, altas temperaturas y alta presión. Es decir, podemos observar sistemas que muestran en PC1 valores de superposición igual a cero, por tanto sus autovectores son ortogonales. Esto parece indicar que bajo las diferentes condiciones de temperatura y presión las cinéticas de desnaturalización en la frataxina no son dominadas por movimientos colectivos intrínsecos de la estructura proteica. Sin embargo, algunos PCs entre sistemas se superponen con valores $\geq 0,5$ (Ver tabla 5.3), indicando patrones globales de correlación de los movimientos. Así, el RMSIP indica que el subespacio esencial entre algunas de la condiciones simuladas se superponen, indicando algún parentesco global entre las cinéticas de desnaturalización.

En el caso de Ice $I_{h}$, este sistema no alcanza valores de RMSIP superiores al 0,5. Sin embargo, presenta la mayor superposición del espacio con el sistema de frataxina a presión creciente $\mathrm{P}_{0,1-3,0 k b a r}, 0,476$; seguido del sistema a $215 \mathrm{~K}$ y $3 \mathrm{kbar}$. Dado que Ice $I_{h}$ presenta el mayor porcentaje de varianza en el subespacio esencial (Ver figura 5.8) y la mayor fluctuación en sus residuos (Ver RMSF de la Figura 5.9 y $\mathrm{R}_{g}$ de la Figura 5.7) parecería que la frataxina bajo estas condiciones explora un espacio conformacional con varios mínimos locales [31] debido a los cambios conformacionales (Transición solido-liquido) que sufre el agua bajo esta condición. De igual manera podemos observar que el subespacio esencial presenta una mayor superposición entre los sistemas de bajas temperaturas y alta presión, tal es el caso de la frataxina a 215 $\mathrm{K}-3$ kbar y $215 \mathrm{~K}-\mathrm{P}_{0,1-3,0 k b a r}$, con valores de superposición de 0,6061 y 0,5298 respectivamente. Pero no observamos superposiciones superiores al 0,5 entre los sistemas a bajas temperaturas con los de altas temperaturas, 
Ice $\mathrm{I}_{h}-323 \mathrm{~K}(0,39) ; 215 \mathrm{~K}-323 \mathrm{~K}(0,42)$. Caso contrario, con los sistemas en alta presión y altas temperaturas, donde el RMSIP de $323 \mathrm{~K}-\mathrm{P}_{0,1-3,0 k b a r}$ es de 0,57 .

Es interesante resaltar, que en todos los sistemas, a excepción de Ice $I_{h}$, presentan superposiciones superiores a 0,5 ; con $293 \mathrm{~K}$. Esto parece indicar que los sistemas guardan similitud en sus movimientos con el sistema control y que la cinética de desnaturalización se caracteriza por cierre y apertura de la estructura y el movimiento giratorio de sus hélices, los cuales no se evidencian en este sistema y que a su vez son más notorios en Ice $I_{h}$, siendo determinantes en la desnaturalización por bajas temperaturas de la frataxina.

\section{Subespacio PC1/PC2 : Conformación Temporal}

Para comprender la dinámica conformacional de la frataxina en el espacio muestreado, nosotros proyectamos los componentes PC1 y PC2 de nuestras trayectorias en función de su secuencia temporal para las seis condiciones simuladas (Ver figura 5.13 y figura 5.14). Con la secuencia temporal podemos entender la transición entre los estados conformacionales en relación a su estructura original (resuelta por RMN).

Nosotros observamos que el espacio conformacional muestreado cambia en cada condición. En Ice $I_{h}$ la proteína explora un mayor rango de estados conformacionales en relación a $215 \mathrm{~K}$, tal como se observa en el RMS de la figura 5.4. Por otra parte, Ice $I_{h}$ progresa durante los primeros $300 \mathrm{~ns}$ entre diferentes estados conformacionales para llegar, pasado este tiempo, a conformaciones vecinas durante los últimos $200 \mathrm{~ns}$. A $215 \mathrm{~K}$ la frataxina presenta una vecindad de estructuras una vez superados los 200 ns iniciales. Seguidamente, a $293 \mathrm{~K}$ el sistema tiene mayor exploración del espacio conformacional presentando una vecindad de conformaciones muy próxima durante los primeros $300 \mathrm{~ns}$, para después transitar un segundo grupo de conformaciones estructurales vecinas durante los 200 ns finales. Con el aumento de la temperatura, $323 \mathrm{~K}$, el sistema explora homogeneamente el espació conformacional, siendo esta exploración muy amplia durante los primeros $100 \mathrm{ns,}$ lo que se relaciona con lo observado en el RMSD de la figura 5.3 y $\mathrm{R}_{g}$ de la figura 5.7.

En el caso de los sistemas de frataxina en alta presión, a $3 \mathrm{kbar}$ el sistema parece salir de su conformación inicial y pasados los 300 ns, regresar a conformaciones más próximas a su estado inicial. Este fenómeno se observa mejor en la figura 5.14, donde la frataxina es analizada en función de la presión. Al igual que lo observado en el $\mathrm{R}_{g}$ de la figura 5.11B, entre los 500 y 1000 bar, la proteína se aleja de su configuración inicial, para retornar a configuraciones cercanas a esta superados los 2000 bar. 
Tabla 5.3: Superposición y RMSIP entre los autovectores de los cinco primeros PCs que definen el subespacio esencial en cada condición simulada, Ice $I_{h}, 215 \mathrm{~K}, 293 \mathrm{~K}, 323 \mathrm{~K}, 3$ kbar y $\mathrm{P}_{0,1-3,0 k b a r}$.

\begin{tabular}{|c|c|c|c|c|c|c|}
\hline \multirow{5}{*}{$215 \mathrm{~K}$} & PC5 & 0,02 & 0,29 & 0,20 & 0,10 & 0,19 \\
\hline & PC4 & 0,24 & 0,10 & 0,21 & 0,20 & 0,50 \\
\hline & PC3 & 0,14 & 0,29 & 0,05 & 0,30 & 0,10 \\
\hline & $\mathrm{PC} 2$ & 0,05 & 0,29 & 0,16 & 0 & 0,06 \\
\hline & PC1 & 0,27 & 0,24 & 0,05 & 0,10 & 0,11 \\
\hline \multirow{2}{*}{\multicolumn{2}{|c|}{$\begin{array}{r}\text { RMSIP } \\
0,4569\end{array}$}} & PC1 & PC2 & PC3 & $\mathrm{PC} 4$ & PC5 \\
\hline & & \multicolumn{5}{|c|}{ Ice Ih } \\
\hline
\end{tabular}

\begin{tabular}{|c|c|c|c|c|c|c|}
\hline \multirow{5}{*}{$\mathrm{P}_{0,1-0,3 \mathrm{kbar}}$} & PC5 & 0,17 & 0,30 & 0,28 & 0,26 & 0,21 \\
\hline & PC4 & 0,10 & 0,06 & 0,24 & 0,11 & 0,17 \\
\hline & PC3 & 0,09 & 0,04 & 0,24 & 0.16 & 0,34 \\
\hline & $\mathrm{PC} 2$ & 0,49 & 0,23 & 0,15 & 0,27 & 0,18 \\
\hline & PC1 & 0,16 & 0,18 & 0,43 & 0,24 & 0,28 \\
\hline \multirow{2}{*}{\multicolumn{2}{|c|}{$\begin{array}{l}\text { RMSIP } \\
\mathbf{0 , 5 2 9 8}\end{array}$}} & PC1 & $\mathrm{PC} 2$ & PC3 & $\mathrm{PC} 4$ & PC5 \\
\hline & & \multicolumn{5}{|c|}{$215 \mathrm{~K}$} \\
\hline
\end{tabular}

\begin{tabular}{|c|c|c|c|c|c|c|}
\hline \multirow{3}{*}{$293 \mathrm{~K}$} & PC5 & 0,08 & 0,21 & 0,19 & 0,40 & 0,21 \\
\cline { 3 - 7 } & PC4 & 0,13 & 0,40 & 0,15 & 0,10 & 0,29 \\
\cline { 3 - 7 } & PC3 & 0,09 & 0,42 & 0,01 & 0,10 & 0,17 \\
\cline { 3 - 7 } & PC2 & 0,03 & 0,08 & 0,05 & 0 & 0,20 \\
\cline { 3 - 7 } & PC1 & 0,15 & 0,35 & 0,13 & 0,10 & 0,18 \\
\hline RMSIP & PC1 & PC2 & PC3 & PC4 & PC5 \\
\cline { 2 - 6 } 0,4566 & \multicolumn{7}{|c|}{ Ice Ih } \\
\hline
\end{tabular}

\begin{tabular}{|c|c|c|c|c|c|c|}
\hline \multirow{5}{*}{$323 \mathrm{~K}$} & PC5 & 0,11 & 0,05 & 0,23 & 0,05 & 0 \\
\hline & $\mathrm{PC} 4$ & 0,12 & 0,15 & 0,61 & 0,06 & 0,37 \\
\hline & PC3 & 0,59 & 0,34 & 0,15 & 0,02 & 0,05 \\
\hline & $\mathrm{PC} 2$ & 0,27 & 0,12 & 0,38 & 0,35 & 0,09 \\
\hline & PC1 & 0 & 0,32 & 0,24 & 0,20 & 0,02 \\
\hline \multicolumn{2}{|c|}{ RMSIP } & PC1 & PC2 & PC3 & PC4 & PC5 \\
\hline
\end{tabular}

\begin{tabular}{|c|c|c|c|c|c|c|}
\hline \multirow{3}{*}{$323 \mathrm{~K}$} & PC5 & 0,23 & 0,05 & 0,34 & 0,10 & 0,10 \\
\cline { 3 - 7 } & PC4 & 0,11 & 0,29 & 0,04 & 0,10 & 0,27 \\
\cline { 3 - 7 } & PC3 & 0 & 0,03 & 0,19 & 0,10 & 0,16 \\
\cline { 3 - 7 } & PC2 & 0,03 & 0,29 & 0,14 & 0,10 & 0,14 \\
\cline { 3 - 7 } & PC1 & 0,12 & 0,13 & 0,22 & 0,20 & 0,25 \\
\hline RMSIP & PC1 & PC2 & PC3 & PC4 & PC5 \\
\cline { 2 - 6 } 0,3951 & \multicolumn{5}{|c|}{ Ice Ih } \\
\hline
\end{tabular}

\begin{tabular}{|c|c|c|c|c|c|c|}
\hline \multirow{4}{*}{3 kbar } & PC5 & 0,32 & 0,17 & 0,16 & 0,27 & 0,37 \\
\cline { 3 - 7 } & PC4 & 0 & 0,25 & 0,09 & 0,04 & 0,07 \\
\cline { 3 - 7 } & PC3 & 0,12 & 0,22 & 0,40 & 0,02 & 0,16 \\
\cline { 3 - 7 } & PC2 & $\mathbf{0 , 5 0}$ & $\mathbf{0 , 5 0}$ & 0,10 & 0,09 & 0,02 \\
\cline { 3 - 7 } & PC1 & 0,15 & 0,09 & 0,26 & 0,27 & 0,47 \\
\hline \multicolumn{2}{|c|}{$\begin{array}{l}\text { RMSIP } \\
\text { 0,5662 }\end{array}$} & PC1 & PC2 & PC3 & PC4 & PC5 \\
\cline { 2 - 6 } & \multicolumn{7}{|c}{$293 \mathrm{~K}$} \\
\hline
\end{tabular}

\begin{tabular}{|c|c|c|c|c|c|c|}
\hline \multirow{5}{*}{$3 \mathrm{kbar}$} & PC5 & 0,02 & 0,08 & 0,06 & 0,10 & 0,19 \\
\hline & $\mathrm{PC} 4$ & 0,12 & 0,10 & 0,27 & 0,10 & 0,17 \\
\hline & PC3 & 0,07 & 0,23 & 0,09 & 0,50 & 0,05 \\
\hline & $\mathrm{PC} 2$ & 0,10 & 0,35 & 0 & 0,10 & 0,36 \\
\hline & PC1 & 0,02 & 0,44 & 0,33 & 0,20 & 0 \\
\hline \multirow{2}{*}{\multicolumn{2}{|c|}{$\begin{array}{l}\text { RMSIP } \\
0,4455\end{array}$}} & PC1 & $\mathrm{PC} 2$ & PC3 & $\mathrm{PC} 4$ & PC5 \\
\hline & & \multicolumn{5}{|c|}{ Ice Ih } \\
\hline
\end{tabular}

\begin{tabular}{|c|c|c|c|c|c|c|}
\hline \multirow{4}{*}{ P $_{0,1-3,0 k \text { bar }}$} & PC5 & 0,46 & 0,16 & 0,35 & 0,12 & $\mathbf{0 , 5 0}$ \\
\cline { 3 - 7 } & PC4 & 0,03 & 0,28 & 0,03 & 0,16 & 0,07 \\
\cline { 3 - 7 } & PC3 & 0,35 & 0,10 & 0,21 & 0,21 & 0,46 \\
\cline { 3 - 7 } & PC2 & 0,25 & 0,32 & $\mathbf{0 , 5 9}$ & 0,24 & 0,19 \\
\cline { 3 - 7 } & PC1 & 0,32 & $\mathbf{0 , 5 4}$ & 0,10 & 0,32 & 0,31 \\
\hline RMSIP & PC1 & PC2 & PC3 & PC4 & PC5 \\
\cline { 2 - 6 } $\mathbf{0 , 6 9 0 0}$ & \multicolumn{5}{|c}{$293 \mathrm{~K}$} \\
\hline
\end{tabular}

\begin{tabular}{|c|c|c|c|c|c|c|}
\hline \multirow{5}{*}{$\mathrm{P}_{0,1-0,3 \text { bar }}$} & PC5 & 0,03 & 0,51 & 0,06 & 0,10 & 0,19 \\
\hline & $\mathrm{PC} 4$ & 0,05 & 0 & 0,27 & 0,10 & 0,17 \\
\hline & PC3 & 0,03 & 0,18 & 0,09 & 0,50 & 0,05 \\
\hline & $\mathrm{PC} 2$ & 0,12 & 0,32 & 0 & 0,10 & 0,36 \\
\hline & PC1 & 0,15 & 0,19 & 0,33 & 0,20 & 0 \\
\hline \multirow{2}{*}{\multicolumn{2}{|c|}{$\begin{array}{r}\text { RMSIP } \\
0,4766\end{array}$}} & $\mathrm{PC} 1$ & $\mathrm{PC} 2$ & PC3 & $\mathrm{PC} 4$ & PC5 \\
\hline & & \multicolumn{5}{|c|}{ Ice Ih } \\
\hline
\end{tabular}

\begin{tabular}{|c|c|c|c|c|c|c|}
\hline \multirow{5}{*}{3 kbar } & PC5 & 0,06 & 0,07 & 0,41 & 0,04 & 0,09 \\
\hline & $\mathrm{PC} 4$ & 0,39 & 0,04 & 0,05 & 0,08 & 0,05 \\
\hline & PC3 & 0,40 & 0,04 & 0,18 & 0,21 & 0,13 \\
\hline & $\mathrm{PC} 2$ & 0,14 & 0,47 & 0,33 & 0,06 & 0,15 \\
\hline & PC1 & 0,09 & 0,02 & 0,13 & 0,11 & 0,42 \\
\hline \multirow{2}{*}{\multicolumn{2}{|c|}{$\begin{array}{c}\text { RMSIP } \\
0,4877\end{array}$}} & PC1 & PC2 & PC3 & $\mathrm{PC} 4$ & PC5 \\
\hline & & \multicolumn{5}{|c|}{$323 \mathrm{~K}$} \\
\hline
\end{tabular}

\begin{tabular}{|c|c|c|c|c|c|c|}
\hline \multirow{3}{*}{$293 \mathrm{~K}$} & PC5 & 0,02 & 0,20 & 0,21 & 0,44 & 0,08 \\
\cline { 3 - 7 } & PC4 & 0,28 & 0,42 & 0,11 & 0,21 & 0,01 \\
\cline { 3 - 7 } & PC3 & 0,19 & 0,33 & 0,09 & 0,12 & 0,04 \\
\cline { 3 - 7 } & PC2 & 0,20 & 0,01 & 0,43 & 0,04 & 0,24 \\
\cline { 3 - 7 } & PC1 & 0,12 & 0,09 & 0,18 & 0,04 & 0,44 \\
\hline RMSIP & PC1 & PC2 & PC3 & PC4 & PC5 \\
\cline { 2 - 6 } & \multicolumn{7}{|c|}{$215 \mathrm{~K}$} \\
$\mathbf{0 , 5 0 7 9}$ & \multicolumn{7}{|c|}{} \\
\hline
\end{tabular}

\begin{tabular}{|c|c|c|c|c|c|c|}
\hline \multirow{5}{*}{$\mathrm{P}_{0,1-3,0 k b a r}$} & PC5 & 0,10 & 0,40 & 0,24 & 0,03 & 0,03 \\
\hline & $\mathrm{PC} 4$ & 0.28 & 0,24 & 0,07 & 0.03 & 0,11 \\
\hline & PC3 & 0,19 & 0,01 & 0,11 & 0,35 & 0,07 \\
\hline & $\mathrm{PC} 2$ & 0,33 & 0,24 & 0,51 & 0,56 & 0 \\
\hline & PC1 & 0,26 & 0,32 & 0,39 & 0,07 & 0,03 \\
\hline \multirow{2}{*}{\multicolumn{2}{|c|}{$\begin{array}{l}\text { RMSIP } \\
\mathbf{0 , 5 6 9 6}\end{array}$}} & PC1 & $\mathrm{PC} 2$ & PC3 & $\mathrm{PC} 4$ & PC5 \\
\hline & & & & $323 \mathrm{~K}$ & & \\
\hline
\end{tabular}

\begin{tabular}{|c|c|c|c|c|c|c|}
\hline \multirow{3}{*}{$323 \mathrm{~K}$} & PC5 & 0,07 & 0,10 & 0,15 & 0,07 & 0,02 \\
\cline { 3 - 7 } & PC4 & 0,04 & 0,25 & 0,07 & 0,19 & 0,01 \\
\cline { 3 - 7 } & PC3 & 0,26 & 0,05 & 0,03 & 0,01 & 0,40 \\
\cline { 3 - 7 } & PC2 & 0,14 & 0,32 & 0,41 & 0,07 & 0,10 \\
\cline { 3 - 7 } & PC1 & 0,30 & 0,08 & 0,09 & 0,30 & 0,16 \\
\hline RMSIP & PC1 & PC2 & PC3 & PC4 & PC5 \\
\cline { 2 - 6 } 0,4249 & \multicolumn{7}{|c|}{$215 \mathrm{~K}$} \\
\hline
\end{tabular}

\begin{tabular}{|c|c|c|c|c|c|c|}
\hline \multirow{5}{*}{$\mathrm{P}_{0,1-3,0 k b a r}$} & PC5 & 0,47 & 0,44 & 0,19 & 0,09 & 0,04 \\
\hline & $\mathrm{PC} 4$ & 0,16 & 0,13 & 0,07 & 0,37 & 0,04 \\
\hline & PC3 & 0,01 & 0,19 & 0,07 & 0,12 & 0,44 \\
\hline & PC2 & 0,01 & 0,07 & 0,51 & 0,06 & 0,10 \\
\hline & PC1 & 0 & 0,58 & 0,15 & 0,03 & 0,38 \\
\hline \multirow{2}{*}{\multicolumn{2}{|c|}{$\begin{array}{l}\text { RMSIP } \\
\mathbf{0 , 5 7 7 9}\end{array}$}} & PC1 & $\mathrm{PC} 2$ & PC3 & $\mathrm{PC} 4$ & PC5 \\
\hline & & \multicolumn{5}{|c|}{$3 \mathrm{kbar}$} \\
\hline
\end{tabular}



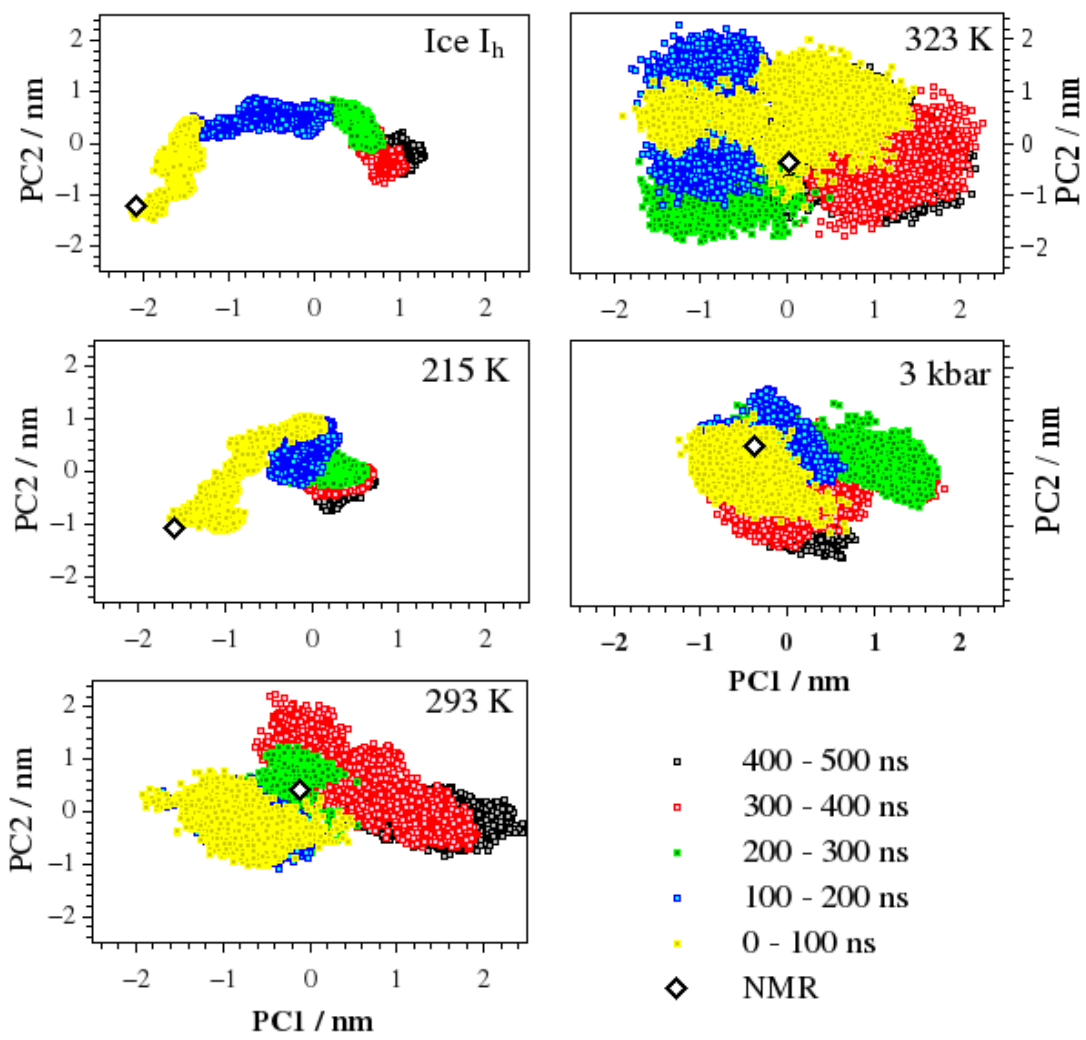

- $400-500 \mathrm{~ns}$

- $300-400 \mathrm{~ns}$

* $\quad 200-300 \mathrm{~ns}$

- $100-200 \mathrm{~ns}$

* $0-100 \mathrm{~ns}$

$\diamond \quad$ NMR

Figura 5.13: Proyección bi-dimensional (2D) de las trayectorias para cada condición simulada dentro PC1 y PC2. Cada punto representa un confórmero transitorio adoptado por la proteína durante su secuencia temporal. La estructura original resulta por RMN se representa por el rombo blanco. El código de colores representa la secuencia temporal.

\section{Paisaje de energía libre}

Sí nosotros determinamos el promedio de ensambles estructurales de la proteína que convergen durante la trayectoria, podríamos determinar la distribución más probable que esta adopta y extraer propiedades termodinámicas de los sistemas simulados. Para esto, analizamos el paisaje de energía libre (FEL) usando como coordenadas de reacción los dos primeros componentes principales obtenidos en el análisis por ED. Así, considerando las dos coordenadas de reacción $q_{i}$ y $q_{j}$, la representación 2D del FEL, esta dada por:

$$
G_{i, j}=-K_{B} T \ln \left[\frac{P\left(q_{i}, q_{j}\right)}{P_{M a x}\left(q_{i}, q_{j}\right)}\right],
$$

donde $K_{B}$, es la constante de Boltzman, $T$ la temperatura de simula- 


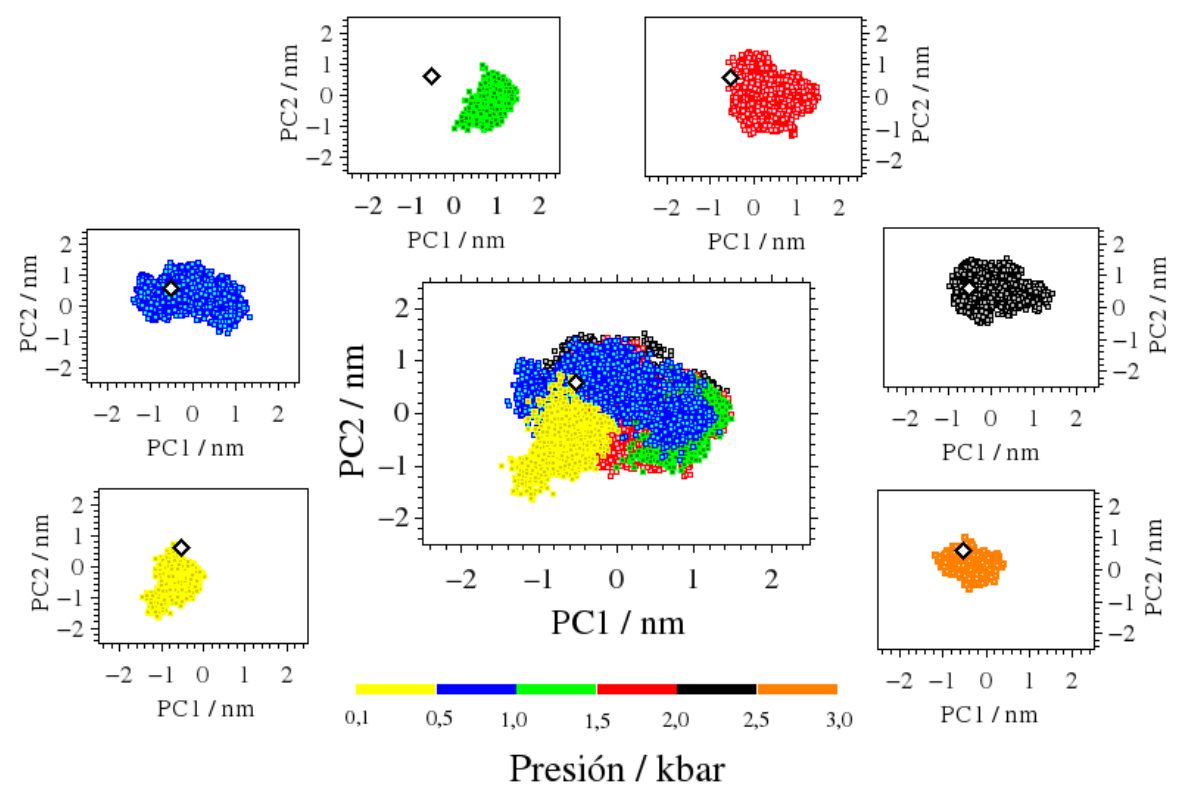

Figura 5.14: Proyección bi-dimensional (2D) de la trayectoria de la frataxina acoplada a presión creciente dentro de los primeros componentes princiapales. Cada punto representa un confórmero transitorio adoptado por la proteína en función de la presión. La estructura original resulta por RMN se representa por el rombo blanco. El código de colores representa el rango en el aumento de la presión. Los recuadros de menor tamaño muestran los subestados de la proteína para cada rango de presión analizado.

ción, $P\left(q_{i}, q_{j}\right)$ es una estimado de la densidad de probabilidad durante la simulación y $P_{\operatorname{Max}}\left(q_{i}, q_{j}\right)$ es el estado conformacional más probable.

En figura 5.15, se muestra el paisaje de energía libre a lo largo de PC1 y PC2 para todas las condiciones simuladas. En Ice $I_{h}$ la frataxina explora estados conformacionales que la alejan de su estado inicial (Ver figura 5.13), observándose varios mínimos locales cuya mayor densidad de subestados se observa después de los $300 \mathrm{~ns}$. Por su parte, la proteína $215 \mathrm{~K}$, tiene una menor exploración del espacio conformacional y menor cantidad de mínimos locales. El aumento de la densidad conformacional se logra una vez sobrepasa los 200 ns. Esto parece indicar que la frataxina en agua estructurada tipo hielo, genera mayor perturbación en la estructura proteica y juega un papel importante en la desnaturalización por bajas temperaturas.

Por su parte, en la frataxina a $293 \mathrm{~K}$ observamos que el muestreo del espacio conformacional cae en dos mínimos locales, que en referencia con la figura 5.13, se forma durante los primeros 200 ns de simulación y esta más cerca de la estructura inicial de la proteína. Pasados los 300 ns, la proteína fluctúa hacia un segundo mínimo local más alejado de la estructura origi- 

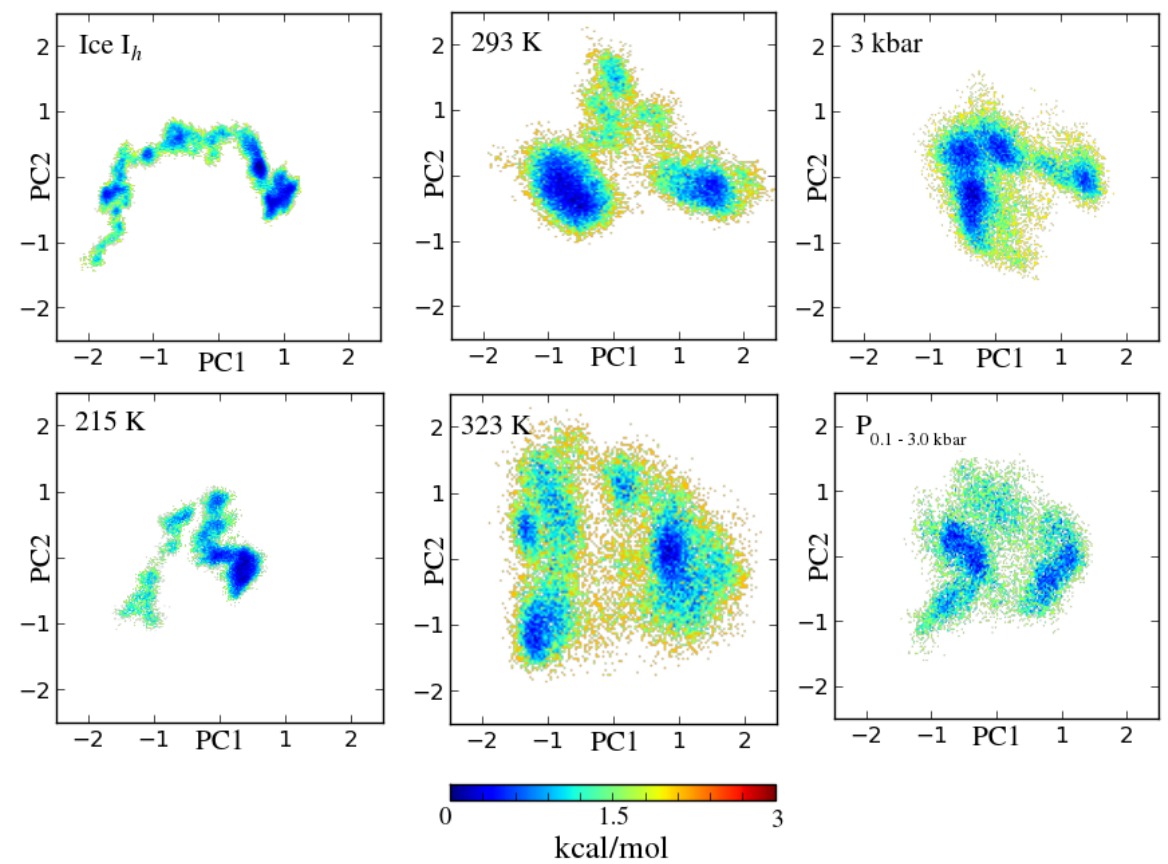

Figura 5.15: Análisis de FEL en cada condición simulada, utilizando como coordenadas de reacción las proyección de los $\mathrm{C} \alpha$ en PC1 y PC2. Los valores de energía libre se dan en $\mathrm{kcal} \mathrm{mol}^{-1}$ indicado por la escala a color.

nal, indicando que durante el tiempo de simulación la proteína describe una transición entre dos estados metaestables. Seguidamente, con el aumento de la temperatura, la frataxina a $323 \mathrm{~K}$ muestrea ampliamente el espacio conformacional alcanzando otras regiones de mínima energía donde algunos de estos guardan parentesco con la regiones metaestables de $293 \mathrm{~K}$ en concordancia con el RMSIP de la Tabla 5.3.

En aquellos sistemas donde la frataxina es expuesta a alta presión y a diferencia de los sistemas expuestos a desnaturalización térmica, la proteína tiende a regresar a conformaciones vecinas más cercanas a la estructura inicial. Aun así, presentan un muestreo conformacional más amplio en relación a los sistemas de bajas temperaturas, aunque, el acceso a regiones apartadas de su estructura nativa es energéticamente desfavorable. Esto es debido a que las altas presiones disminuyen la entropía conformacional y el acceso de la frataxina a regiones muy alejadas de su estructura nativa no es favorecida. Por tanto, la proteína en altas presiones se desnaturaliza adquiriendo conformaciones estructurales inactivas cercanas a su estado nativo, dadas las restricciones conformacionales impuestas por la presión. Este hecho parase ser una característica impuesta por la presión ya que estudios hechos en alta presión por RMN y cristalografía en Lisozima y Mioglobina, respectivamente, muestran valores de RMSD bajos entre las estructuras nativas y las 
desnaturalizadas por alta presión [33, 34].

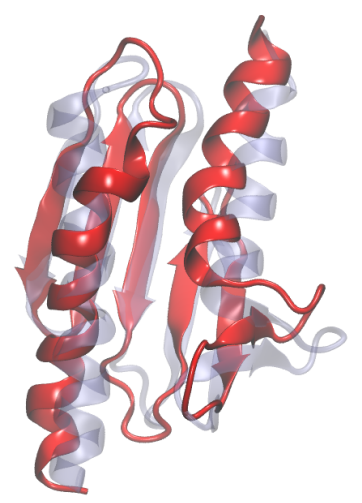

A

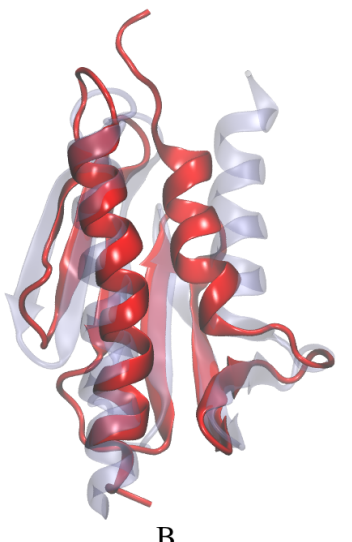

B

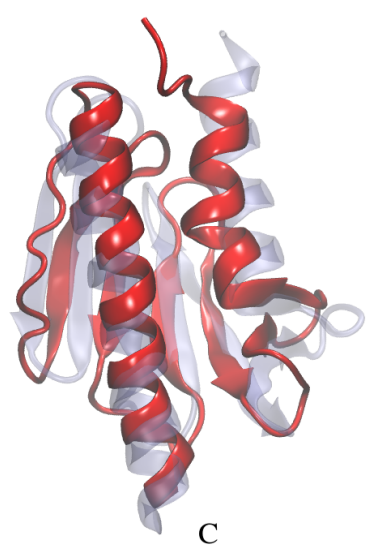

Figura 5.16: Representación estructural de máxima probabilidad en (A) Bajas Temperaturas, (B) Alta Presión y (C) Altas Temperaturas. Conformación inicial trasparente, estructura de mayor probabilidad en rojo.

El análisis de las estructuras de mayor probabilidad para las condiciones de desnaturalización dadas, y comparadas con su estructura inicial (Ver figura 5.16), sugiere que el acceso de la frataxina a nuevas conformaciones en bajas temperaturas esta dada por la marcada actividad en sus $\alpha$-hélices. Tal como se observa en nuestras simulaciones y se reporta experimentalmente por Adrover et.al. [7] H1 es la responsable del colapso y permanencia de la estructura secundaria, donde la región C-terminal es la más flexible (Ver figura 5.16A). Por otra parte, cuando comparamos el subespacio escencial entre los sistemas de alta y baja temperatura concluimos que los sistemas presentan cinéticas de desnaturalización diferentes (Ver tabla 5.3), tal como lo indican los resultados por RMN [26]. En nuestra simulación encontramos que al contrario de los sistema a bajas temperaturas, la desnaturalización por alta temperatura tiene una mayor incidencia sobre $\mathrm{H} 2$ y hojas $\beta$, en especial S1(Ver figura 5.16C). Por ultimo, el alineamiento estructural de la frataxina en alta presión en relación con sus movimientos indica que su cinética de desnaturalización comprende el despliegue parcial de región terminal de sus $\alpha$-hélices y S1, sumando a esto la compactación de la estructura.

Dado que no observamos un mecanismo cinético de desnaturalización proteica en común entre la desnaturalización en frío y por altas temperaturas, esto podría estar indicando que los movimientos intrínsecos de la proteína están determinados por el efecto que causa la presión y la temperatura en la estructura del solvente. Así, hemos notado que el aumento de la presión restringe la fluctuación de los residuos en la proteína (Ver figura 5.9) y por tanto, la frataxina ve limitado su espacio conformacional adquiriendo configuraciones inactivas con vecindades conformacionales cercanas a su estado 
nativo (Ver figuras 5.13 y 5.14). Al respecto, la perdida de la estructura del agua por el aumento de la presión ocasiona un colapso en la estructura nativa de la proteína debido a la perdida del efecto hidrofóbico y la compactación de la estructura (Ver figura 5.7 y 5.15). Efecto que es presentado en detalle en la figura 5.17, donde observamos que el área superficial accesible al solvente (SASA) hidrofílica e hidrofóbica disminuye con la presión y presenta el menor valor entre los sistemas estudiados. Sin embargo, es interesante notar que al analizar la frataxina en función de la presión (Ver figura 5.17 C y D) vemos que al acercarse a los 1000 bar la proteína aumenta su SASA hidrofílico e hidrofóbico muy cercano a su valor nativo (teniendo en cuenta las barras de desviación estándar). Con el subsecuente aumento de la presión el valor SASA disminuye, manteniéndose relativamente constante cerca de los 2300 bar donde decae a su mínimo valor. Es en este punto, 2300 bar, donde el modelo SPC/E representa la transición de las propiedades del agua (Baja densidad-Alta densidad) observadas experimentalmente en alta presión [35, 36], perdiendo su estructura tetrahédrica y reduciendo el volumen de la proteína.
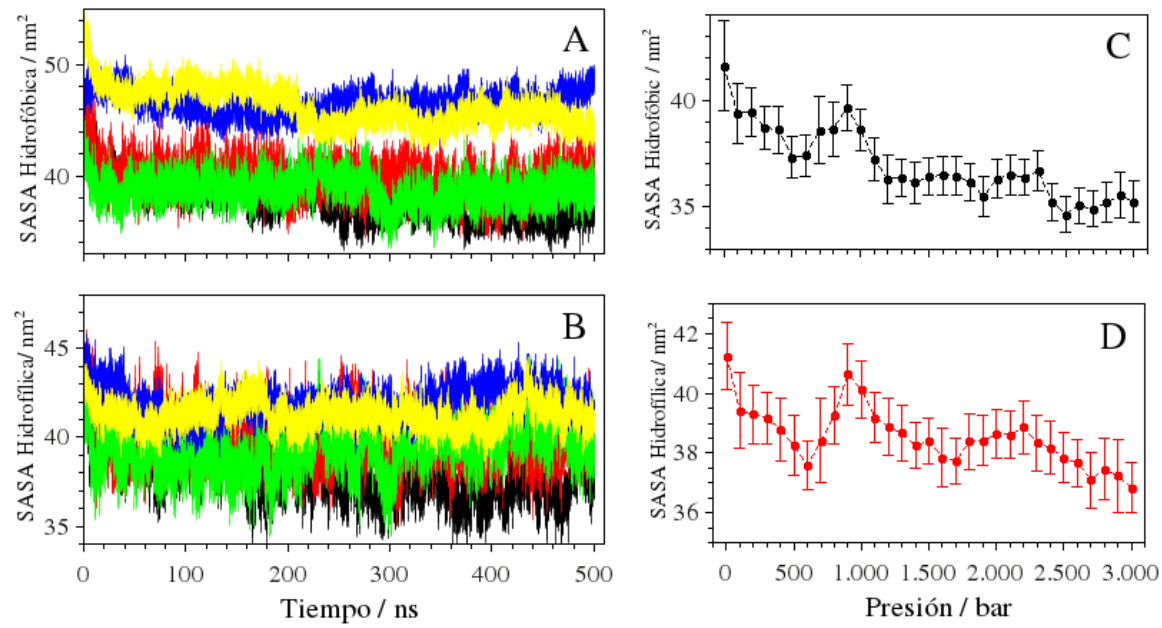

Figura 5.17: Área superficial accesible al solvente (SASA).En (A) y (B) SASA hidrofóbica e hidrofílica, respectivamente. Los datos fueron recolectados durante 500 ns de simulación. Frataxina en Ice $I_{h}$ (amarillo), agua líquida a: $215 \mathrm{~K}$ (azul), $293 \mathrm{~K}$ (verde) $323 \mathrm{~K}$ (rojo) y alta presión $3 \mathrm{kbar}$ (negro).SASA hidrofóbica (C) e hidrofílica (D) a presión creciente $\left(\mathrm{P}_{0,1-3,0 k b a r}\right)$ Los puntos y las barras de error representan el promedio y la desviación estandar, respectivamente.

En otras palabras, presiones cercanas a 1 kbar debilitan el efecto hidrofóbico y se hace posible la exposición de los residuos hidrofóbicos al solvente. Seguidamente, presiones superiores compactan el sistema, reducen su volu- 
men y por tanto desciende la exposición de los residuos. Este aumento en el SASA en alta presión puede ser correlacionando cualitativamente con lo observado experimentalmente en la lisozima. Donde el aumento en la presión puede causar una expansión local en la estructura ocasionando cambios positivos y negativos en el volumen en función de la presión [33].
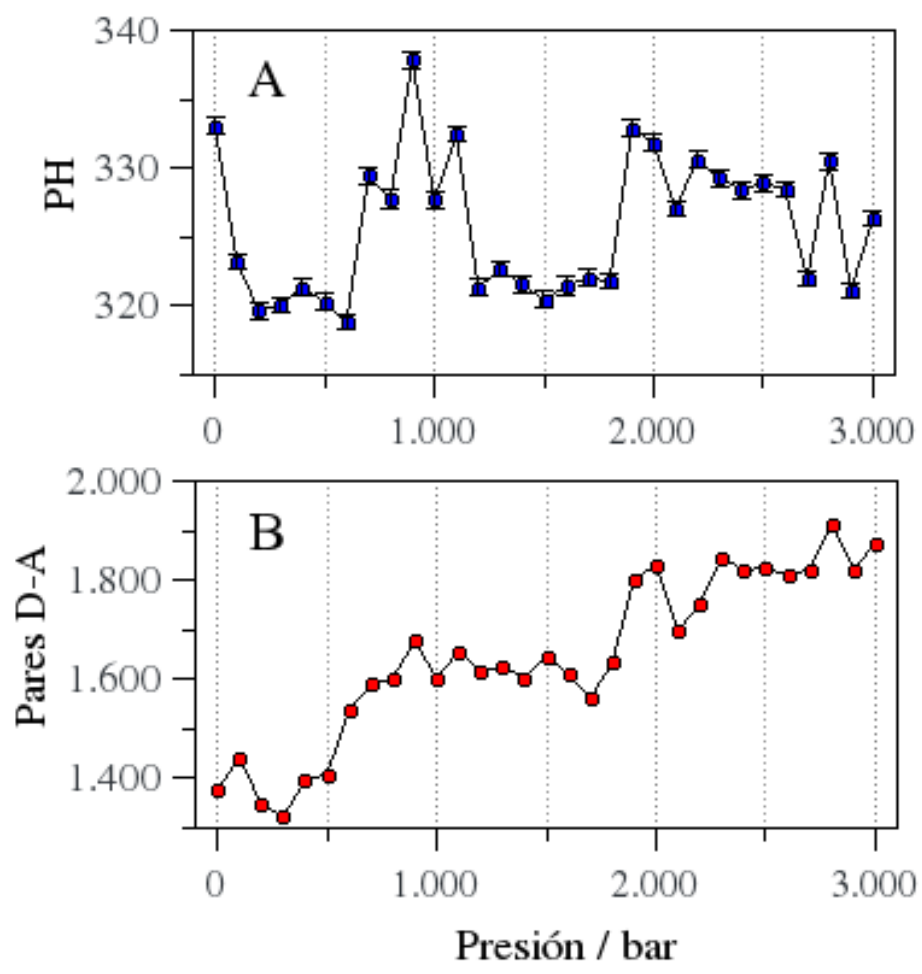

Figura 5.18: En A, promedio de puentes de hidrógeno (PH) entre el agua y la frataxina para cada aumento de presión (las barras de error indican la desviación estandar). En B, conteo de los pares donor-aceptor (D-A) para un radio de corte $R_{C u t}=0,24 \mathrm{~nm}$. Como se observa, con el aumento de la presión el número de pares D-A incrementa. Entre los 600-900 bar, los PH y los pares D-A aumentan con la presión. Una vez se alcanza los 1000 bar el número de $\mathrm{PH}$ descienden, mientras los pares D-A se mantienen estables hasta $\sim 1700$ bar. Esto indica que con el aumento de la presión la población de pares de D-A incrementan por efecto de la compresión, pero esto no supone la formación PH entre el agua y la proteína. En este cálculo se usó como criterio geométrico una distancia donor-aceptor de $0,24 \mathrm{~nm}$ y un ángulo $D-H-A$ entre $0-45^{\circ}$

Es interesante notar que cuando calculamos el número de puentes de hidrógeno formados entre el agua y la proteína, estos aumentan en determinados valores de presión, tal como se observa en la figura 5.18. Por tanto, en 
regiones cercanas a $1 \mathrm{kbar}$ los puentes de hidrógeno formados en el sistema incrementan en relación con el SASA de las figuras 5.17 C y D. Asimismo, la compresión en el sistema ayuda a incrementar el número de pares de átomos donor-aceptor disponibles para la formación de puentes de hidrógeno (figura 5.18 B). Sin embargo, esto no certifica la formación de los mismo, ya que como se observa en la región entre 1-1,7 kbar de la figura 5.18 A, el número de puentes de hidrógeno desciende. Por encima de los 2000 bar observamos que los pares donor-aceptor y los puentes de hidrógeno aumentan nuevamente, pero sabemos que para estos valores de presión el agua ya ha perdido su estructura y la población de puentes de hidrógenos se ha re-distribuido (esto se analizará en mayor detalle en el siguiente capitulo).

En los sistemas a bajas temperaturas, el SASA hidrofóbico es el más alto de los sistemas simulados. Este efecto se relaciona directamente con las características de desnaturalización por bajas temperaturas reportadas experimentalmente para la frataxina donde se exponen los grupos no polares al agua $[5-7,26]$ tal como se observa en la figura 5.17 A y B. En los sistemas donde la desnaturalización proteica depende de la temperatura, notamos que poseen una mayor libertad del espacio conformacional en relación con las altas presiones, aun así, el creciente aumento en la estructuración de la moléculas de agua al rededor del soluto a bajas temperaturas, parecen generar una ligera restricción en la proteína, lo que no permite un amplio muestro del espacio conformacional como en el caso de las altas temperaturas (Ver figura 5.15).

Por tanto, con la disminución en la temperatura hay una perdida del efecto hidrofóbico, ya que la contribución entrópica $(-T \Delta S)$ a la energía libre disminuye, esto explicaría la disociación de los grupos no polares y la consecuente disrupción de la estructura globular compacta de la proteína incrementando la SASA. Un efecto parecido ocurre en altas temperaturas solo que en este caso la entropía del sistema incrementa por acción de la temperatura colapsando la estructura proteica y disminuyendo su SASA (Ver figura 5.17 A y B), tal como se observa experimentalmente en la desnaturalización térmica para bajas y altas temperaturas [28].

\section{Conclusiones}

El modelo de frataxina en nuestros estudios de desnaturalización en frío y por altas temperaturas mostró una amplia similitud con los resultados experimentales, a diferencia de los análisis reportados por MD para este sistema, donde la frataxina a bajas temperaturas permanece en un mínimo local y no explorar nuevas configuraciones que permitan analizar este proceso [26]. Nuestros análisis de MD por ED permitieron obtener información valiosa al respecto, y a pesar de que no observamos la pérdida total de la estructura proteica, sí evidenciamos su tendencia a la desnaturalización y las caracte- 
rísticas de sus respectivas cinéticas.

Los análisis por dinámica esencial muestran que las regiones de mayor fluctuación en la frataxina observadas en nuestras simulaciones son las responsables de los cambios conformacionales, relacionándose con los resultados experimentales de Adrover etal. (2010) [7] para la fraxina en bajas temperaturas.

El espacio esencial en cada condición simulada, mostró patrones de parentesco entre las diversas variantes, es decir, notamos que el subespacio esencial en Ice $I_{h}$ y $215 \mathrm{~K}$ tienen a explorar casi con la misma amplitud su espacio conformacional. Este mismo hecho se observa al aumentar la fluctuación térmica, 293 y $323 \mathrm{~K}$ donde el espacio conformacional recorrido por la frataxina es mayor. Para el caso de los sistemas bajo presión, 3 kbar y $\mathrm{P}_{0,1-3,0 k b a r}$, es notable observar que los dos sistemas retornan a configuraciones vecinas con su estado nativo. Esto indica de que a pesar de que las condiciones iniciales fueron diferentes para aquellos sistemas que compartían similitudes entre el tipo de desnaturalización (altas, bajas temperaturas y alta presión), observamos tendencias que marcaron características relevantes en al dinámica de los mismo, indicando que el modelo de frataxina converge acorde con las condiciones simuladas.

Los análisis de los movimientos esenciales evidenciaron que los sistemas no tienen patrones de movimiento correlacionando y que son sensibles a los cambios térmicos y por presión aquí analizados. Ademas, la influencia de la estructura del agua modifica la dinámica conformacional en la frataxina, apoyando la hipótesis de la importancia en la alteración del efecto hidrofóbico en el proceso de la desnaturalización de proteínas en condiciones extremas de presión y temperatura. 


\section{Bibliografía}

[1] Bowu Luan, Bing Shan, Carlos Baiz, Andrei Tokmakoff, and Daniel P Raleigh. Cooperative cold denaturation: The case of the c-terminal domain of ribosomal protein 19. Biochemistry, 52(14):2402-2409, 2013.

[2] Peter L Privalov. Cold denaturation of protein. Critical reviews in biochemistry and molecular biology, 25(4):281-306, 1990.

[3] Bing Shan, Sebastian McClendon, Carla Rospigliosi, David Eliezer, and Daniel P Raleigh. The cold denatured state of the c-terminal domain of protein 19 is compact and contains both native and non-native structure. Journal of the American Chemical Society, 132(13):4669-4677, 2010.

[4] Eduardo Ascolese and Giuseppe Graziano. On the cold denaturation of globular proteins. Chemical Physics Letters, 467(1):150-153, 2008.

[5] Annalisa Pastore, Stephen R Martin, Anastasia Politou, Kalyan C Kondapalli, Timothy Stemmler, and Piero A Temussi. Unbiased cold denaturation: low-and high-temperature unfolding of yeast frataxin under physiological conditions. Journal of the American Chemical Society, 129(17):5374-5375, 2007.

[6] Piero Andrea Temussi. Cold denaturation and protein stability. In Supramolecular Structure and Function 10, pages 75-85. Springer, 2011.

[7] Miquel Adrover, Veronica Esposito, Gabriel Martorell, Annalisa Pastore, and Piero Andrea Temussi. Understanding cold denaturation: the case study of yfh1. Journal of the American Chemical Society, 132(45):16240-16246, 2010.

[8] Hana Koutnikova, Victoria Campuzano, Françoise Foury, Pascal Dollé, Ornella Cazzalini, and Michel Koenig. Studies of human, mouse and yeast homologues indicate a mitochondrial function for frataxin. Nature genetics, 16(4):345-351, 1997.

[9] Victoria Campuzano, Laura Montermini, Maria Dolores Moltò, Luigi Pianese, Mireille Cossée, Francesca Cavalcanti, Eugenia Monros, François Rodius, Franck Duclos, Antonella Monticelli, et al. Friedreich's 
ataxia: autosomal recessive disease caused by an intronic gaa triplet repeat expansion. Science, 271(5254):1423-1427, 1996.

[10] Massimo Pandolfo and Annalisa Pastore. The pathogenesis of friedreich ataxia and the structure and function of frataxin. Journal of neurology, 256(1):9-17, 2009.

[11] Jiri Adamec, Frank Rusnak, Whyte G Owen, Stephen Naylor, Linda M Benson, A Marquis Gacy, and Grazia Isaya. Iron-dependent self-assembly of recombinant yeast frataxin: implications for friedreich ataxia. The American Journal of Human Genetics, 67(3):549-562, 2000.

[12] Salvatore Adinolfi, Margie Nair, Anastasia Politou, Elena Bayer, Stephen Martin, Pierandrea Temussi, and Annalisa Pastore. The factors governing the thermal stability of frataxin orthologues: how to increase a protein's stability. Biochemistry, 43(21):6511-6518, 2004.

[13] Yanan He, Steven L Alam, Simona V Proteasa, Yan Zhang, Emmanuel Lesuisse, Andrew Dancis, and Timothy L Stemmler. Yeast frataxin solution structure, iron binding, and ferrochelatase interaction. Biochemistry, 43(51):16254-16262, 2004.

[14] Herman JC Berendsen, David van der Spoel, and Rudi van Drunen. Gromacs: A message-passing parallel molecular dynamics implementation. Computer Physics Communications, 91(1):43-56, 1995.

[15] David Van Der Spoel, Erik Lindahl, Berk Hess, Gerrit Groenhof, Alan E Mark, and Herman JC Berendsen. Gromacs: fast, flexible, and free. Journal of computational chemistry, 26(16):1701-1718, 2005.

[16] Nathan Schmid, Andreas P Eichenberger, Alexandra Choutko, Sereina Riniker, Moritz Winger, Alan E Mark, and Wilfred F van Gunsteren. Definition and testing of the gromos force-field versions $54 \mathrm{a} 7$ and $54 \mathrm{~b} 7$. European biophysics journal, 40(7):843-856, 2011.

[17] Wei Huang, Zhixiong Lin, and Wilfred F van Gunsteren. Validation of the gromos $54 a 7$ force field with respect to $\beta$-peptide folding. Journal of Chemical Theory and Computation, 7(5):1237-1243, 2011.

[18] HJC Berendsen, JR Grigera, and TP Straatsma. The missing term in effective pair potentials. Journal of Physical Chemistry, 91(24):6269$6271,1987$.

[19] C Vega, E Sanz, and JLF Abascal. The melting temperature of the most common models of water. Journal of Chemical Physics, 122(11):114507114507, 2005. 
[20] Ramón García Fernández, José LF Abascal, and Carlos Vega. The melting point of ice ih for common water models calculated from direct coexistence of the solid-liquid interface. The Journal of chemical physics, 124(14):144506, 2006.

[21] D Van der Spoel, E Lindahl, and B Hess. the gromacs development team, gromacs user manual version 4.6.5 (2013).

[22] Giovanni Bussi, Davide Donadio, and Michele Parrinello. Canonical sampling through velocity rescaling. The Journal of chemical physics, 126(1):014101, 2007.

[23] Michele Parrinello and Aneesur Rahman. Polymorphic transitions in single crystals: A new molecular dynamics method. Journal of Applied physics, 52(12):7182-7190, 1981.

[24] Mark J Abraham and Jill E Gready. Optimization of parameters for molecular dynamics simulation using smooth particle-mesh ewald in gromacs 4.5. Journal of computational chemistry, 32(9):2031-2040, 2011.

[25] Berk Hess, Henk Bekker, Herman JC Berendsen, Johannes GEM Fraaije, et al. Lincs: a linear constraint solver for molecular simulations. Journal of computational chemistry, 18(12):1463-1472, 1997.

[26] Miquel Adrover, Gabriel Martorell, Stephen R Martin, Dunja Urosev, Petr V Konarev, Dmitri I Svergun, Xavier Daura, Pierandrea Temussi, and Annalisa Pastore. The role of hydration in protein stability: Comparison of the cold and heat unfolded states of yfh1. Journal of molecular biology, 417(5):413-424, 2012.

[27] Wolfgang Kabsch and Christian Sander. Dictionary of protein secondary structure: pattern recognition of hydrogen-bonded and geometrical features. Biopolymers, 22(12):2577-2637, 1983.

[28] Mikayel Aznauryan, Daniel Nettels, Andrea Holla, Hagen Hofmann, and Benjamin Schuler. Single-molecule spectroscopy of cold denaturation and the temperature-induced collapse of unfolded proteins. Journal of the American Chemical Society, 135(38):14040-14043, 2013.

[29] Andrea Amadei, AB Linssen, and HJ Berendsen. Essential dynamics of proteins. Proteins Structure Function and Bioinformatics, (17):412-25, 1994.

[30] Berk Hess. Convergence of sampling in protein simulations. Physical Review E, 65(3):031910, 2002.

[31] Berk Hess. Similarities between principal components of protein dynamics and random diffusion. Physical Review E, 62(6):8438, 2000. 
[32] Paulo Ricardo Batista, Mauricio Garcia de Souza Costa, Pedro Geraldo Pascutti, Paulo Mascarello Bisch, and Wanderley de Souza. High temperatures enhance cooperative motions between cbm and catalytic domains of a thermostable cellulase: mechanism insights from essential dynamics. Physical Chemistry Chemical Physics, 13(30):13709-13720, 2011.

[33] Mohamed Refaee, Tomoko Tezuka, Kazuyuki Akasaka, and Michael P Williamson. Pressure-dependent changes in the solution structure of hen egg-white lysozyme. Journal of molecular biology, 327(4):857-865, 2003.

[34] Paul Urayama, George N Phillips, and Sol M Gruner. Probing substates in sperm whale myoglobin using high-pressure crystallography. Structure, 10(1):51-60, 2002.

[35] Osvaldo Chara, Andrés N McCarthy, and J Raúl Grigera. Crossover between tetrahedral and hexagonal structures in liquid water. Physics Letters A, 375(3):572-576, 2011.

[36] Samuele Fanetti, Andrea Lapini, Marco Pagliai, Margherita Citroni, Mariangela Di Donato, Sandro Scandolo, Roberto Righini, and Roberto Bini. Structure and dynamics of low-density and high-density liquid water at high pressure. The journal of physical chemistry letters, $5(1): 235-240,2013$. 


\section{Capítulo 6}

\section{Conclusión}

Como se ha podido observar a lo largo de la presente tesis, hemos tratado de presentar los paradigmas de la desnaturalización en frío de proteínas, haciendo relevancia en la contribución que tiene el efecto hidrofóbico en el proceso. Por tanto, siguiendo esta idea, creamos dos sistemas de simulación fuertemente dependientes de la interacción hidrofóbica, como lo es la agregación y formación de estructuras micelares. Esto es, surfactantes anfifílicos iónicos, e.g., Dodecilsulfato Sódico (SDS) y no iónicos e.g., Tritón X-100 (TX-100) y los sometimos a efectos de la presión y la temperatura, analizando la tendencia de sus resultado y observando que ocurre bajo estas mismas condiciones en el sistema proteico, frataxina Yfh1. Asimismo, hemos abordado esta problemática mediante un estudio por simulaciones computacionales empleando como herramienta de análisis la Dinámica Molecular y la Dinámica Esencial (esta ultima exclusiva de sistemas proteicos).

En el sistema SDS es notable que el efecto de la presión ocasiona una reestructuración de la geometría micelar debido a la perdida del efecto hidrofóbico que lleva al sistema a configuraciones geométricas totalmente diferentes a su estado de referencia, direccionado en parte por las interacciones electrostáticas vigentes entres los iones y contraiones del sistema. Asimismo, un sistema neutro carente de iones en alta presión nos muestra una dinámica totalmente diferente. Para TX-100, el gran tamaño en su región hidrofóbica al igual que su gran región hidrofílica de cabeza lleva a que el sistema tenga una dinámica de hidratación tal, que podamos ver el ingreso de agua con el aumento de la presión.

Tanto en sistemas micelares iónicos y neutros, observamos que los cambios en la estructura del agua ocurren en valores similares de presión, así para los mismo valores, de lo que se denomina baja presión, $<1,5 \mathrm{kbar}, \mathrm{y}$ alta presión, > 1, $5 \mathrm{kbar}$, los sistemas presentan dinámicas de sus áreas accesibles al solvente (SASA) con tendencias similares. Cuando analizamos estos efectos en proteínas utilizando el modelo frataxina, es evidente que existe una expansión en el volumen del sistema en la regiones de baja presión, que 
se ve traducido en el incremento del SASA de la proteína, y que a su vez se correlaciona con la disminución en el número de agregación en el SDS y con los incrementos en el radio y el SASA hidrofílico de la micela de TX-100.

Entonces, los resultados en los tres sistemas parecen indicar, que las modificaciones en la estructura del agua son importantes en el mantenimiento de la interacción hidrofóbica y que son estas las que contribuyen en la desnaturalización en frío en proteínas. Incluso al someter las micelas de SDS a un solvente no estructurado de Lennard-Jones, observamos un cambio en la geometría que expone la cola hidrofóbica de los anfifílos al solvente y oculta la región hidrofílica y sus contraiones.

En trabajos previos publicados en nuestro grupo, considerando al agua en estado líquido como una combinación de estructuras de baja (tetraédrica) y alta (hexagonal) densidad estrechamente entrecruzadas, se ha propuesto un parámetro de orden, $P_{r}$, que permite dicha caracterización mediante el análisis de la Función de Distribución Radial $(g(r))$ del agua SPC/E (Ver figura 6.1) [1].

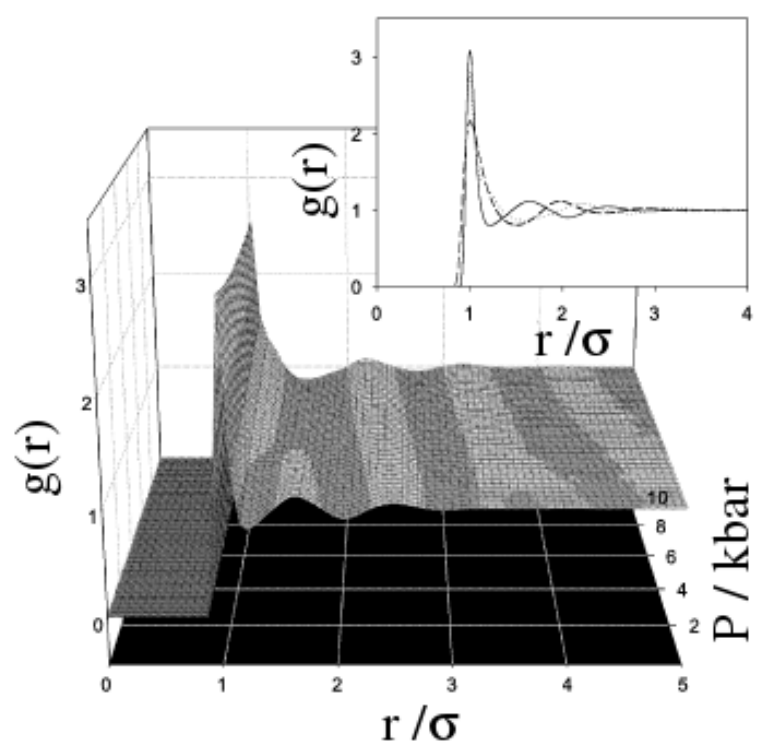

Figura 6.1: Cambios en la $g(r)$ con el aumento de la presión. Cada $g(r)$ muestra el cambio de ordenamiento estructural del modelo SPC/E, observándose la pérdida gradual de estructura tetraédrica con el aumento de la presión. En el recuadro superior (linea negra continua) se aprecia la posición del segundo pico, a 1 bar de presión, revelando el componente tetraédrico de la estructura del agua bajo estas condiciones, contrastado con la posición del segundo pico de la $g(r)$ que muestra la presencia la de una estructura simple de geometría hexagonal para el argón líquido (curva a trazos). Así, el incremento de la presión modifica la $g(r)$ del agua haciéndola más parecida a la del argón (curva punteada a $10 \mathrm{kbar}$ ). 
Así, utilizando simulaciones por MD bajo diversas condiciones de temperatura y presión se demostró que para $\mathrm{SPC} / \mathrm{E}, P_{r}$ sigue un comportamiento monótonamente decreciente con la presión, identificándose el valor de presión en el cual no existe prevalencia de ninguna de las contribuciones estructurales tetraédrica y hexagonal $\left(P_{r}=0\right)$ o punto de crossover estructural; estableciendo el punto en el que se produce el cambio en la predominancia de una contribución estructural sobre la otra (2,3 kbar en SPC/E) (Ver figura 6.2).

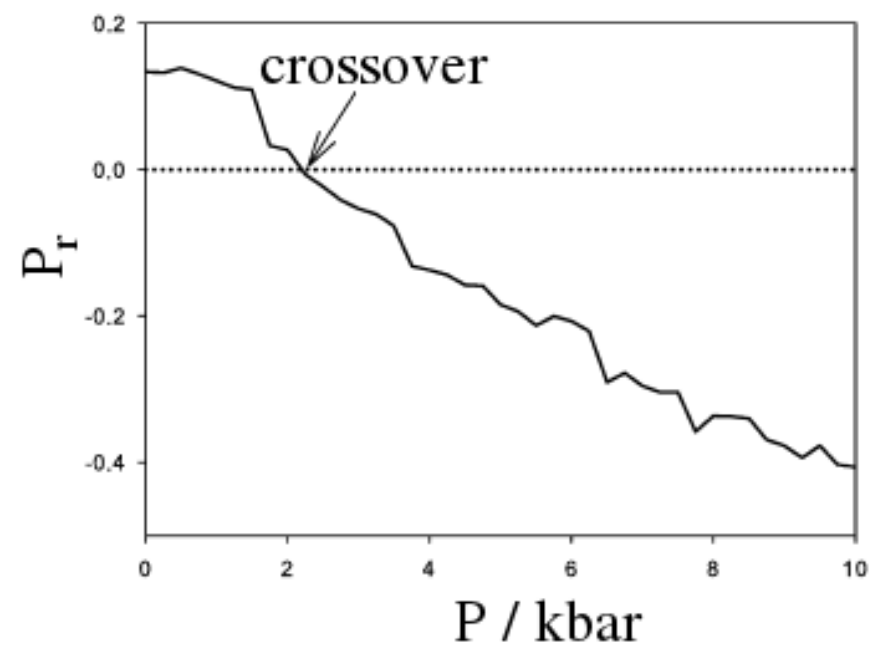

Figura 6.2: Parámetro de orden, $P_{r}$, en función de la presión hidrostática ejercida sobre el sistema (caja de simulación con agua SPC/E). El modelo expresa la coexistencia de dos contribuciones entrelazadas de hidratación; es decir, una estructura tetraédrica abierta y una hexagonal más compacta. Tomado de [1].

Este resultado es interpretado bajo el argumento de que la presión modifica la red de puentes de hidrógeno que une las moléculas de agua, tal como se demuestra en el trabajo de Grigera y McCarthy (2010) [2], los cuales estudian el efecto de la presión en la desnaturalización de la lisozima y la apomioglobina, reportando una redistribución de los puentes de hidrógeno por molécula de agua con el aumento de la presión (Ver figura 6.3A). Este efecto también es analizado por Caffarena y Grigera [3] quienes estudian la distribución de los puentes de hidrógeno en la estructura del agua relacionando los efectos de la presión y los cambios en la densidad de la misma (Ver figura 6.3).

De igual manera, dos fenómenos coexisten bajo alta presión, $(i)$ el debilitamiento de interacción hidrofóbica a bajas presiones, lo que permite la exposición de los residuos hidrofóbicos y que conduce a un aumento en el volumen; y (ii) con el aumento de la presión el volumen del sistema disminuye debido a el incremento en la compresibilidad. 

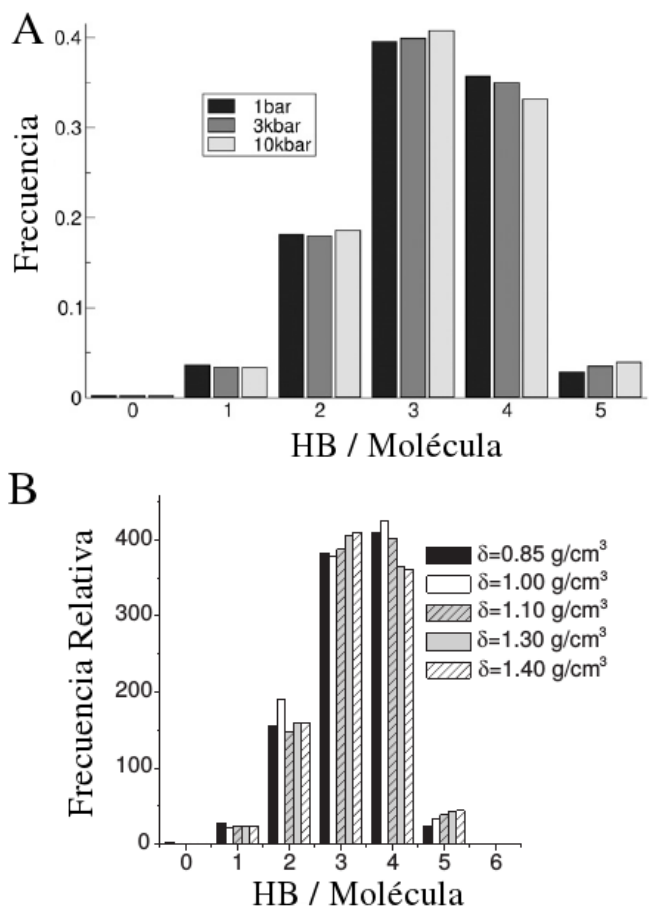

Figura 6.3: En A, distribución de los puentes de hidrógeno (HB) en agua SPC/E a $300 \mathrm{~K}$ y 1 bar (negro), 3 kbar (gris oscuro) y 10 kbar (gris claro) obtenidos por MD. Podemos notar de que con el aumento de la presión, la formación de cuatro HB por molécula disminuye, incrementando la población de tres y cinco HB formados, mostrando el debilitamiento de las red de HB con el incremento de la presión. En B, distribución de los HB a $280 \mathrm{~K}$ a diferentes densidades en función de la presión. Al igual que en A, para las altas presiones $\left(\delta=1,10 ; 1,30 ; 1,40 \mathrm{~g} / \mathrm{cm}^{3}\right)$ se observa una redistribución de los puentes de hidrógeno de 4 a 3 y 5 HB por molécula de agua. Figura A y $\mathrm{B}$, tomadas de $[2,3]$, respectivamente.

Podemos decir entonces, y sin el animo de generar conclusiones tajantes, que a diferencia de la desnaturalización térmica, la cual varia según la proteína en cuestión, parecería posible que exista tal vez no una única, pero si una acotada región de presión en la cual todas la proteínas sufran los efectos de la desnaturalización, ya que independientemente de la proteína, una vez se pierde la interacción hidrofóbica por el incremento de la presión esta deja de ser funcional.

Por otra parte, y no tan alejados de esta problemática de la estructura del solvente, hemos notado que las bajas temperaturas ocasionan una redistribución en la geometría de los surfactantes, como en el caso del SDS, donde las fases lamelares no son solo evidentes en alta presión. De igual forma, el efecto de la desnaturalización en frío por bajas temperaturas en proteínas, es 
observado en nuestras simulaciones para la frataxina en concordancia con los datos experimentales para este sistema, que hasta ahora representa el primer y único sistema capaz de desnaturalizarse antes de $\operatorname{los} 0{ }^{\circ} \mathrm{C}$ en condiciones fisiológicas. Así, nuestro datos parecen indicar que al igual que con la presión la disminución en la temperatura lleva a una perdida del efecto hidrofóbico, que ocasiona que el sistema exponga sus residuos hidrofóbicos al solvente.

Finalmente, solo cabe mencionar que los modelos aquí propuestos han representado características y comportamientos en una notable concordancia cualitativa con los datos experimentales, que nos permiten obtener información valiosa referente al papel que juega en efecto hidrofóbico en la estructura de proteínas. 



\section{Bibliografía}

[1] Osvaldo Chara, Andrés N McCarthy, and J Raúl Grigera. Crossover between tetrahedral and hexagonal structures in liquid water. Physics Letters A, 375(3):572-576, 2011.

[2] J Raúl Grigera and Andres N McCarthy. The behavior of the hydrophobic effect under pressure and protein denaturation. Biophysical journal, 98(8):1626-1631, 2010.

[3] Ernesto R Caffarena and J Raúl Grigera. On the hydrogen bond structure of water at different densities. Physica A: Statistical Mechanics and its Applications, 342(1):34-39, 2004. 



\section{Capítulo 7}

\section{Perspectivas}

Si bien el presente trabajo a estudiado el efecto de la interacción hidrofóbica en la desnaturalización en frío de proteínas por medio de análisis dinámicos y estructurales, no hemos abordado el aporte energético de las interacciones no covalentes al sistema proteína-proteína y proteína-solvente, dadas las limitaciones de la Dinámica Molecular, e.g., en representar transiciones de fase líquido-sólido. Esto abre una perspectiva en el estudio del aporte energético de las interacciones no covalentes en los cambios conformacionales de las proteínas en solución en relación al diagrama de fase $p$ - $T$, analizando la organización de los microestados proteína-solvente y los aportes entrópicos y entálpicos a la energía libre del proceso.

De esta forma seria interesante y valioso poder analizar por medio de un algoritmo de muestreo multidimensional el paisaje de energía libre de estos sistemas y poder comparar con los datos experimentales los valores termodinámicos, dinámicos y estructurales, de forma tal que nos permita comprender la magnitud del aporte energético y la dinámica de acción de las interacciones no covalentes en la estructura y función de proteínas. 